(x) 12
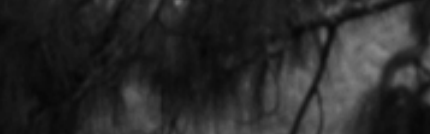



\section{Assessing household and landscape trajectories for improving ecosystem services and nutritional self-sufficiency in south Mexico}

Ivan Pontin Novotny 


\section{Thesis committee}

\section{Promotors}

Prof. Dr P.A. Tittonell

Professor of Farming Systems Ecology

Wageningen University \& Research

Dr W.A.H. Rossing

Associate professor, Farming Systems Ecology

Wageningen University \& Research

\section{Co-promotors}

Dr M.H. Fuentes-Ponce

Associate professor, Animal and Plant Production Group

Universidad Autónoma Metropolitana Unidad Xochimilco, Mexico City, Mexico

Dr S. López-Ridaura

Senior Scientist

International Maize and Wheat Improvement Center (CIMMYT), Mexico City, Mexico

\section{Other members}

Prof. Dr P.J.M. Oosterveer, Wageningen University \& Research

Prof. Dr J.S.C. Wiskerke, Wageningen University \& Research

Dr P. Reidsma, Wageningen University \& Research

Dr K. Kok, Wageningen University \& Research

This research was conducted under the auspices of the C.T. de Wit Graduate School for Production Ecology and Resource Conservation (PE\&RC) 


\title{
Assessing household and landscape trajectories for improving ecosystem services and nutritional self-sufficiency in south Mexico
}

\author{
Ivan Pontin Novotny
}

\section{Thesis}

submitted in fulfilment of the requirements for the degree of doctor

at Wageningen University

by the authority of the Rector Magnificus,

Prof. Dr A.P.J. Mol,

in the presence of the

Thesis Committee appointed by the Academic Board

to be defended in public

on Friday 29 May 2020

at 11 a.m. in the Aula. 
Ivan Pontin Novotny

Assessing household and landscape trajectories for improving ecosystem services and nutritional self-sufficiency in south Mexico,

180 pages.

PhD thesis, Wageningen University, Wageningen, the Netherlands (2020)

With references, with summary in English, Spanish and Dutch

ISBN: 978-94-6395-332-0

DOI: https:/ /doi.org/10.18174/516608 
A mi familia, amigos y todos los campesinos de Santa Catarina Tayata y San Cristobal Amoltepec

Gracias por tornar realidad este trabajo 



\begin{abstract}
In agricultural landscapes, humans impact the environment through land use change, causing natural resource depletion and potentially reducing crop and animal production. These changes, in turn, can impact the livelihood and food security of the rural population, and lead to socio-economic changes such as induced marginalization and land abandonment. In Mesoamerica, rural development policies aimed at intensifying agriculture in detriment of traditional indigenous systems. These policies are expected to have an impact on rural landscapes and its people, and understanding this intricate interaction is key for assessing household, community, and landscape trajectories. Therefore, this thesis aimed to assess these trajectories as affected by several drivers of change and to evaluate current landscape performances in terms of ecosystem services and food provision to propose landscape alternatives for improving food self-sufficiency without sacrificing other ecosystem services. This study was performed in the geo-cultural Mixtec region in south Mexico, and two municipalities were selected for in-depth analysis. The thesis is divided into four main chapters. First, I assess livelihood strategies and household typologies as affected by migration, government support, and changes in land tenancy policies. Second, I evaluate landscape change at the watershed and municipal level and link these changes to socio-economic and environmental drivers. I then highlight how communities manage their landscape according to their context-specific conditions, demonstrating that regional drivers of change might not be enough for describing land use change. Third, I evaluate changes in food self-sufficiency over time and show the nutritional advantages of milpa, an indigenous polycropping system, over the predominant monocrops of maize and bean. In the last main chapter, I assess the current landscape performance in terms of several nutritional, environmental, and socio-economic indicators to propose landscape configurations that asses multiple stakeholder objectives in conjunction.
\end{abstract}




\section{Contents}

1 Chapter 1: Introduction 3

1.1 Landscape and human interaction $\ldots \ldots \ldots \ldots$

1.2 Major transformations in the Mixteca Region . . . . . . . . . . . . . . . 3

1.2.1 The Mixteca region . . . . . . . . . . . . . . . . . . . . 3

1.2.2 Landscape changes and implications to Ecosystem Services . . . . 4

1.2.3 Socio-economic and livelihood changes . . . . . . . . . . . 6

1.3 Traditional agricultural systems and their importance to nutritional self-

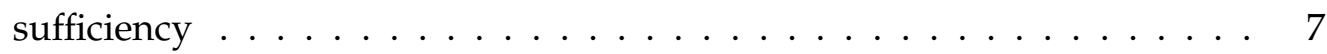

1.4 The need for managing productive and sustainable landscapes . . . . . . . . 8

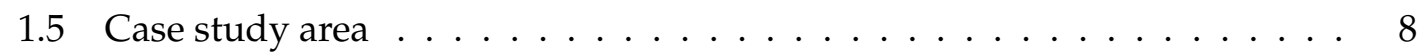

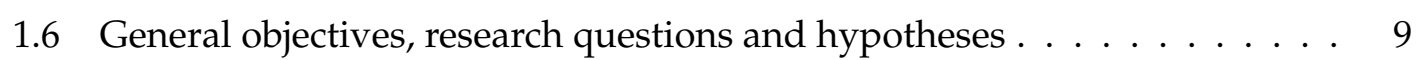

1.7 Thesis outline . . . . . . . . . . . . . . . . . . . . 10

2 Chapter 2: Longitudinal analysis of household types and livelihood trajec$\begin{array}{ll}\text { tories in Oaxaca, Mexico } & 13\end{array}$

2.1 Introduction . . . . . . . . . . . . . . . . . . . . . 15

2.2 Case study description and research methods . . . . . . . . . . . . . . . . . . . . . . . . . . 16

2.2.1 Case study area . . . . . . . . . . . . . . . . . . 16

2.2.2 Policies affecting change . . . . . . . . . . . . . . 17

2.2 .3 Data collection and analysis . . . . . . . . . . . . . . . . 19

2.3 Results . . . . . . . . . . . . . . . . . . . . . . 22

2.3.1 Household type description and changes over time . . . . . . . . 22

2.3.2 Levelihood trajectories and strategies . . . . . . . . . . . . . 23

2.4 Discussion . . . . . . . . . . . . . . . . . . . . . . . . . . . . . . 29

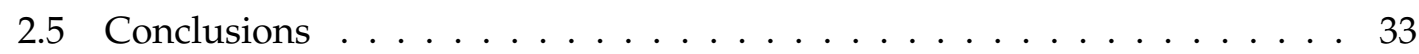

2.6 Acknowledgements . . . . . . . . . . . . . . . . . . . . . . 34 
3 Chapter 3: Back to the people: the role of global drivers versus communitybased responses at shaping landscape trajectories in Oaxaca, Mexico 37

3.1 Introduction . . . . . . . . . . . . . . . . . . . . . . . . 39

3.2 Materials and methods . . . . . . . . . . . . . . . . . . 41

3.2.1 Land tenure systems . . . . . . . . . . . . . . . . 41

3.2 .2 Case study area . . . . . . . . . . . . . . . . . 42

3.2.3 Land use change analysis for the Río-Sordo watershed . . . . . . . . 42

3.2.4 Land use change analysis for San Cristóbal Amoltepec and Santa Catarina Tayata . . . . . . . . . . . . . . . . . 44

3.3 Results . . . . . . . . . . . . . . . . . . . . . 46

3.3.1 Río-Sordo Watershed Land Use Change . . . . . . . . . . . . . . 46

3.3.2 Land Use Change in Santa Catarina Tayata and San Cristóbal Amoltepec . . . . . . . . . . . . . . . . 50

3.3.3 Local responses in SCA and SCT and impact on the land cover . . 54

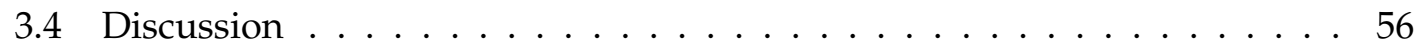

3.5 Conclusions . . . . . . . . . . . . . . . . . . . . . . . . . 59

3.6 Acknowledgements . . . . . . . . . . . . . . . . . . . . 60

4 Chapter 4: The role of traditional milpa in food security and food self$\begin{array}{ll}\text { sufficiency in the highlands of Oaxaca, Mexico } & 63\end{array}$

4.1 Introduction . . . . . . . . . . . . . . . . . . . . 65

4.2 Materials and methods . . . . . . . . . . . . . . . . 67

4.2 .1 Case study areas . . . . . . . . . . . . . . . 67

4.2 .2 Data sources . . . . . . . . . . . . . . . . . 67

4.2 .3 Land use change analysis . . . . . . . . . . . . . . . . 68

4.2.4 Calculations and statistical analysis . . . . . . . . . . . . 69

4.3 Results ........................... 72

4.3.1 Land use and food production dynamics . . . . . . . . . . . 72

4.3 .2 Nutritional self-sufficiency . . . . . . . . . . . . . . . 73

4.3.3 The role of traditional intercropping systems in nutrition . . . . . . 79

4.4 Discussion . . . . . . . . . . . . . . . . . . . 81

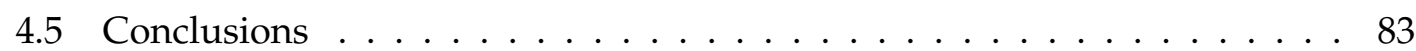

4.6 Acknowledgements . . . . . . . . . . . . . . . . 84

5 Chapter 5: Exploring alternatives for nutrient-sensitive landscapes $\quad 87$

5.1 Introduction . . . . . . . . . . . . . . . . . . . . . 89

5.2 Materials and methods . . . . . . . . . . . . . . . . . . . . 91 
5.2.1 Study area and production systems . . . . . . . . . . . . 91

5.2 .2 Modeling framework . . . . . . . . . . . . . . . 91

5.3 Results . . . . . . . . . . . . . . . . . . . 95

5.3.1 Current landscape performance . . . . . . . . . . . . 95

5.3.2 Exploring landscape configuration alternatives . . . . . . . . . . . . . . . . . . . . . . . . . . . . . . . .

5.4 Discussion . . . . . . . . . . . . . . . . . . . . 103

5.5 Conclusions . . . . . . . . . . . . . . . . . . . . 105

5.6 Acknowledgements . . . . . . . . . . . . . . . . . 106

6 Chapter 6: General discussion $\quad 109$

6.1 Introduction . . . . . . . . . . . . . . . . . . . . . . . 109

6.2 Assessing multi-level change: how households and landscape trajectories are related . . . . . . . . . . . . . . . . . . 111

6.3 The role of communities in landscape conservation . . . . . . . . . . 113

6.4 Integrating multi-scale trajectories in landscape management . . . . . . . 114

6.5 The importance of nutrition-sensitive landscapes approach . . . . . . . . . 115

6.6 Bringing the nutrition-sensitive landscapes approach to the Mixteca Alta and other contexts . . . . . . . . . . . . . . . . . 116

6.7 Conclusions . . . . . . . . . . . . . . . . . . . . . 118

$\begin{array}{ll}\text { References } & 119\end{array}$

$\begin{array}{ll}\text { Appendices } & 143\end{array}$

$\begin{array}{ll}\text { Summary } & 147\end{array}$

$\begin{array}{ll}\text { Samenvatting } & 151\end{array}$

$\begin{array}{ll}\text { Resumen } & 155\end{array}$

$\begin{array}{lr}\text { Acknowledgments } & 159\end{array}$

$\begin{array}{ll}\text { About the author } & 161\end{array}$

$\begin{array}{ll}\text { List of publications } & 163\end{array}$ 


\section{List of Figures}

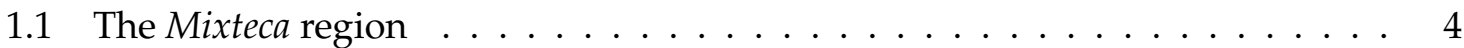

1.2 Erosion in the Mixteca region $\ldots \ldots \ldots \ldots \ldots \ldots$

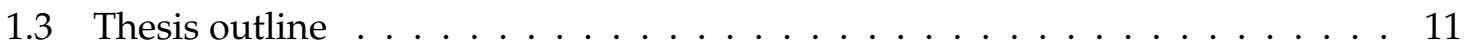

2.1 Case study geographical location $\ldots \ldots \ldots \ldots$. . . . . . . . . . 17

2.2 Drivers of change timeline . . . . . . . . . . . . . . . 20

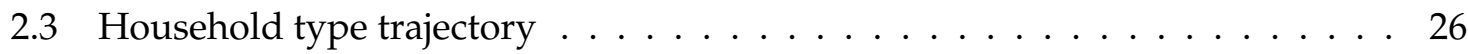

2.4 Household livelihood strategy $\ldots \ldots \ldots \ldots \ldots$. . . . . . . . . . 27

2.5 Off-farm income . . . . . . . . . . . . . . . . . . . . . . 28

2.6 Subsidies and family allowances . . . . . . . . . . . . . . . . . . 29

3.1 Current study cases land use . . . . . . . . . . . . . . . . . . 43

3.2 Land use change in the Rio-Sordo watershed between 1989 and 2017 . . . . . . 48

3.3 Drivers of change importance rank . . . . . . . . . . . . . . . . . . . 49

3.4 Marginalization and reforestation/deforestation relation . . . . . . . . . . . 49

3.5 Land use change in the study cases between 1984 and 2017 . . . . . . . . . . . 52

3.6 Land use change in the case study area . . . . . . . . . . . . . 53

3.7 Local drivers of change . . . . . . . . . . . . . . . . . . . . 55

3.8 Changes in animal production . . . . . . . . . . . 56

4.1 Case studies demographic change . . . . . . . . . . . . . . . . . 74

4.2 Changes in cropland and grassland . . . . . . . . . . . . . . . 75

4.3 Changes in the demand and supply of calories and protein . . . . . . . . 76

4.4 Nutrient and vitamin production according to the food source . . . . . . . 78

4.5 Nutrient and vitamin production according to the cropping system . . . . . 80

5.1 Current land use distribution in the case studies $\ldots \ldots$. . . . . . . . 97

5.2 Performance of alternative Pareto-optimal landscapes . . . . . . . . . . . . . 100 
5.3 Alternative landscape vitamin A production . . . . . . . . . . . . . 102

6.1 Main findings per chapter . . . . . . . . . . . . . . . 110

$1 \quad$ Appendix $1 \ldots \ldots \ldots \ldots \ldots \ldots$. . . . . . . . . . . . . . . . . . . . . . . . .

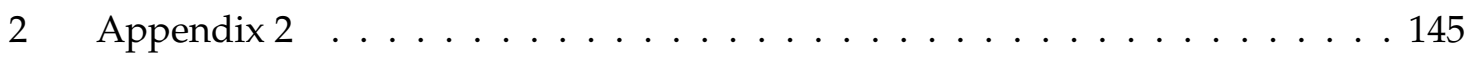




\section{List of Tables}

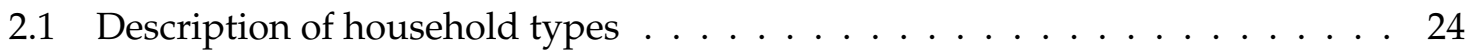

3.1 Satellite imagery . . . . . . . . . . . . . . . . . . . . 44

3.2 Percent of land use change in the Río-Sordo watershed between 1989 and 201747

3.3 Percent of land use change in the study cases between 1984 and 2017 . . . . . 51

4.1 Household types description $\ldots \ldots \ldots \ldots \ldots$

4.2 Nutritional facts of major food sources in the case studies . . . . . . . . . . 71

4.3 Total crop and animal production . . . . . . . . . . . . . 77

4.4 Labor efficiency and nutritional self-sufficiency according to the cropping

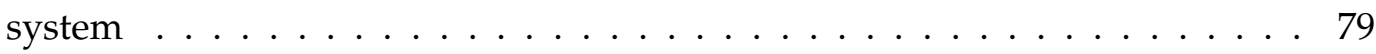

5.1 Indicators used to qualify nutritional, socio-economic and environmental

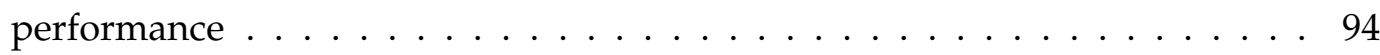

5.2 Current nutritional, socio-economic and environmental performances . . . 99 


\section{List of Abbreviations}

NSL Nutrition-Sensitve Landscapes

ES Ecosystem Services

LI Landscape IMAGES

SCT Santa Catarina Tayata

SCA San Cristóbal Amoltepec

PRONASOL Programa Nacional de Solidaridad

PROGRESA Programa de Educación, Salud y Alimentación

PROCAMPO Programa de Apoyos Directos al Campo

NAFTA North American Free Trade Agreement

GATT General Agreement on Tariffs and Trade

OOM out-of-bag 



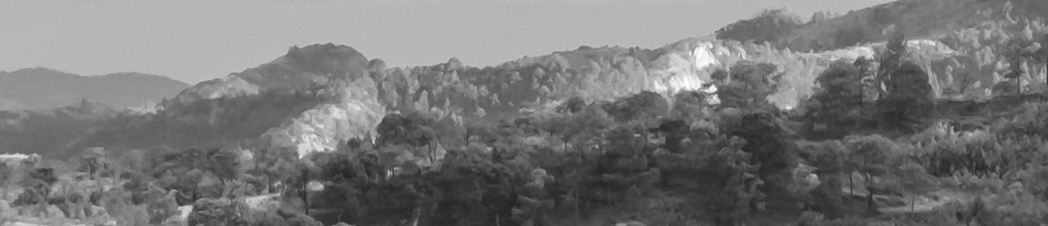

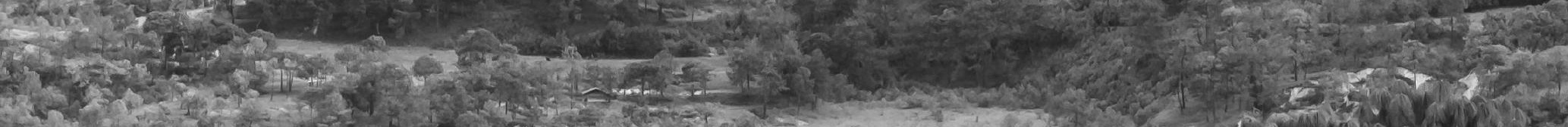

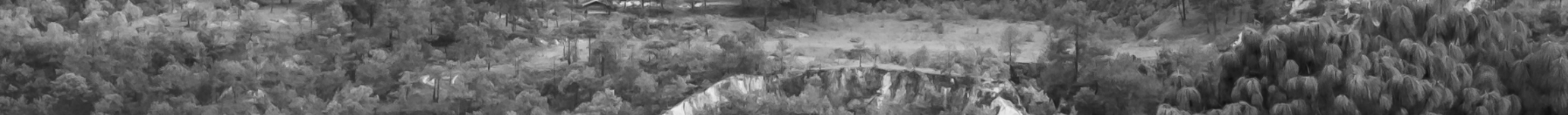

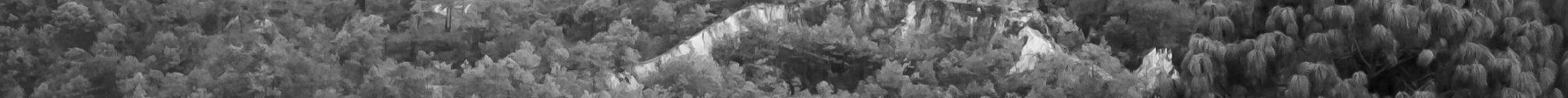
SA C.

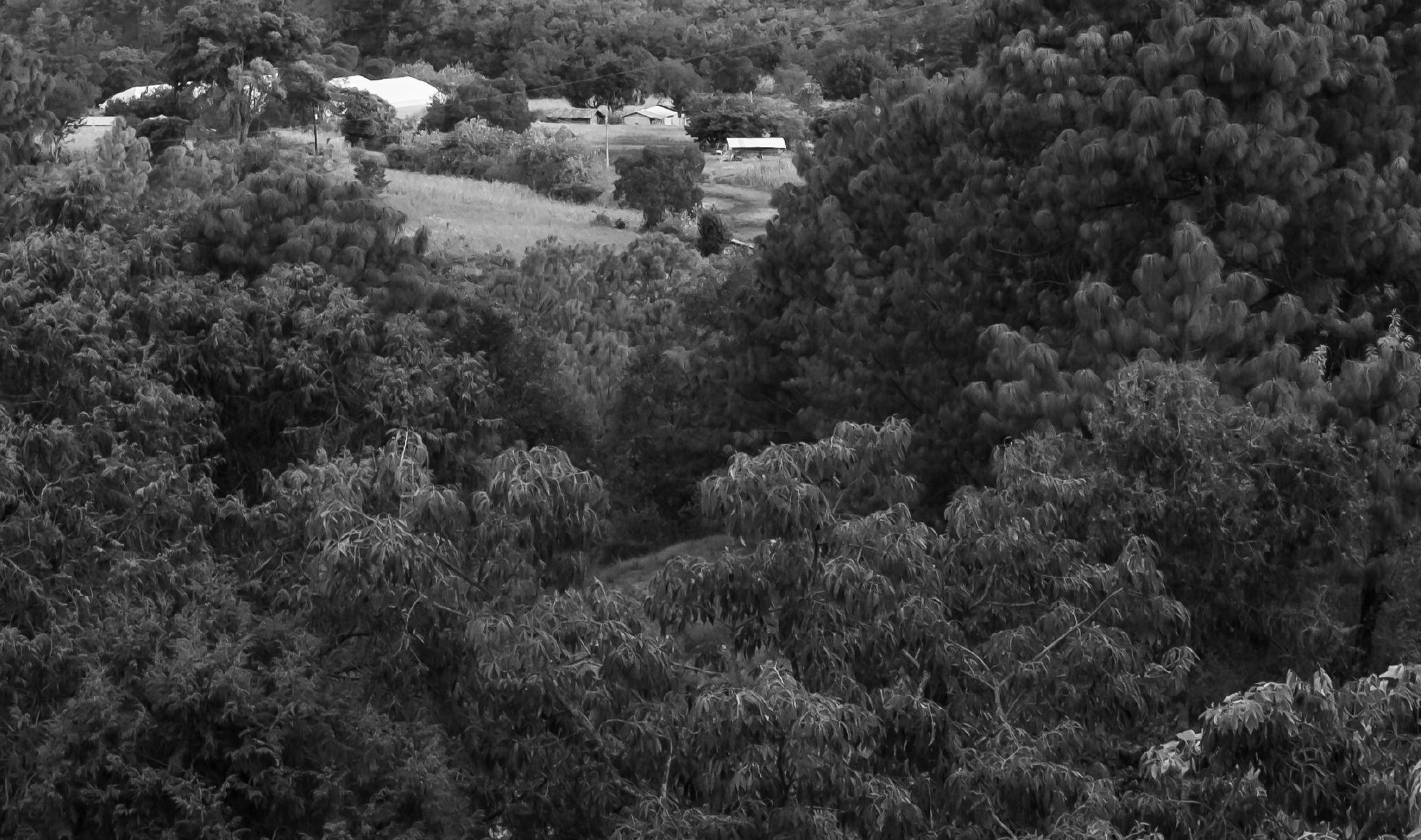




\section{Chapter 1: Introduction}

\section{1 | Landscape and human interaction}

Biophysical changes to landscapes affect their capacity to provide long-term Ecosystem Services, such as soil protection, carbon stocks, and climate regulation for sustaining and improving human well-being $(\mathrm{Wu}, 2013)$. These landscape changes are often associated with agricultural expansion and urbanization processes (Quintas-Soriano et al., 2016; Tolessa et al., 2017), and can cause natural resource depletion and reduce crop and animal production, which impacts rural livelihoods (or their capacity, assets, and activities of rural people for sustaining a means of living) and can lead to socio-economic changes such as induced marginalization (Carr, 2008; Keeler and Polasky, 2014; Xu et al., 2007). Therefore, landscape and socio-economic changes are related (Misselhorn, 2005; Shackleton and Luckert, 2015), and understanding how landscape and household trajectories affect one another is essential in the development of sustainable landscape-level alternatives for improving performance, in terms of ecosystem services and food production.

\section{2 | Major transformations in the Mixteca Region}

\subsection{1 | The Mixteca region}

The Mixteca region is located in the south of Mexico and is an estimated $33000 \mathrm{~km}^{2}$ in size. The region is known for its geographical and cultural diversity. The Mixtec civ- 
ilization developed quickly during the Mesoamerican postclassic period between AD 900 and 1500 (Palacio-Prieto et al., 2016); the population was known as Nuu Savi (People of the rain), a name that is still used to refer to people from this region (Mindek, 2003). Additionally, it is home to the fourth most populous indigenous group of Mexico, the Mixtecos, with a population of 0.5 million people (León Portilla and de México, 2013). The area extends across three neighboring states: Puebla, Guerrero and Oaxaca (PalacioPrieto et al., 2016) (Figure 1.1) and is divided into three major climatic zones (León Portilla and de México, 2013). The northern-most zone mostly consists of desert and semidesert. The highlands in the mid-section are characterized by temperate weather, erratic rainfall and a pronounced dry period. The southern-most part experiences tropical conditions, in part due to its proximity to the coast (Berumen Barbosa, 2004).

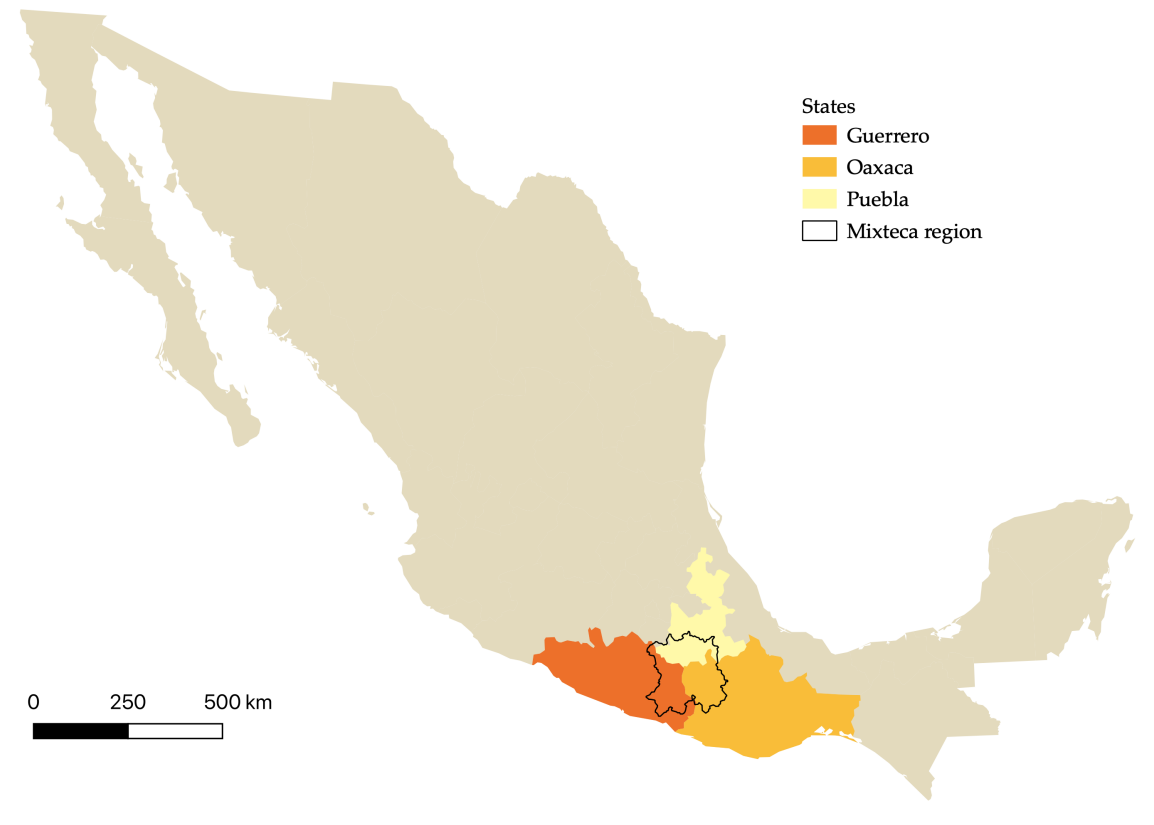

Figure 1.1: The Mixteca region inserted in three states, Guerrero, Oaxaca and Puebla.

\subsection{2 | Landscape changes and implications to Ecosystem Services}

The landscape in the Mixteca was shaped by land use changes arising from agricultural expansion, forest clearing and soil exposure. Agricultural expansion occurred around 
1400 B.C., when farmers settled in the fertile valley for maize cultivation (Mindek, 2003). Mixtec agriculture relied on terracing systems called lama-bordos, which were used to retain soil and increase crop yield (Pérez, 2006). Many of these terraces started degrading when farmers were displaced from their fields to live in settlements during Spanish colonization (Pérez, 2017, 2006). Soil degradation was further intensified when the Spanish colonists introduced sheep and goats, as well as began to log the area. These processes in combination with a soil formation sensitive to degradation (López, 2015) have left the characteristic red soil exposed in a large part of the Mixteca Alta region (Figure 1.2).

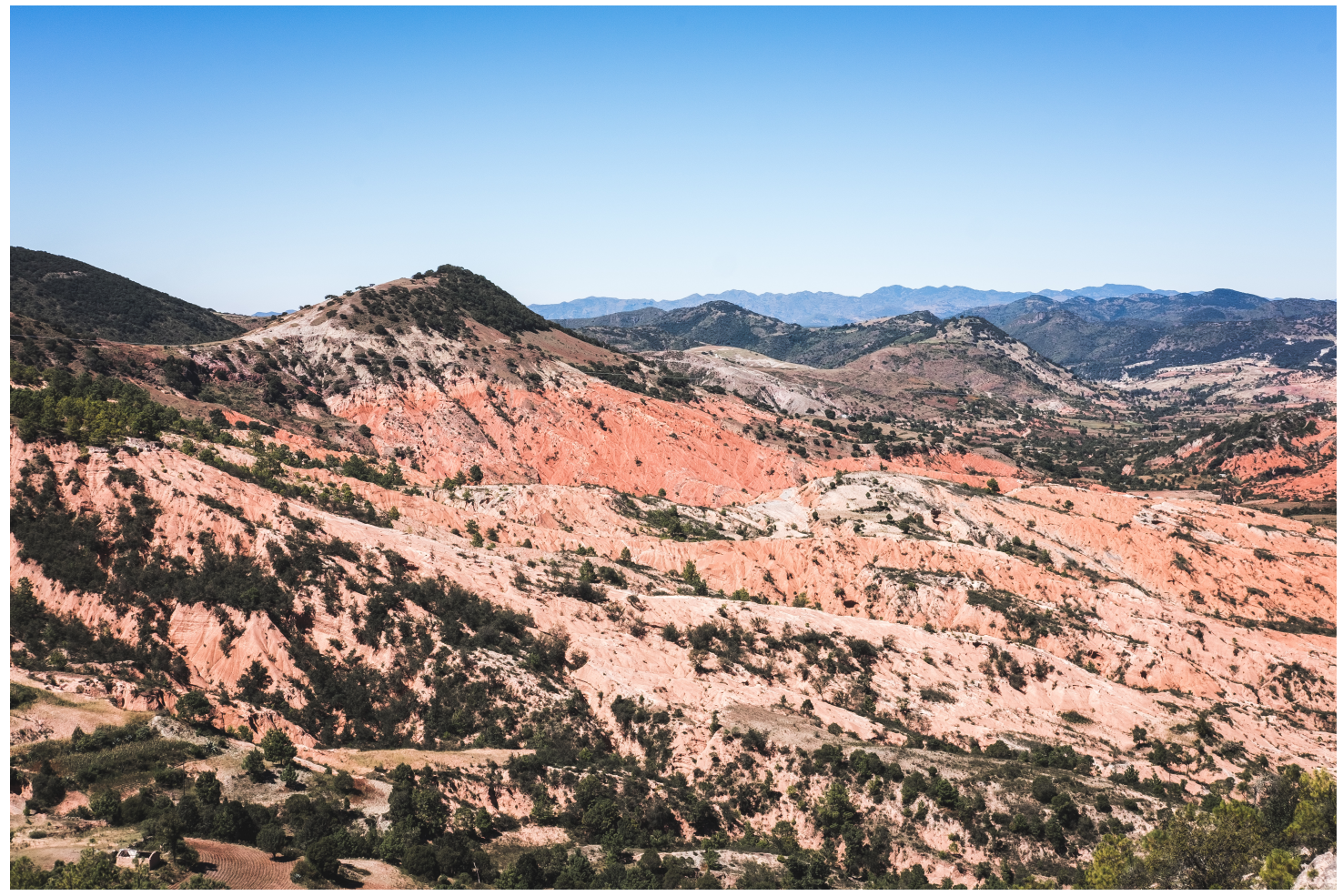

Figure 1.2: A typical view of the extent of soil erosion in the Mixteca region

Land use changes are associated with ecosystem service trade-offs (Iverson et al., 2014). Ecosystem services (ESs) are benefits that nature supplies to humans (Sullivan, 2009). They are classified into four categories: provisioning (e.g. water, timber, and food), regulating (e.g. climate, flood, and pest control), supporting (e.g. nutrient cycling, soil formation, and photosynthesis) and cultural (e.g. aesthetics, recreational, and spiritual) (Millennium Ecosystem Assessment, 2005). Human society depends on these ESs for their survival, and yet, anthropogeic influences in the landscape threaten their existence (Balmford and Bond, 2005; de Groot et al., 2012; Galán et al., 2012; Millennium 
Ecosystem Assessment, 2005; Mouchet et al., 2014; Quintas-Soriano et al., 2016; Swallow et al., 2009; Tolessa et al., 2017).

In the Mixteca region, the intensification of deforestation, overgrazing, and cropping activities during the Spanish colonization contributed to locally severe soil erosion. Soil losses negatively affect other ESs such as food production (Contreras-Hinojosa et al., 2003, 2005) and water quality and availability due to sediment deposition (BautistaSánchez et al., 2013). Intensive deforestation increased biodiversity loss of fauna and flora, which, consequently, impacted the region's tourism industry (Guerrero-Arenas et al., 2010).

Between 1917 and 1991, Mexico went through a land reform process, which granted rural communities more autonomy to manage their land according to locally agreed upon rules and regulations (Assennato and León, 2007; Morett-Sánchez and Cosío-Ruiz, 2017; Osorio, 1999; Pérez and Mackinlay, 2015). Community landscape management is common among the indigenous groups in the Mixteca region (Palacio-Prieto et al., 2016), and number of studies showed some promising results for forest conservation enacted by these communities (Bray et al., 2008; Duran et al., 2005; Ellis and Porter-Bolland, 2008). Considering estimations that $80 \%$ of the forest in Mexico is under communities' control (Bray and Merino-Pérez, 2007), communities play an important role in natural resources conservation. Nevertheless, there is little insight into what drives these communities to conserve their landscapes.

\subsection{3 | Socio-economic and livelihood changes}

Poverty in Mexico is high and persistent. The overall average poverty for the country marginally decreased from 44.4 to 41.9\% between 2008 and 2018 (CONEVAL, 2018). Over the same period, poverty in the state of Oaxaca rose from 62 to $66.5 \%$. Associated with this, rural households face problems such as low opportunities for investments in agriculture (e.g. irrigation systems and inputs), low yields from crop and animal production, a lack of technical support for agriculture, low financial returns on agriculturerelated investments, and a lack of employment alternatives (Aguilar, 2008). This has led to the migration of many people to other regions (Guerrero-Arenas et al., 2010; Katz, 2008) and has caused a population decline in several communities (Bocco et al., 2019; Juárez and Margarita, 2008).

Fighting rural poverty has been part of the government's agenda, but its approach to tackling the issue shifted after the North American Free Trade Agreement (NAFTA). Before NAFTA, policies largely focused on subsidizing agriculture (Ávalos-Sartorio, 2006). After the agreement, Mexico changed its focus to become more competitive in the global 
market. It has been criticized for providing the support that mostly benefited largescale farmers while stimulating disinterest in agriculture among smallholder farmers (Zarazúa-Escobar et al., 2011). Even though policies tried to enhance the agricultural sector, 1.3 million jobs were lost in about 10-years' time (Audley et al., 2003). While recognizing that these socio-economic situations and policies affect rural households, few analyses have revealed how different households react to these drivers. Such knowledge would give deeper insight into the impact that policies have on livelihood changes.

\section{3 | Traditional agricultural systems and their impor- tance to nutritional self-sufficiency}

Mesoamerica is one of the six cradles of global agriculture (Harlan, 1971). The rich bio and cultural diversity in Mexico contributed to the domestication of at least 100 plant species such as maize (Zea mays), common bean (Phaseolus vulgaris), squash (Cucurbita spp.), cacao (Theobroma cacao), papaya (Carice papaya) and tobacco (Nicotiana tabacum) (CONABIO, 2010). Milpa systems are of particular importance to Mexico. This term is derived from Spanish and refers to maize fields (Nigh and Diemont, 2013). These systems involve intercropping maize with other species, such as common bean, fava bean (Vicia faba), squash, and chili (Capsicum spp.) (Lozada-Aranda et al., 2017; Semillas de Vida, 2014). Traditionally, milpa is a type of swidden, and its cycle can take up to 25 years (Nigh and Diemont, 2013). Milpa composition and cycles depend on the agroclimatic conditions of the area (Lozada-Aranda et al., 2017).

Milpa also has a nutritional and cultural relevance, as the crops that it constitutes are commonly found in Mexican cuisine (Oikos, 2017). Furthermore, milpa is the nutritional foundation of many subsistence farmers (de Frece and Poole, 2008; Gurri and Moran, 2002; Horst, 1989; Isakson, 2009; Klepeis et al., 2004; Nigh and Diemont, 2013). Nevertheless, there are accounts of households abandoning the milpa production in favor of monocropping systems (Gutierrez-Carbajal and Magaña-Magaña, 2017; Otero Prevost et al., 2018; Vázquez González et al., 2018). Such system simplification has been attributed to policies that focus on cash crops instead of subsistence production (Morales et al., 2015; Zarazúa-Escobar et al., 2011), and to the high labor requirements and low availability of labor (Aguilar, 2008). Abandoning the milpa system can have consequences for nutritional self-sufficiency (or the ability of a place to provide food that satisfies its nutritional needs). Therefore, it is necessary to understand the nutritional implications of replacing milpa with other systems, while promoting alternatives to gain back farmers' interest in growing milpa. 


\subsection{The need for managing productive and sustain- able landscapes}

The Nutrition-Sensitve Landscapes approach combines ESs with UNICEF's nutritional conceptual framework to integrate nutrition and landscape conservation (Kennedy et al., 2017). The approach aims to account for the "complex interactions and interconnectivity within a given landscape to optimize the multiple goals of food and nutrition security, sustainable use of natural resources and conservation of biodiversity, both for human health, as well as environmental health" (Bioversity International, 2014). A growing body of literature has studied landscape performances in terms of trade-offs between ESs and/or how these services are bundled (Andersson et al., 2015; Balbi et al., 2015; Martín-López et al., 2012; Mouchet et al., 2014; Queiroz et al., 2015; Rodríguez et al., 2006; Tomscha and Gergel, 2016; Yang et al., 2019; Zhang et al., 2007). While these studies are useful for understanding the interactions among ESs, they do not propose how landscapes should be re-designed to optimize the ESs in a way that is useful to the population. The Landscape IMAGES modeling framework (Groot et al., 2007) offers a robust option for exploring landscape alternatives in terms of multiple objectives. This framework can help landscape planners at different governance levels to implement NSL principles for improving nutritional self-sufficiency while avoiding or mitigating ESs degradation. The approach also helps planners to identify trade-off relations between ecosystem services to promote landscape alternatives that minimize the effects of these relations.

\section{5 | Case study area}

This study was conducted in two municipalities in the Mixteca Alta region, Santa Catarina Tayata and San Cristóbal Amoltepec. These communities are representative of the area, reflecting their economic marginalization, population migration, and resource degradation. Both municipalities comprise common land, private land and, settlement areas. Common land is where most of forest and grassland areas are found. Private land is used for cropping activities. Settlements mostly consist of housing and were not included in this study. The predominant cropping systems in the communities were monocultures of maize and bean. Milpa systems, while still present in the area, were the least frequent cropping system. Sheep were the most common type of livestock. 


\section{6 | General objectives, research questions and hy- potheses}

The overarching goal of this thesis is to assess household and landscape trajectories as a basis for re-designing landscapes to meet the nutritional self-sufficiency of local populations while improving ecosystem services provision. The specific objectives and the associated research questions are:

- To describe household trajectories and their responses to different drivers of change over the past 30 years (Chapter 2)

- Which categories of drivers of change exist and how did they affect the evolution of different household types?

- To describe land use change in the Mixteca Alta region at the watershed and municipal levels, and its association with socio-economic and environmental drivers (Chapter 3);

- What drives landscape change at the watershed and municipal level and what is the role of the communities in these changes?

- To assess the nutritional benefits of milpa in comparison with monocultures of maize and bean (Chapter 4);

- What are the relative contributions of milpa and maize and bean monocultures to nutritional self-sufficiency at the municipal level?

- To propose future landscape configurations that are designed based on multiobjectives that account for community-specific problems for maximizing nutritional self-sufficiency and reducing environmental damage (Chapter 5).

- What are landscape alternatives for improving nutritional self-sufficiency and mitigating ESs losses?

The following four hypotheses were discussed in the four main chapters of this thesis:

- Households respond differently to drivers of change, leading to diversification of household types; 
- Communities have an active role in landscape change, which is shaped by community history, demography, land pressure and population demand for food;

- Food security through self-sufficiency in rural communities can be improved through traditional and complex agricultural systems, but labor restrictions and low production are obstacles to achieving food self-sufficiency, and;

- Improving nutritional self-sufficiency at the landscape level requires a multiobjective analysis for proposing landscape configurations that aim at improving these objectives.

\section{7 | Thesis outline}

This study was performed in the Mixteca Alta region in the Oaxaca state, Mexico and addressed three levels: watershed, municipality and household. The thesis is divided into an introduction (this chapter), four chapters with novel research results, and a general discussion (Figure 1.3).

Chapter 2 explores the relation between drivers of change and household trajectories as well as actors like household response to land tenure, government support and migration.

Chapter 3 addresses the topic of landscape change as it is affected by socio-economic and environmental drivers. Watershed-level landscape trends are compared to municipal changes, highlighting the role of communities in land use change.

Chapter 4 focuses on the communities' nutritional self-sufficiency. The traditional milpa system is compared with maize and bean monocultures in terms of nutritional production. The performance of each system in terms of people fed per area is compared as well.

Chapter 5 focuses on landscape performance in terms of ESs and nutritional selfsufficiency. Here the findings of the previous chapters are used in the LI modelling approach to take local stakeholders' objectives into account and explore alternative landscape configurations.

The general discussion (Chapter 6) explores the connection between household and landscape changes. The role of communities in landscape management and the importance of nutrition-sensitive landscapes in the Mixteca Alta context are discussed. 


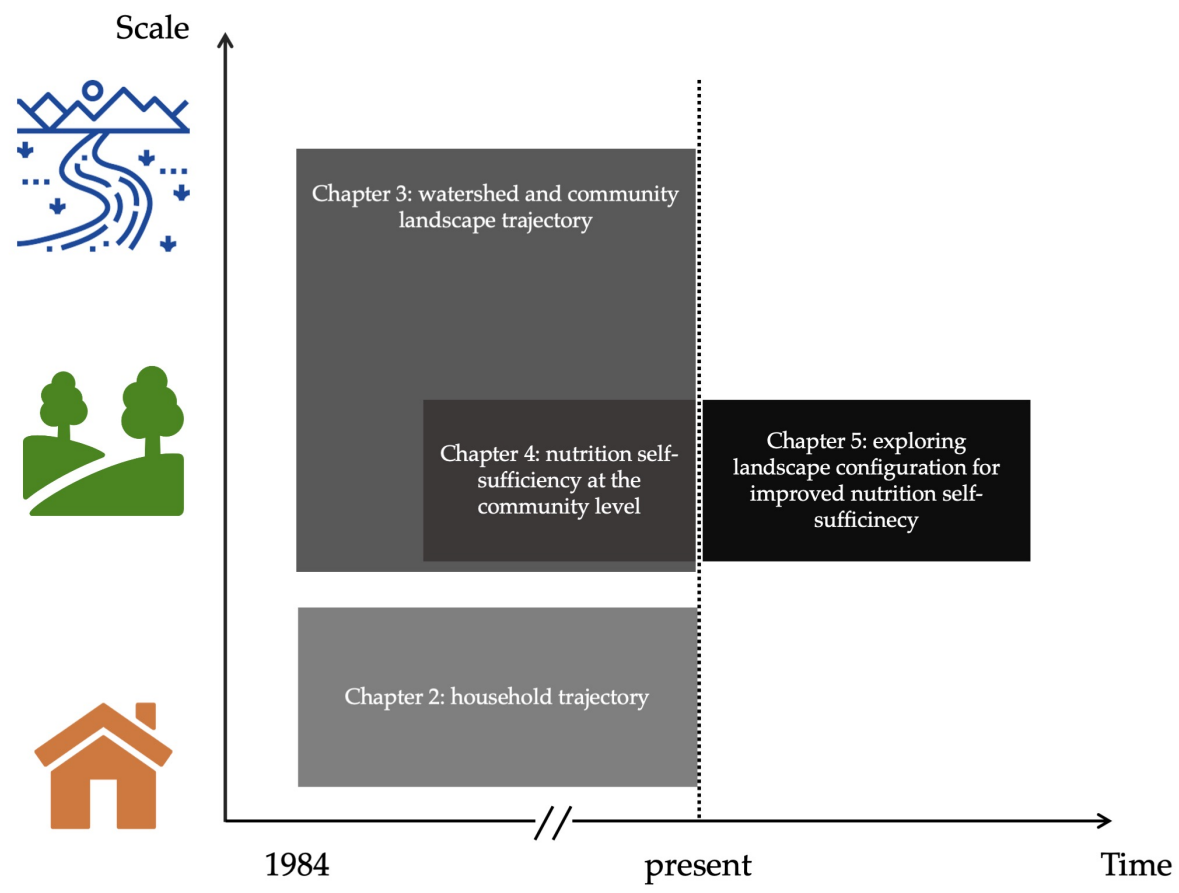

Figure 1.3: Thesis outline according to the temporal and spatial scales studied 


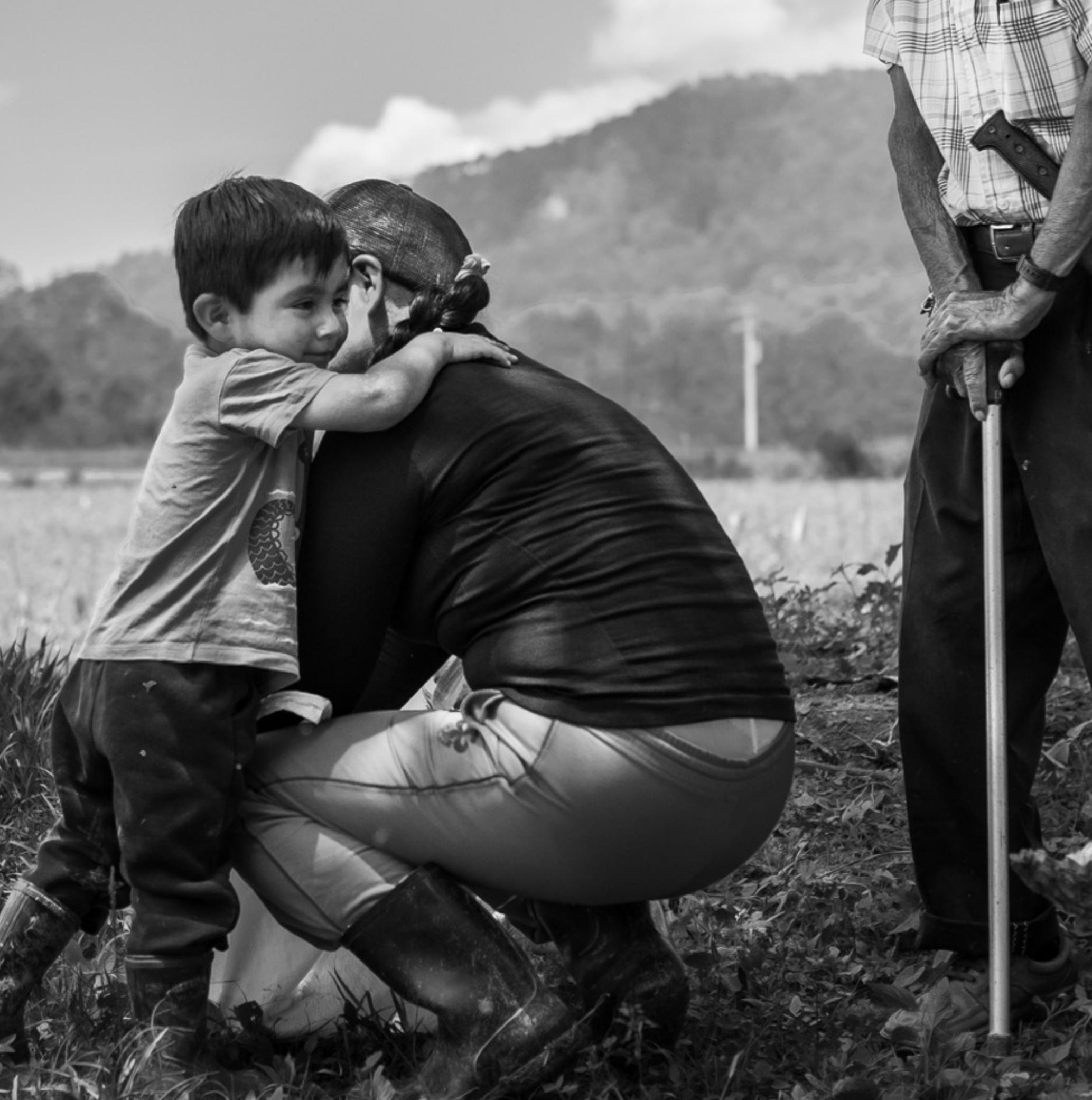




\section{Chapter 2: Longitudinal analysis of household types and livelihood trajectories in Oaxaca, Mexico*}

\section{Abstract}

Rural households are subject to the influence of multiple drivers of change and the response to these drivers defines unique trajectories. This study focused on the relation between drivers of change and household trajectory. The study was carried out in Santa Catarina Tayata, in the state of Oaxaca, Mexico. We asked 44 household heads about the history of the household and to recall the status of their farm at significant moments. The results were summarized as variables describing the socio-economic and agronomic situation of the households over three decades: 1988-1997, 1998-2007 and 2008-2017. We then identified household types for each decade. Three household types were distinguishable in the first two decades, and five in the last decade. We assessed the drivers of change such as international markets, land tenure, government support and migration, and their impact on livelihood trajectories. Our results showed that household type diversity increased, while half of the households changed types at one point according to different strategies. We observed changes in land tenure in our study

*Based on article under review by the Journal of Rural Studies: Novotny, I; Rossing, W; López-Ridaura, S, Tittonell, P; Fuentes-Ponce, M. Longitudinal analysis of household types and livelihood trajectories in Oaxaca, Mexico 
area in the early 2000s that were attributable to the PROCEDE national program, which acted to lift restrictions on land tenure, facilitating the buying and selling of land. As result of PROCEDE, less households relied on borrowing or renting land, while other households were able to expand their land and form a new household type. We observed that migration allowed some households to invest in land or animal production as a "step up" strategy. The majority of households that received agriculture-related subsidies tended to engage solely in agricultural activities. Households that had off-farm income either received family allowances or did not receive any type of government support, suggesting that the type of governmental support can have an impact on farming activities. Furthermore, household types that had more animal production or larger areas did not tend to engage in off-farm activities. This type of study can be used to monitor policy impact and households' strategic responses, to arrive at better articulation of policy objectives and policy impact while considering household type diversity. 


\section{1 | Introduction}

The livelihoods of smallholders, or, their capabilities, assets, and activities for producing a means of living, change as they adapt to globalized processes such as international and rural-urban migration or increased global trade (Fabricius et al., 2007; Speelman et al., 2014; Tittonell, 2014; Zimmerer, 2007). In addition to globalization, local drivers of change exist in socio-ecologically complex contexts such as traditional small-scale Mexican agriculture that contribute to shaping livelihoods over time. Changes over time in patterns of household livelihoods are called livelihood trajectories (Bagchi et al., 1998). Analysis of long-term livelihood trajectories can bring out the role of political, demographic, economic, and environmental drivers of change (Carney, 1998; Reidsma et al., 2010) on households' on- and off-farm income, social relations and material assets (Mushongah and Scoones, 2012). By contextualizing these trajectories, insights are gleaned with which to enhance the efficacy of policies, development interventions, and research agendas for improving livelihoods in rural areas.

Agriculture in Mexico is subject to several drivers, particularly in the case of smallscale agriculture in poor areas, challenged by lack of natural, economic and social resources (Speelman et al., 2014). Furthermore, the contribution of agriculture to the Mexican GPD has been declining, and the agricultural labor force diminishing (UN, 2014). In Mexico, the General Agreement on Tariffs and Trade in 1986 and the North American Free Trade Agreement in 1994 had several effects on poor rural areas (González and Alferes, 2010; Klepeis and Vance, 2003; Sweeney et al., 2013). Both implied a shift in policy focus from controlling crop prices to opening the market and reducing protectionism. Competition with maize imports from the US resulted in decreases in the price of maize and other agricultural products (Barnes, 2009) and led to a decrease in farmer income (Nicita, 2004), which forced farmers to diversify their income sources (Avalos and Graillet, 2013; Patel and Henriques, 2003). Many households also resorted to migration making remittances an important source of household economic stability (Taylor et al., 1999). The GATT and NAFTA agreements resulted in greater legal options to buy and sell land, enhancing land use dynamics in rural areas (Barnes, 2009). Several types of government support were deployed to mitigate socio-economic hardship in rural areas and increase the competitiveness of Mexican farmers in an open market (Winters and Davis, 2009). Considering the diversity in agricultural systems and socio-ecological contexts in Mexico (Speelman et al., 2014), it is safe to expect that these drivers affected households in different ways. Yet little is known about the relations between drivers of change and household trajectories, hampering feedback on the efficacy of policy measures. 
One way to assess the degree to which drivers impact households is by categorizing households into types (Iraizoz et al., 2007). However, this approach only provides a single snapshot in time, failing to capture the dynamics of households. Studies by Falconnier et al. (2015) and Chopin et al. (2015) addressed this issue by considering that individual households may change over time. They assumed, however, that the household types remained unchanged, thereby ignoring changes in the pattern of livelihoods. We hypothesize that drivers not only affect individual livelihood trajectories but also affect household types and their evolution through time. Here we studied the pattern of livelihood trajectories in a case study municipality in Oaxaca, one of the poorest states in Mexico (Juárez and Pfutze, 2015). Like other communities in the state (Juárez and Margarita, 2008) the municipality is experiencing high migration and a declining demography (INEGI, 2010). We decided on the case study approach for its advantages over other approaches to explain how drivers affect households (Yin, 2018). We gathered quantitative and qualitative information from the literature and through household interviews to identify drivers of change related to international trade, migration, land reforms and government support in the form of agriculture subsidies and family allowances. In the interviews we used a recall method to reconstruct the household histories up to 30 years. This information was then combined into household typologies to reveal how household types evolved over time, and to relate these household-level changes to changes in the drivers.

In this paper we describe the case study area and list policies that may have affected livelihoods over the past three decades. We then elaborate the approach used to elucidate the changes in household livelihoods and the classification of households into types. We finally present the pattern in livelihood trajectories and discuss the consequences for policies.

\section{2 | Case study description and research methods}

\subsubsection{Case study area}

The municipality of Santa Catarina Tayata (SCT) $\left(37.22 \mathrm{~km}^{2}\right)$ is located in the state of Oaxaca, Mexico, at an elevation of 2000 to $2500 \mathrm{~m}$ above sea level. The climate is temperate sub-humid, with average temperatures ranging from 16 to $18^{\circ} \mathrm{C}$ and annual rainfall between 1000 and $1200 \mathrm{~mm}$. Land use in SCT can be divided into three major categories; settlement areas, privately-owned plots and communal land (Figure 2.1). Settlement areas comprise the majority of houses and the local administration facilities. Privately-owned plots are predominantly used for crop production. Communal plots 


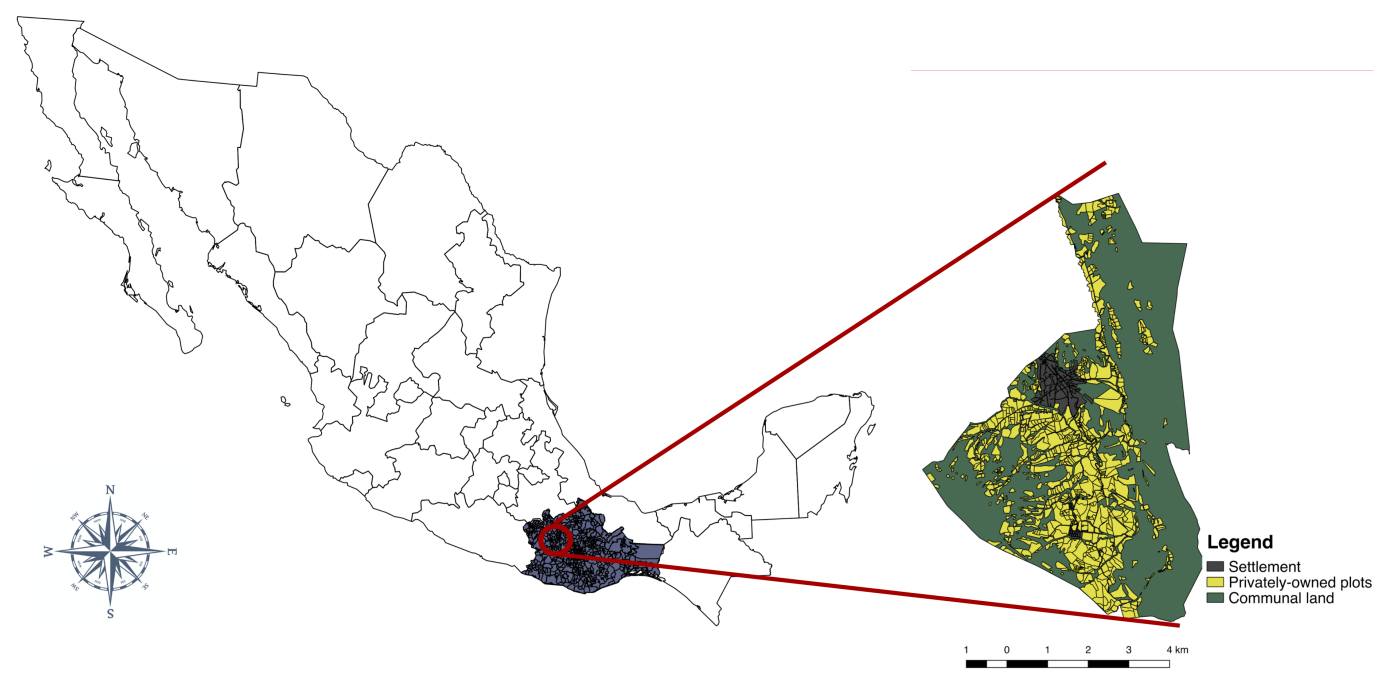

Figure 2.1: Geographical situation of Santa Catarina Tayata in the state of Oaxaca, Mexico. Colors on the map represent land uses: settlement area (gray), agriculture (yellow), communal land (green).

mostly comprise forests, but farmers use areas without trees as pasture for their animals. The main economic activity in the area is rainfed agriculture, although small irrigation systems can be found. The area of arable land per household ranges from 0.5 to 12.5 ha. The agroecosystems are diverse, with a predominance of maize (Zea mays L.) for human and animal consumption and beans (Phaseolus vulgaris L., Vicia faba L.) exclusively for human consumption. Maize and beans are grown either as monoculture or in mixed crop stands such as the milpa system that also includes squash (Cucurbita spp.) (Ebel et al., 2017; Hernández and Bello, 1995). Every household is involved in animal production. On average households have 7 chickens and 10 sheep. Households usually do not sell their production due to physically difficult access to larger towns. Instead, production is used for consumption within the household. Income is mainly generated by providing labor for sowing, weeding and harvesting on the land of other local farmers.

\subsection{2 | Policies affecting change}

Based on a literature review and a survey performed in the area prior to this study, we identified four domains in which policies potentially affected livelihood trajectories 
in the case study area. These domains comprise land tenure, international trade, government support and migration (Figure 2.2). The review included articles, reports and books on topics of importance to rural dynamics in Mexico.

Land tenure - The Mexican constitution of 1917 stipulated the creation of the Ejido system of communal land tenure as part of the agrarian reform (Assennato and León, 2007), which enabled the distribution of land to formerly landless people. This land could not be sold and was to be worked by the owner (Núñes, 2000). The Ejido system was changed in 1992 as one of the consequences of the NAFTA (Barnes, 2009), giving farmers the right to sell their land (Klepeis and Vance, 2003). The federal Program for the Certification of Ejido and Land Ownership Titles (PROCEDE by its Spanish acronym) was introduced in order to implement the privatization process and provide clarity on land tenure. While the land tenure regulation process implemented through PROCEDE started in 1992, the local authority of Santa Catarina Tayata only permitted the process to take place in 2000, after approval by the local assembly. Within 5 years tenure of the land in the municipality was regulated.

International trade - The General Agreement on Tariffs and Trade (GATT) had an impact on the Mexican agrarian sector by reducing state influence and increasing the role of markets in agriculture by 1990 (Núñes, 2000; Pérez-Soto et al., 2016; Sweeney et al., 2013). As a consequence of the GATT, tariffs on imports of agricultural products and subsidies on inputs were either removed or reduced (Foley, 1995; Klepeis and Vance, 2003). Furthermore, government intervention in crop prices, established to guarantee a minimum price, was abolished for all crops except maize and beans (Foley, 1995). The North American Free Trade Agreement (NAFTA) consolidated the reforms started during the GATT period.

Government support - The National Solidarity Program (PRONASOL by its Spanish acronym) was created in 1991 to mitigate poverty in rural areas (Yúnez and Barceinas, 2000). Considering that two thirds of the Mexican population lived in extreme poverty (Bank, 2005), the PRONASOL provided monetary loans for subsistence production and development of sustainable agricultural activities. It supported activities such as forestry, agroindustry and extracting industries, and stimulated regional development through better infrastructure, such as road access (FAO, 2003). Since the creation of PRONASOL, the program has undergone changes with each new president, changing its name to PROGRESA, OPORTUNIDADES, and to its current title PROSPERA. From PROGRESA onwards, governmental support mainly consisted of providing family allowances for poor households.

In 1993, the PROCAMPO program was created to support farmers and mitigate hardship ensuing from the agricultural section of NAFTA (Shwedel, 1994). The main 
objectives of PROCAMPO were to improve domestic and international competitiveness in the private and social sector, improve the livelihood of rural families and modernize the marketing system by providing financial resources to stimulate production of crops more profitable than maize (Pérez-Soto et al., 2016; Zarazúa-Escobar et al., 2011). In practice, the program gave financial support to farmers in proportion to the acreage of particular crops (Avalos and Graillet, 2013; Klepeis and Vance, 2003; Sweeney et al., 2013). PROCAMPO changed its name in 2014 to PROAGRO (SAGARPA, 2016), but we only refer to PROCAMPO in this article. PROCAMPO together with the PROGRESAPROSPERA programs aimed to reduce poverty in rural areas (Naude et al., 2015).

Migration - An important phase in managing migration between Mexico and the USA was the Bracero program, which was a bilateral agreement on temporary migration between the countries. The program started in 1942 and ended in 1964. After the Bracero program ended, migration became characterized by the illegal flow of Mexicans to the USA. This flow of migrants was stimulated by the perception of better prospects in the USA and facilitated by emigrants themselves, who provided financial assistance to their family members still living in Mexico (Santos, 2017). The state of Oaxaca has around 4 million inhabitants and ranks $9^{\text {th }}$ in terms of state-wide migration (INEGI, 2010). While migration from Oaxaca to the USA is important, domestic migration is also common. For instance, between 1995 and 1999 0.5\% of inhabitants of Oaxaca left for another state on an annual basis. In 2010, migration numbers dropped to $0.12 \%$ (CONAPO, 2016). Migration resulted in negative population growth in many municipalities of Oaxaca, especially during the 1990s (Juárez and Margarita, 2008).

\subsection{3 | Data collection and analysis}

Livelihood trajectories of farm households were collected through in-depth interviews. In mid 2017, local authorities in SCT were consulted on candidate households, wellspread across the geographic extent of the municipality. This resulted in 44 households that were available and willing to participate in the study out of around 160 households in the municipality. The interviews followed a semi-structured format to enable exploring topics that would have been overlooked in a structured interview (Mapedza et al., 2003). We included questions regarding past animal and crop production, migration and different sources of income, as is common in studies on livelihoods (Mushongah and Scoones, 2012; Scoones, 2009; Tittonell, 2014). We tried to make farmers recollect their past by asking them about important events in their lives and connecting these to changes in their households. For instance, we would begin by asking them the time by which they were responsible for their first plot, marking thus the beginning of their 
Chapter 2.

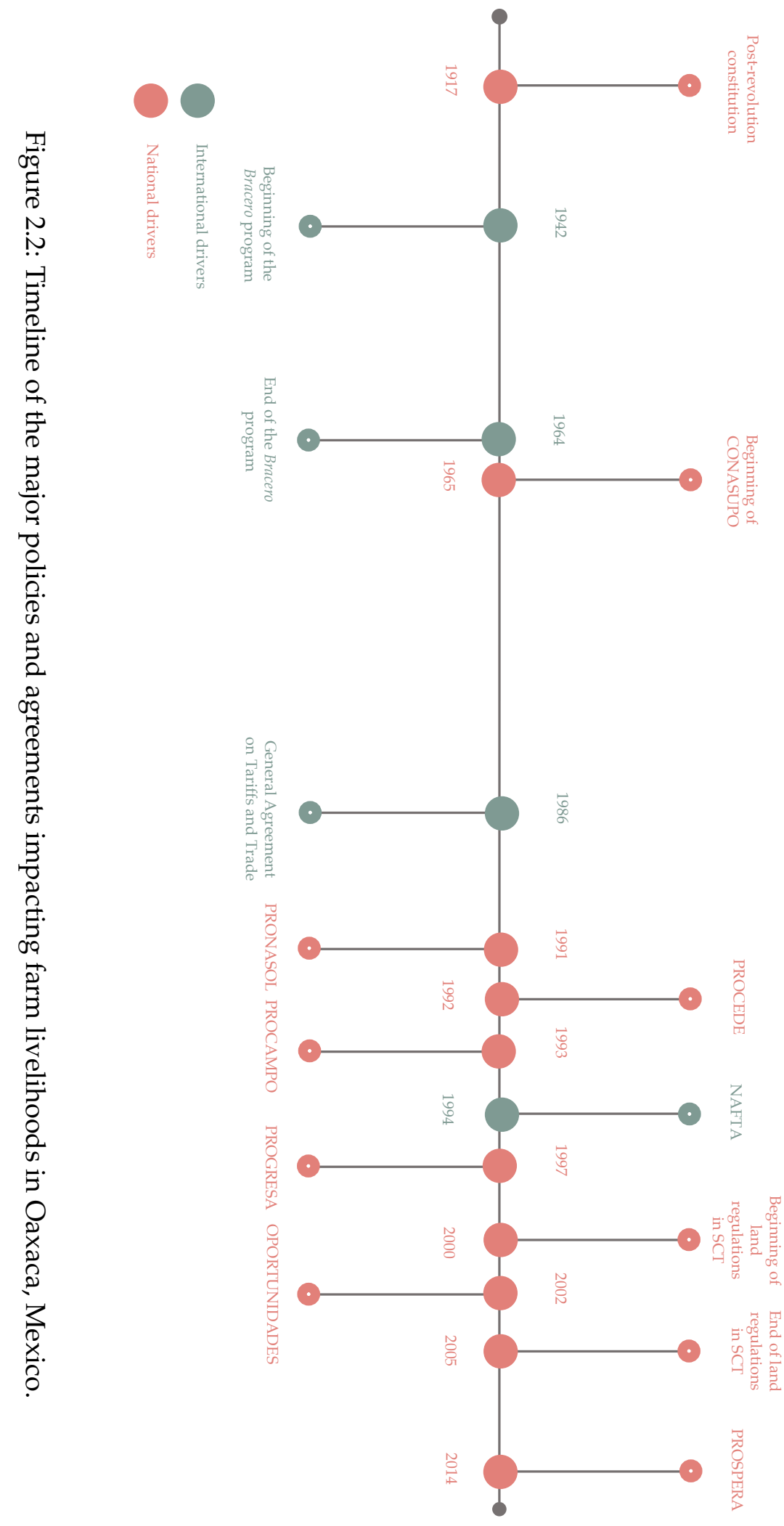


farm household. To track major changes in their production system, we would ask, for example, about the size of the current herd and consequently we would ask if they used to have more or fewer animals in the past. This process was repeated until we could no longer identify changes. During the interviews, we would also ask farmers to explain why a certain change occurred. In the case of migration, we asked when a family member had left, where they had gone and whether they had returned. When we finished talking about a specific topic we would repeat the answers provided so the interviewees could corroborate or correct them. Results of the interviews were discussed with the local authorities in September 2018 to corroborate the trends in the data.

The interview data were organized into three sub-periods of ten years each, starting in 1988 and ending in 2017. The resulting sub-periods were 1988-1997, 1998-2007 and 2008-2017. We selected 1988 as the starting year because more than 20 of the 44 household heads were farming at that time. In addition, 1988 was several years prior to the NAFTA, allowing to see changes in household trajectories caused by this driver. The number of households analyzed per decade increased over the three decades as a consequence of farmers establishing their own households. The number of households per decade was 24, 34 and 44 for 1988-1997, 1998-2007 and 2008-2017, respectively. Organizing the data in 5-year periods did not yield new insights and proved to be harder to interpret.

We classified households into types per decade and associated the household trajectories across decades with household strategies identified in the literature. To make the classification into types per decade, households were clustered based on quantitative variables using principal component analysis (PCA) followed by hierarchical cluster analysis (HCA) (Alvarez et al., 2014; Chopin et al., 2015; Tittonell et al., 2010). We used the following quantitative variables: land area (owned, borrowed or rented), tropical livestock units (TLU), number of crops and number of household members who migrated. Animals owned were converted to TLU based on 1 TLU being equivalent to a cow of $250 \mathrm{~kg}$ (Jahnke, 1982). TLU for other animals were derived from the base value of $250 \mathrm{~kg}$, resulting in a TLU of 0.1 and 0.01 for sheep and chicken, respectively. To address intradecadal variation (i.e. change in a variable from one year to another within the decade), we took the weighted average of the variables for each decade. For instance, if a certain farmer had a TLU of 1 for 6 years and a TLU of 2 for 4 years over the period of 10 years, the weighted average for the decade was 1.4 TLU. Values across decades were compared using the non-parametric Kruskal-Wallis test. After clustering household types per decade were characterized in terms of their main variables. Following Falconnier et al. (2015), a variable was assumed to characterize a particular type if its range did not overlap with the ranges found for the other types. We defined the 
minimum observed value for the household type with the greatest median value as the threshold between two types within the same decade. We used these threshold values to identify households that changed type over time. For instance, for a household to shift to a type characterized by a high TLU, it would have to surpass the threshold defining that type. We used R! 3.5.1 for Mac and the package ade4 for the PCA and the stats and factoextra packages for hierarchical clustering. We compared household types across decades using the non-parametric Kruskal-Wallis test, using the pgirmess package. Where a household type differed significantly from every other type in the previous decade, we considered it an emergent household type.

The livelihood trajectory, i.e. the progress of each household through time was analyzed by associating each household with one of the categories of livelihood strategies proposed by Dorward (2009) and Mushongah (2009): "Hanging in", "Stepping up", "Dropping out" and "Stepping down". "Hanging in" households are the ones that sustain their level of wealth and well-being while coping with threats, stresses, and shocks. For our study, we considered those households that did not change type over time as "Hanging in" households. "Stepping up" households invest in assets to improve their crop production through land acquisition or to expand their sheep herd. Trajectories involving migration were classified as "Dropping out". Trajectories that involved the decrease of resources such as land or animals were labeled as "Stepping down".

The household types were evaluated in terms of the role of off-farm activities and the importance of government support through agricultural subsidies (through PROCAMPO) and family allowances (through PRONASOL and PROSPERA). For testing the association between household types, off-farm activities and government support, we performed a Cochran-Mantel-Haenszel test with the data nested in decade. This test identifies partial associations between factors within a stratum (Wittes and Wallenstein, 1987). To complement the evaluation of income sources, the 44 households were asked to calculate the share of income from crop production, animal production, local off-farm income, governmental support and remittances. This was only done only for 2017, the year of the interview as recall for earlier years turned out to be inaccurate.

\section{3 | Results}

\subsubsection{Household type description and changes over time}

We identified three household types for the first decade (1988-1997), which we labeled "Mid-scale", "Livestock", and "Land tenant" household types. For the second decade (1998-2007), we identified a further household type, which was labeled "Labor mi- 
grants". For the last period, another new household type appeared, labeled "Largescale" (Table 2.1). Details on PCA and HCA are provided in Appendix 1.

The Mid-Scale household type was found throughout the 30-year period. Unlike the other types, households from the Mid-scale type had no features that set them apart from the others. We detected no statistical differences in variables between the first and second decades, while the area of owned land was significantly lower in the third decade compared to the second $(\mathrm{p}<0.05)$.

The main focus of the Livestock household type was sheep production. The Livestock type was found in each period and consistently harbored only a few farm households. We found no statistically significant differences between the variables characterizing this type across the three decades.

The Land tenant household type was characterized by comparatively large areas of land borrowed or rented from other households. This type was found in every decade. Households from this type did not have family members who migrated and had average numbers of TLU and cultivated crops. The Land tenant households significantly increased the area of owned land during the last decade compared to the previous decade, while the other variables did not change significantly over time.

The Labor migrant household type appeared in the second decade (1998-2007) and was characterized by relatively large numbers of migrants per household. The average TLU and number of cultivated species in this type were the lowest of all the groups. We found no significant difference between the second and third decades for any variable.

The Large-scale household type only appeared in the last period and was characterized by households owning greater land areas than other types. This was usually achieved by purchasing land. While migration occurred, the number of persons per household that migrated was lower than for the Labor migrant type. The few households in this type had an average number of TLU, but a below-average number of cultivated crops.

\subsection{2 | Levelihood trajectories and strategies}

On average, household heads started their agricultural activities at age 34 , with a minimum observed age of 15 and a maximum of 84 years. Out of the 44 households 20 had members who temporally migrated within Mexico and started their farming activities later. Across the three decades, 23 out of the 44 households changed from one household type to another. Of the 24 households present in 1988-1997, 17 had changed type by 2017. Six out of ten households that were established during the second decade also changed type. Half of the new households started as the Mid-scale type, with the other 


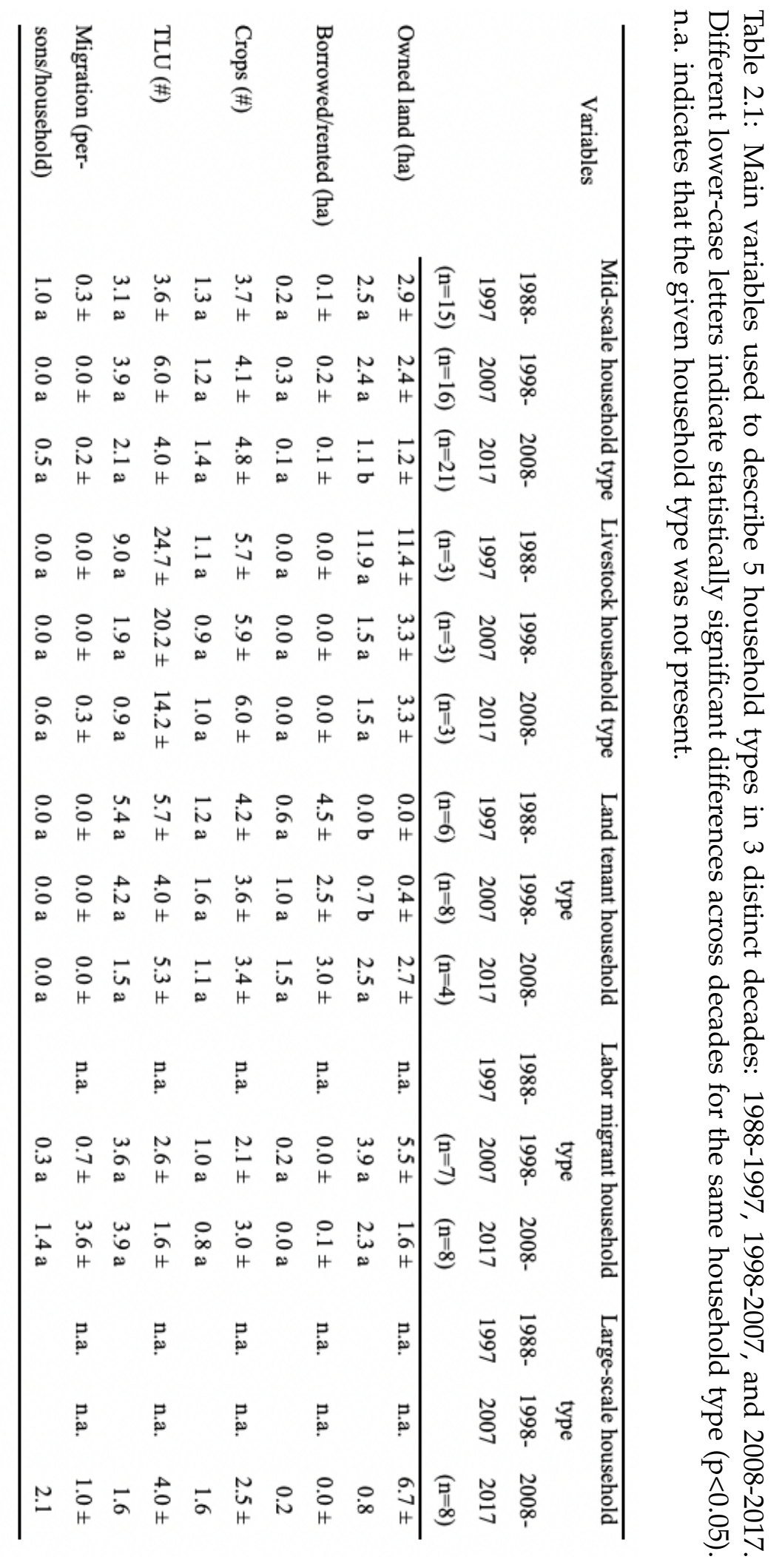


half distributed among other groups (Figure 2.3). Most of the households that formed the two new household types (Labor migrant and Large-scale) in the second and third decades originated from the Mid-scale type. During the first and second decades, the Land tenant type comprised about $25 \%$ of households, but only $10 \%$ during the third decade. Most households that left the Land tenant type changed to the Mid-scale type. The Livestock type was represented by three households in each period (although not the same households).

The classification of the livelihood trajectories in terms of the four livelihood strategies distinguished in this study revealed "hanging in" as the most frequent strategy, followed in descending order by "stepping up", "dropping out" and "stepping down" (Figure 2.4). More than half of the households that adopted a "hanging in" strategy belonged to the Mid-scale type. In total we recorded three households that "stepped down", while 8 "dropped out" as consequence of migration. We observed a strong increase in the number of households "stepping up" between the $2^{\text {nd }}$ and $3^{\text {rd }}$ decade.

Households that "dropped out" were associated with migration of family members. During the first decade, we found 5 cases of domestic migration and none of the interviewees reported a case of international migration. In the second period, 6 persons had migrated nationally, and 5 persons went to the USA. This increase in the number of migration cases resulted in the emergence of the Labor migrant type. We observed a higher number of people migrating during the last decade of 2008-2017, with 34 persons having migrated nationally and 20 persons to the USA. This increase in migration is also reflected in the demography of SCT, which decreased from 864 to 663 between 1980 and 2017 (INEGI, 1980, 2015).

We observed seven households "stepping-up" from the Land tenant type. Five of these seven households changed types by reducing the rented/borrowed cropping area while inheriting land during the implementation of PROCEDE. The remaining two households purchased land with their savings when the PROCEDE program facilitated the process of purchasing land. The PROCEDE program also permitted that eight households purchased or inherited larger areas of land and "stepped up" to the Large scale type.

The proportion of households engaging in off-farm activities increased from 15 to $40 \%$ between the first and last decade. The Cochran-Mantel-Haenszel test showed a significant association between the household type and the income source $(p<0.0001)$. We observed an increasing proportion of households having an off-farm income source in the Mid-scale and Land tenant household type (Figure 2.5). Households from the Livestock and Large scale types generally did not have off-farm income. Households from the Livestock type stated that animal husbandry activities were incompatible with 


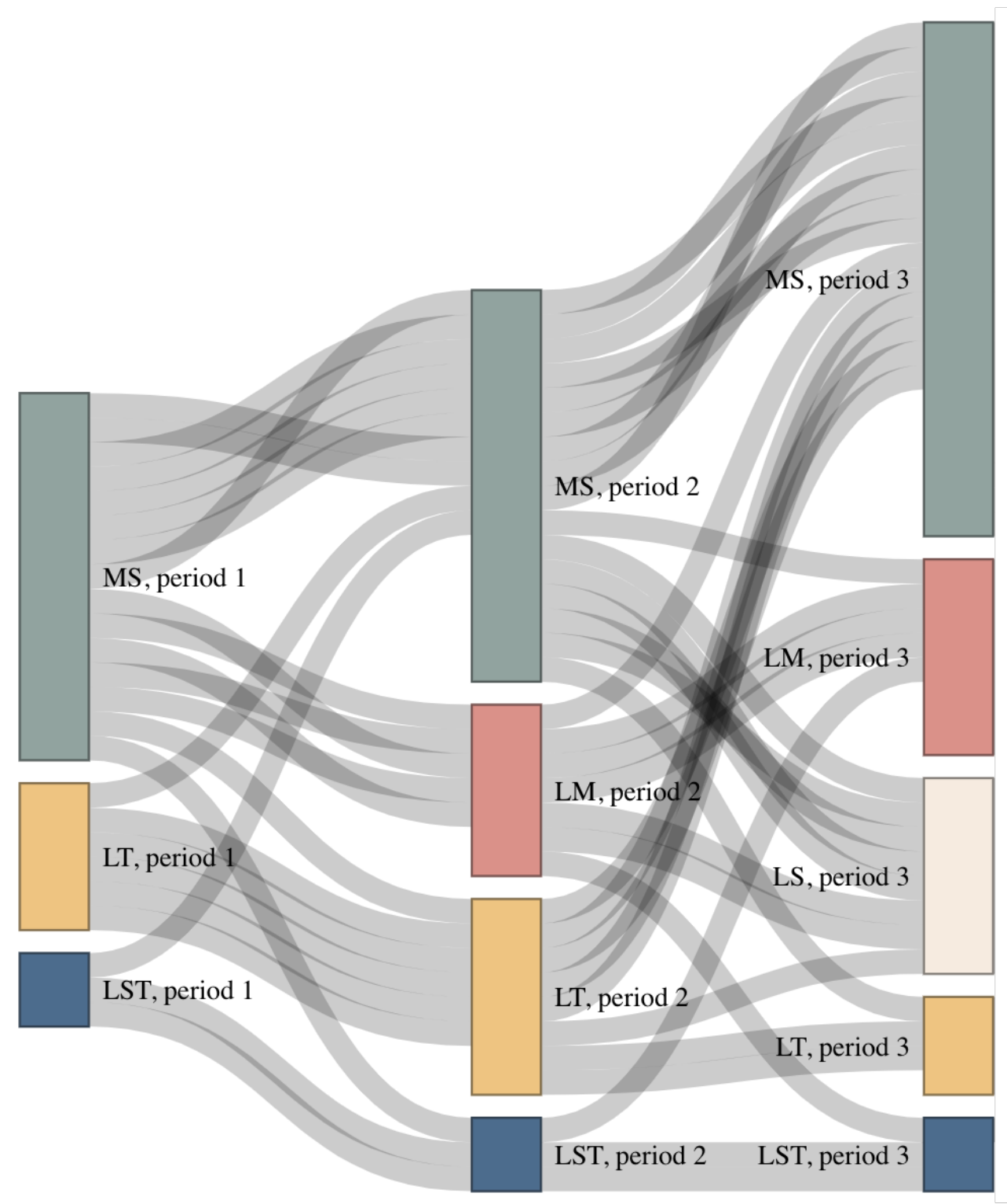

Figure 2.3: Sankey diagram showing the fluxes of households into and out of farm types between decades. MS= Mid-scale; LT= Land tenants; LST= Livestock; LM= Labor migrants; LS= Large scale. 


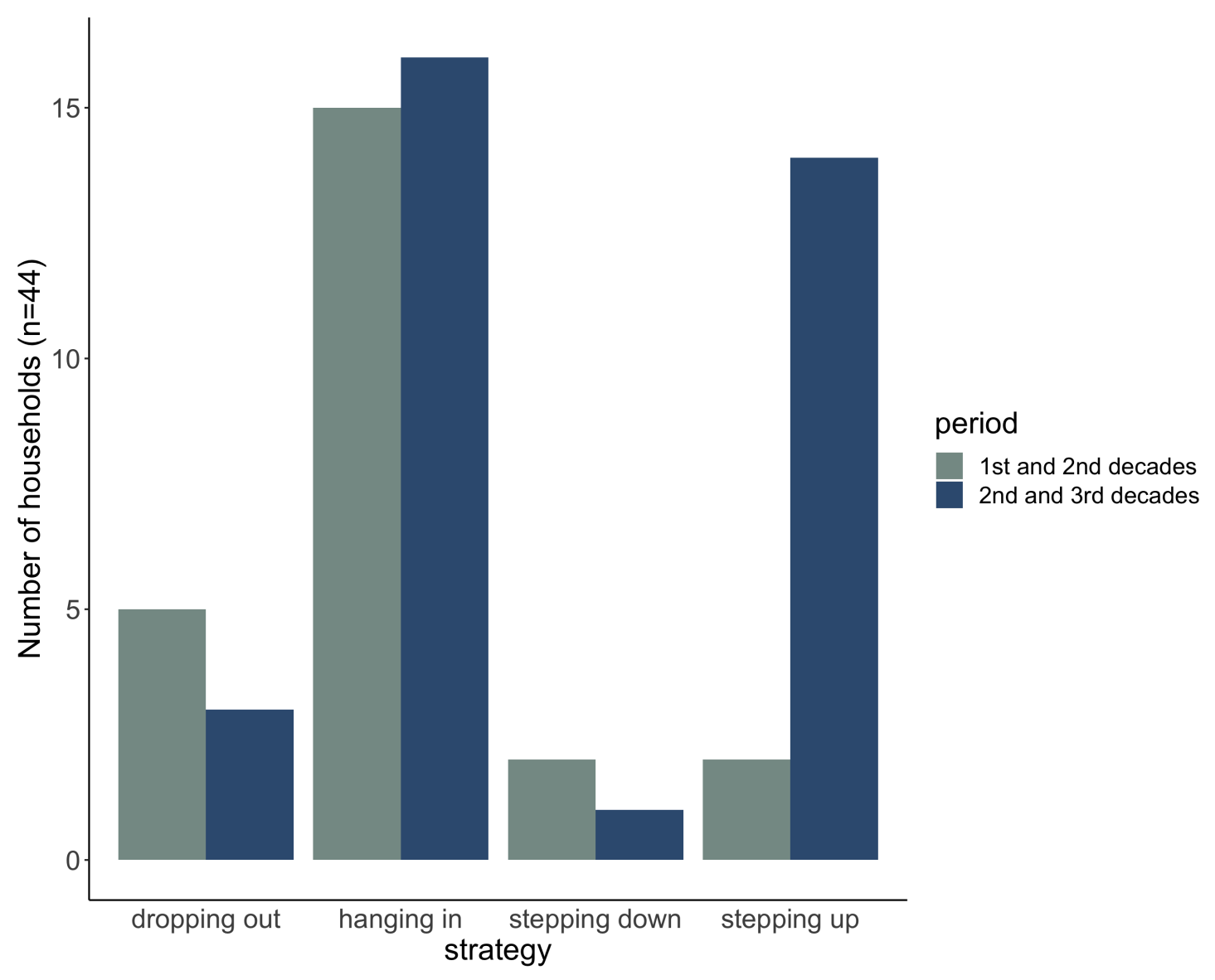

Figure 2.4: Number of households and their livelihood strategies between the 1st and 2nd decades and between the 2nd and 3rd decades.

off-farm income, while those from the Large scale type mentioned that labor in their plots did not allow them to work elsewhere.

The association between household type and the type of government support was significant (Cochran-Mantel-Haenszel test, $\mathrm{p}<0.0001$ ). During the first decade of 19881997, 33\% of households had agriculture-related subsidies (i.e. PROCAMPO), mostly among the Mid-scale type (Figure 2.6). This proportion, however, was reduced to $22 \%$ in 2008-2017, with a larger share of households receiving PROCAMPO coming from the Large scale and Labor migrant types.

Family allowances through PROGRESA-PROSPERA were not commonly found among households in 1988-1997 (Figure 2.6). Nevertheless, 34\% of the households received family allowances in 1998-2007, mainly in the Land tenant type. By 2008-2017, around $40 \%$ of the households were receiving family allowances. The Mid-scale type had an increased share of households receiving family allowances during that decade. 


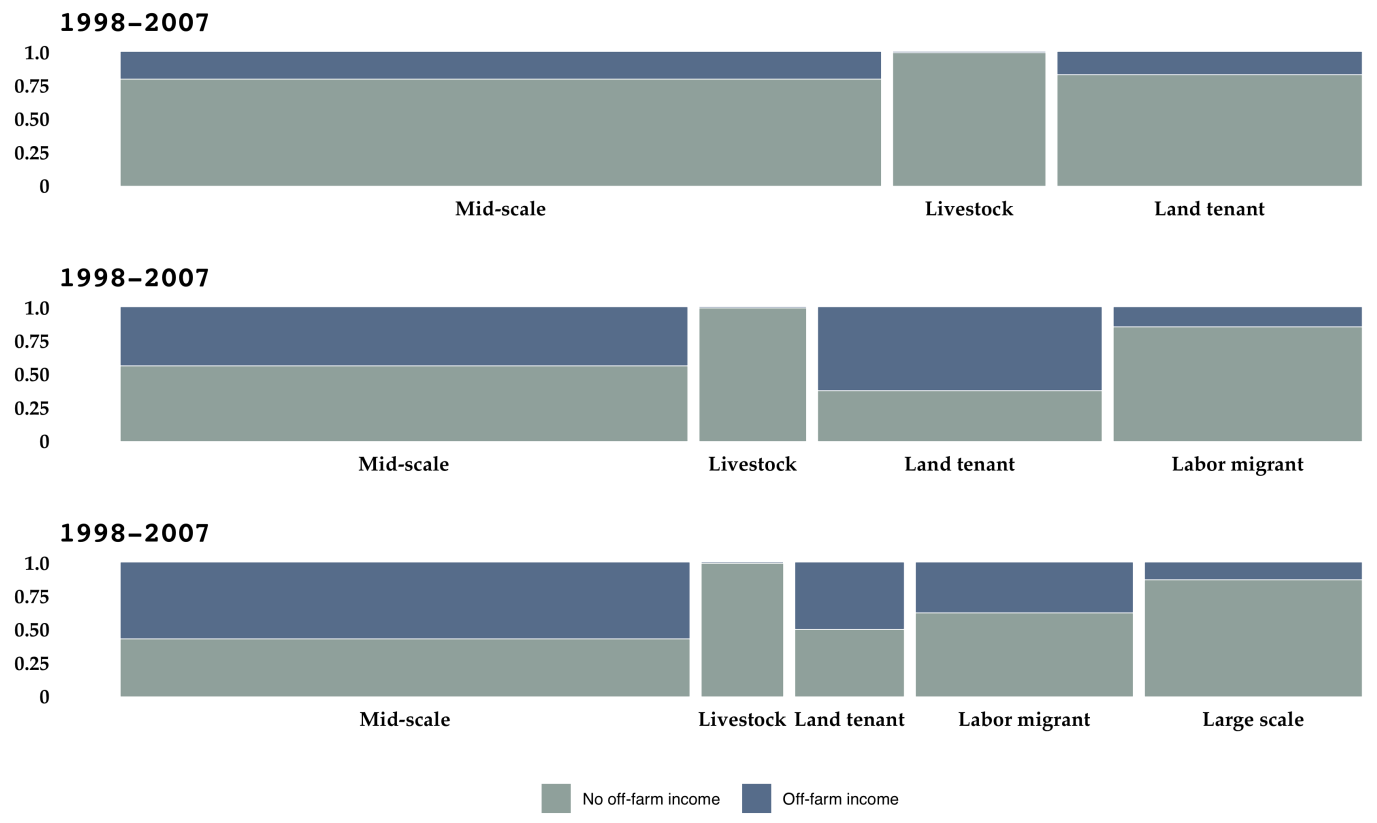

Figure 2.5: Proportion of household heads with or without off-farm according to household type in three decades: 1988-1997, 1998-2007 and 2008-2017. Bar width represent the relative proportion of a given households type of the total number of households. Stacked bars represent the relative proportion of households engaged or not in off-farm activities for a given household type.

This increased share was because households that moved from the Land tenant to the Mid-scale type between 1998-2007 and 2008-2017 were already receiving family allowances. When combining the households that either received agriculture subsidies or family allowances, government support rose from 35 to $65 \%$ between the first and last decade, showing a clear increase in financial support in rural areas.

We observed a significant association between government support and off-farm income ( $\mathrm{p}=0.029$, Cochran-Mantel-Haenszel test). Households receiving PROSPERA tended not to have off-farm income, while those receiving either family allowances or no support had a higher probability of also having off-farm income sources. We found no significant effect of government support on crop diversity.

In $2017,7 \%$ of the household income came from crop production, $20 \%$ from animal production, 39\% from local off-farm income, 25\% from governmental support and 9\% from remittances. Maize production was primarily destined for household consumption (human consumption first, animal consumption second), rather than for selling. The high diversification of income we found is reflected in the population censuses, which shows that $75 \%$ of the economically active population of SCT worked in the agri- 
cultural sector in 1990, while by 2010 that proportion was 45\% (INEGI, 1990, 2010).

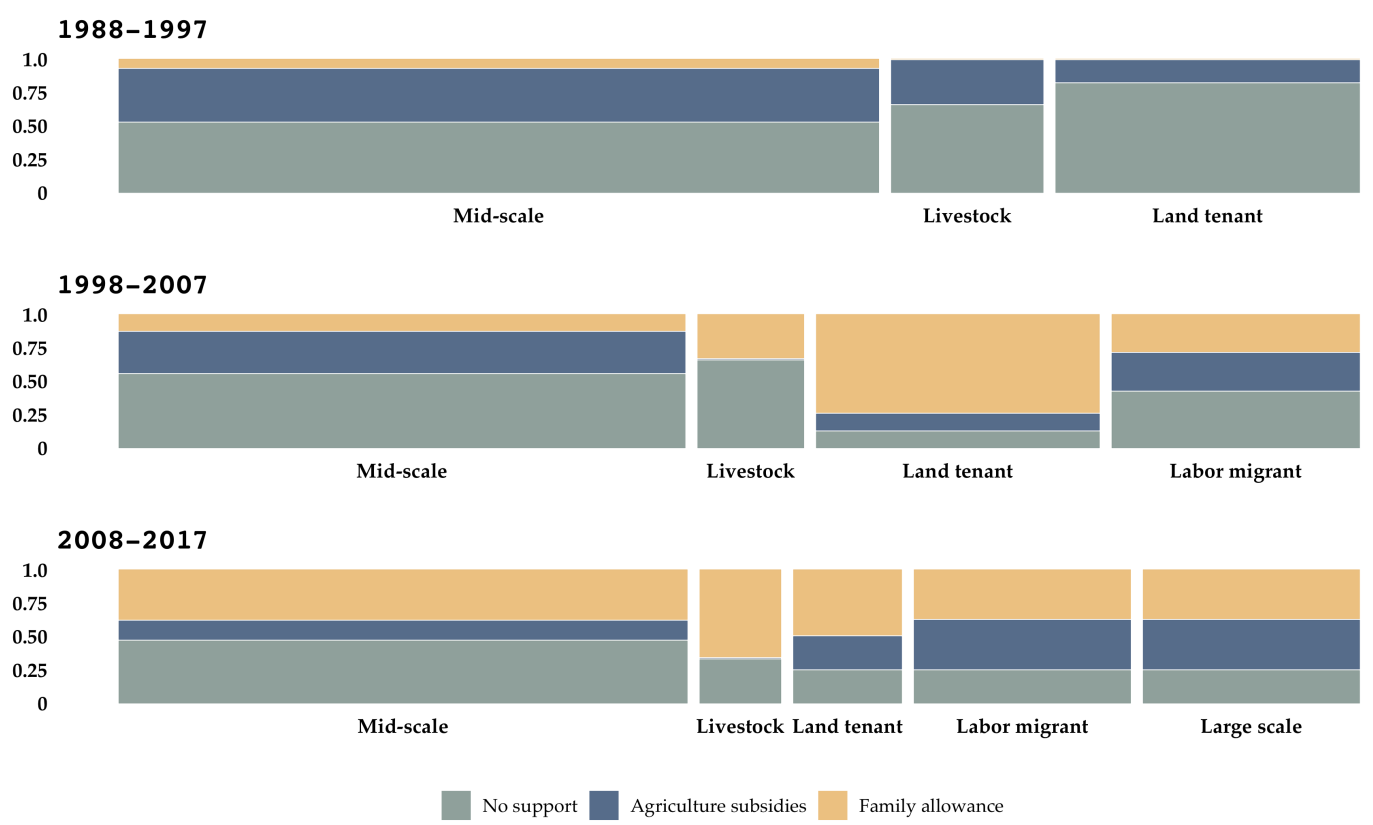

Figure 2.6: Proportion of households receiving agricultural subsidies through PROCAMPO, family allowance through PROGRESA-PROSPERA or no assistance according to household type in three decades: 1988-1997, 1998-2007 and 2008-2017. Bar width represent the relative proportion of a given households type to the total number of households. Stacked bars represent the relative proportion of households according to the government support received for a given house-hold type.

\section{4 | Discussion}

The analysis showed that household type diversity increased over the past 30 years, thus supporting the hypothesis that drivers of change affected not only individual livelihood trajectories but also affected the evolution of household types. Nevertheless, a substantial number of households was associated with a "hanging in" strategy and largely maintained the status quo across the 30 years. We found associations between the easing of restrictions on land markets and migration on the one hand, and the association between household types and the type of government support and off-farm income on the other. Engagement in off-farm activities appeared as a source of income for all types except for Livestock and Large-scale households, where agricultural activities took up all labor. An increasing number of households received government support over time, irrespective of household type. The engagement in off-farm activities was associated 
with households that either had no government support or received family allowances only, as not having agricultural subsidies gave households more freedom to explore other sources of income. Households receiving agricultural subsidies did not tend to partake in off-farm activities.

Recent longitudinal livelihood analyses by Falconnier et al. (2015) and Chopin et al. (2015) tracked household dynamics assuming that household types were stationary. In our approach we allowed the appearance of new household types and changes in characteristics of established types over time. Iraizoz et al. (2007) and Mignolet et al. (2007) created household typologies on a yearly basis in order to study trajectories. Such approach has to deal with variation from year to year and runs the risk of failing to capture larger trends over time. Sallu et al. (2010) used narrative-driven methods to describe diversification of activities and specialization as livelihood strategies but did not classify households into types. By developing a typology for each of three decades, we were able to reduce the noise caused by yearly typologies and could describe household type diversity over time.

The PROCAMPO agriculture subsidy was expected to stimulate a production shift away from maize production towards greater crop diversity (Zarazúa-Escobar et al., 2011). However, our results showed that across the 30 years households continued to produce maize and crop diversity did not change markedly. Many households produced maize for self-consumption (Avalos and Graillet, 2013). In Brazil, a plan known as "Brasil sem miséria" (Brazil without extreme poverty) was implemented that focused on both improving food production for self-consumption and the socio-economic conditions of poor rural households. The plan increased the income of the rural poor in Brazil by 88\% between 2011 and 2014 (MDS, 2015) and, rather than trying to shift food production away from self-consumption and towards economic gain (as attempted by PROCAMPO), "Brasil sem miséria" acknowledged the importance of production for self-consumption to improve food security, reduce extreme poverty and enhance social inclusion (IPEA, 2013). In order to obtain the PROCAMPO subsidy, households are required to own land, which explains the low proportion of this subsidy in the Land tenant type, where only few households owned small areas for cropping. We found households benefiting from PROCAMPO subsidies to dedicate exclusively to agricultural activities, but not the other way around, as household type also had an influence on off-farm income. For instance, Livestock and Large scale households dedicated exclusively in agricultural activities (with the exception of one household in the Large scale type), but no household in the livestock type received PROCAMPO and only three out of eight households from Large scale type received PROCAMPO. This agricultural subsidy is coupled with the obligation to grow crops in order to keep receiving the sup- 
port, which reduces the chances of engaging in off-farm activities. Thus, this type of coupled payment may have negatively affected participation of the households in offfarm activity. This result contrasts with findings of Ahearn et al. (2006) who concluded that the type of government support in the United States, either coupled or not to certain rules, had no effect on on-farm labor. In their study they attributed the off-farm income as an ongoing trend, which was happening years prior their study, and that the type of government support was not enough for reverting that trend.

The proportion of households in SCT working exclusively on the farm decreased from $85 \%$ to $60 \%$ during the 30 years considered, while the proportion of households that received either agricultural subsidies or family allowances increased from 40 to $65 \%$. Off-farm work became more popular over the decades, which was associated with the type of subsidy. Unlike PROCAMPO, PRONASOL (and the subsequent programs OPORTUNIDADES and PROSPERA) is a type of direct payment that is not coupled to agricultural production. This is a type of program that is described by Stamoulis and Zezza (2003) as a method by which to improve food security. After PROGRESA began in 1997 (Figure 2.2), mothers who had children attending health care centers and enrolled in schools received direct payments. The decoupled payments may have stimulated households to work off-farm as was shown for Ireland by Hennessy and Rehman (2008). In the decade 2008-2017, around half of the households that engaged in local offfarm activities also received direct payments from PROGRESA-PROSPERA, while the other half did not receive any type of government support. Households from the Land tenant type were the most frequent beneficiaries of this type of support over the 30 years considered. Many Land tenant type households shifted to the Mid-scale type by the last decade, thus giving a more even distribution across the different types of households receiving family allowances.

Before the PROCEDE program, land could only be inherited by the first-born child and could not be divided and distributed to other children. PROCEDE was expected to guarantee property rights to land users, giving users more flexibility to rent, sell and buy land (Ita, 2006). The PROCEDE program allowed farmers to register ownership at the plot level. During this process, many farmers decided to pass their land on to their children, thus leading to a boost in land inheritance. During the second decade (19982007) and coinciding with the period that PROCEDE was implemented in the region, the number of households inheriting land in SCT increased. This was associated with Land tenant households moving to the Mid-scale type, and in the emergence of the Large scale household type (Figure 2.3).

As more households began to own land between the second and third decades, many of them left the Land Tenant group, equivalent to a "stepping up" strategy (Figure 
2.3 and Figure 2.4). In defining the "stepping up" strategy, Dorward (2009) considered that in order to step up a household would have to invest and expand their current activities to improve their livelihood (e.g. expand land to increase crop production, or increase animal production). In the Mexican case, asset accumulation resulted from changes in ownership rights, rather than investments or changes in activities. While agriculture-related policies is common in Mexico and other Latin American countries like Haiti, Nicaragua, Brazil, Uruguay and Peru (Egas and De Salvo, 2018), this is not the case in most countries in Africa, where the strategy concepts were coined (Scoones et al., 2005). Stepping up thus needs to be interpreted within the context with more influence from the government.

Migration increased following the implementation of the NAFTA, as a consequence of reduced rural employment (Taylor et al., 1999). Our data showing that people migrated either within Mexico or to the USA are in agreement with the findings of Sadoulet et al. (2001). The increase in migration in SCT coincided with the Labor migrant type, marked by households that were "dropping out" of agriculture. At the same time, many migrants returned home; as 20 out of the 44 interviewed households had started their agricultural activities after having migrated for a given time. All household members returned voluntarily because of family-related reasons, similar to results found by Mestries (2013) for the state of Vera Cruz. He also found other reasons for coming back, such as fear of deportation from the USA and opportunities to invest in agricultural systems. While his study focused on migrants returning from the USA, in our study all returnees had previously migrated within Mexico.

We observed that migration was not only related to "dropping out" strategies. Our results showed two households that "stepped up" from the Labor migrant to the Large scale type using their accumulated resources to purchase more land. Another household "stepped up" to the Livestock type by purchasing more sheep, thus underlining possible pathways for households from the Labor migrant type. Interestingly, the household heads from the Labor migrant group did not engage in off-farm activities. Mushongah (2009) says "dropping out" strategy is marked by households in the process of migrating away. However, the fact that households from the Labor migrant do not usually engage in off-farm activity suggests that they are not really "dropping out". Furthermore, some of them even had the opportunity to "step up" as consequence of remittances sent by the household members who migrated. The notion of "dropping out" should probably be readjusted to fit these situations where migration is used to invest in agriculture. The effect of accumulating resources by off-farm activity to invest on-farm is also discussed by Pfeiffer et al. (2009).

Our findings lead to a number of policy implications. We first observed that tenancy 
regulations or restrictions can affect household type diversity. By easing the process of buying and selling land, some households expanded their land and consequently led the establishment of a household type marked by this area increase. While we did not observe a negative impact on that policy in the households in Santa Catarina Tayata, as none of them seemed to have "stepped down" as a consequence of it, it is likely that municipalities with higher population density and low migration rate would have a different outcome. For example, in highly populated rural municipalities, some households might begin "stepping up" by purchasing other household's land. This might not only lead to an accumulation of land, but also drive other households to "step down" as consequence. Barnes (2009) draws the attention that the effect of over-privatization of land, as a consequence of PROCEDE, would only be seen 30 years after its implementation. Another policy implication was regarding the type of government support households received. Although we did not find evidence that PROCAMPO attained the desired effect of shifting maize production in favor of other crops, we did observe that households receiving this subsidy tended to only dedicate to agricultural activities. On the other hand, households receiving family allowances through PROGRESA-PROSPERA were more inclined to diversify their income sources. Therefore, by having distinct consequences for livelihood strategies, these policies allowed individual households to choose between more or less reliance on agriculture.

We assessed household dynamics and their interaction with several drivers of change for the case study community Santa Catarina Tayata. Mexico, however, features many different socio-ecological contexts. For example, in the neighboring states of Chiapas and Guerrero ethnic groups, poverty levels and agroecological zones differ partly from those found in SCT. Studies under different contexts would give insights into whether generic policies have effects that differ by context.

We used recall based on interviews. Quantitative information provided during the interviews on the size of owned land is likely to be accurate as households drew on official ownership papers. Information on migration of household members was likely also accurate. Information on rented/borrowed areas, numbers of animals and numbers of cultivated crops is expected to be less accurate, but the only source available for our historical analysis.

\section{5 | Conclusions}

We showed the evolution of households and household type diversity over time in relation to major drivers of change. Half of rural households in our study adjusted to 
policy-based and socio-economic drivers, including changes in land tenure laws and regulations, public financial support and migration opportunities, and changed their livelihood strategy as a result. Over the last 30 years, this led 1) $20 \%$ of the households to expand the area land owned resulting in the Large scale group, 2) the proportion of households to receive government support increasing from 35 to $65 \%$, 3) a proportion of household heads engaged in off-farm activities increasing from 15 to $40 \%$ and 4 ) the emergence of the Labor migrant type reflecting an increasing number of household members migrating.

We found a diversity of partly conflicting drivers of change. Households selected opportunities that fitted them, thus forgoing others. This was apparent in the choice for PROCAMPO subsidies, where households receiving that subsidy tended to work on farm, exclusively. A trade-off between migration and agricultural activities that is apparent in the short term, was found to not exist in the longer term, as many migrants returned to their home grounds. Although migration is oftentimes associated with a negative impact on agriculture, households from the Labor migrant type were able to step up by either accumulating owned land or increasing the size of their sheep herd. Furthermore, households from the Labor migrant type did not tend engage in off-farm income, suggesting that they are not actually "dropping out" of agriculture.

Results of this case study show the diversity of drivers and household responses, and their dynamics over time. Some of the responses were contrary to expected effects, such as the longer-term impact of migration on rural assets and agricultural activities, and the lack of crop diversification response to PROCAMPO. In addition, our results show that $35 \%$ of households were not using governmental support programs, although some of them would be eligible. This type of study can be used to monitor policy impact and households' strategic responses, to arrive at better articulation of policy objectives and policy impact. As a next step, the approach could be repeated in contexts that differ from the current study area in terms of proximity to large cities and their labor demand, current agricultural land use, demography in relation to migration and socio-economic status.

\section{6 | Acknowledgements}

The authors would like to thank all the farmers for kindly providing information to enable this study. The authors also would like to give a special thanks to Jesus Cruz Galicia, who provided guidence and facilitated the interviews. This study was funded by CIMMYT (International Maize and Wheat Improvement Center). 


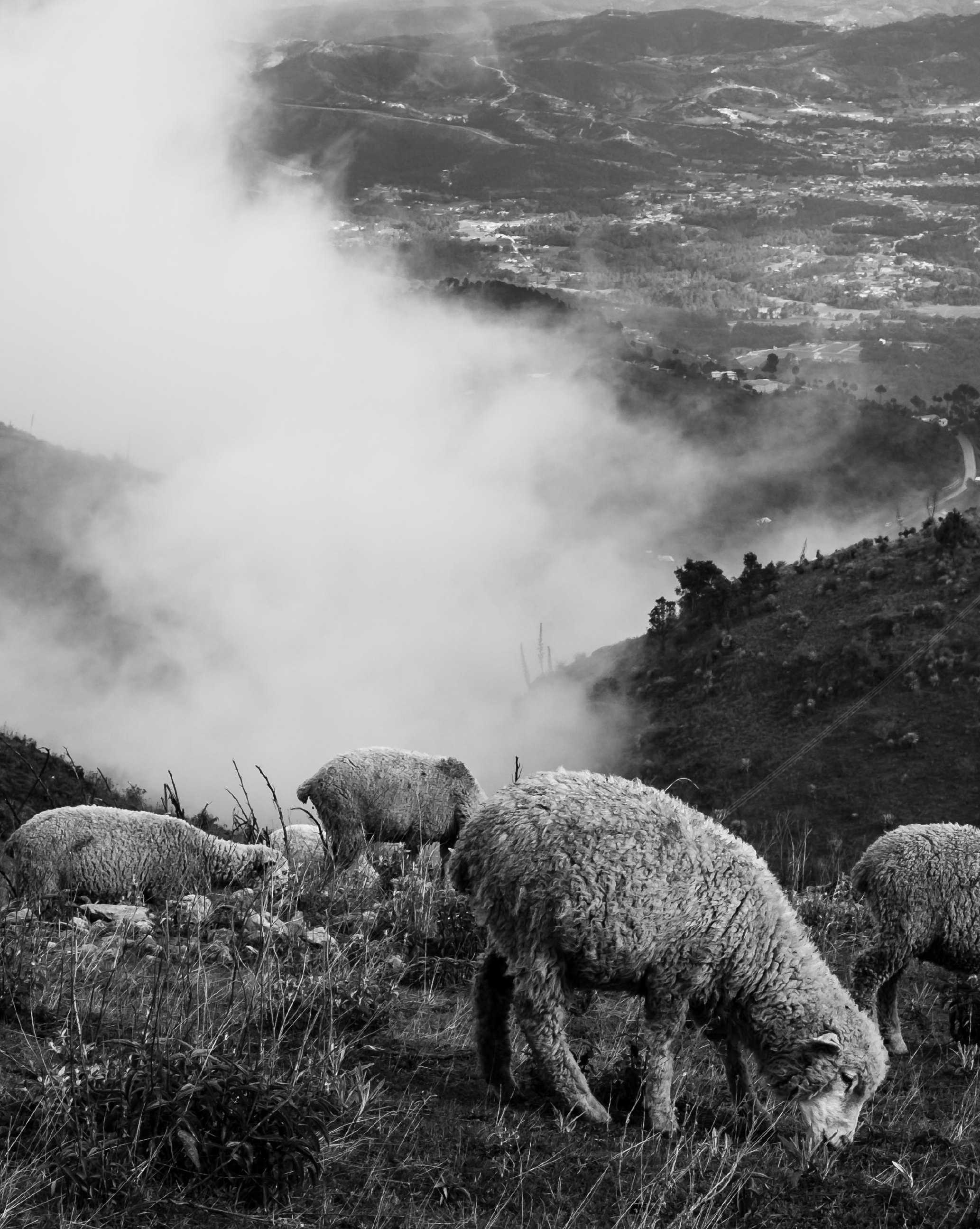


\section{Chapter 3: Back to the people: the role of global drivers versus} community-based responses at shaping landscape trajectories in Oaxaca, Mexico*

\section{Abstract}

Land use change results from a combination of top-down drivers such as global economy and policies and actors in communities. Here we study how community characteristics affect communities' decisions and consequently shape landscape transformation. Land use change over the period 1989 to 2017 was assessed for the Rio-Sordo watershed in Oaxaca, Mexico, and the importance of regional variables driving landscape change were ranked using random forest models. At a more detailed level, land use change was assessed for two communities within the same watershed over the period 1984 to 2017. Former and current local officials were involved in reconstructing a timeline of major external and internal drivers and to highlight the responses of the communities

*Based on article under review by the Land Use Policy journal: Novotny, I; Rossing, W; López-Ridaura, S, Tittonell, P; Fuentes-Ponce, M. Back to the people: the role of global drivers versus community-based responses at shaping landscape trajectories in Oaxaca, Mexico 
that contributed to landscape management. Results at the watershed level showed high initial percent of forest area and high degree of marginalization to be associated with net deforestation. At the municipality level, in both communities around $20 \%$ of the area was reforested, and the area of bare land decreased by $10 \%$ over the 30 years period. These changes were attributed to the establishment and functioning of the local institution Bienes Comunales, which enabled the communities to issue rules on land use management. Among the actions enforced by Bienes Comunales were logging and grazing regulations, and reforestation campaigns, effectively addressing overgrazing, land degradation and excessive logging. Considering that more than half of the world's land is managed by communities, our results show how alignment of community and governmental goals, as happened over the studied period of time may facilitate effective natural resource conservation. 


\section{1 | Introduction}

Land use changes are commonly considered to result from top-down drivers such as global economy and demands, trade and policies (Lambin and Meyfroidt, 2011; Meyfroidt et al., 2013). In addition to these drivers, there is a number studies showing the role of communities in landscape planning and conservation, pointing to the relevance of dual governance systems by governments as well as communities (Baynes et al., 2015; Bixler, 2014; White and Martin, 2002). Social actors in communities and their goal-oriented perspectives can affect the degree to which land use changes will follow either a natural resource conservation or a depletion and degradation pathway (e.g. overexploitation of forests, overgrazing, agricultural expansion and contamination of resources by inputs). The emerging pathway will influence resource availability and will ultimately determine the possibilities for the development of human communities (Ploeg, 2009).

At regional and larger scales, most of the landscape transformation is attributed to agricultural and urban expansion (Corona et al., 2016; Izquierdo et al., 2011; Lambin et al., 2003; Lambin and Meyfroidt, 2011; Tapia-Armijos et al., 2015), biophysical conditions (Bray et al., 2008) and global markets (Aide et al., 2012). Controlling land use change to preserve current natural vegetation can contribute to mitigate climate change (Boit et al., 2016), urging the need to preserve the remaining forests. Although these factors are important, local drivers should also be incorporated to enable a more complete assessment of landscape change. Local drivers are of particular interest when evaluating the impact of community-based management on the landscape. Furthermore, policies can integrate community-based landscape management and even offer incentive to them. For instance, Carabias et al. (2010) compiled 100 documented cases of community-based management in Mexico that were successful in elaborating a territorial landscape plan for their municipalities in order to raise money from different governmental organs.

Aide et al. (2012) observed how forest expansion in Mexico and Brazil, was driven by several demographic (e.g. population density, migration, municipality size) and environmental variables (precipitation, temperature, biome). They also showed that in some areas high population density was associated with reforestation. A growing body of literature addresses the importance of giving more autonomy to communities by pointing out their efficacy in avoiding deforestation. In a meta-analysis study from 69 cases around the world, Pagdee et al. (2006) associated factors like property rights, institutional arrangements, and community incentives and interests to be related to the success of communities when managing their resources. Bray et al. (2008) found de- 
forestation rates to be similar or marginally less under community management than strictly protected areas in Mexico and Guatemala. Ellis and Porter-Bolland (2008) found deforestation under community-based management to be very small, even under conditions of high land pressure in the Yucatan peninsula, Mexico.

Another body of literature addresses the effect of local migration patterns and the slowing of agricultural activities on forest regrowth. For instance, Corona et al. (2016) observed an increase in forest area and a reduction in agricultural land between 1995 and 2006 in two communities in the southern part of Oaxaca, which they attributed to an increase in off-farm income and migration. In contrast, Cárdenas-Hernández and Gerritsen (2015) showed how livestock activities drove an indigenous community in the central-west region of Mexico to increase pastures at the expense of forest. In a study in the Argentinian Patagonian steppe, Gowda et al. (2012) concluded that afforestation was negatively affected by distance to roads and the associated human influence, even under favorable conditions for seedling germination and survival, such as precipitation, topography and wind regimes. Since these studies were centered around forest, they usually did not contain detail on other land uses (e.g. agriculture and shared grasslands) that are especially important to communities relying on food production for self-consumption. All of these studies, with the exception of the one from CárdenasHernández and Gerritsen (2015), addressed large areas and several communities, making it difficult to assess in more detail the decision making process and specificities of each community that led to landscape transformation.

Here we study how community characteristics affect communities' decisions and consequently trigger landscape transformation. Results contribute to the debate on the balance between landscape governance by higher government levels and by local communities. In this study we focus on a watershed in the state of Oaxaca, Mexico that has been documented to have high deforestation rates (Velázquez et al., 2003), but at the same time has been showing local reforestation over the past decades Aide et al. (2012). Our goal was to assess how context specific conditions affect community landscape management decisions and land use transformation. We hypothesize that even though communities are granted the same basic rights to have some degree of control over the common land, the outcomes vary depending on community characteristics such as history, demography, land pressure and population requirements for food. This hypothesis follows the idea that local people are capable of understanding their environment, which entails temporal heterogeneities and biophysical conditions, and of drawing action plans according to their reality (Zimmerer, 1994), which we can expect to lead to different landscape pathways. To test our hypothesis, we use satellite images to assess regional landscape change over the past 30 years. We provide a detailed 
analysis at the level of two communities in order to understand the major local drivers that shaped the incumbent landscape by combining population and agricultural census data, and workshops with former local government officials. Results are discussed in relation to consequences for effective community-based landscape management systems in general and in Mexico specifically, where most of the land is maintained by small communities.

\section{2 | Materials and methods}

\subsection{1 | Land tenure systems}

After the Mexican revolution and the proclamation of the Mexican constitution in 1917, rural communities were legally recognized as comunidades agrarias (conceded to indigenous people) or ejidos (conceded to petitioners who did or did not have prior connection to the land granted to them) (Baynes et al., 2015). The major difference between comunidades agrarias and ejidos is that buying and selling land is not allowed in the comunidades agrarias and land is passed on through heritage. The comunidades agrarias can be converted into ejidos if the local assembly so desire in order to permit the land owners to buy and sell land (Morett-Sánchez and Cosío-Ruiz, 2017). Combined, comunidades agrarias and ejidos cover around 53\% of the land area in Mexico (Morett-Sánchez and Cosío-Ruiz, 2017). In both comunidades agrarias and ejidos, water bodies and forest belong to the community while cropland, orchards and fallow land used are usually privately owned (Merino-Perez, 2013). The decision-making process for the common lands resides with the Comisariado de Bienes Comunales, which is headed by a community-elected president, treasurer and deputy. Together they are part of Bienes Comunales (BC, literally: Common Goods). The BC are responsible for officially delimiting the common areas, and for elaborating and maintaining local laws on management of the common areas. Local law proposals are voted on by an assembly of the community. Since 1917, establishment of Bienes Comunales is voluntary for municipalities (PA, 1992). The law provides communities with a say in the management of their area by delimiting their territory and distinguishing common and private lands. Before this revision, many communities had limited control over their land due to a political trend to give concessions to private companies for extracting wood. After the revision, the control of the common land by communities was enhanced (Bray, 2004). Community empowerment through assemblies have been documented to be successful in resource conservation as they can detect mismanagement and replace leaders whom they consider not suitable (Klooster, 2000). 


\subsection{2 | Case study area}

The state of Oaxaca comprises 9.4 million ha. Around 1.6 million ha lies within ejidos and 5.8 million ha within comunidades agrarias (Morett-Sánchez and Cosío-Ruiz, 2017). The area with forest in Oaxaca covers 6.3 million ha, of which 5.0 million ha belong to comunidades agrarias or ejidos. The communities have autonomy to manage and protect their land, subject to some restrictions. For instance, communities are not allow to exploit wood unless an official government organ gives a concession to the community, which states the volume of wood to be exploited (Madrid, 2008).

The Mixteca Alta is an ethnic-geographic region inhabited by indigenous communities called Mixtecos. It is located in a mountainous area at 1700 to $2600 \mathrm{~m}$ above sea level that extends from the northwest of the Oaxaca to the south of Puebla. Rainfall mostly occurs between May and October (Mueller et al., 2012), with an annual precipitation between 300 and $750 \mathrm{~mm}$ (Velázquez et al., 2003). The Mixteca Alta is known for its barren slopes, gully erosion, dry streams and poor small villages (Mueller et al., 2012). Widespread erosion in the area is possibly related to over-exploration by farmers before the hispanic era (Mueller et al., 2012). A large part of the Mixteca Alta is within the Río Atoyac-B watershed. We selected the watershed of Rio-Sordo, which comprises around $7700 \mathrm{~km}^{2}$ (Galindo et al., 2017). Among the 63 municipalities in this watershed all of which have autonomy to manage their common land, we focused on San Cristóbal Amoltepec (SCA) and Santa Catarina Tayata (SCT).

San Cristóbal Amoltepec (SCA) (Figure 3.1) covers $32 \mathrm{~km}^{2}$ and has a population density of 60 people $\mathrm{km}^{2}$, calculated from 2010 census data (INEGI, 2010). Crop production in SCA is mostly for self-consumption and comprises predominantly maize (Zea mays L.) and bean (Phaseolus vulgaris L.). Sheep husbandry is the most important type of animal husbandry though households usually have a few chickens and sometimes pigs in their yard.

Santa Catarina Tayata (SCT) stretches across $37 \mathrm{~km}^{2}$ (3.1). The population density in the municipality is 19 people $\mathrm{km}^{2}$ (INEGI, 2010), and has been strongly influenced by high emigration (Novotny et al., 2020). Since labor is scarce, households usually leave a portion of their land under fallow. Types of crops and animals in SCT are similar to SCA and are mainly used for self-consumption.

\subsubsection{Land use change analysis for the Río-Sordo watershed}

We used Landsat images from 26 October 1989 and 22 November 2017 (both with a 30m resolution) for the land use classification of the Rio-Sordo watershed (3.1 1). Since the 


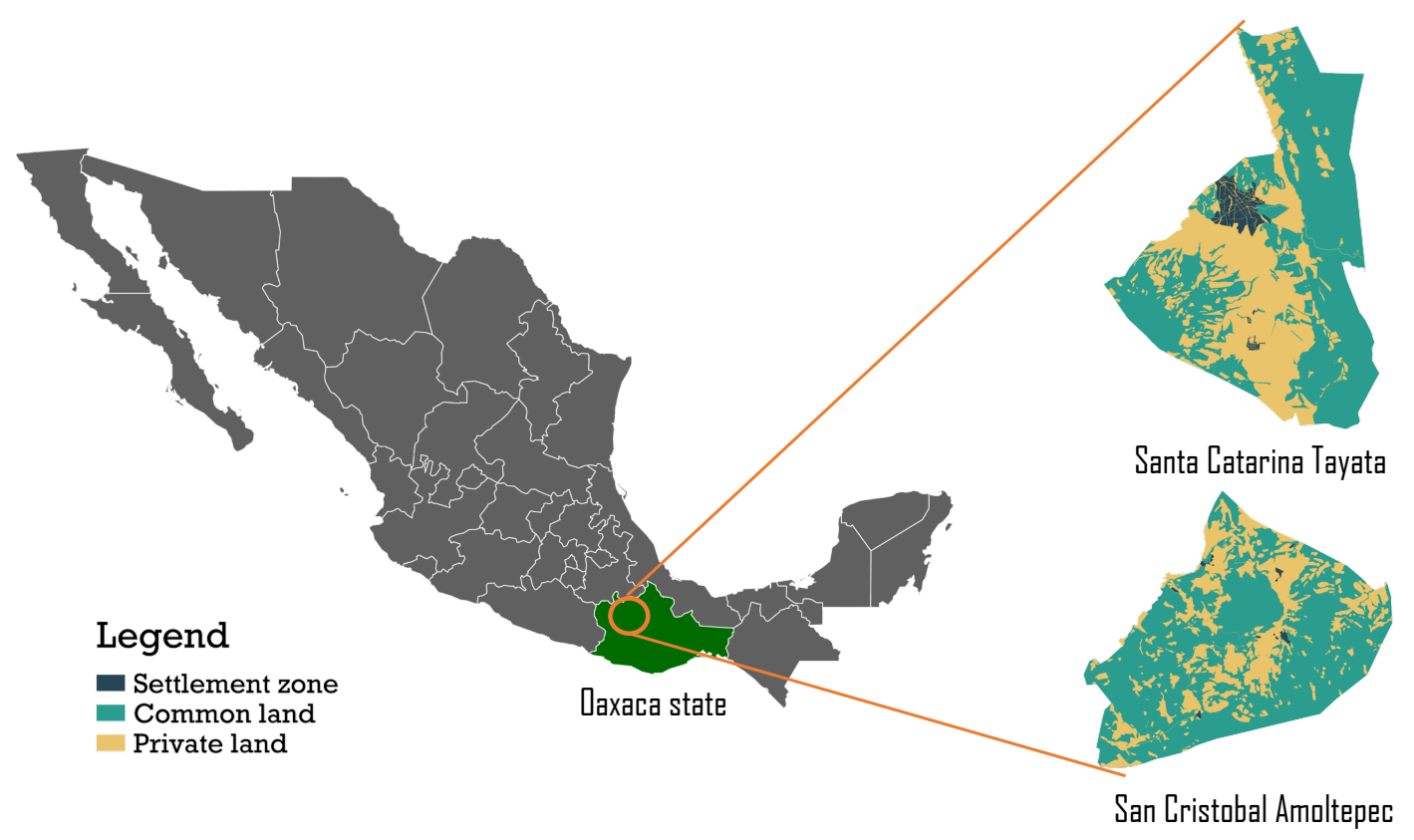

Figure 3.1: Study sites San Cristobal Amoltepec and Santa Catarina Tayata, and their land use according to the Registro Agrario Nacional (2018 https://datos.gob.mx/busca/organization/ran).

watershed fell into two different Landsat tiles taken months from each other, we selected a single tile with around $2 / 3$ of the watershed for the analysis. The analyzed images were taken at the end of the crop cycle, allowing for an easier distinction between land uses. A 1984 image was available but not used for the Rio-Sordo watershed analysis because it was taken late in the season when most of the fields in the region had been harvested, resulting in misclassification of agricultural land as bare land. We applied atmospheric correction on the images to improve reflectance values (Ellis and PorterBolland, 2008). The land use classes were forest, agricultural land (including cropland and grassland), shrub land (with grass between shrubs) and bare land. The classification was done using a semi-supervised classification method, where samples for each class were obtained by overlaying a high-resolution map from Google Earth (WorldView2 with a resolution of $0.5 \mathrm{~m}$ ) (Mekasha et al., 2014). We applied a maximum likelihood algorithm on the training samples to obtain the final classification map (Ellis and PorterBolland, 2008; Tolessa et al., 2017). Using the 1989 and the 2017 land use maps, we calculated areas of land use for each one of the 63 municipalities within the Rio-Sordo watershed. Differences in land use area for each class and municipality between 2017 and 1989 were calculated to assess the change over the three decades.

We used spatial explanatory variables to run logistic regression models and regres- 


\begin{tabular}{ccc}
\hline Acquisition date & Type of Mapper & Analyzed area \\
\hline 22 November, 2017 & OLI/TIRS & Río-Sordo, SCA and SCT \\
15 December, 2010 & ETM+ & SCA and SCT \\
30 October, 1999 & TM & SCA and SCT \\
26 October, 1989 & TM & Río-Sordo, SCA and SCT \\
23 December, 1984 & TM & SCA and SCT \\
\hline
\end{tabular}

Table 3.1: Acquisition date, type of mapper and analyzed area of the Landsat images used in this study

sion trees. The variables used were: (1) drought risk, (2) annual rainfall, (3) migration rate, (4) income sources, (5) human development index, (6) marginalization index, (7) population without education, (8) population with income inferior to minimum wage, (9) population with social deprivation, (10) population working in agriculture, (11) population working in other activities, (12) demographic density, (13) distance to highway and (14) distance to large settlements/cities (exceeding 10,000 people). Variables 1 to 11 were obtained for the year 2010, and were made spatially available by "Comisión Nacional para el Conocimiento y uso de la Biodiversidad" (CONABIO, 2012). Demographic density was calculated by dividing each municipality's population by its area. Variables 13 and 14 were calculated based on the distance between the municipality's centroid to the nearest highway and settlement/city, respectively.

We ran random forest models using a land use binary response variable (e.g. deforestation/reforestation) and variables 1 to 14 as explanatory variables. We only considered municipalities with more than $2 \mathrm{~km}^{2}$ of reforestation/deforestation in our analysis, leaving 43 municipalities in the analysis. The overall performance of the random forests were assessed by the out-of-bag, a measure to evaluate prediction performance (Janitza and Hornung, 2018). We ranked the most important variables describing deforestation/reforestation using the mean decrease in Gini. In random forest models, "strong features" are used in the classification process and the "Gini importance" is used to rank these features (Menze et al., 2009). Analyses were done in R! version 3.51 for Mac, using the randomForest package, v. 4.6-14.

\subsubsection{Land use change analysis for San Cristóbal Amoltepec and Santa Catarina Tayata}

Land use change analysis was performed on 5 Landsat images taken in 1984, 1989, 1999, 2010 and 2017 (Table 3.1). The 1984 image was the oldest usable image that had a reso- 
lution of $30 \mathrm{~m}$ and no cloud cover. For the land use change analysis, we used the same workflow described in the previous section. Land use was classified as forest, grassland, cropland or bare land. Shrub land was not present in SCA and SCT, unlike in the regional anlaysis. Although cropland and grassland/fallow are distinct classes, the images' resolution in combination with the small plot sizes (less than one ha) and the common presence of fallow lands did not allow for a direct separation during the image classification. We instead separated cropland and grassland by using shape files containing the delineation of private and common areas in both municipalities. Since common areas do not have crops, every pixel classified as cropland within common areas was considered to be grassland. Similarly, every pixel classified as cropland within private land was considered cropland. We could not apply the same land use separation method for the Rio-Sordo watershed analysis because of lack of information. The generated land use maps were later used in our workshops with the local officials from SCA and SCT.

To analyze the causes of land use change, we approached former municipal officials that had been in office around the time the land use images had been taken. A total of 5 former officials for SCA and 6 for SCT were found willing to contribute. Respondents for SCA had been in office in the following periods: 1979-1981, 1988-1990, 1996-1998, 2002-2004, 2011-2013. For SCT the periods included: 1969-1971, 1981-1983, 1987-1989, 1996-1998, 2002-2004, 2014-2016. In each municipality a workshop was organized in September 2018 (Appendix 1).

Each workshop consisted of two stages: 1) description of major changes in the municipality from the mid-60s to 2018 and 2) evaluation of land use change using the classified maps. We asked the participants to first describe the major drivers of change around the time of their term in office. On each topic mentioned, we asked details until no new elements were mentioned. At the end of this stage, drivers that we had heard of but were not mentioned were brought forward to check their relevance according to the participants. During the second stage of the workshop, we explained our classified images to the participants and asked them to explain what they considered to be the drivers of change associated with the landscape change, using the list of drivers that had been established in the first stage. The workshops were recorded. Results were used to create a timeline per municipality describing drivers of change.

To complement the results from the workshops, we obtained data from the 1991 and 2007 agricultural censuses and the 1980, 1990, 1995, 2000, 2005 and 2010 population censuses (available on https://www.inegi.org.mx/datos/?ps=Programas). These censuses provided data on population size, income sources, crop and animal production. We compared population size across the censused years to identify population growth, 
stagnation or decline. Furthermore, we categorized the population into five-year age categories to build an age pyramid. Data on income sources showed the proportion of household heads relying on off-farm income. Crop production was expressed as average arable land per household, and animal production as average number of sheep, goat, cattle, equine and pig heads per household. We used data from a survey done in 2015 for more recent data on crop and animal production, based on 31 and 51 observations from SCA and SCT, respectively. Crop and animal production and demographic change were used to assess the impact of these activities on land use change.

\section{3 | Results}

\subsubsection{Río-Sordo Watershed Land Use Change}

In 2017, forest covered the largest area in the Rio-Sordo watershed, occupying $66 \%$ of the territory, followed by agriculture, shrub land and bare soil, which occupied 19.4, 12.2 and $2.4 \%$, respectively (Table 3.2). Overall, agriculture was the land use that had the highest change rate, having a net change of $-6.5 \%$ between 1989 and 2017. The decrease in agriculture was attributed to its conversion to forest first and shrub land second. Forest increased 4.3\% between 1989 and 2017, mostly because of the agriculture to forest conversion. Similar to forest, shrub land presented a $4.3 \%$ increase over the same time, due to agriculture to shrub land conversion.

Out of the 63 municipalities in the Río-Sordo watershed, 18, 38, 58 and 23 decreased in cover by forest, shrub land, agriculture and bare soil, respectively (Figure 3.2). Application of random forest models generated an OOB error of 16.3, 23.3, 9.3 and $44.2 \%$ when predicting forest, shrub, agriculture and bare soil, respectively. Considering the high OOB when predicting bare soil, we left this land use out for the subsequent analysis. The two most important variables explaining both forest and shrub changes were percent of forest in 1989 and the marginalization index (Figure $3.3 \mathrm{a}$ and b). A regression tree showed municipalities with an initial forest cover of $70 \%$ or more to be related with deforestation (Appendix 2). From the 12 municipalities that had around 70\% or more of their area covered by forest in 1989, also deforested by 2017 , except for two municipalities he two most important variables explaining land use under agriculture were migration and drought risk (Figure $3.3 \mathrm{c}$ ).

Deforestation started occurring at marginalization rates exceeding 0.5 (Figure 3.4). In $46 \%$ of the municipalities with a marginalization index of 0.5 and above forest area increased, with San Cristóbal Amoltepec being among them. 


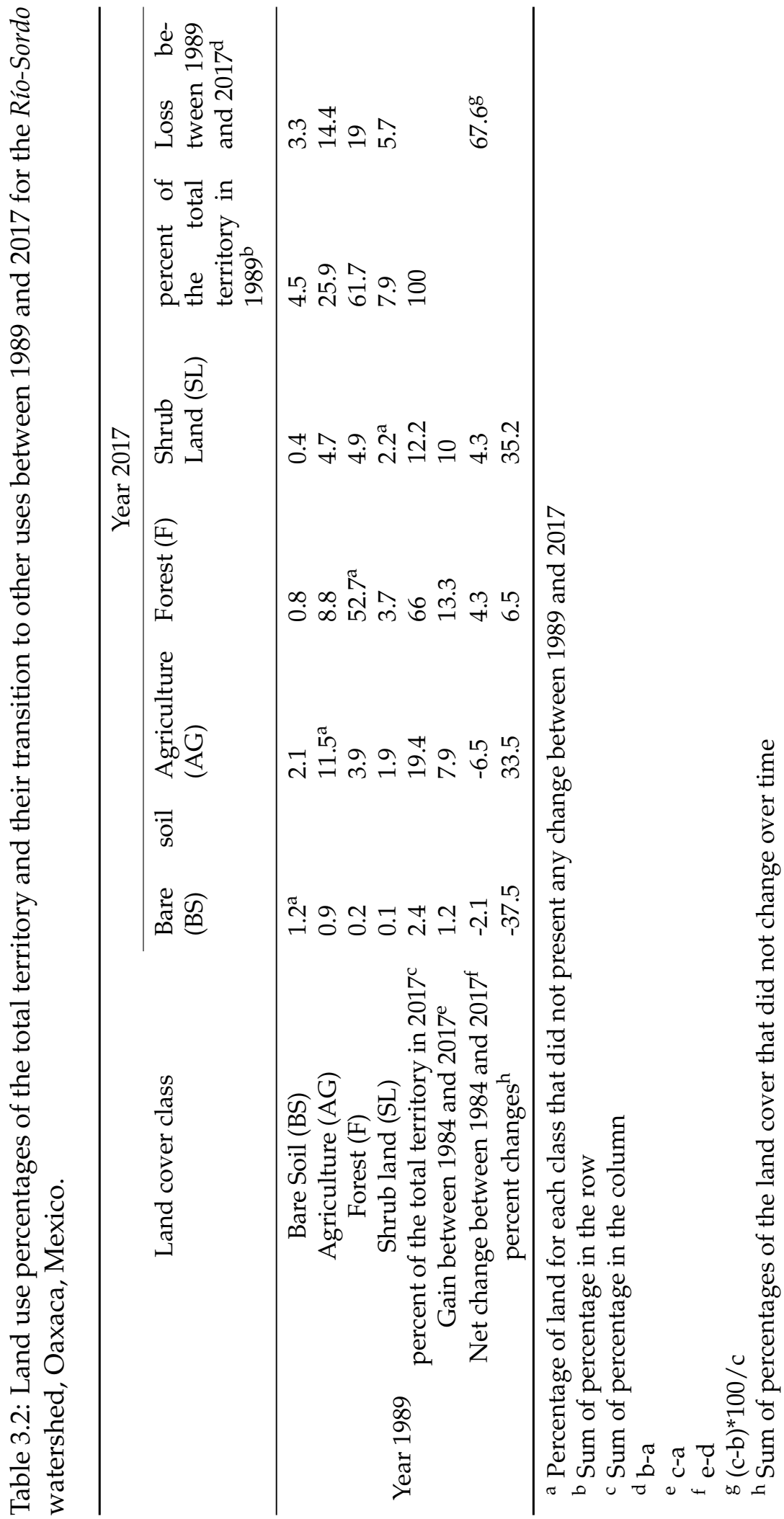




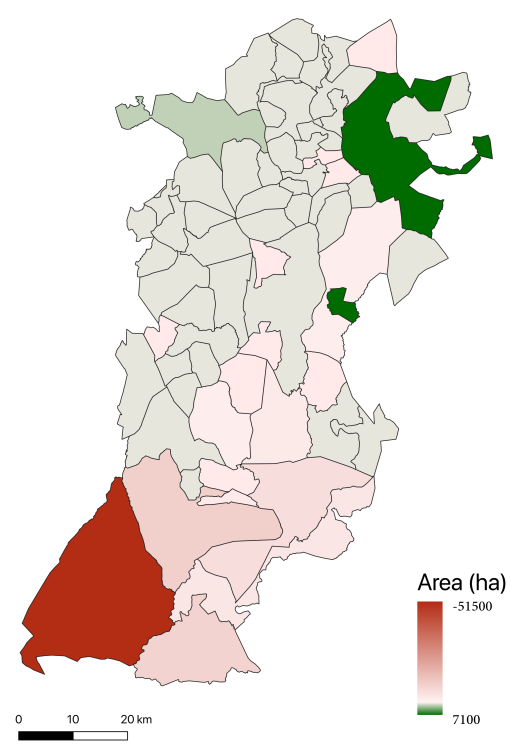

a Forest

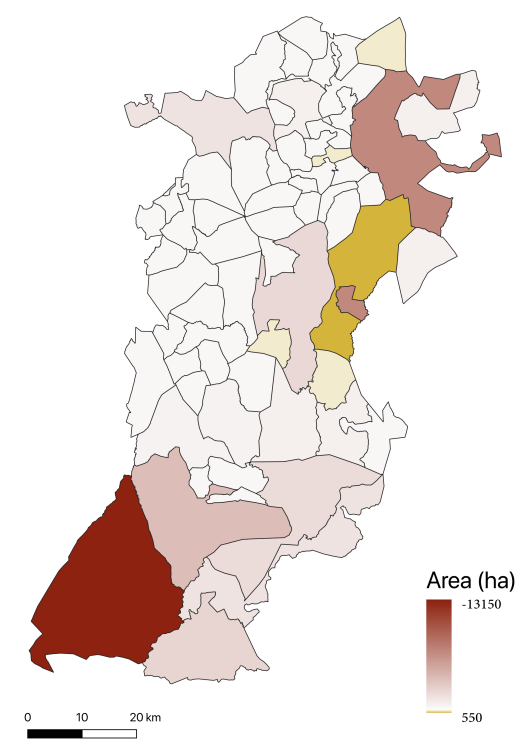

c Agriculture

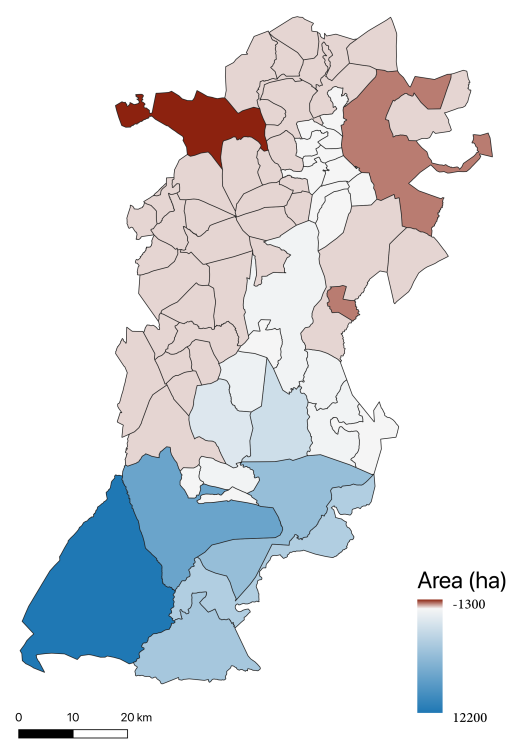

b Shrub land

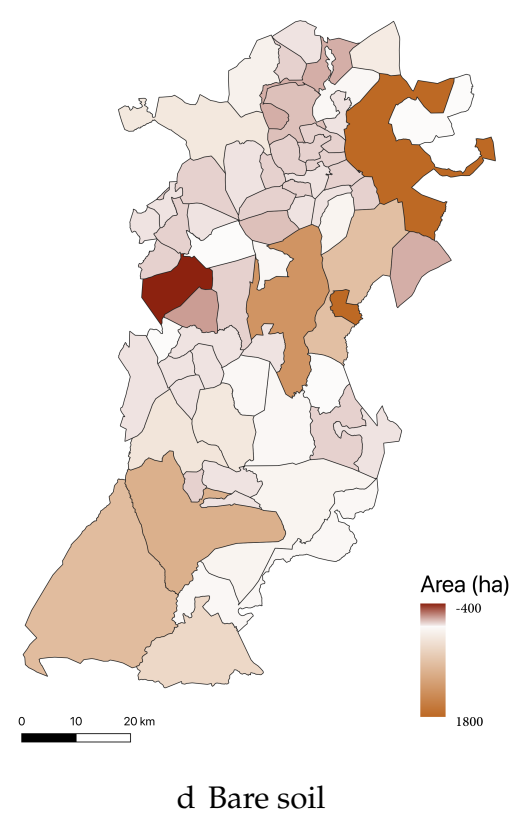

Figure 3.2: Changes in forest, shrub land, agriculture and bare soil per municipality within the Río-Sordo watershed, Oaxaca, Mexico, for the period 1989-2017. 

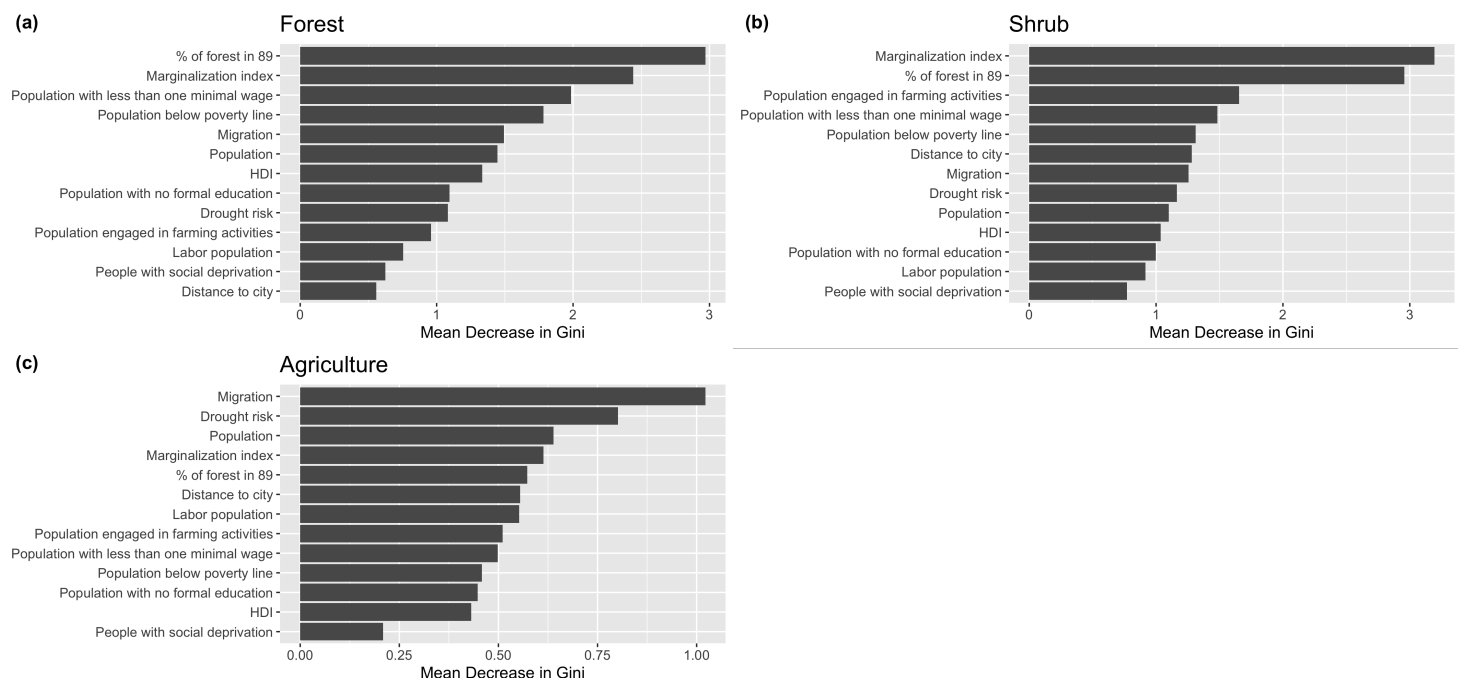

Figure 3.3: Variable importance rank as expressed by the Mean Decrease in Gini for predicting forest, shrub land and agriculture.

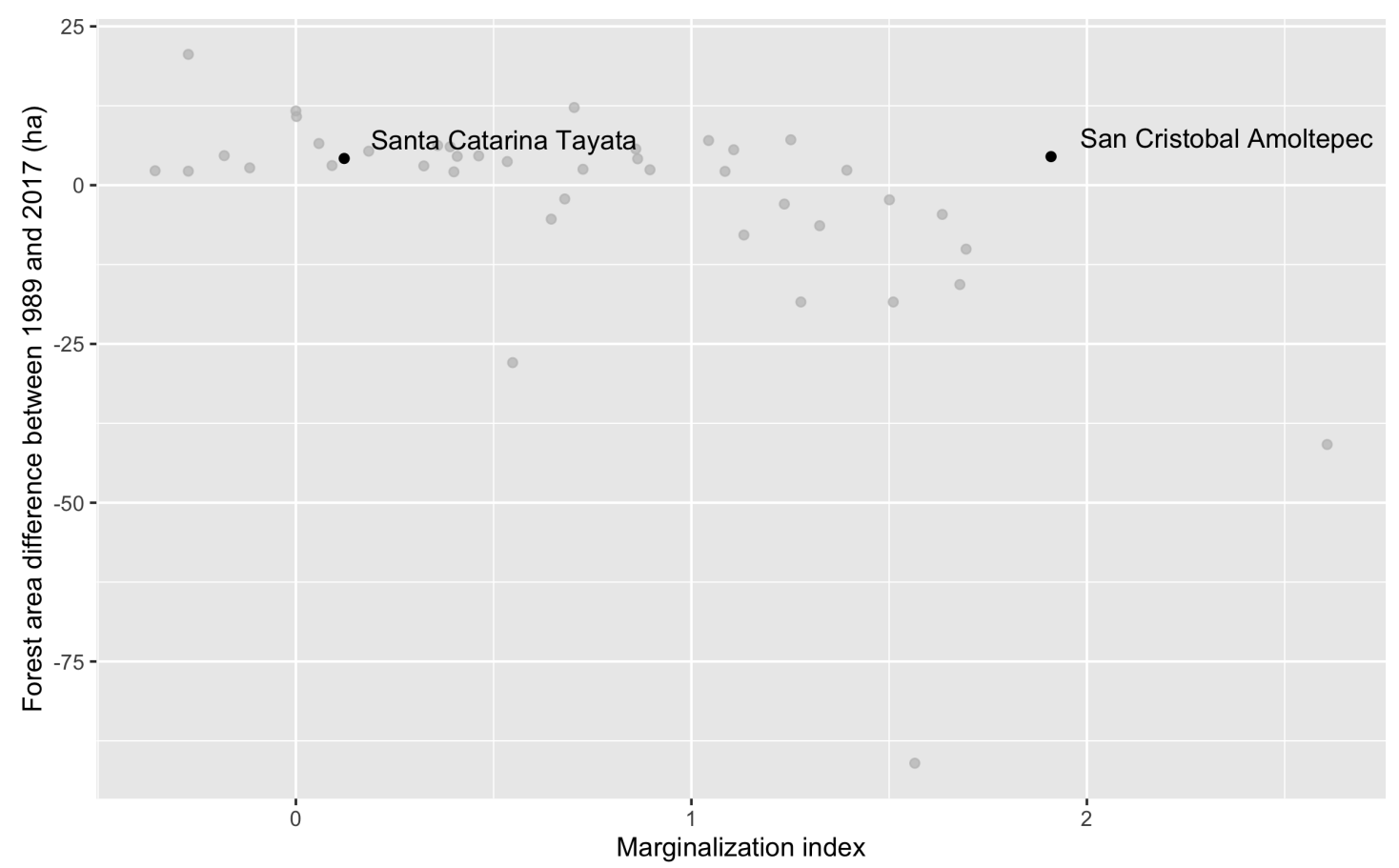

Figure 3.4: Relation between marginalization index and forest area change between 1989 and 2017. Case study municipalities are highlighted in black. 


\subsection{2 | Land Use Change in Santa Catarina Tayata and San Cristóbal Amoltepec}

In 1984, cropland, grassland, forest and bare land occupied 17, 28, 32 and $23 \%$ of the total territory of SCA (Figure 3.5). By 2017, cropland in SCA had not changed much in area, occupying 19\% of the total area. Grassland decreased from 28 to $20 \%$, forest increased from 31 to $51 \%$ and bare land decreased from 23 to $9 \%$ of the total area. These changes represent an average annual growth in cropland, grassland, forest and bare land of 0.13 , $-0.28,0.62$ and -0.61 percentage points.

In SCT, cropland, grassland, forest and bare land occupied 21, 17, 13 and 49\% of the total area in 1984. Similar to SCA cropland barely changed between 1984 and 2017, going from 21 to $22 \%$, grassland decreased from 17 to $9 \%$, forest increased from 49 to $65 \%$ and bare land decreased from 13 to $4 \%$ of the total territory of SCT. The average annual growth of cropland, grassland, forest and bare land was $0.07,-0.44,0.40$ and -0.68 percentage points.

In SCA, forest expanded by 1\% annually between 1989 and 2010, but only by $0.15 \%$ between 2010 and 2017. While in SCA forest growth seemed to have been stabilizing in recent years, SCT showed no signs that forest expansion was slowing down. Most of the forest growth occurred at the expense of grassland and, to some extent, cropland (Table 3.3). The expansion of forest to cropland can be seen in yellow in Figure 3.5, where there is an increase of this land use located in private areas. This type of conversion can be seen in Figure 3.5, where forest is found on private land in SCT.

Land use changes mostly concerned forest and grassland (Table 3.3). Forest loss was not common in SCA, with conversion to grassland limited to less than $5 \%$ of the total territory. On the other hand, changes from grassland were mostly to forest, with $14 \%$ of the total territory being converted between 1999 and 2010. We also observed some changes in bare land, especially to grassland and cropland, at similar rates, which varied from 2 to $7 \%$ of the total territory.

Similar to SCA, forest area in SCT increased. Grassland was mostly converted to forest, with a conversion peak of 7\% of the total territory between 1999 and 2010. A small amount ( 2 to $4 \%$ per period) of cropland was converted to forest. Bare land in SCT was mostly converted to cropland; the decadal conversion rate varied from 2 to $6 \%$ of the total area. In both municipalities, forest increase mostly occurred around existing woody vegetation, rather than through newly established patches, suggesting natural reforestation (Figure 3.6). 
Table 3.3: Percent of land use change from each classified class to the rest over 1984 to 2017.

\begin{tabular}{|c|c|c|c|c|c|}
\hline \multirow[b]{2}{*}{ Changed from } & \multirow[b]{2}{*}{ Changed to } & \multicolumn{4}{|c|}{ Percent change during } \\
\hline & & 1984-1989 & 1989-1999 & $1999-2010$ & 2010-2017 \\
\hline \multicolumn{6}{|c|}{ San Cristóbal Amoltepec } \\
\hline \multirow[t]{4}{*}{ Forest } & Forest & 27 & 27 & 34 & 46 \\
\hline & Cropland & 1 & 1 & 1 & 1 \\
\hline & Grassland & 5 & 1 & 0 & 4 \\
\hline & Bare land & 0 & 0 & 0 & 0 \\
\hline \multirow[t]{4}{*}{ Grassland } & Forest & 1 & 2 & 3 & 2 \\
\hline & Cropland & 14 & 18 & 15 & 15 \\
\hline & Grassland & 0 & 0 & 0 & 0 \\
\hline & Bare land & 2 & 3 & 3 & 2 \\
\hline \multirow{4}{*}{ Cropland } & Forest & 1 & 7 & 14 & 4 \\
\hline & Cropland & 0 & 0 & 0 & 0 \\
\hline & Grassland & 21 & 23 & 12 & 12 \\
\hline & Bare land & 5 & 3 & 3 & 1 \\
\hline \multirow[t]{4}{*}{ Bare land } & Forest & 0 & 0 & 0 & 1 \\
\hline & Cropland & 7 & 2 & 3 & 3 \\
\hline & Grassland & 7 & 4 & 4 & 4 \\
\hline & Bare land & 10 & 10 & 9 & 7 \\
\hline \multicolumn{6}{|c|}{ Santa Catarina Tayata } \\
\hline \multirow[t]{4}{*}{ Forest } & Forest & 43 & 44 & 49 & 57 \\
\hline & Cropland & 1 & 1 & 1 & 1 \\
\hline & Grassland & 3 & 2 & 1 & 2 \\
\hline & Bare land & 0 & 0 & 0 & 0 \\
\hline \multirow[t]{4}{*}{ Cropland } & Forest & 2 & 2 & 4 & 4 \\
\hline & Cropland & 18 & 20 & 20 & 19 \\
\hline & Grassland & 0 & 1 & 0 & 0 \\
\hline & Bare land & 3 & 2 & 2 & 1 \\
\hline \multirow{4}{*}{ Grassland } & Forest & 2 & 5 & 7 & 3 \\
\hline & Cropland & 0 & 1 & 0 & 0 \\
\hline & Grassland & 13 & 12 & 8 & 6 \\
\hline & Bare land & 2 & 1 & 0 & 0 \\
\hline \multirow[t]{4}{*}{ Bare land } & Forest & 0 & 0 & 0 & 0 \\
\hline & Cropland & 6 & 3 & 4 & 2 \\
\hline & Grassland & 2 & 1 & 1 & 1 \\
\hline & Bare land & 5 & 6 & 4 & 3 \\
\hline
\end{tabular}




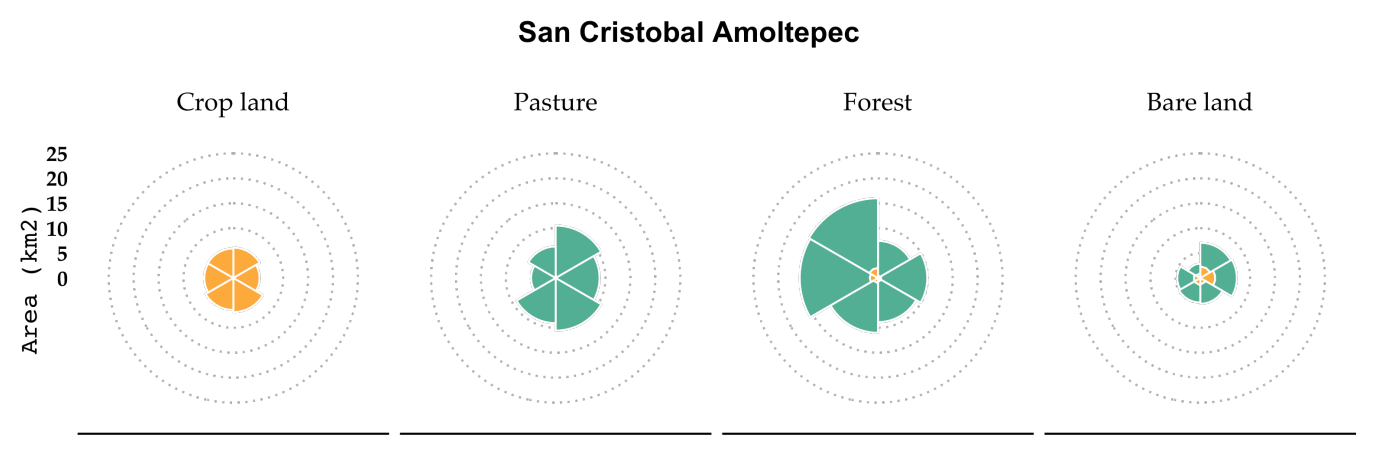

Santa Catarina Tayata

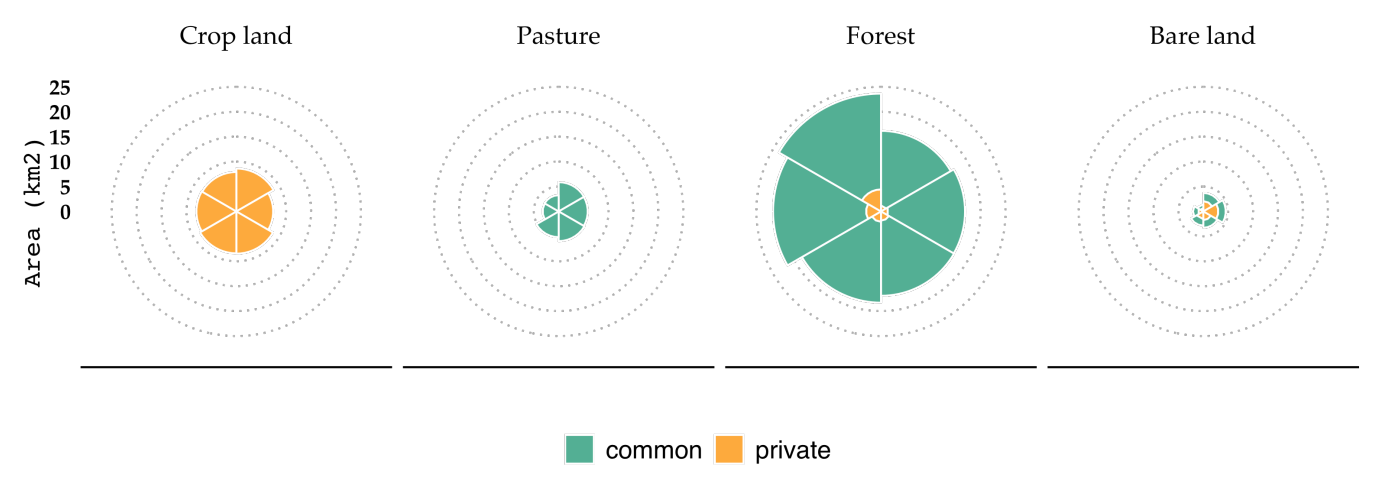

Figure 3.5: Fraction land use from 1984 to 2017 in the Mixteca Alta municipalities San Cristóbal Amoltepec and Santa Catarina Tayata in Mexico, based on analysis of Landsat images from 1984, 1989, 1999, 2010 and 2017. 

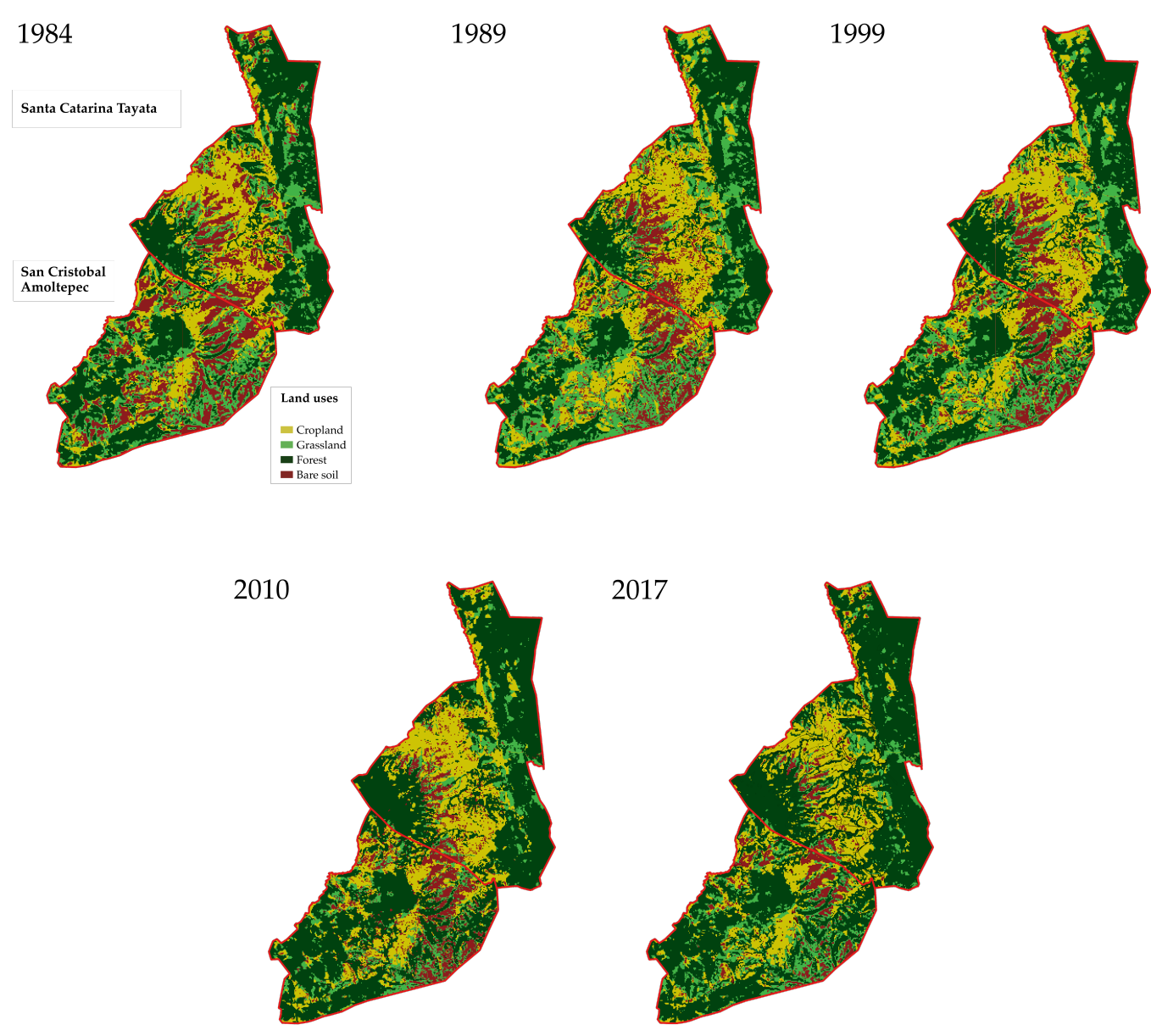

Figure 3.6: Land use in San Cristobal Amoltepec and Santa Catarina Tayata from 1984, $1989,1999,2010$ and 2017 


\subsubsection{Local responses in SCA and SCT and impact on the land cover}

In the workshops with local actors Bienes Comunales was identified as the most important local institution for landscape change (Figure 3.7). Bienes Comunales was established in 1946 and 1962 in SCA and SCT, respectively. The establishment of Bienes Comunales was a response of the communities wanting to legally delineate their borders to reduce conflicts with neighboring communities about felling trees on what they considered their territory. The Bienes Comunales in both areas issued several regulations concerning logging and ruling out slash-and-burn. In SCA, the slash-and-burn restriction occurred around the same time as in SCT, but logging was restricted only in 1994, while in SCT logging was restricted in 1962. The logging regulations forced the communities' dwellers to seek approval of Bienes Comunales for logging, which would only be permitted for personal use (e.g. for firewood and construction materials).

Grazing, although not directly correlated to deforestation, was perceived by the local population as a damaging activity. The workshop participants stated that the local population deemed goats responsible for degradation of common land. Therefore, a local regulation that would forbid goats to graze on common areas was approved in the local assembly in 2000 and 1990 in SCA and SCT, respectively. This grazing regulation resulted in a decrease in the number of goats per household, while increasing the number of sheep in both communities (Figure 3.8). In spite of the increase in sheep densities, forest area replaced grassland in both municipalities (Figure 3.6). Our workshop participants attributed this increase in forest and reduction in grassland to the fact that in contrast to goats, sheep allowed growth of spontaneous tree saplings.

In order to restore degraded areas, both municipalities conducted a reforestation campaign targeting the eroded bare lands. These campaigns happened between 1990 and 2000 in SCA and between 2003 and 2015 in SCT. The workshop participants considered these campaigns only partially successful, as around $50 \%$ of the sapling trees planted did not survive. They attributed this failure to the tree species chosen for the reforestation, the Pinus oaxacana, which required deeper soils than prevalent in the area. The communities had no choice but to use this species, as this was the only option provided by the agency responsible for the forestry resources of Mexico (nowadays called CONAFOR). Planting was done by the locals through tequio - an unpaid collective action/work that the locals have to perform as part of the community duties.

Census data from 1980 to 2010 showed that the population size remained stable in SCA, with around 1200 inhabitants. Between 2010 and 2015 the population declined from 1271 to 1004 . In SCT, on the other hand, population numbers have been declin- 
ing from at least 1980. From 1980 to 2010, the population size dropped from 864 to 679 people. According to the workshop participants, out-migration has led to land abandonment and forest growth.

\section{San Cristobal Amoltepec}

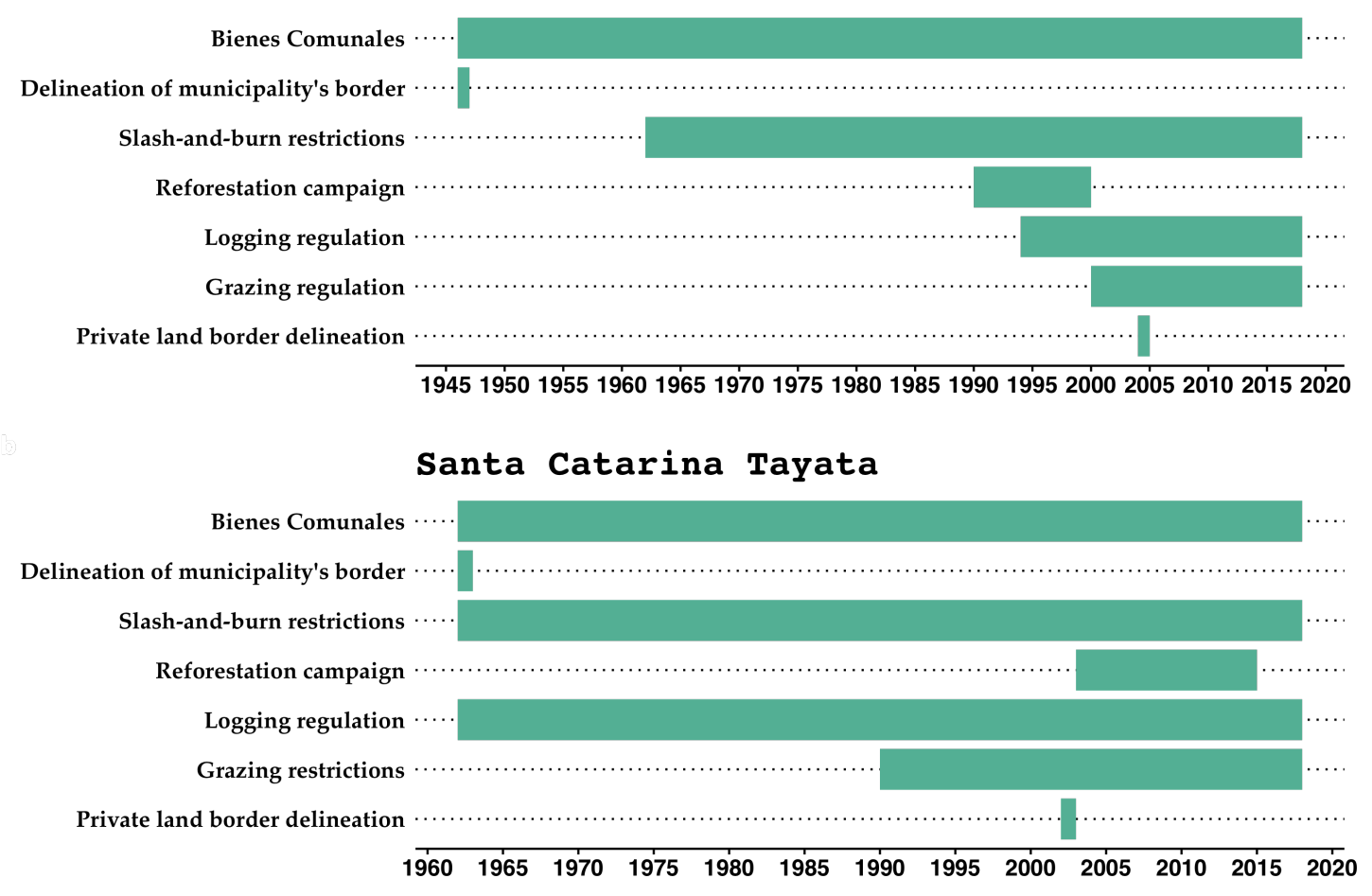

Figure 3.7: Timeline of the major drivers of change developed with the local officials. 


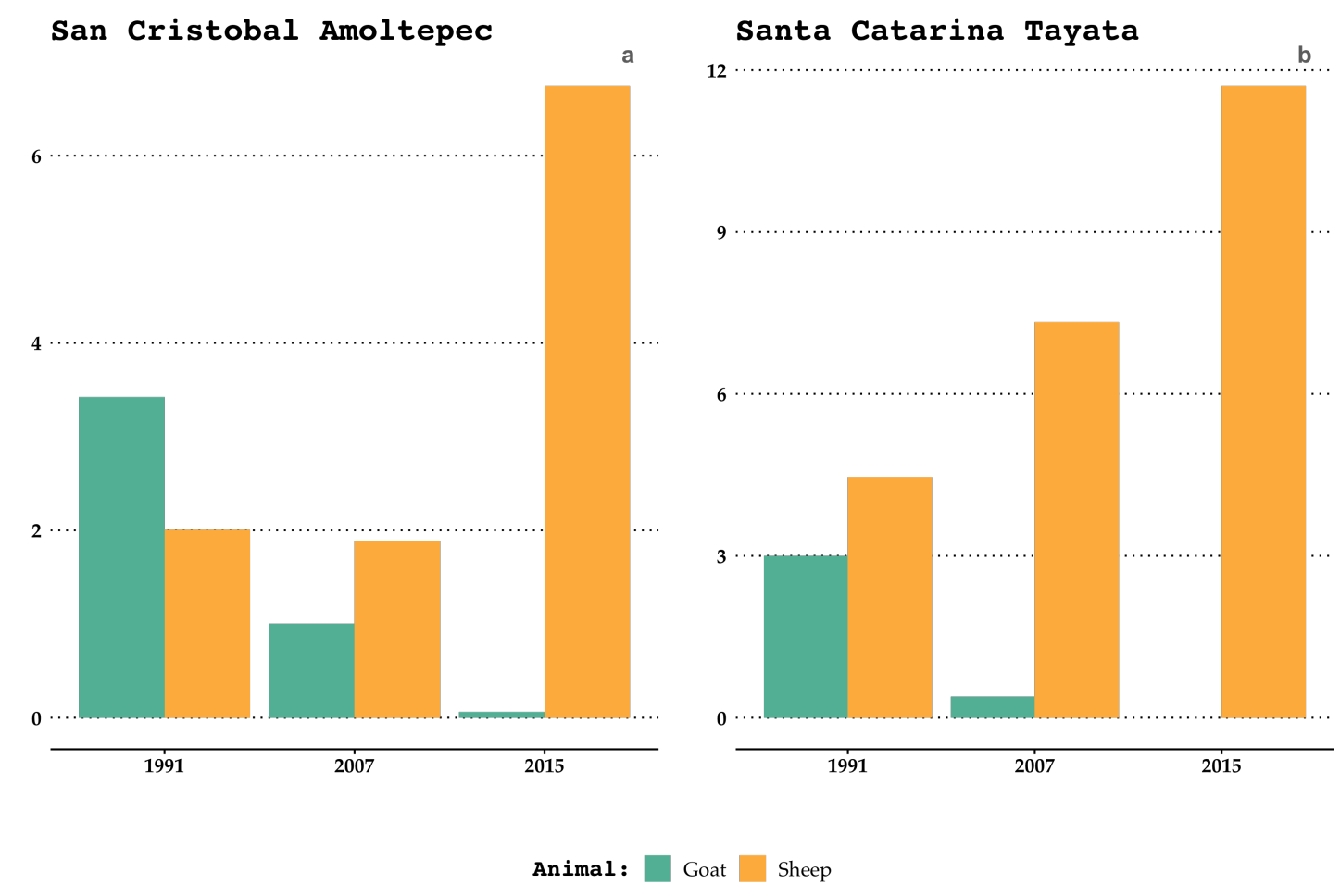

Figure 3.8: Shifts in the average animal production per household ( $a$ and $b$ ) in San Cristóbal Amoltepec and Santa Catarina Tayata.

\section{4 | Discussion}

We hypothesized that community characteristics explain differences in landscape transformation outcomes. At the watershed level the majority of municipalities exhibited increases in afforested area over the past 30 years, others exhibited high deforestation rates. Deforestation was associated with marginalization index values exceeding 0.5. Agricultural cover in the Rio-Sordo generally decreased, associated with migration and drought risk. In the local land use governance processes Bienes Comunales were found to play a key role. Among the actions enforced by Bienes Comunales were logging and grazing regulations, and reforestation campaigns. These actions stimulated an increase in forest area, while reducing areas of grassland and bare soil.

Other studies also found reduced agricultural activities to be related to migration and land abandonment (Aide et al., 2000a; Romero-Calcerrada and Perry, 2004; Sitzia et al., 2010) and to drought risks (Martin et al., 2016). Explaining reforestation/deforestation, however, is less clear-cut. Many authors agree that forest patterns 
in human-influenced landscape change are strongly affected by a combination of socioeconomic and environmental factors that are site-specific (Angelsen, 1995; Bernard and Koninck, 1997; Geist and Lambin, 2002; Mather et al., 1998; Murali and Hedge, 1997; Rudel and Roper, 1996; Twongyirwe et al., 2018; Walker, 2010)

The percent of forest in 1989 and marginalization index were found to be the most important variables explaining reforestation/deforestation at the watershed scale. Similar to our results, Aide et al. (2012) found that the initial percentage of forest cover in a municipality was the most important variable explaining woody vegetation cover for Latin America and the Caribbean: high initial forest cover resulted in a higher probability of being deforested and vice versa. Our results showed that municipalities with an initial forest cover of around $70 \%$ or more were more likely to undergo deforestation. Initial forest cover may have been confounded with marginalization, which we found to explain deforestation in municipalities with a marginalization index above 0.5. Municipalities with a marginalization index below 0.5 generally showed an increase in forest cover. The greater the marginalization index, the higher the deforestation rate. Despite having the second highest observed marginalization index value in the Rio-Sordo watershed, San Cristóbal Amoltepec showed an increase in afforested area. In a country-wide study for Mexico, Mas and Cuevas (2015) found indigenous areas with high marginalization rates such as SCA to be associated with reforestation. In contrast to our results Mas and Cuevas (2015) found more deforestation to be associated with low marginalization outside indigenous areas of the central-south region of Mexico. This may be explained by the inclusion of highly developed areas in their study that focused on all of Mexico, suggesting that low levels of marginalization can lead to highly different effects on forest cover and other indicators are needed to understand dynamics under such conditions. Deininger and Minten (1999) concluded in a study for Mexico that poverty was associated with deforestation. Other studies around the world tried to link poverty to deforestation, with oftentimes contrasting results (Busch and Ferretti-Gallon, 2017; Gaveau et al., 2009; Khan and Khan, 2009). Since poverty and marginalization in rural areas is common around the world (FAO, 2008) and 65\% of the global area is under community control (Wily, 2010) more understanding of the drivers of sustainable land management is called for.

A number of cases have been documented on the role of indigenous communities in reforestation processes worldwide (Herrmann, 2006; Ravindranath et al., 2008; Smith, 2001). Innah et al. (2013) described 4 typologies of collective indigenous action related to reforestation in Indonesia. These types were mostly defined by their leadership (e.g. formal authority and traditional leaders), motivation (e.g. innovation, rewards for reforestation, conservation of traditional customs and commercial) and law structure (e.g. 
indigenous or formal law). Our results showed that both SCT and SCT had a formal leadership, sustained by the indigenous people who would vocalize their ideas and vote for approval of new local regulations through the local institution Bienes Comunales.

Although the Bienes Comunales were established to put an end to conflicts with neighboring communities, their delineation and regulation of private and common land also served to decrease land degeneration and enhance forest development within the communities. This zoning process has also been identified by others as a measure that avoids deforestation (Bray, 2004; Dalle et al., 2006; Ellis and Porter-Bolland, 2008). In common areas, Bienes Comunales restricted agriculture expansion by forbidding slashand-burn practices during a period of high pressure on land in the 1960s. Restricting grazing, specifically by goats, affected land use in both communities. Goats are an exotic species to Mexico introduced during the Spanish colonization (Mindek, 2003), and their feeding preferences impede the forest regeneration (Sierra et al., 1997). Perceiving the negative impacts caused by the goats on the environment, the local population through Bienes Comunales forbid goats to graze in common areas. The impact of the regulations on goat numbers was confirmed by comparing the 1991 and 2007 agricultural censuses and our 2015 survey data, from which we observed a reduction in average goat numbers per household (Figure 3.7). Associated with the change in goat numbers forest area in both municipalities increased, while grassland and bare land decreased (Table 3.3 and Figure 3.6). Although we also observed a spike in sheep production, it was not associated with deforestation, as information from the local population revealed that sheep avoided feeding on sapling trees, thus allowing the forest regeneration process to continue.

Land use planning is often driven by experts implementing top-down processes with limited inclusion of local communities, and sometimes even favoring particular interests of planners, policy makers and others (Berkes, 2004; Glover et al., 2008; Hu et al., 2016). Our study shows how communities that are engaged in land use planning using knowledge of their own unique context and benefiting from national drivers took an active role in land use planning by developing and voting local rules and regulations for natural resource management, in spite of their marginalization rates. A limitation of our study is that we only evaluated two municipalities out of the 63 in the watershed and their specific needs and backgrounds. More studies linking local to regional and national developments may bring out patterns of local governance and their higher level support successful in sustainable landscape change. These type of studies will require research engagement with each communities to understand their historical context from often undocumented materials, and are thus resource-intensive.

At the time of writing, Mexico had just changed to a social-democratic government 
after years of neo-liberal rule. The new government elaborated and implemented several projects focusing on connecting rural areas through the construction of roads and highways, provision of trees for fruit and timber production, guaranteed prices for basic crops like maize, bean and rice, and dual-trust credit (crédito a la palabra) for stimulating animal production. In the latter program the government gives a farmer some animals to breed, and the farmer in turn has to return the first young animal to the government so that other farmers can also benefit. The idea is to boost meat and dairy production and improve food self-sufficiency. In the Mixteca region, this program might lead to a step back in resource conservation strategies that the communities built over the past decades. By offering farmers the possibility of enhancing animal production, the local population might shift their goal of conserving natural resources towards one of food production and short-term economic benefits that could hamper forest growth. The program that aims at planting trees for fruit and timber production seems to be aligned with current communities' goals to conserve natural resources. Therefore, the way the government decides to implement plans has the potential to go in favor or against communities' visions for their landscape. This shows the importance of understanding the local background to target programs to maximize their acceptance, while predicting possible pitfalls.

\section{5 | Conclusions}

At the watershed level, initial forest area, marginalization, migration and drought risks were important predictors of land use change and in particular forested areas. Detailed analyses at the municipal level involving local officials and farmers showed how communities used local knowledge together with the opportunities afforded by national laws and regulations to counter landscape degradation. Although deforestation was associated with marginalization, even in situations of high marginalization reforestation was found to occur. Our results also suggest that indigenous communities may provide learnings on resource aware communal decision making. These results are promising, considering that more than half of the world's land is managed by communities. For this promise to materialize, community and governmental goals need to be carefully aligned to allow communities to effectively manage their natural resources. 


\section{6 | Acknowledgements}

The authors would like to thank all participating local officials and farmers for their kindness and willing to provide all the information that made this study possible. We would like to give a special thanks to Jesus Cruz Galicia and Martha Ortiz who guided use and facilitate the interviews. The authors would also like to thank the support provided by the CGIAR, which funded this project, 'Agro-ecosystem diversity and the Trajectories and Trade-offs for Intensification of Cereal-based systems' (ATTIC, grant agreement: A4032.09.20). 



\section{Chapter 4: The role of traditional milpa in food security and food self-sufficiency in the highlands of Oaxaca, Mexico*}

\section{Abstract}

Around $30 \%$ of the global food is produced by smallholder farmers, and yet they are the most food insecure group. In Mexico, food self-sufficiency is declining. Policies in the country stimulated production of profitable crops and pushed farmers away from traditional polycropping milpa systems. The decline of milpa can have nutritional consequences to subsistence farmers. Therefore, the aim of this study was to assess changes in the nutritional self-sufficiency over the last 30 years and the role of milpa systems in food nutrition security. The study was conducted in two case study municipalities in Oaxaca, Santa Catarina Tayata (SCT) and San Cristóbal Amoltepec (SCA). A land use classification was performed to quantify cropland for three periods: 1989, 2010 and 2017. We used agricultural two censuses and a survey to estimate crop yields from around the same period as the land use classification. We estimated production of dietary energy,

*Article to be submitted to the Global Food Security journal: Novotny, I; Rossing, W; López-Ridaura, S; Fuentes-Ponce, M; Tittonell, P. The role of traditional milpa in food security and food self-sufficiency in the highlands of Oaxaca, Mexico 
protein, 5 nutrients and 7 vitamins for three cropping system, milpa, monoculture of maize and monoculture of bean. As consequence of increasing crop yields and demographic decline, SCT was able to reach self-sufficiency for every nutritional element, except for Vitamin A and C. In addition to these vitamins, SCA had a low production of other elements such as zinc, iron and magnesium. The low levels of vitamin A and C in each municipality was associated with a low milpa production, as farmers were not interested in this system due to high labor demands. Future efforts should be around gaining farmers interest back in milpa systems, which could be achieved by integrating practices that reduce the amount of labor required while increasing crop yields. 


\section{1 | Introduction}

There is a long-standing debate on the role of food self-sufficiency as a strategy for food security (Clapp, 2017; Minot et al., 2010). Food self-sufficiency relates to the ability of a country, region or household to reach their food requirements without the need of importing food (FAO, 2006). Food security is met when people have food availability, access, use and stability (FAO, 2006). Recent estimations show that households with less than 2 ha supply $30-34 \%$ of global food (Ricciardi et al., 2018). Yet, the majority of food insecure people also live in rural areas (Thornton et al., 2019). This food insecurity can be a consequence of drought, conflicts, land pressure and poverty (FAO, 2000). Furthermore, food security is threatened by a shift away from diverse cropping systems towards more simplified systems such as monocropping (Remans et al., 2011). In Mexico, nation-wide food self-sufficiency has been declining as the country started relying more on imported staple grains (Otero, 2011). The indigenous people constitute the most food insecure group in the country (USDA, 2010). Indigenous groups oftentimes rely on diverse and traditional agricultural systems (Lozada-Aranda et al., 2017). Yet, there are no studies quantifying the contribution of such traditional systems to the food security of the rural poor in Mexico. In this study, we show how food production and self-sufficiency (i.e. availability) have changed over time (i.e. stability), while also addressing the role of food diversity provided by traditional agricultural systems (i.e. use) in feeding the local population (i.e. access).

The North American Free Trade Agreement (NAFTA) of 1994 had several political and social implications in Mexico, most notably affecting the country's food selfsufficiency, its labor sovereignty (the ability of a nation to provide its citizens with living wages), and causing an increased out-migration rate (the process of moving from one place to live in another place) (Otero, 2011). To adjust to the NAFTA, Mexican policies incentivized households to move away from traditional food production systems and towards more economically productive crops (Zarazúa-Escobar et al., 2011). In an assessment, Preibisch et al. (2002) showed that although there was strong disincentive to produce maize after NAFTA, households kept producing this staple crop. They found a decrease in crop areas, associated with out-migration and increasing off-farm income.

In Mexico, the traditional maize production systems called milpa provide the basis for rural households' food supply. Milpa systems can be found in the whole of the Mexican territory (Ibarrola-Rivas and Galicia, 2017), extending to South America (LozadaAranda et al., 2017). In these systems, maize (Zea mays L.) is usually inter-cropped with common bean (Phaseolus vulgaris L.), and squash (Cucurbita spp.) (Ebel et al., 2017), although the crop species composition might change depending on the agroclimatic zone 
(Lozada-Aranda et al., 2017). According to Mann (2006), the diversity of crops found in milpa are nutritionally and environmentally complementary. Although milpa systems have been found to be ineffective in terms of generating sufficient family income due to generally low yield levels, they have been found to be important in affording food security as milpa can guarantee household access to a diversity of food (Ibarrola-Rivas and Galicia, 2017; Isakson, 2009). Nevertheless, the potential of milpa to supply an adequate diet in terms of macro/micro-nutrients and vitamins and its role in nutritional self-sufficiency in rural areas remains largely unexplored.

To assess food security, studies have addressed major staple crops such as maize, wheat, rice, and other grains, and their caloric and protein supply. While these crops are important sources of calories and protein, they are usually not sufficient to provide a balanced diet. This requires more nutrition-sensitive approaches (FAO, 2014; Ruel et al., 2018). Recent studies have called attention to aspects of food security such as diversity of food sources and the nutritional quality of products in terms of micro-nutrient and vitamin provision (Aberman et al., 2018; Hidrobo et al., 2018; Ickowitz et al., 2019). (Remans et al., 2011) adapted the functional diversity metric used in ecology into a nutritional functional diversity metric. This metric considers species composition as well as their nutritional contributions. Cassidy et al. (2013) introduced assessment of the number of people nourished per area in terms of calories and proteins, which DeFries et al. (2015) refined later to include other nutrients.

Against a background of policies that discourage traditional systems, a widespread decrease in interest in agricultural activities, and out-migration the objective of our study was to assess long-term changes in food demand and supply in a rural context, the Mixteca Alta Oaxaqueña, and to analyze the role of the traditional agricultural systems for local food and nutrition security. We hypothesize that milpa can provide a balanced diet and that demographic decline in rural areas negatively affects milpa production due to reduced labor availability. To test our hypotheses we investigated the following questions: 1) how has demographic decline caused by out-migration affected nutritional self-sufficiency? 2) What is the nutritional benefit of milpa compared to monocropping systems? 3) Which factors limit the renaissance of traditional milpa systems? Answering these questions contributes to the development of policies that support food and nutrition security of rural populations in conditions with net migration to cities.

More specifically, we assess how changes in the food production system have affected the nutritional self-sufficiency in two communities in the state of Oaxaca, Mexico. Oaxaca is characterized by high migration levels both nationally and internationally, and an increasing trend to pursue local off-farm activities as a livelihood strategy. These communities are representative of many others in Central America, in that milpa still 
constitutes the basis of food production (Lozada-Aranda et al., 2017; Nigh and Diemont, 2013).

\section{2 | Methodology}

\subsection{1 | Case study areas}

Both case studies are situated in the highlands of Oaxaca. Santa Catarina Tayata (SCT, Figure 3.1) has an area of $37 \mathrm{~km}^{2}$ and is located at an elevation between 2000 and $2500 \mathrm{~m}$ above sea level. Climate is classified as sub-humid, with monthly average temperatures ranging from 16 to $18^{\circ} \mathrm{C}$, and annual rainfall between 1000 and $1200 \mathrm{~mm}$. Land use in SCT comprises settlements, private land and communal land. Settlements are usually an agglomerate of houses interspersed with cropland. Private land consists of cropland and fallow land. Communal land includes forest and grassland, both of which are managed by the municipality's officials, who enforce rules for their management. A survey carried out in 2015 showed 4 household types in SCT (Table 4.1).

San Cristóbal Amoltepec (SCA) is spread over $32 \mathrm{~km}^{2}$ at elevations from 2100 to $2700 \mathrm{~m}$. Climate is also sub-humid, with monthly average temperatures of 14 to $18^{\circ} \mathrm{C}$, slightly lower than SCT. Annual rainfall is also lower, ranging from 800 to $1000 \mathrm{~mm}$. Land use in SCA is divided in the same way as in SCT. The same survey carried out in 2015 revealed 3 household types in SCA (Table 4.1).

The diversity in food produced varies within the area. Most simplified systems consist of maize and common bean grown as sole crops. Milpa systems in the area comprise maize intercropped with at least one of the following crops: common beans (Phaseolus vulgaris), fava bean (Vicia faba) and squash (Cucurbita spp.). Sheep production potentially provides animal protein and vitamin B12, however, its production is usually not for subsistence. Common bean varieties differ depending on the system, exhibiting a climbing or creeping behavior when grown as milpa or sole culture, respectively.

\subsection{2 | Data sources}

Population and agricultural census: we obtained data on demography at municipality level from the population censuses in 1980, 1990, 1995, 2000, 2005 and 2010 and from the agricultural censuses in 1991 and 2007.

Spatial data: For up to 3 years before or after the agricultural censuses Landsat satellite images were queried and evaluated. Based on knowledge of landscape dynamics in the area (Chapter 3 ) we assumed that landscape changes over a period of 3 years were 
of negligible influence on subsequent analyses. Image availability and cloud coverage limited the data to the years 1989, 2010 and 2017. The images selected were taken at the end of the crop season, allowing robust differentiation of land uses. To facilitate the identification of the different land uses we overlaid a high resolution image from Google Earth (WorldView-2; resolution of $0.5 \mathrm{~m}$ ) with a shapefile containing all fields registered in the municipalities (RAN, 2019a).

Survey: To complement the agricultural census of 2007, we carried out a survey in December 2018 and January 2019. Our survey focused on information on crop and animal production. To estimate crop production, we visited 30 households in both SCT and SCA immediately after the harvest season. Since farmers store their harvested maize and beans in $100 \mathrm{~L}$ tanks, $50 \mathrm{~kg}$ bags, or $4.5 \mathrm{~kg}$ cans, we counted these storage units as an estimate of total farm crop production. This method has proven to provide reliable results when performed soon after harvest (GSARS, 2017). We also counted the number of harvested squash fruits per farm and we multiplied by an estimated average weight of $6.5 \mathrm{~kg}$ per fruit in order to obtain the total production. To obtain crop yields $(t / h a)$, we used Google Earth images with a shapefile containing all privately-owned plots from the RAN (2019b). With this image, we asked the 30 farmers to identify their crop fields, the crops grown on them, the proportion of a field allocated to each crop in case more than one crop was grown, and the type of intercropping. To estimate animal production, we focused our questions on sheep husbandry since this is the most common type of animal husbandry in the area (although households usually have from 5 to 10 chickens). Farmers were asked about the size of the herd, the fields used for grazing, and whether these fields were private property or belonged to the community. Based on the total grazing area and number of sheep, we estimated stocking rate (sheep/ha).

\subsection{3 | Land use change analysis}

We performed a semi-supervised land use classification, which revealed three land uses: cropland, grassland and forest. As in this study focus is on the food produced by farmers, forest was excluded from the analysis. To improve reflectance values we applied an atmospheric correction on the three Landsat images (Ellis and Porter-Bolland, 2008). We used a high resolution Google Earth image to aid in training the data according to the aforementioned land uses (Mekasha et al., 2014). With the training samples we applied a maximum likelihood algorithm, which resulted in a land use map for each of the 3 Landsat images (Ellis and Porter-Bolland, 2008; Tolessa et al., 2017). 


\subsubsection{Calculations and statistical analysis}

Nutrient and vitamin production and requirements at the municipality level: since maize is mostly consumed in tortilla form, we transformed the maize kernel production to tortilla. Based on farmer information, $1 \mathrm{~kg}$ of air-dry maize kernels produced around $1.4 \mathrm{~kg}$ of tortilla, as water and calcium oxide is added in the process. For each plant and animal food source identified in the survey, we derived the provision of calories, protein, calcium, iron, magnesium, phosphorus, and vitamins A, B2, B3, B6, B9, B12 and $C$, using the concentrations shown in Table 4.2. Nutrient and vitamin requirements per person per year were derived from the Dietary Reference Intake (DRI) (National Academy of Sciences, 2011), applying the methodology used by de Ruiter et al. (2018) and DeFries et al. (2015). We used the DRI for the age group of 31-50, representative of the population's average age, ignoring requirements of pregnant or lactating women and children.

Crop production at the municipality level: we calculated the production $P_{i j}$ of crop $\mathrm{j}$ in municipality $\mathrm{i}$ in tonne as:

$$
P_{i j}=C A_{i} * C P_{i j} * C Y_{i j}
$$

Where $C A^{*}$ is the cropping area (ha, excluding fallow), $C P^{\dagger}$ is the proportion of the area a crop species occupies and $C Y^{\dagger}$.

Sheep production at the municipality level: production was derived from the average number of sheep per household and an animal-to-meat conversion rate of $15 \mathrm{~kg}$ per sheep. The conversion rate was obtained from farmer interviews and is within the range mentioned for mutton production in extensive, grass-fed systems in Mexico (Partida de la Peña et al., 2017).

Cropping systems comparison: based on our survey, average crop yields for the different cropping systems, i.e. maize monoculture, bean monoculture and milpa (maize intercropped with common and fava bean and squash) were compared by the nonparametric Kruskall-Wallis test, using the PMCMR (version 2016-01-06) package in R! (version 3.6.1).

\footnotetext{
* Derived from land use classification

${ }^{\dagger}$ Derived from census and survey data
} 


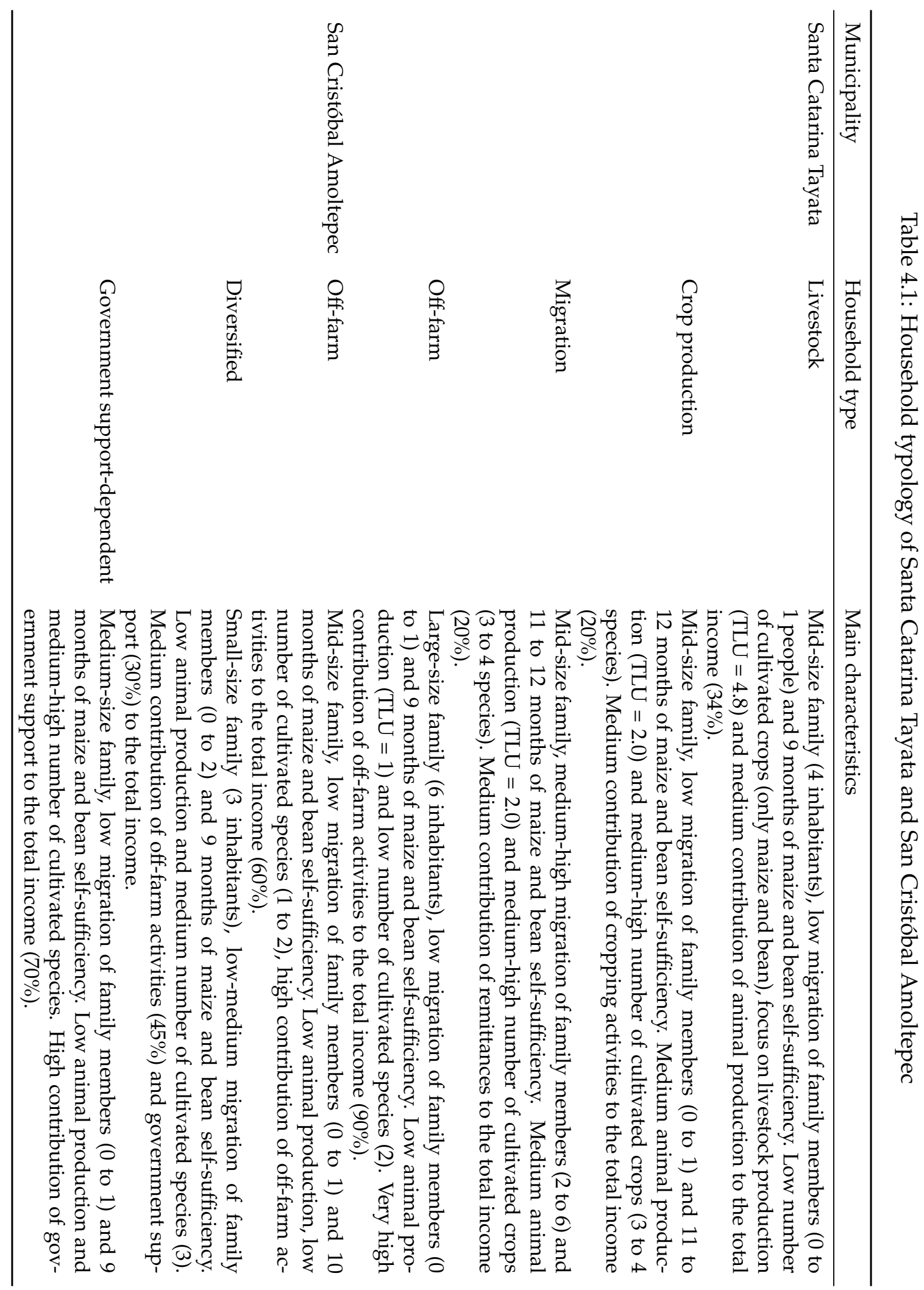




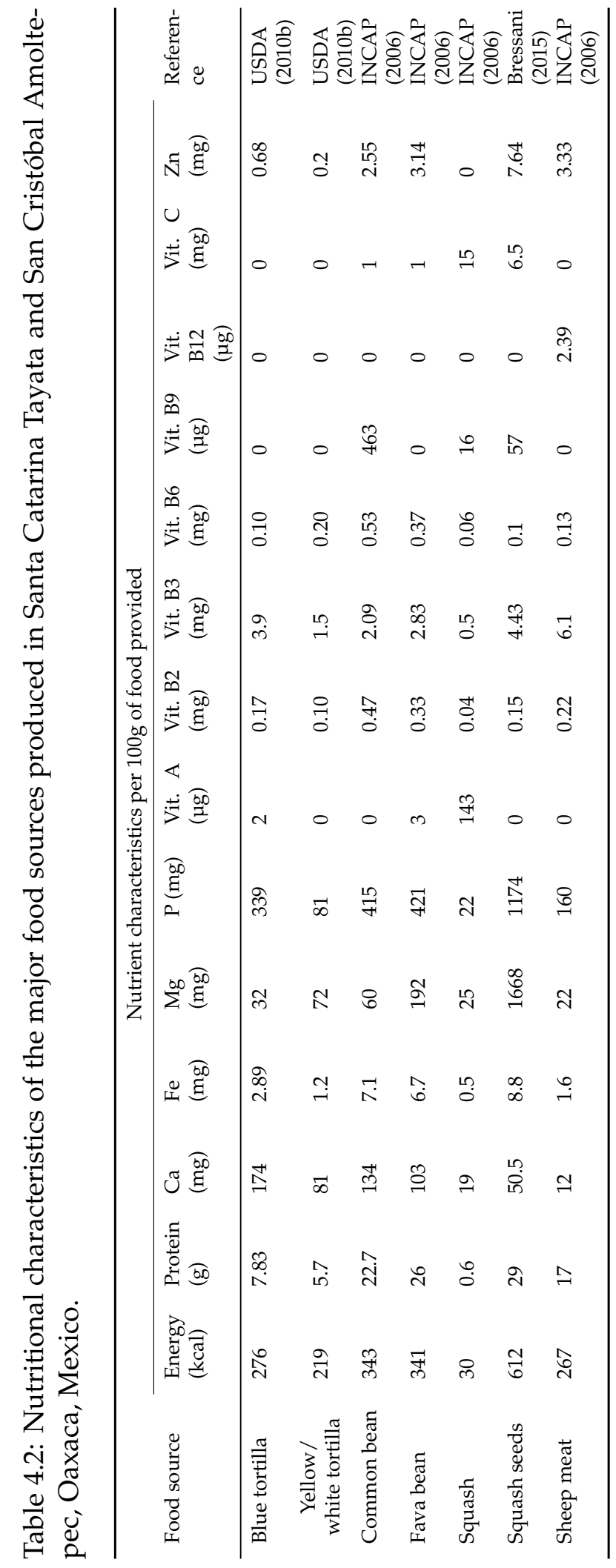




\section{3 | Results}

\subsection{1 | Land use and food production dynamics}

Between 1980 and 2015 the population in SCT declined from 864 to 679. In SCA the population remained close to 1200 persons until 2010. From 2010 to 2015, however, numbers declined from 1271 to 1004 persons (INEGI, 1990, 2010, 2015). In SCT the number of potential workers, aged between 16 and 60 years was 400 persons in 1980 and 342 in 2010, with the lowest value 290 recorded in 2005 (Figure 4.1). The portion of the population above 60 years increased from 7 to $19 \%$. The increase of senior inhabitants may be the result of higher life-expectancy and of an older population returning to their municipalities for retirement (a common phenomenon in SCT). The age pyramid thus shows an out-migration of people of working age and possibly a return at a higher age. In SCA the age structure was characterized by a large base of young people and narrow tip of older people.

While a decline of the population implied a lesser demand for food (Figure 4.3), the decrease in cropland indicated also a decline in cropping activities (Figure 4.2). The supply of energy and protein in SCT increased as the result of higher production at the same time that the demand decreased as a consequence of demographic decline (Figure 4.3). The municipality's demand for energy and protein was met in each year in SCT. SCA showed contrasting results. Although the demand for energy and protein decreased over time, production was not able to meet demand, except for protein in the year 2018.

Land use classification (Figure 4.2) revealed that the communities had similar areas of cropland, which had in each case decreased by around 100 ha, a 15 and $20 \%$ decrease for SCT and SCA, respectively, between 1991 and 2018 (Table 4.3). Total production per crop varied between years, except for fava beans, which remained low (around $1 \mathrm{t}$ ) for every year assessed. Data from the censuses and our survey showed that maize yield in SCT increased from 0.4 to 0.8 t/ha between 1991 and 2017, respectively. For SCA annual maize yields fluctuated between 0.3 and $0.5 \mathrm{t} /$ ha over the same period.

Between 1991 and 2017, the area of grassland decreased by around 150 and 450 ha for SCT and SCA, respectively. Surprisingly, the number of sheep doubled for SCT, reaching around 2000 heads in 2017, and numbers increased 5 times in SCA, achieving about 2500 heads. Assuming a carrying capacity of 3.5 heads/ha (SEMARNAT, 2014) total flock size thus approached the potential, with stocking rates of 2.9 heads/ha in SCT and 3.2 heads/ha in SCA. 


\subsection{2 | Nutritional self-sufficiency}

Food production in SCT was sufficient to meet the population's demand in each year analyzed for all nutrients and vitamins except for the vitamins A, B12 and C (Figure 4.4). Both vitamins $A$ and $C$ were provided almost exclusively by squash. In contrast to the previous years, in 2018 SCT attained self-sufficiency for vitamin B12 as a consequence of a higher sheep production (Table 4.3). While the production of sheep increased the production of vitamin B12, our contact with farmers revealed that sheep consumption by households was restricted to just 1 to 2 sheep/year. The different landraces of maize used to produce blue, white and yellow tortilla together satisfied most of the nutritional needs, except for zinc and vitamins A, C, B9 and B12. Despite its relatively low yields, common bean was an important source of protein, iron, phosphorus, zinc and vitamins from the B-complex, especially B9. Fava bean and squash seeds did not supply significant amounts of nutrients and vitamins as consequence of their very low production levels.

SCA did not reach a nutritional self-sufficiency for most nutrients and vitamins, with phosphorus as the only exception. Like in SCT, vitamins A and C were in low supply in SCA. Compared to SCT, nutrients from tortilla were less important and from sheep and bean more important in SCA, especially in 2018. 


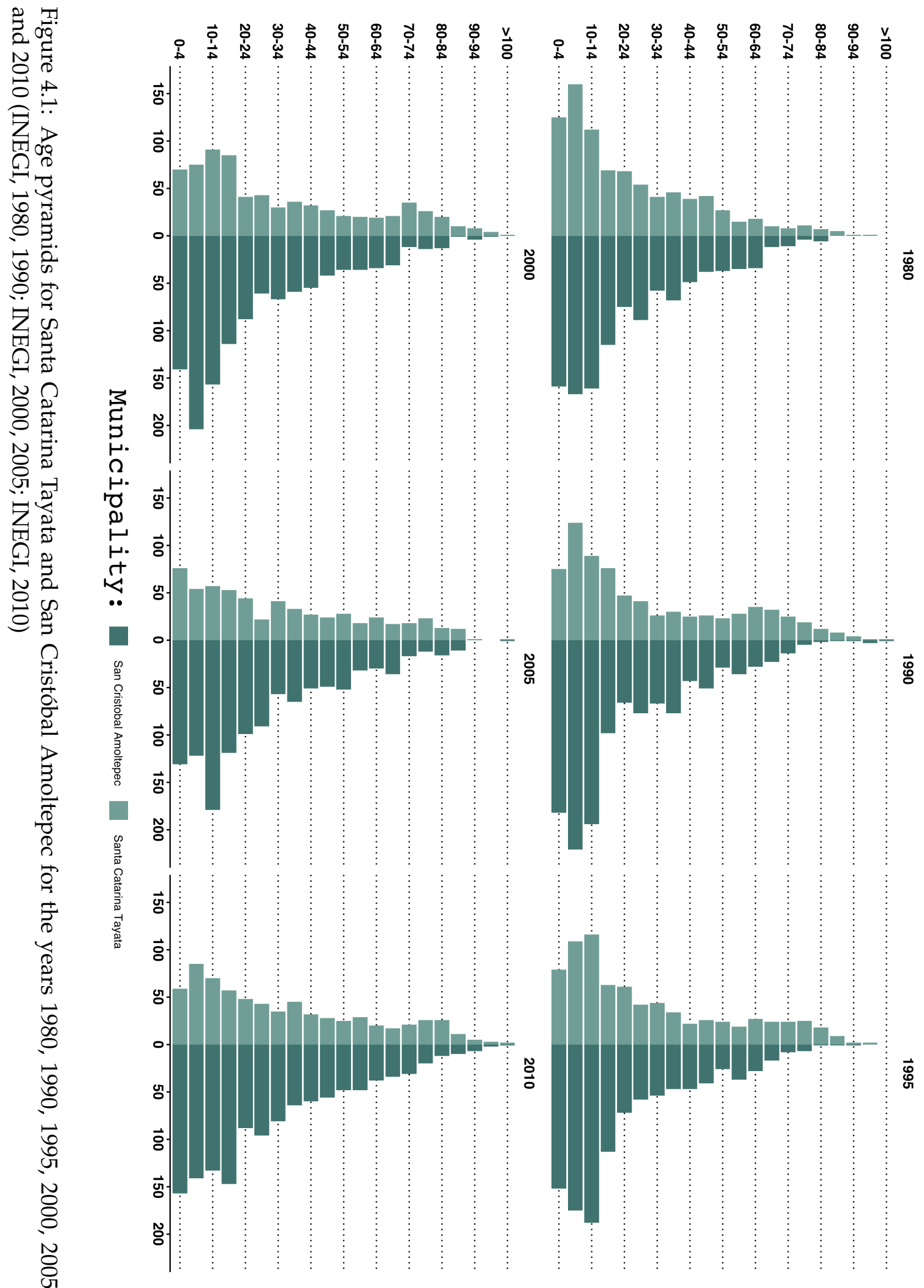




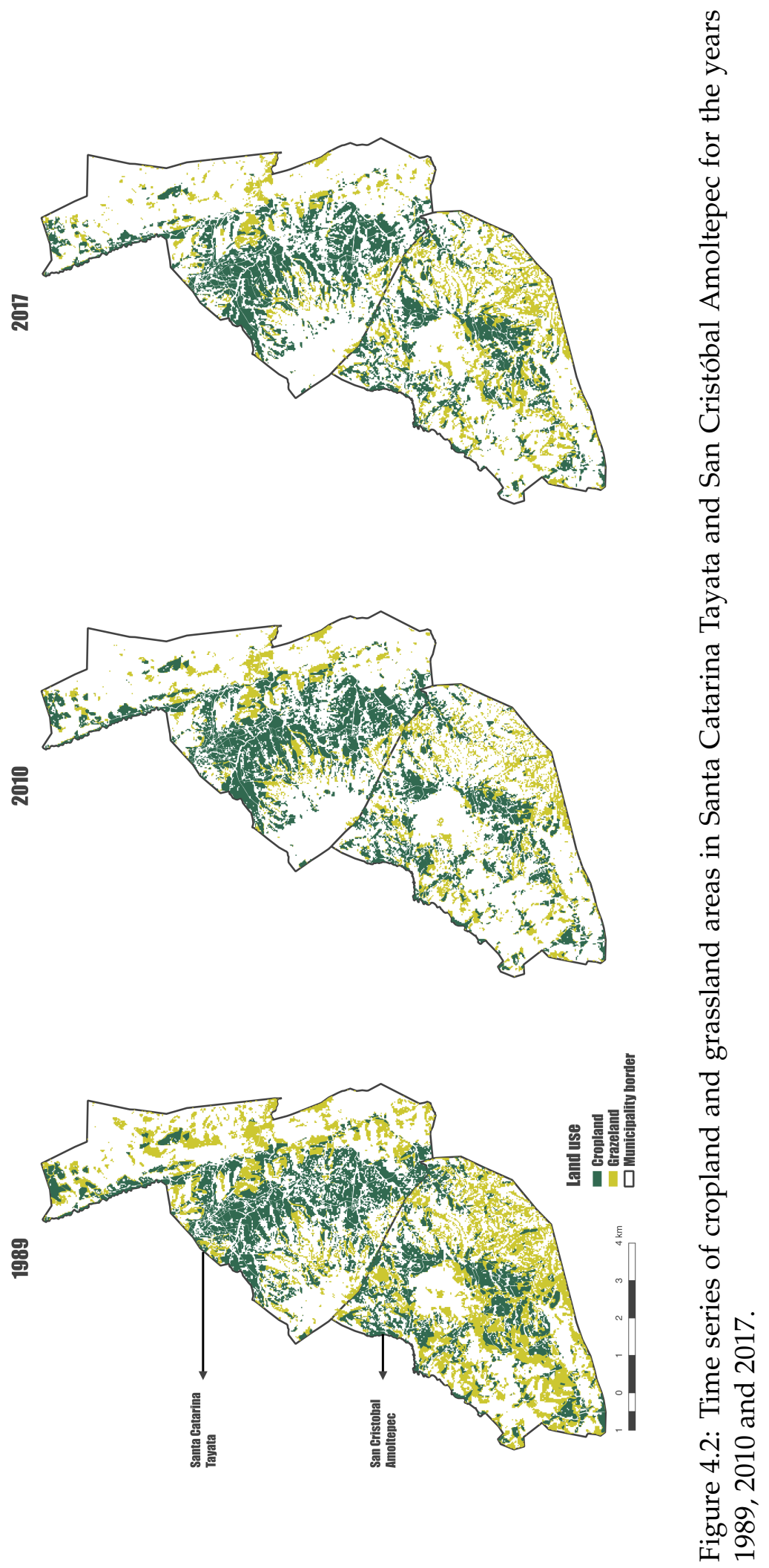



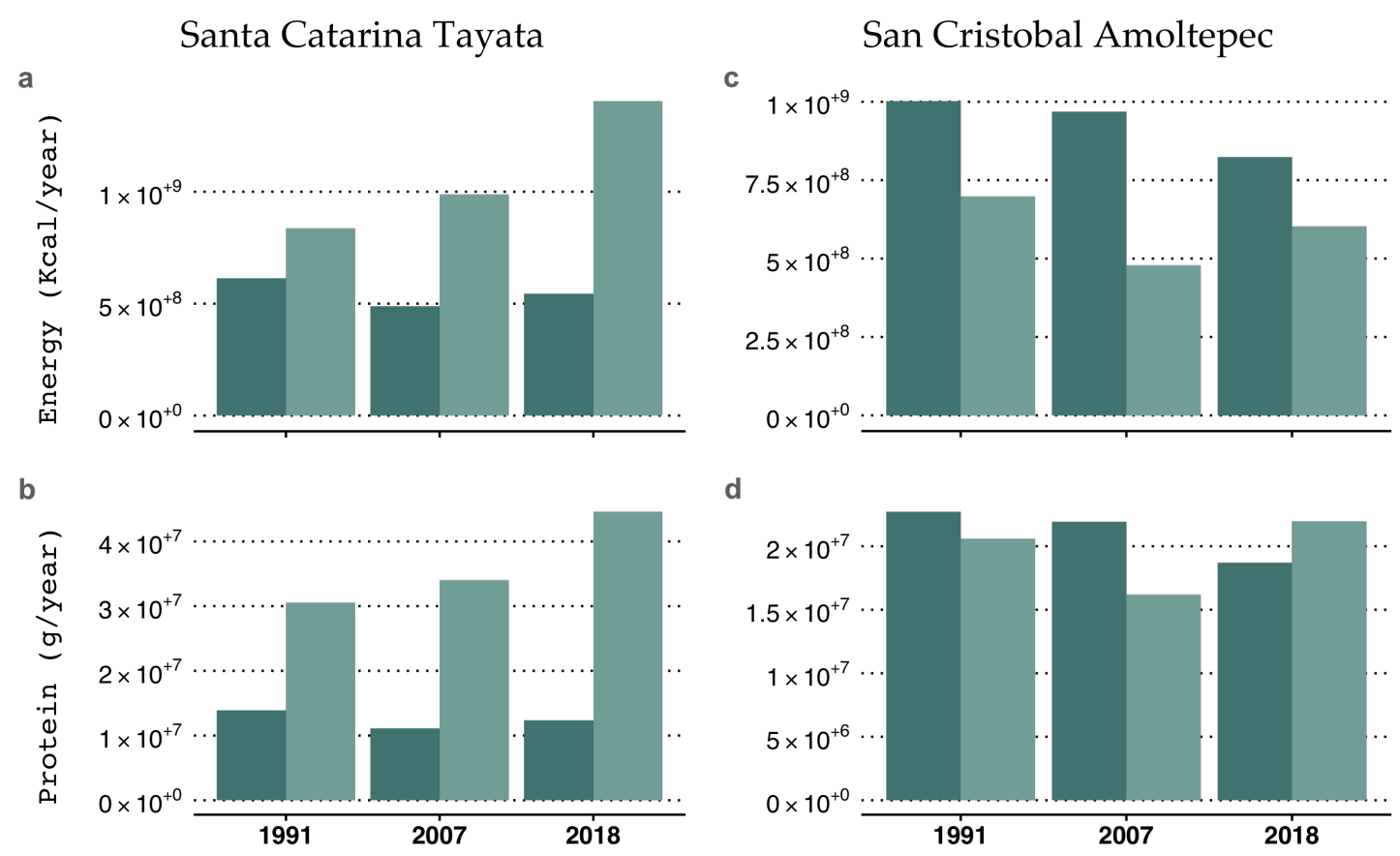

Figure 4.3: Demand and supply of calories and protein for the years 1991, 2007 and 2018. 


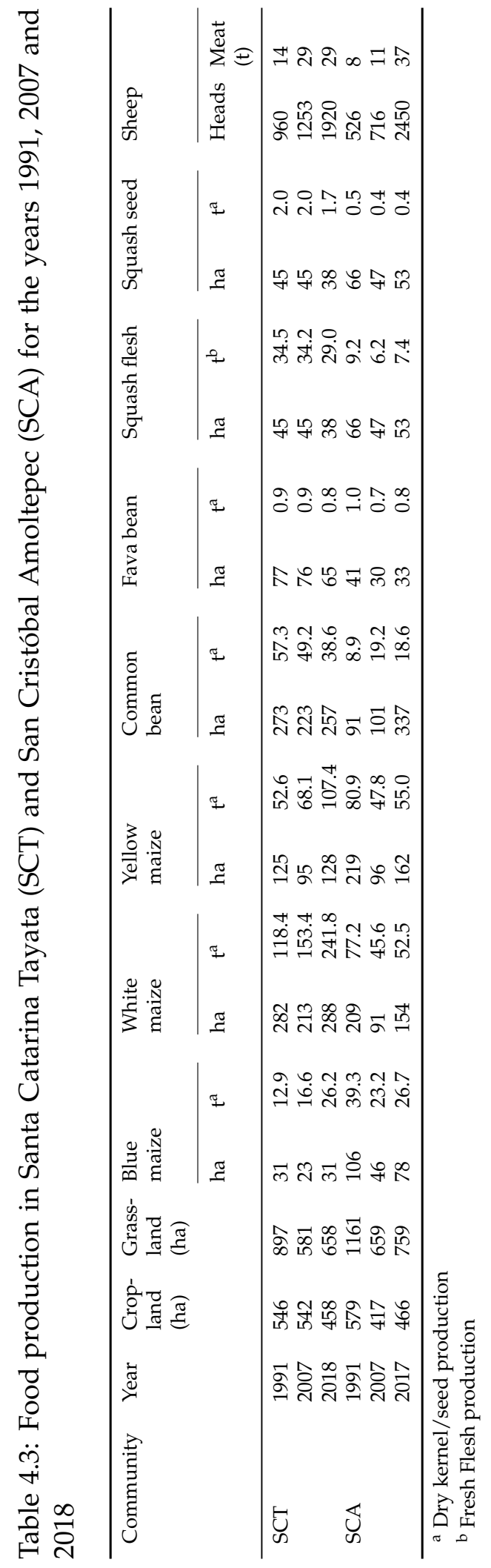




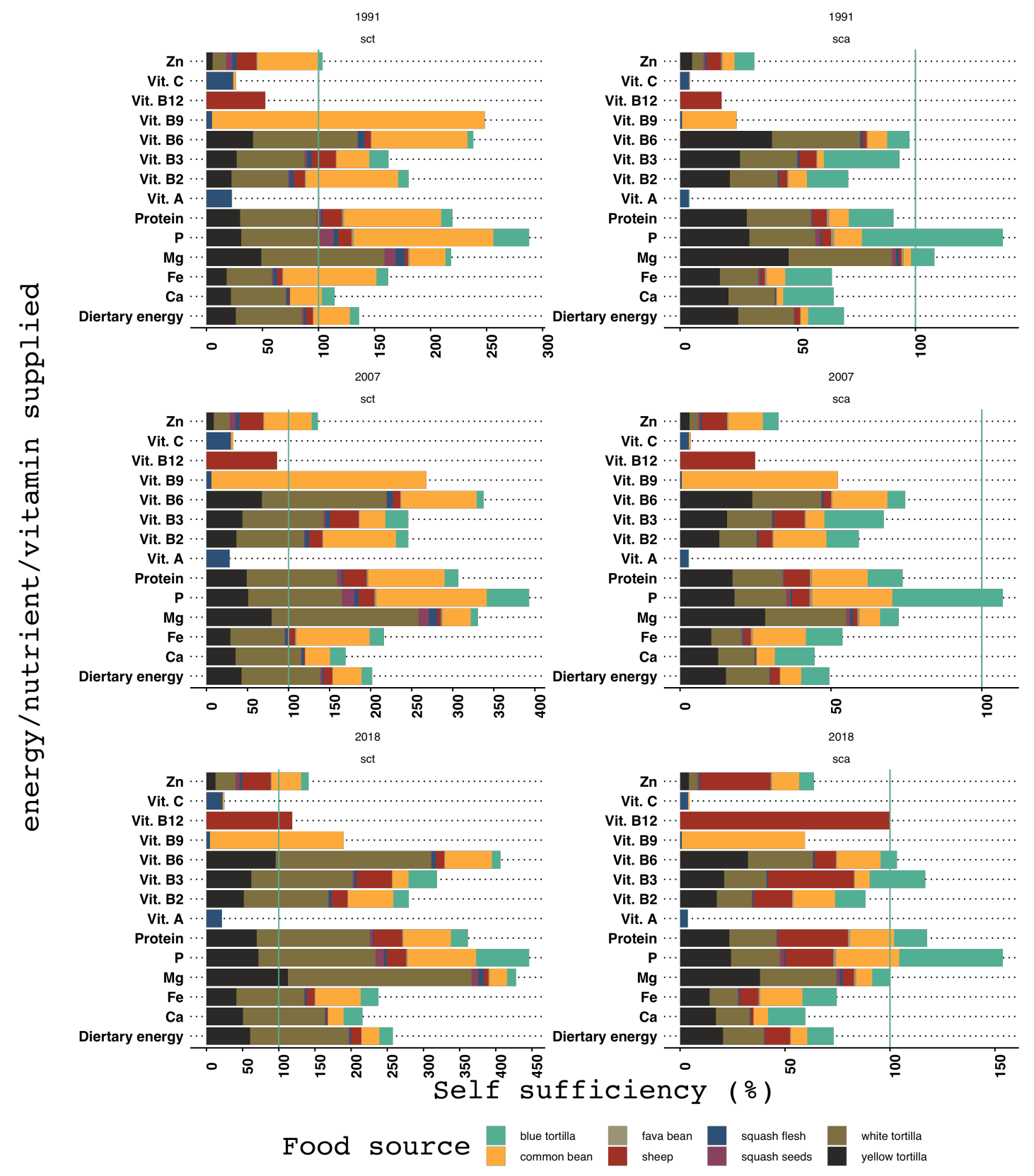

Figure 4.4: Relative supply of dietary energy (kcal), protein $(\mathrm{g})$, calcium $(\mathrm{mg})$, iron $(\mathrm{mg})$, magnesium (mg), phosphorus (mg), vitamin A ( $\mathrm{gg})$, B2 (mg), B3 (mg), B6 (mg), B9 ( $\mathrm{gg})$, B12 $(\mu \mathrm{g}), \mathrm{C}(\mathrm{mg})$ by the different food sources in SCT (panels on the left) and SCA (panels on the right), in 1991, 2007 and 2018. The vertical line represents the population demand reference, set at $100 \%$. 


\subsubsection{The role of traditional intercropping systems in nutrition}

Milpa was the least common cropping system. It only occupied around 1.5 and $3 \%$ of the total territory of SCT and SCA, respectively. Milpa systems with common and fava beans, maize and squash grown together provided more persons per hectare with a complete set of nutrients and vitamins than sole crops of maize or common bean (Figure 4.5). Except for zinc and vitamins A, C, B9 and B12 and depending on crop yields and crop composition, milpa systems provided complete nutrition sufficiency for up to 3 persons/ha, while sole crops of maize and common bean provided enough to feed up to 2 and 0.5 persons, respectively.

As expected, all cropping systems performed better in SCT, as crop yields in the municipality were consistently higher than in SCA (Table 4.3). Common bean yield under milpa was significantly lower by a factor 3 than when grown as sole crop (KruskallWallis, $\mathrm{P}=0.025)$. This was largely explained by the difference in plant density of common beans under milpa (around 40,000 plants/ha) and as sole crop (100,000 plants/ha). Maize yields under milpa and as sole crop were similar. Since fava beans and squash were only produced in milpa, we could not compare their yields to sole crops. One ha of traditional milpa provided enough nutrients and vitamins to feed at least two people per year in SCT and one in SCA when including zinc, vitamin A, C, B9 and B12.

Comparing the labor efficiency of different cropping systems, bean had the lowest performance of 0.65 and $0.52 \mathrm{~kg} / \mathrm{h}$ for SCT and SCA, respectively (Table 4.4). Maize and milpa produced around 5 and $4.13 \mathrm{~kg} / \mathrm{h}$ for SCT, respectively, and 2.03 and $1.83 \mathrm{~kg} / \mathrm{h}$ for SCA, respectively.

Table 4.4: Labor efficiency and nutritional self-sufficiency for common bean, maize and milpa in Santa Catarina Tayata and San Cristóbal Amoltepec

\begin{tabular}{|c|c|c|c|c|}
\hline \multirow[t]{2}{*}{ Cropping system } & \multicolumn{2}{|c|}{$\begin{array}{l}\text { Labor efficiency } \\
\left(\mathrm{kg} \mathrm{h}^{-1}\right)\end{array}$} & \multicolumn{2}{|c|}{$\begin{array}{l}\text { Nutritional self- } \\
\text { sufficiency (per- } \\
\text { sons fed ha }{ }^{-1} \text { ) }\end{array}$} \\
\hline & SCT & SCA & SCT & SCA \\
\hline Common bean & 0.65 & 0.52 & 0.5 & 0.4 \\
\hline Maize & 5.02 & 2.03 & 2.0 & 1.0 \\
\hline Milpa & 4.13 & 1.83 & 3.0 & 1.0 \\
\hline
\end{tabular}




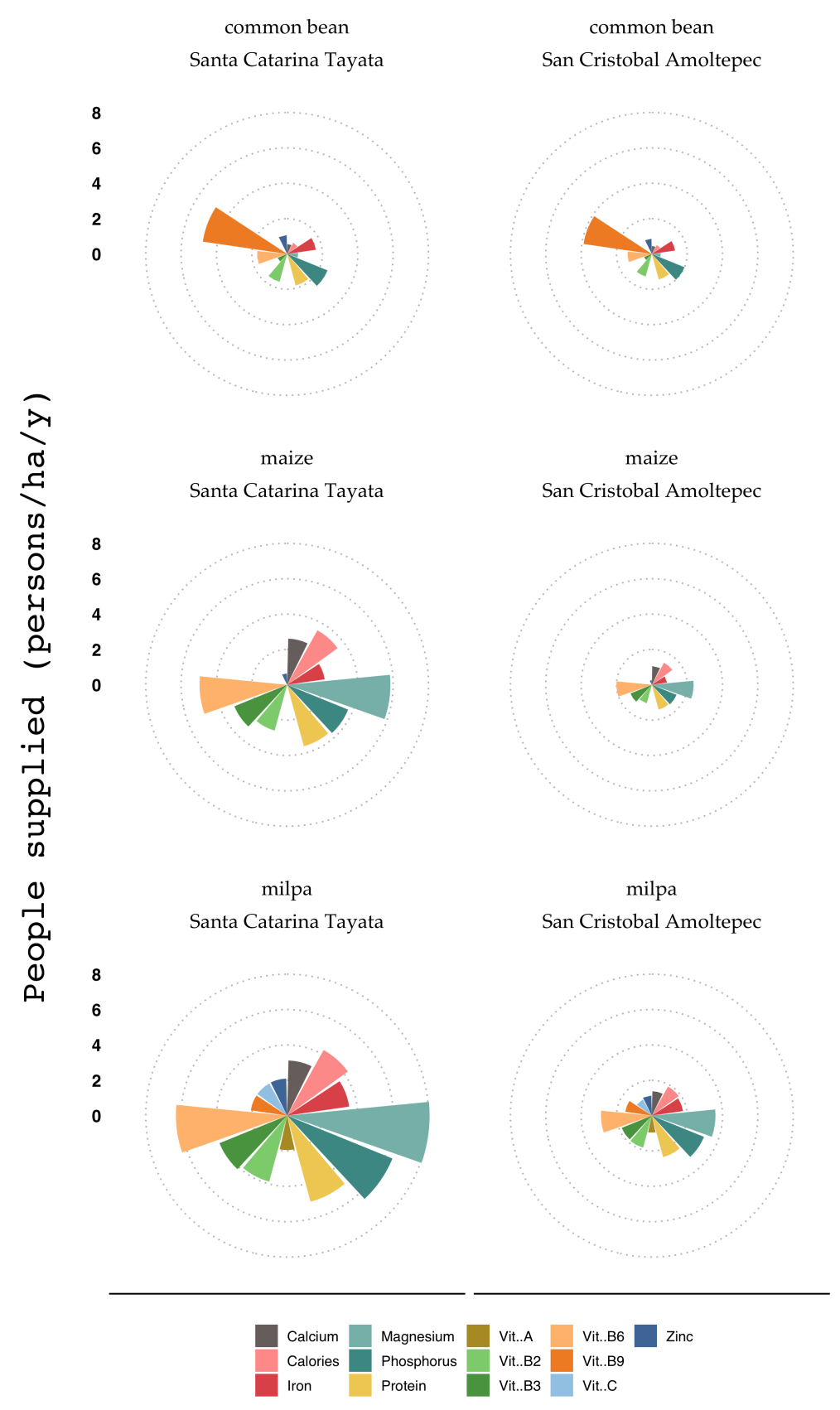

Figure 4.5: Provision of nutrients and vitamins by maize and common bean as sole crops and by milpa, consisting of community-specific mixtures of maize, common bean, fava bean and squash expressed in persons/ha per year. Each dotted circle represents 2 persons/ha per year. Based on yield data of 2017/2018 for Santa Catarina Tayata (SCT) and San Cristóbal Amoltepec (SCA). 


\section{4 | Discussion}

The two study cases presented here differed in their nutritional self-sufficiency over the years, albeit having similar areas for crop and animal production. In SCT relatively high and increasing yields in $\mathrm{kg}$ /capita due to stable yields in $\mathrm{kg} / \mathrm{ha}$ and demographic decline resulted in increasingly higher surpluses of calories and protein between 1991 and 2018. In SCA demographic decline decreased the shortfall in food supply, and the municipality reached self-sufficiency for protein in 2018. Maize production provided greater quantities of most nutrients and vitamins in SCT and SCA. Common bean and sheep meat were important sources of vitamin B9 and B12, respectively. Though sheep produce enough vitamin B12, its real consumption by households was very low. Pumpkin was found to be an important vitamin A and C source, but its production was insufficient to meet demand. Milpa provided a complete set of dietary energy, protein, vitamins and micronutrient, being able to feed up to two persons/ha/year, while common bean and maize lacked in several micronutrients and vitamins. Maize had a clear advantage over other cropping systems when labor efficiency was concerned, explaining why households tended to grow maize instead of milpa. Although bean was the cropping system that produced less volume per hour worked, households preferred consuming the creeping variety, grown as sole crop, over the climbing variety grown in milpa.

Out-migration from the state of Oaxaca intensified in late 60s, and it has led to demographic declines in various communities (Juárez and Margarita, 2008). Low foodsecurity can trigger migration processes, and migration in turn can improve agriculture through remittances (FAO et al., 2018). At the same time, the departure of a family member reduces labor availability, decreases pressure on resources and increases food availability (IFPRI, 2018). Although these conclusions were made for the household level, our data show similar linkages between food availability and migration at the municipality level.

While migration reduces the demand for food, it also reduces labor availability, which can be linked to the low nutritional self-sufficiency. Results showed that milpa has a lower labor self-sufficiency when compared to sole maize. Households in the area have showed they understand that milpa can produce more food volume, but they argue that it requires a high amount of labor (Table 4.4). Other studies also related lack of interest in milpa systems with the relatively high labor demand (Aguilar, 2008; Rosales et al., 2003).

In recent years the assessment of the dietary contribution of crops shifted from a focus on energy and protein to assessment of a set of nutritional values (de Ruiter et al., 
2018; de Valença et al., 2017; DeFries et al., 2015; Remans et al., 2011; Ruel et al., 2018; Willett et al., 2019). Milpa had a clear advantage over monocropping systems, especially when vitamin A and C are concerned, and also showed high levels of $\mathrm{Zn}$. Leatherman et al. (2019) found a relation between low milpa production and deficiencies of vitamin A and C and Zn in Yucatán. Also in Yucatán, Calix de Dios et al. (2014) showed that milpa provided a little over 6 months of food self-sufficiency to the majority of households. Other studies showed the advantage of polycropping systems for improving nutrition (Panneerselvam et al., 2010; Remans et al., 2011; Rusinamhodzi et al., 2012).

Bringing milpa production back in farmers systems becomes key for improving nutritional self-sufficiency and efforts should target reducing required labor or producing more with similar amounts of labor. Flores-Sánchez et al. (2015) showed that milpa production could be improved through better plant nutrition. Reyna-Ramírez et al. (2018) found higher milpa production in organic systems. Since weeding is the most laborious activity in milpa, (Parsons et al., 2009) recommended using herbicides in mid-season to avoid damages to companion crops. Recommendations based on herbicide application should be considered prudently, as herbicides damage edible weeds (called quelites) in milpa systems that are usually also harvested (Daniel et al., 2019). Mulching has been recommended as weed suppressing measure for several crops, and it could offer an alternative to hand weeding (Altieri et al., 2012; Kayeke et al., 2017; Matković et al., 2015; Murungu et al., 2011). However, mulching croplands with residues would compete with animal nutrition. Finally, designing or adapting machines that would facilitate weeding in milpa could facilitate the weeding management and convince farmers to grow milpa.

While this study focused on two case study locations, milpa is decreasing across Mexico, and we showed how this affects communities' nutritional self-sufficiency. The role of milpa for food security is recognized (Altieri et al., 2012; Calix de Dios et al., 2014; Frison et al., 2006; Isakson, 2009), but this is according to our knowledge the first report of the nutritional value of a milpa system in terms of how many persons it can feed per area. The results can vary among locations, given how diverse milpa systems are (Lozada-Aranda et al., 2017). The contribution of diversified cropping systems to higher nutritional self-sufficiency found in this study, however, may serve to inspire solutions for other food insecure places in Latin America, Africa and Asia (Clapp, 2017; Graham et al., 2007; IFPRI, 2016; Sibhatu and Qaim, 2017).

This study has some limitations. Each municipality produced adequate quantities of vitamin B12, however, animals usually serve households as safety-nets to deal with financial stresses and less for consumption. Therefore vitamin B12 provision is likely less than we calculated. Future research could test blood samples for deficiencies, along 
with dietary recall that included provenance of the food eaten (Das et al., 2014; Remans et al., 2011). Although we showed that the food production in the area was not providing enough vitamin $C$, it does not necessarily mean that the population suffers from vitamin $C$ deficiency. During our surveys we observed that many households had citrus trees in their yard. Such minor food sources are not usually contemplated in the census data, making it harder to obtain a full panorama of food security and nutritional self-sufficiency. We focused on the nutritional supply and the population demand on an annual basis. This does not reflect food availability and consumption in the course of the year, as several studies showed how households usually face shortages in the months prior to the harvest season (Calix de Dios et al., 2014; Hammond et al., 2017; Kc et al., 2016; Noromiarilanto et al., 2016; Sibande et al., 2015). Obtaining nutritional values for the different locally grown crops proved to be difficult. Despite the fact that Mexico is a genetic hotspot for maize and common bean, very few studies are available that reveal the diversity in terms of nutritional value, which may be further affected by production method and production location (FAO and UN, 1995; González-Cortés et al., 2016). Finally, in our analyses we used average population age for the dietary intake and did not consider children or pregnant woman. Including these would provide a more nuanced perspective, as these categories are known to be particularly sensitive to nutritional deficiencies.

\section{5 | Conclusions}

Traditional cropping systems with a diverse species composition are recognized as being important for improving food security and nutritional quality of diets. Yet recent policy shifts in Mexico stimulate moving away from these traditional systems in favor of more profitable crops. Such shifts can worsen the already fragile food security situation for the rural poor. As shown in this study, these communities are able to reach a nutritional self-sufficiency status, as long as a high diversity of food is produced in sufficient quantities to meet the population's demand for energy, nutrients and vitamins. In such a context, milpa emerges as the cropping system that is capable of feeding more people per unit of area that the constituent sole cultures, despite its recognized low economic performance. Sole crops can be used to remedy nutritional deficiencies, such was the case of bean with its high production level of vitamin B9. This highlights the importance of having a full panorama of the cultivated crops and the nutrients they provide in order to tackle any nutritional deficiency. We conclude that efforts should be made to improve the performance of traditional diversified cropping systems to im- 
prove nutritional self-sufficiency in communities that have high demand and low food production.

\section{6 | Acknowledgements}

The authors would like to thank all the farmers who kindly accepted to participate in this research. We would like to give our special gratitude to Jesus Cruz Galicia, as a vital contact between us and the several households that participated in the process. We would also like to give a special thanks to Dr. Inge Brouwer of Department of Agrotechnology and Food Sciences, Sbdivision Human Nutrtion \& Health of Wageningen Universit and Reseach for providing nutritional values for Mexican crops. Finally we thank the support provided by the CGIAR, which funded this project, 'Agro-ecosystem diversity and the Trajectories and Trade-offs for Intensification of Cereal-based systems' (ATTIC, grant agreement: A4032.09.20) 



\section{Chapter 5: Exploring alternatives for nutrient-sensitive landscapes*}

\section{Abstract}

Although food security has been improved globally, the issue remains. Recently, the number of food insecure people in Latin America and the Caribbean even increased. In Mexico, traditional milpa polycultures of maize, beans and other crop species provide a wider spectrum of nutritional factors than monocultures of the constituent crops. The decline of the milpa systems and the increase of modernized agriculture are impacting rural household nutrition and provision of ecosystem services. We explored nutrientsensitive landscape solutions for improving nutritional self-sufficiency and ecosystem services. In particular we addressed the question under which conditions milpa would lead to nutritional self-sufficiency at the municipal level We used the LandscapeIMAGES modelling framework to assess landscape alternatives that satisfy multiple locally salient objectives for two case study municipalities in Oaxaca, Mexico; Santa Catarina Tayata (SCT) and San Cristóbal Amoltepec (SCA). We assessed the provision of nutritional factors (dietary energy, protein, 5 micro-nutrients and 7 vitamins), ecosystem services (carbon stocks and habitat connectivity), and labor requirements associated with different land use options in the municipalities. Compared to SCT, SCA had a lower nutritional self-sufficiency because of lower crop yields and larger population size. Nu-

*Article in preparation for submission: Novotny, I; Rossing, W; López-Ridaura, S; Fuentes-Ponce, M; Tittonell, P; Groot, J. Exploring alternatives for nutrient-sensitive landscapes 
tritional self-sufficiency based on milpa production would require $30 \%$ of the area in SCA, resulting in trade-offs with other ecosystem services. Santa Catarina Tayata could reach nutritional self-sufficiency with around $10 \%$ of its territory used for milpa. While milpa may contribute substantially to nutritional self-sufficiency, high labor input and low yield levels would require agronomic innovations. These should be associated by changes in rural support policies to enhance the attractiveness of polycultures compared to monocultures. 


\section{1 | Introduction}

Around $10 \%$ of the world population lives in extreme poverty (UN, 2018), and more than half of food insecure people live in rural areas (Shackleton et al., 2019). From the FAO (1996) summit on food security, three key components for reaching food security were highlighted: food availability (e.g. amount of food available), access to food (e.g. how much food is available to households) and food utilization (e.g. nutritional and cultural value of food). Ingram (2011) later added more detail to each of these components, and emphasized stability over time. Food security status varies among regions, with Africa, Asia, and Latin America and the Caribbean the most affected places (Thornton et al., 2019). Because food insecurity is most prevalent in rural areas, some consider smallholder farmers the key to achieving greater food security (Chappell and LaValle, 2011; Horlings and Marsden, 2011; UN, 2016). Despite global improvements in food security status, the number of undernourished people in Latin America and the Caribbean increased between 2016 and 2017 (Thornton et al., 2019). In Latin America, two major types of food production systems concur, the modernized techno-centric system and the traditional agricultural system (Parraguez-Vergara et al., 2018). The former, although having brought increased yields through improved genetic material and intense use of inputs, has not been effective against hunger and induced migration, unemployment and ecosystem degradation (Altieri and Nicholls, 2008; FAO, 2014; Gordillo, 2004; Jokisch, 2002). Ruel et al. (2018) identified 6 pathways for reaching food security, placing food access from own production as first. Increasing food security through local production implies that human nutrition and ecosystem performance should be assessed simultaneously (Lebel, 2003). In agricultural landscapes, humans impact the environment through land use change and the way they exploit natural resources. In return humans are impacted by the degree of ecosystem services provided by the landscape through a feedback (Bioversity International, 2014; Deckelbaum et al., 2006; Millennium Ecosystem Assessment, 2005; Ottaviani, 2011). Insight into the relation between the spatial configuration of different land uses and ecosystem services can help to identify sustainable development options that avoid as much as possible tradeoffs among the services.

In landscape assessments, trade-off analysis is used to assess the relation between agricultural production and other ecosystem services (e.g. soil losses, carbon sequestration, water quality, pest control, and pollination) (Andersson et al., 2015; Gulickx et al., 2013; Mouchet et al., 2014; Queiroz et al., 2015; Villamagna et al., 2013; Yang et al., 2019; Zhang et al., 2007). Provision of food is typically only considered in terms of produced volume, and not in terms of the number of people that can be healthily fed. To fill in 
that gap, the Nutrition Sensitive Landscape (NSL) framework was proposed for analysis of landscape ecosystem services and nutritional performance (Bioversity International, 2014; Kennedy et al., 2017). Here we use the NSL approach to assess trade-offs and synergies between nutritional self-sufficiency (i.e. producing the most essential nutrients and vitamins for human health) and ecosystem services. Smallholder farmers who relied on traditional systems are shifting away from crop diversity towards simplified systems (Parraguez-Vergara et al., 2018), with possible negative implications for food security in rural areas (Isakson, 2009). Globally, the shift in food production systems oriented towards high-yielding crops has caused not only environmental impacts, but also increased micronutrient deficiencies and health issues (Timler et al., 2020). In Latin America and the Caribbean, vitamin A and B12 deficiencies are widespread problems (Brito et al., 2015; Mora et al., 1998). Considering the negative implications of simplification of agricultural systems for food security (Remans et al., 2011), there is a need for designing landscapes that provide nutritional food self-sufficiency for their inhabitants while incorporating ecosystem services in the process.

The traditional Mesoamerican agricultural milpa system revolves around maize, which is intercropped with other species such as common beans (Phaseolus vulgaris), fava beans (Vicia faba) and squash (Cucurbita spp.). This system is of great importance for subsistence households, as it guarantees their basic food requirements regardless of the households' economic performance (Isakson, 2009). Yet, milpa is being abandoned. This decrease of milpa has been attributed to lack of available labor caused by migration (Gutierrez-Carbajal and Magaña-Magaña, 2017; Kontoleon et al., 2009; Otero Prevost et al., 2018), land fragmentation, low maize prices, decreased fallow periods (Rodriguez and Arias 2014), unpredictable rainfall and lack of government support (Richard, 2008).

In this paper we aim to identify options for nutrition sensitive landscapes arising from re-arranging current land uses and inclusion of land use alternatives that could be implemented with a time horizon of 5 years. Two neighboring municipalities in south Mexico were selected as case studies to reveal the potential of the approach. The municipal level is the smallest administrative unit in Mexico that is bestowed autonomy to manage the common land. We used the LandscapeIMAGES (LI) framework for assessing nutritional and ecosystem services performance and their associated trade-offs and synergies (Groot et al., 2010, 2007, 2018). Starting from an initial set of landscape alternatives LI evaluates each landscape in terms of a set of objectives and constraints, and then uses an evolutionary algorithm in combination with Pareto-ranking to generate new landscapes that perform better in terms of the objectives. In this way, iteratively better landscapes are identified and trade-offs among the objectives are revealed. In defining the objectives and constraints viewpoints of different stakeholders can be 
taken into account, as it has been shown to improve the local salience of the results (Estrada-Carmona et al., 2014). This research aimed at answering the following questions: 1) what is the current level of nutritional self-sufficiency and ecosystem services performance in the case study municipalities? 2) what is the role of the different cropping systems in the nutritional self-sufficiency? and 3) how does achieving nutritional self-sufficiency affect other ecosystem services?

\section{2 | Materials and methods}

\subsubsection{Study area and production systems}

This study was conducted in two municipalities, Santa Catarina Tayata (SCT) and San Cristóbal Amoltepec (SCA), located in the state of Oaxaca, Mexico (Figure 3.1). The two communities are similar in terms of climate conditions, agricultural systems and community landscape management (Chapter 4). They differ, however, in demography, crop performance and land use configuration. The three dominant cropping systems in the area are monocultures of maize and common bean, and milpa. Milpa systems in this region always include maize in combination with one or more of the following crops: common bean, fava bean and squash. Crops may be followed by a fallow period, which can last up to five years. Sheep husbandry is the most common type of animal production. Sheep mostly forage on fallow fields and grasslands in common areas. During winter, sheep are also given crop residues.

Like in other communities of Mexico, land is divided in common and private land (Figure 3.1). Cropping activities in the municipalities are performed exclusively on private land although that is not a strict rule for other municipalities. Common land is managed by Bienes Comunales (BC), a local institution that enforces local regulations decided on by municipal assemblies. Forest and grassland are the most frequent land uses on common land. Settlement areas were left out of the analysis as they are not managed by the community.

\subsection{2 | Modeling framework}

The LandscapeIMAGES (Landscape Interactive Multi-Goal Agroecosystem Generation and Evaluation System) framework was used for this study (Groot et al., 2007). The framework uses a Pareto-based multi-objective Differential Evolution (P-MODE) to explore trade-offs and synergies among landscape performance indicators (Groot et al., 2007, 2009). Decision variables include land use on each map polygon. Pareto- 
optimality is achieved when the performance of a landscape in terms of a particular indicator cannot be improved without deteriorating the performance in terms of one or more other indicators (Groot et al., 2018).

LI was used to first characterize the current landscape performance in terms of production, nutritional, environmental and socio-economic indicators. We then explored the trade-offs and synergies between the different indicators and assess the consequences for the associated landscape configurations.

\subsubsection{1 | Land use classification}

A land use map describing current land use was derived from a Landsat 8 image taken in October 2017 with a spatial resolution of $30 \mathrm{~m}$ (https://earthexplorer.usgs.gov). In selecting the image the aim was to avoid cloud cover and to maximize contrast between different land uses. An atmospheric correction was applied to improve the image's reflectance (Ellis and Porter-Bolland, 2008). A semi-supervised method was used to classify the landscape according to the following three land uses: forest, agriculture/grassland and bare soil. Agriculture and grassland were grouped together as these produced very similar spectral signatures. To train the classification algorithm samples of the land uses were obtained from a high-resolution $(0.5 \mathrm{~m})$ Google Earth map (WorldView- 2) (Mekasha et al. 2014), applying a maximum-likelihood algorithm (Ellis and Porter-Bolland, 2008; Tolessa et al., 2017). The land use classification was performed using the Semi-Automatic Classification Plugin (version 6.4.2) for QGIS (version 3.4).

The land use classification was further refined using shapefiles containing private plots and common land (RAN, 2019b). Considering there is no agriculture in common areas, every pixel classified as agriculture/grassland within common land was classified as grassland/fallow, while agriculture/grassland pixels within private plots were classified as agriculture. Agricultural plots were randomly subdivided using the average incumbent proportion of fallow, maize, bean and milpa systems obtained from survey data described below.

\subsubsection{2 | Variable selection and data source}

We used 25 production, nutritional, environmental and socio-economic indicators as attributes for the resulting land use classification options (Table 5.1). Crop and animal production indicators were obtained from 30 household surveys from each SCT and SCA, comprising data from 157 plots (see Chapter 4). Nutrient and vitamin contents were calculated from crop and animal yields, using nutritional references for each product (see Chapter 4). Nutritional self-sufficiency was estimated based on the population 
size of each municipality, which was 680 persons for SCT and 1005 for SCA. Soil loss and water infiltration data were estimated for each land use based on data from a field experiment done in the area (Naranjo-Macias, 2019). To estimate above ground carbon, we measured tree height and diameter at breast height $(1.3 \mathrm{~m})$ at 13 sample sites following the methodology used for the Mexican carbon inventory (SEMARNAT and CONAFOR, 2011). Each site was composed of four sub-sample plots of $200 \mathrm{~m}^{2}$. Below ground carbon was obtained from 38 and 31 soil samples taken from SCT and SCA, respectively. Samples were taken up to $30 \mathrm{~cm}$ depth, and the Walkey-Black method was used for estimating soil organic carbon (Bhattacharyya et al., 2015). Potential labor and unused labor were calculated from INEGI (2010). For the potential labor we only considered the population between 15 and 60 years and assumed $8 \mathrm{~h}$ of work per day and around 300 working days per year. Labor requirement for each cropping system was obtained from Reyna et al.. Unused labor was calculated as potential labor minus the labor used for cropping activities and off-farm activities. Nutritional evenness was estimated using shannon-index calculations to assess food richness and evenness, or in other words, to measure food relative abundance in each municipality (Remans et al., 2011). We also calculated the Satoyama index for assessing landscape patchiness, and the habitat connectivity as proxy for landscape quality, using the methodologies described by Kadoya and Washitani (2011) and Urban and Keitt (2001), respectively. 


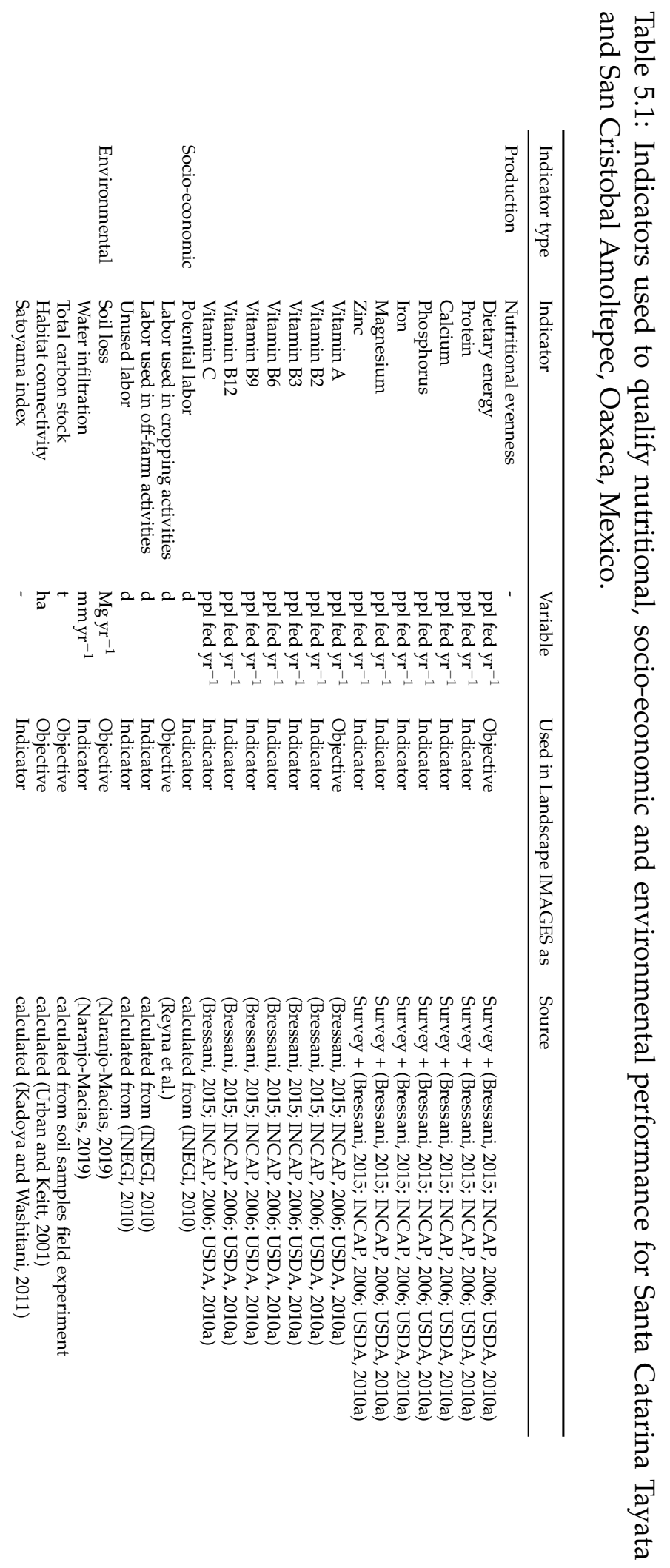




\subsubsection{3 | Objectives and restrictions}

Objectives were defined by consulting the three major stakeholder categories; farmers, local officials and NGO. The NGO and local officials' objectives were defined in a workshops held in 2015 and in 2017. We asked farmers about their objectives when visiting households for estimating crop production. Objectives for each community were similar. The two most frequently expressed goals by farmers were improving crop performance and minimizing labor. The local NGO had as goals improving food security, minimizing soil losses and increasing forest cover. In addition to the NGO's goals, the local officials also wanted to protect rivers and streams.

We translated the crop performance and food security goals into objectives for LI in terms of maximizing produced dietary energy and vitamin A. Vitamin A was selected because reaching self-sufficiency also guarantees that minimal requirements for other nutrients and vitamins would be met (Chapter 4). Maximizing carbon stocks and habitat connectivity were used as objectives to account for forest cover and spatial coherence. For more detailed information on calculation and justification of the habitat connectivity indicator we refer to Groot et al. (2010). The objectives used in LI are shown in Table 5.1.

Interaction with local officials and farmers revealed community regulations and goals, which were implemented as restrictions in LI: 1) no forest clearing in common areas, 2) no expansion of the cropped area, 3) each river and stream should be protected by a $15 \mathrm{~m}$ forest buffer on each side, and 4) land use changes between cropping and fallow were allowed.

\section{3 | Results}

\subsubsection{Current landscape performance}

Total areas of SCT and SCA were 4220 and 3490 ha, respectively. Forest and fallow/grassland were the most common land uses in both municipalities, occupying around 50 and $30 \%$ of the total territory in SCT, and 35 and $30 \%$ in SCA, respectively (Figure 5.1). Crops occupied 20\% of the total territory in SCT and SCA. Maize was grown on around 15 and $10 \%$ of SCT and SCA territory, respectively. Bean took around $6 \%$ in each place. Milpa occupied less than $3 \%$ of the total territory in each municipality.

Both municipalities had similar nutritional evenness (Table 5.2). In SCT nutrient and vitamin production was enough to feed the population of 679 people, except for vitamin A, B9 and C. Vitamin A and C are found in high concentrations in squash, while vitamin B9 is prevalent in common beans, and both crops are grown in milpa. The same defi- 
ciencies in vitamin production were found in SCA (Table 5.2). In addition, production in SCA fell short of the population's requirements for dietary energy, calcium, iron and zinc. The lower nutritional performance in SCA was attributable to lower crop yields and less cropland area compared to SCT. Nutritional performance in both municipalities would benefit from a greater area with milpa.

Average maize yield in the milpa system was similar to the monoculture system in both municipalities. Yields in SCT $(0.8 \mathrm{t} / \mathrm{ha})$ exceeded those of SCA $(0.35 \mathrm{t} / \mathrm{ha})$. The greatest observed maize yield in a milpa the system was $1.6 \mathrm{t} / \mathrm{ha}$ in each community. The highest observed maize yield in monoculture differed, with SCT producing up to 2 $\mathrm{t} / \mathrm{ha}$ and SCA $1.6 \mathrm{t} / \mathrm{ha}$. Bean production under milpa was lower by a factor three when compared to its monoculture counterpart. In SCT yields of bean were $0.15 \mathrm{t} /$ ha under monoculture and $0.05 \mathrm{t} / \mathrm{ha}$ under milpa. The highest observed bean yield as sole crop was $0.45 \mathrm{t} /$ ha for SCT and $0.25 \mathrm{t} /$ ha for SCA. In SCA monocultures of bean yielded 0.12 $\mathrm{t} / \mathrm{ha}$ as opposed to $0.04 \mathrm{t} / \mathrm{ha}$ when grown in milpa. The greatest bean yield recorded under milpa was $0.2 \mathrm{t} / \mathrm{ha}$ in each community. On average, squash yields were $0.45 \mathrm{t} / \mathrm{ha}$ in SCT and $0.22 \mathrm{t} / \mathrm{ha}$ in SCA. The greatest recorded squash yield was $1 \mathrm{t} / \mathrm{ha}$ in each community. These results show that both communities had similar attainable yields, but actual yields for SCA were consistently lower.

The amount of available labor in SCA $(102,600 \mathrm{~h})$ was double the amount in SCT. The working population in SCT spent more time cropping and working off-farm, and consequently had less of unused time (Table 5.2). In both municipalities the amount of labor allocated to off-farm activities exceeded the time spent cropping. Since SCA had more bare soil area, soil losses exceeded those in SCT (Table 5.2). The distribution of plots across the municipalities affected habitat connectivity. The concentration of plots in the mid-section of SCT (Figure 5.1) decreased its forest habitat connectivity by physically separating the forest on each side of the community. In SCA, forest cover was found interspersed among plots, which permitted a greater habitat connectivity. Considering SCT had a larger forest area, it performed better than SCA in terms of carbon stock. Satoyama index values in each municipality were 0.9 (the maximum possible value is 1), meaning that both municipal landscapes had a high diversity of land uses and showed patchy patterns.

Both municipalities had similar nutritional evenness (Table 5.2). Nevertheless, SCT presented a higher production for every nutrient and vitamin assessed, and it was able to produce enough nutrients and vitamins to feed its population of 679 people, except for vitamin A, B9 and C. Vitamin A and C are found in high concentrations in squash, while vitamin B9 is prevalent in common beans, and both crops are grown in milpa. The same deficiency in vitamin production was found in SCA. Production deficiencies 


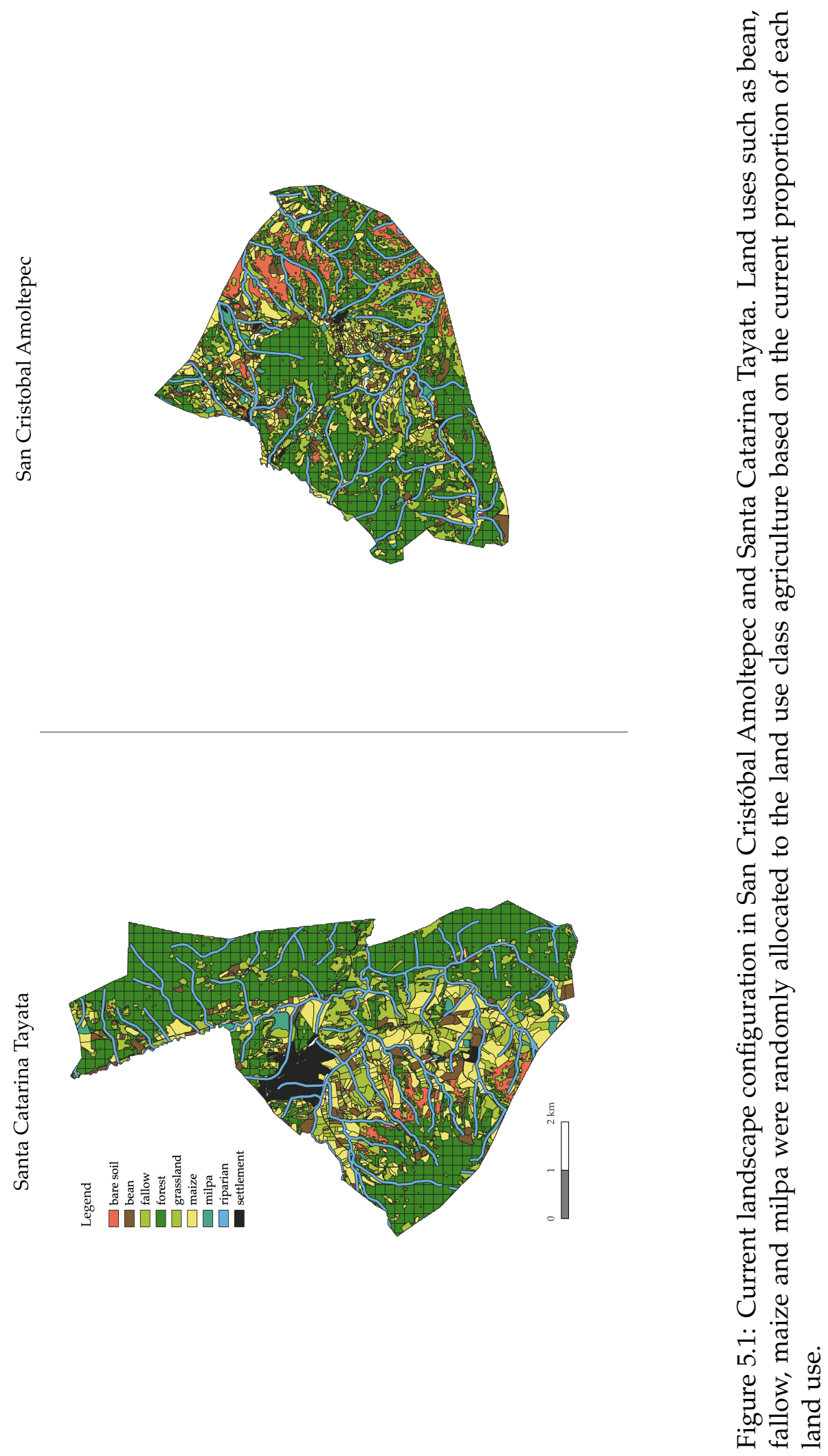


for dietary energy, calcium, iron and zinc were also found in SCA. The lower nutritional performance for SCA was attributable to lower crop yield, and less cropland area, and nutritional performance in both municipalities would benefit from more milpa production. 


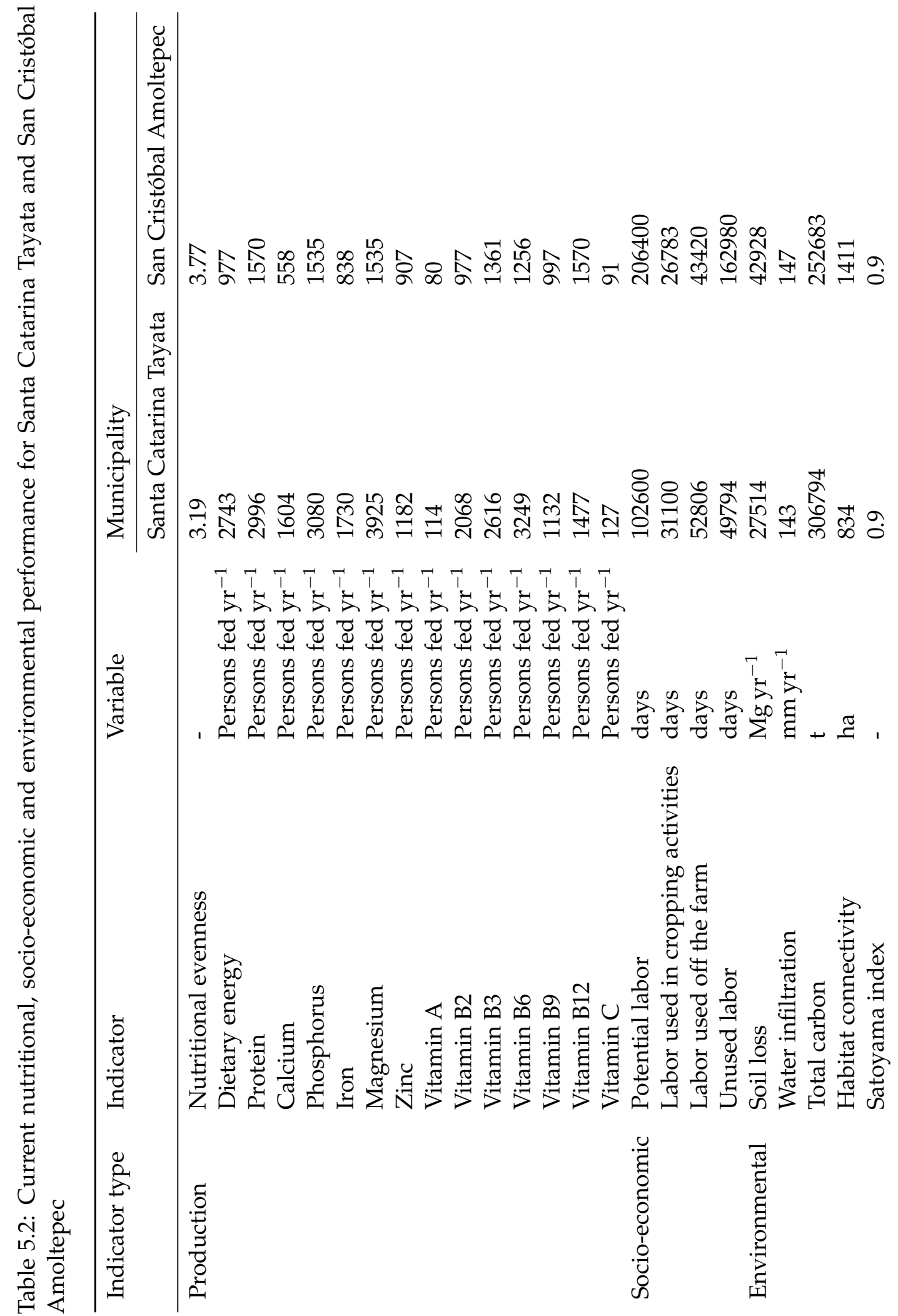




\subsection{2 | Exploring landscape configuration alternatives}

Synergies were found between vitamin A and dietary energy, although at the expense of higher labor requirements (Figure 5.2). Synergies also existed between landscape connectivity and carbon stock, with greater landscape connectivity being associated with greater carbon stock. Solutions that increased dietary energy and vitamin A traded-off with carbon stock and connectivity, and increased soil losses.

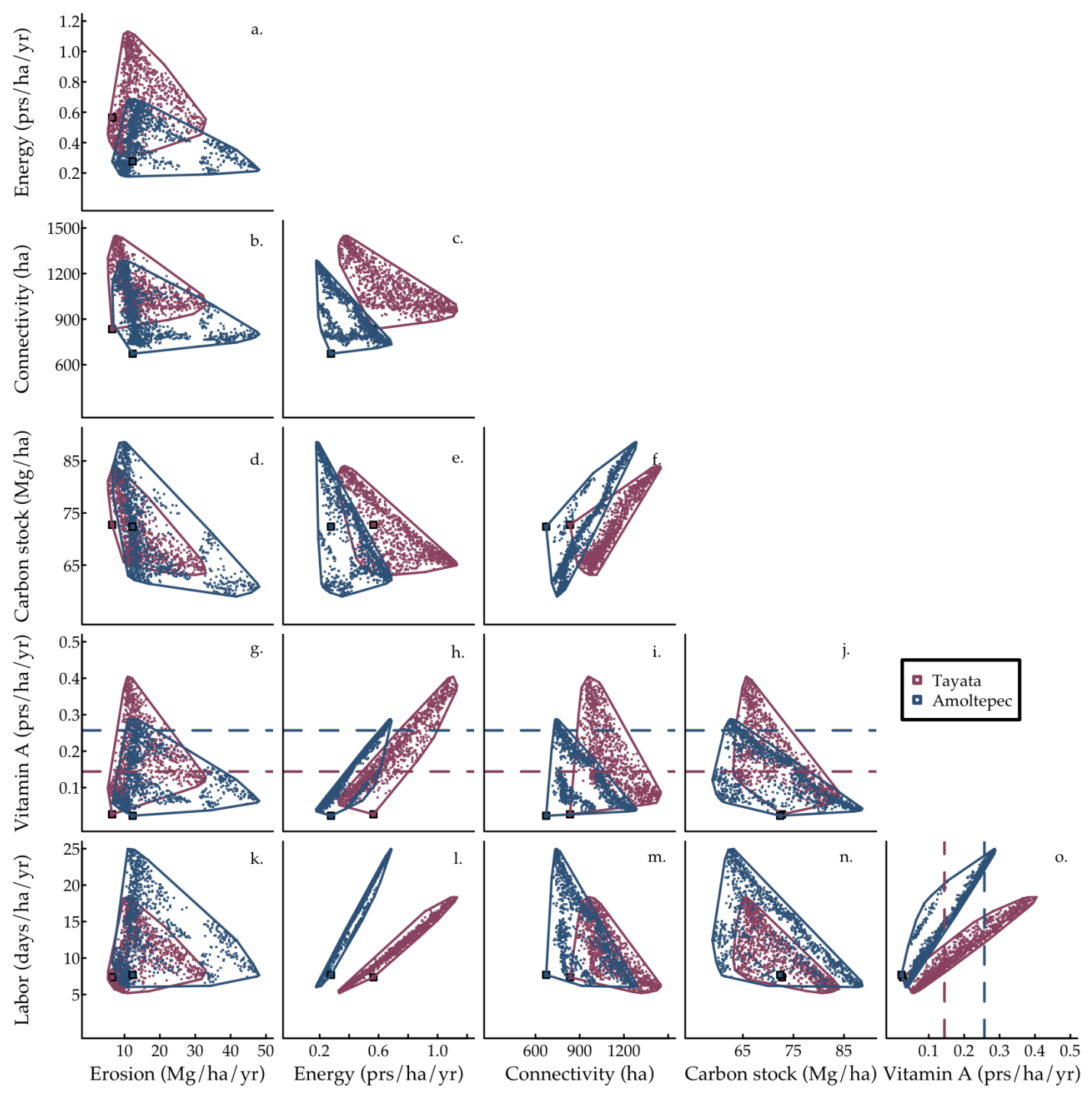

Figure 5.2: Performance of alternative Pareto-optimal landscapes expressed in six objectives: dietary energy, connectivity, carbon stock, vitamin A, labor, and erosion. Squares represent current landscape performance. Dashed lines indicate the food self-sufficiency threshold. Blue: San Cristóbal Amoltepec, red: San Catarina de Tayata. 
Compared to land use configuration alternatives, current soil losses for both municipalities were low. Therefore, other landscape solutions implied more erosion. This suggests that other agricultural practices should be considered for reducing soil losses.

When considering all solutions (Figure 5.2) current carbon stocks represented intermediate levels. Improving carbon stocks can be achieved by increasing forest cover, but also by allocating land to grassland (Figure 5.3). These land uses compete with use as cropland, and therefore result in trade-offs with nutritional self-sufficiency.

Current municipal landscapes performed relatively poorly in terms of landscape connectivity, vitamin A and dietary energy in comparison with the generated alternatives (Figure 5.2). As consequence of higher milpa yield, SCT was found to be able to potentially produce more vitamin A than SCA, while using less labor per ha. Landscape solutions involving an increase in vitamin A usually involved a reduction in grassland, and resulted in increased soil erosion. Nevertheless, it was possible to improve vitamin A production while also improving carbon stock and landscape connectivity. The dotted lines in Figure 5.2 represent the threshold for reaching nutritional self-sufficiency; the solution space above the dotted lines guarantees nutritional self-sufficiency. For SCT a larger number of Pareto-optimal alternative landscapes could be found, offering a larger window of opportunity when compared to SCA.

Both municipal landscapes currently have a low production of vitamin A when compared to alternative configurations (see black arrows in Figure 5.3). Vitamin A selfsufficiency is reached with $10 \%$ and $30 \%$ of the total area allocated to milpa in SCT and SCA, respectively. The increase in milpa area is associated with less area under grassland, forest, and, to a lesser extent, monoculture of maize and bean. SCT has enough labor to produce milpa on up to $12 \%$ of its territory without requiring a reduction in the time spent on off-farm activities (see vertical black bar in Figure 5.3). 

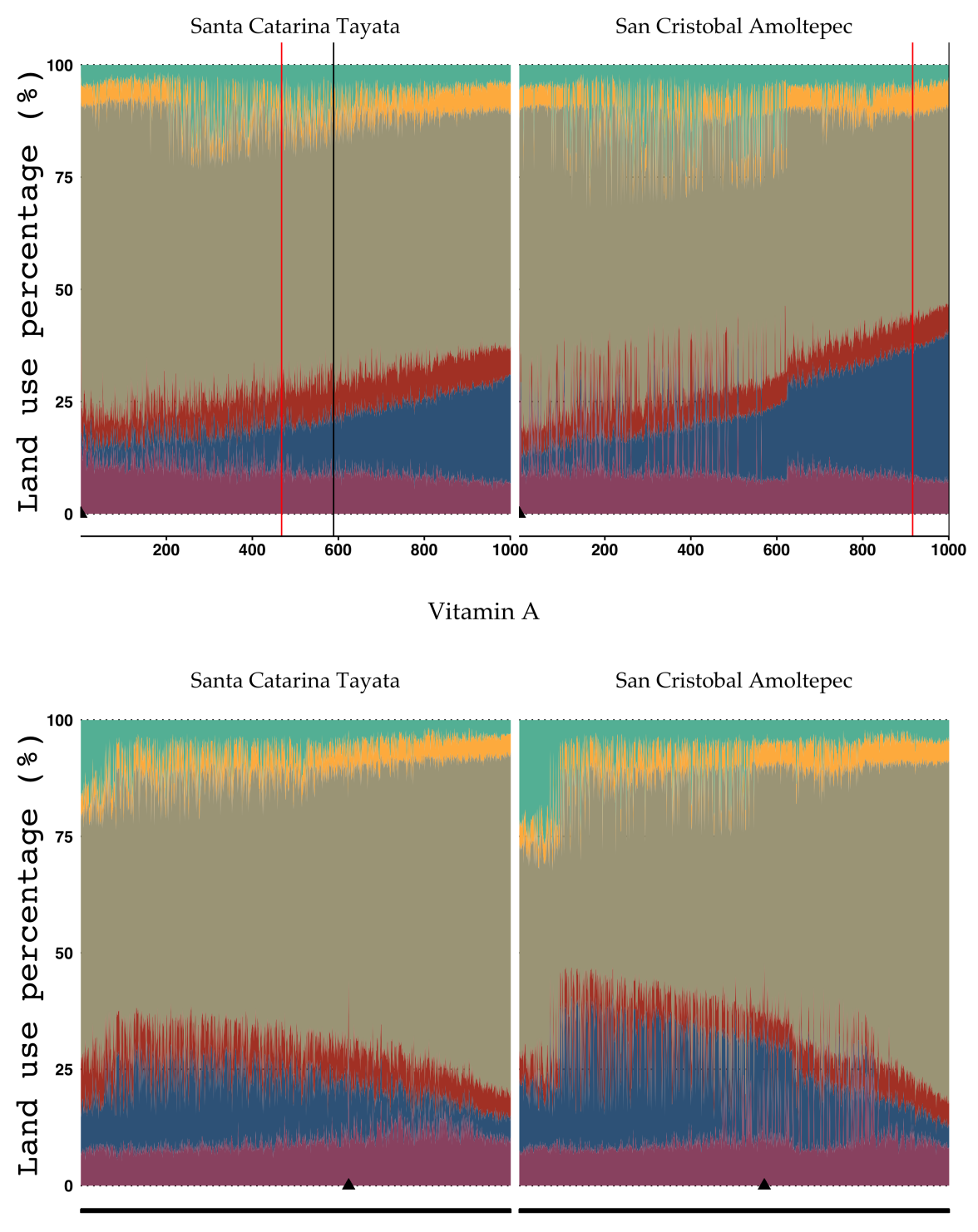

Carbon sequestration

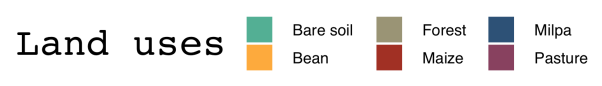

Figure 5.3: Land use in relation to vitamin A production, as derived from Landscape IMAGES optimization with 6 objectives (see Figure 5.2). Vitamin A production was sorted from low to high and the associated land use allocation is displayed. Vertical red lines represent the nutritional self-sufficiency threshold, and vertical black lines represent the threshold in which labor required for cropping would affect off-farm activities. Black arrows represent the current land use proportions. 


\section{4 | Discussion}

Compared to Santa Catarina Tayata, San Cristóbal Amoltepec had lower nutritional self-sufficiency and higher soil losses. However, SCA showed a larger degree of habitat connectivity. In neither municipality nutritional self-sufficiency was reached. Increasing milpa production area was effective for improving nutritional self-sufficiency. Results showed several landscape configuration alternatives for reaching nutritional self-sufficiency while increasing carbon stocks and habitat connectivity for SCT. However, most solutions would increase soil erosion. For SCA, reaching nutritional selfsufficiency would reduce the solution space for improving other ecosystem services, as a large part of the territory would have to be used for milpa instead of other land uses.

International organizations call for nutrient-sensitive landscapes solutions (Bioversity International, 2014; IFPRI, 2014). Sayer et al. (2013) draw attention to the relevance of food security in land use planning. Broegaard et al. (2017) followed a NSL approach to a wide array of food from forests, fallow and agricultural fields to demonstrate wild food relevance in decreasing protein deficiency. Kennedy et al. (2017) applied the NSL approach in three African countries, where they aimed at identifying nutritional gaps and potential ways for improving food diversity. However, their study did not explicitly incorporate landscape elements. Alders and Kock (2017) used the NSL approach principles to connect food security to wildlife conservation. Powell et al. (2015) called for research to understand how communities manage their landscapes to achieve healthy food production, and to assess whether these landscapes can support healthy dietary choices. Similar to the study from Broegaard et al. (2017), our study assessed food production according to different land uses. However, our study is the first to include a set of nutritional components in the analysis and relate nutritional self-sufficiency with ecosystem services. Furthermore, it answers the question raised by Fabricius et al. (2007) regarding how landscapes can sustain healthy food production.

While municipalities had the same objectives for their landscapes, current municipal landscapes performed differently for most indicators. These differences were mostly caused by demography and crop yields. The population size of SCA was double that of SCT, while in SCA crop yields and nutritional values were lower than in SCT. Landscape connectivity in SCA was larger because of the plot pattern, with plots scattered across the municipality instead of being concentrated in one area like in SCT. Despite the greater landscape connectivity in SCA, soil erosion levels exceeded those in SCT due to larger areas of bare soil. Although poverty and population density are usually associated with land degradation, a global study showed no clear correlation between degradation on the one hand and population size and poverty on the other (Bai et al., 
2013; Schild et al., 2018). Results in Chapter 3 also did not find any link between degradation and population size and poverty at the watershed level.

Vitamin A and C were produced in low quantities in each case study municipality. Vitamin A deficiency is a common problem for Mexico (Leatherman et al., 2019; Mora et al., 1998), with alarming cases of severe deficiency in children (Brito et al., 2015). Also for other places in Latin America (Brito et al., 2015; Mora et al., 1998) and the world (Laillou et al., 2012; Timler et al., 2020) vitamin A deficiency has been reported as an important problem. Reaching full self-sufficiency for every nutrient and vitamin was possible in the case studies by cultivating greater areas of traditional milpa systems, as these produce not only high amounts of vitamin A, but also harness production of other nutritional components such as vitamin C, zinc and iron (Figure 4.5).

Reaching nutritional self-sufficiency in each municipality is possible without improving crop performance, expanding agriculture or changing agricultural systems or practices. However, effectively improving nutritional self-sufficiency would require an increase in milpa production, which proved to be the cropping system with the smallest share of the land in both communities. Other places in Mexico exhibit similar preferences for cropping systems other than milpa (Birol et al., 2009; Gutierrez-Carbajal and Magaña-Magaña, 2017; Kontoleon et al., 2009; Otero Prevost et al., 2018; Richard, 2008; Rodriguez and Arias, 2014). Lack of available labor is usually one of the main causes of abolishing milpa. Our results showed that currently available labor was enough to increase the area under milpa in both municipalities. Labor peaks associated with cropping activities especially during sowing, weeding and harvesting season, however, were not taken into account in our calculations.

Manual weeding is the operation that takes up most time and farmers prefer using herbicides to reduce labor. In milpa, use of herbicides is not practical as dicots and monocots are grown in close proximity (Reyna et al.). Furthermore, an increasing number of farmers are engaging in off-farm activities (see Chapter 2), which can compete with milpa production. Therefore, solutions for improving self-sufficiency should focus on increasing crop yields while decreasing labor. Flores-Sánchez et al. (2015) showed that it is possible to improve crop yields without increasing too much labor through better crop nutrition in south-west Mexico. Reyna-Ramírez et al. (2018) showed some benefits of applying organic amendments to improve milpa production, while maintaining labor requirements. Parsons et al. (2009) found alternative herbicide strategies for milpa by delaying its application to mid-season in Yucatán to reduce herbicide impact on companion crops.

Reaching food self-sufficiency in SCT would require at least $10 \%$ of the territory under milpa, and 30\% in SCA. Increasing milpa to 30\% of the SCA territory, equivalent 
with $65 \%$ of the cropland area would require a decrease of monocropping of maize and bean and of fallow. Fallow and the volunteer weeds growing on it is used as food source for sheep. Sheep in turn have an important role in soil fertility. In addition, decreasing the area under fallow has been associated with lower crop yields due to less time for the soil to recover chemically, physically or biologically (Dalle and de Blois, 2006; Parsons et al., 2009). Thus, improving milpa yields in SCA appears as a more viable alternative. Comparing maximum observed crop yields shows that there is ample room for improvement and interventions should focus on this. At the political level, efforts should be made to stimulate milpa production instead of steering farmers away from it towards monoculture production.

This type of study helped identifying major issues such as nutritional self-sufficiency problems, low food production and crop yield. Based on these, targeted actions can be implemented. The multi-objective analysis permitted including communities' goals into the modelling phase. the modelling approach can be adjusted to different contexts and regions that require landscape-level solutions. Fitting policies to the diversity of local contexts, especially in Mexico with over 2000 municipalities could address solutions that benefit as many people as possible, such as supporting milpa systems for improving self-sufficiency.

This study has some shortcomings. First, the study focused on nutritional selfsufficiency, which assesses points like food availability and food utilization. While both are important for a food security assessment, data on access to food is required for a full panorama on food security. Second, while this study explored landscape alternatives based on the context of two municipalities, it leaves questions about how to scale-up and incorporate the findings in regional landscape planning.

\section{5 | Conclusions}

The nutrient-sensitive landscapes approach requires evaluating the potential landscapes have to sustain a healthy nutrition while improving ecosystem services. Reaching food self-sufficiency in each study case was possible by increasing milpa production. As consequence of low crop yield and larger population size in SCA, the landscape alternatives that would improve both nutritional self-sufficiency and ecosystem services were limited without technical interventions. Furthermore, solutions for improving nutritional self-sufficiency involved increasing milpa, which farmers avoid due to its high labor requirements. Therefore, technical interventions should target increasing milpa production while reducing labor requirements. With successful interventions, nutritional 
self-sufficiency would be achieved with less area, providing more landscapes alternatives for improving ecosystem services.

\section{6 | Acknowledgements}

The authors thank Sergio Naranjo for his valuable work on soil erosion in the area. We would also like to express our thanks to Tim Bos, Erick Rebollo and Dulce Zuñiga for their dedication, without which we would have not been able to estimate carbon stocks. Finally, we thank the support provided by the CGIAR, which funded this project, 'Agroecosystem diversity and the Trajectories and Trade-offs for Intensification of Cerealbased systems' (ATTIC, grant agreement: A4032.09.20) 




\section{Chapter 6: General discussion}

\section{1 | Introduction}

Changes in land use can degrade ecosystem services and impact rural livelihoods through reduced crop and animal production. My overarching goal was to assess livelihood and landscape trajectories as a basis for exploring landscape alternatives that would improve nutritional self-sufficiency while reducing the deterioration of ecosystem services. Using different methodologies and assessing multiple temporal and spatial scales in two municipalities in Oaxaca, Mexico, I was able to answer my research questions by: 1) describing how changes in land tenure policies, government support, and migration affected household type dynamics, 2) showing how communities change their landscape based on the landscape-level issues they perceive, 3) estimating nutritional self-sufficiency at the municipal level, and quantifying and contrasting cropping systems according to their nutritional value, and 4) revealing landscape configuration options and trade-offs, based on different stakeholder objectives for improving nutritional self-sufficiency. Each chapter discusses associates methodological shortcomings and identifies further research needs based on our findings. This study is the first to integrate household and landscape trajectories in a nutrition-sensitive landscapes approach, as well as the first to include the role of communities in landscape management, focusing on improving nutritional self-sufficiency. In Figure 6.1, I summarize the connection between chapters, demonstrating the way that knowledge of household and landscape trajectories contributed to the overarching goal of this thesis. 
Figure 6.1: Thesis structure and main findings per chapter. Chapters 2 to 4 describe household and landscape trajectories and their influence on the potential for improving current nutritional self-sufficiency and ecosystem services, described in Chapter 5

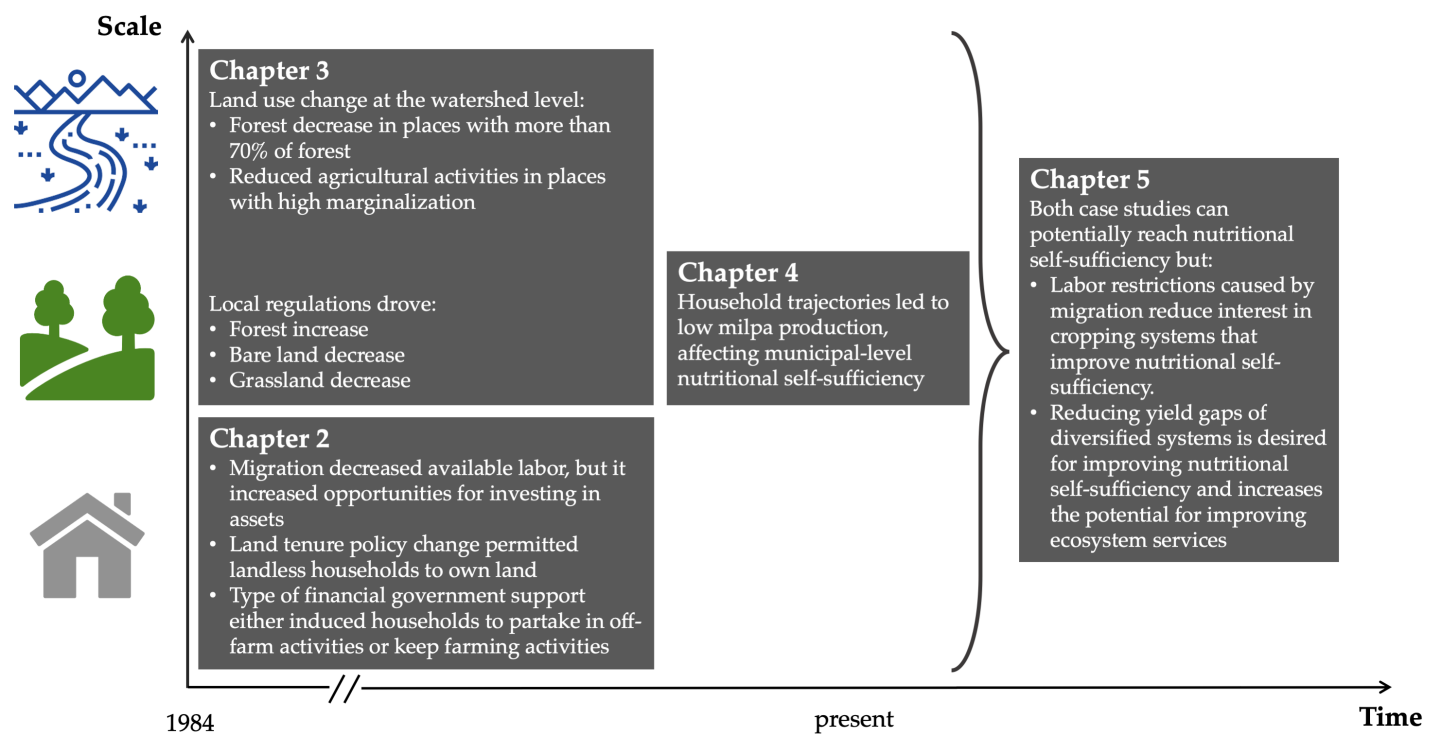

Chapter 2 shows how drivers of change contributed to the diversification of household types over time. Land tenure policies in the 1990s facilitated ownership transfer. Landless households began to own land during this process. Other households bought land and a new household type emerged, marked by a larger plot area. As more people started migrating, the labor migrant household type emerged. A number of households from that group "stepped up" by accumulating assets such as land or animals. Different government support types had different effects on households. Households that received agriculture-targeted subsidies continued to manage their farming activities, while family allowances gave them more freedom to explore off-farm activities.

In Chapter 3, I analyze landscape change at the watershed and municipal levels. At the watershed level, communities with high marginalization and forest coverage above $70 \%$ were more prone to deforestation. Decreases in agricultural land were related to drought risk and migration, which I demonstrate by assessing the evolution of community landscape management. This uncovers drivers of change that could not be identified with a watershed-level analysis. Both communities showed similar trends of drivers and land use change. In order to target soil degradation and forest regeneration problems, communities enforced grazing regulations. Additionally, they 
restricted slash-and-burn agricultural expansion, which was rapidly causing deforestation. Presently, communities have tight control over their forests and do not allow any logging activity.

Nutritional self-sufficiency is explored in Chapter 4. The two case study municipalities showed different levels of nutritional self-sufficiency, despite the fact that they are located in similar agroecological areas. Low crop yields and a higher relative population density resulted in lower nutritional self-sufficiency in the community of San Cristóbal Amoltepec compared to Santa Catarina Tayata. I also showed that in both communities, the consumption of vitamins $A$ and $C$ from their own crops was consistently low, which can be attributed to the low milpa production.

Finally, in Chapter 5 I use the insights compiled from the other chapters to explore landscape configuration alternatives for improving nutritional self-sufficiency and ecosystem services. Trade-offs were found between the production of vitamin A, carbon stocks, and landscape connectivity. For both communities, it was found to be possible to reach nutritional self-sufficiency while respecting the local landscape restrictions that were identified in Chapter 3. Options for improving ecosystem services in San Cristóbal Amoltepec were reduced due to the lower crop performance and higher population demands for food. In comparison, Santa Catarina Tayata had more opportunity to improve nutritional self-sufficiency and ecosystem services (such as habitat connectivity and carbon sequestration).

\section{2 | Assessing multi-level change: how households and landscape trajectories are related}

Landscape and socio-economic changes are connected (Misselhorn, 2005; Shackleton and Luckert, 2015), and land use changes are affecting the capacity of landscapes to provide, regulate and support ecosystem services that humans depend upon (Kebede, 2019). Therefore, studies on landscape trajectories are not complete without the inclusion of a human or socio-economic perspective.

Combining Chapters 2 and 3 reveals how a particular driver of change can impact the different scales that are being analyzed. At the watershed level, migration was associated with a decrease in land use for agriculture, but it was not associated with changes in forested area. At the municipal level, local officials and farmers reported observations of an increase in forest (in abandoned cropland), which they associated with migration. The municipal land use change analysis corroborated their reports. Land abandonment, which is followed by an increase in forest cover, has been reported in other parts of 
Mexico (García-Barrios et al., 2009), in the Caribbean (Aide et al., 2000b; Timms et al., 2013), Central America (Kull et al., 2007), the Mediterranean (Malavasi et al., 2018), Asia (Ashraf et al., 2017) and Africa (Jacob et al., 2017; Njwaxu and Shackleton, 2019). At the household level, we observed that migration had a negative impact on agricultural activities. A number of farmers reported a reduction in animal production, or a simplification of cropping systems related to labor constraints. Other authors also found migration to affect crop production as a result of labor constraints (Atamanov and Van den Berg, 2012; Collins, 2017; Nguyen et al., 2019), although Yang et al. (2016) found that it did not. We observed several cases where migration leveraged households by allowing them to invest in animal production or purchase land. Other cases where migration resulted in opportunities for investing in farming activities have been recorded in Asia (Dulal et al., 2018; Maharjan et al., 2013) and Africa (Mabrouk and Mekni, 2018).

Changes in land tenure policies impacted the watershed, municipal and household levels in different ways. In the early 1990s, private plots and common areas were officially delineated with the goal to insert Mexico into an open market context (INEGI, 2000). The restricted access to land limited agricultural expansion, as was evident in the land use change analysis for the Rio-Sordo watershed over the last 30 years (Chapter 3). At the municipal level, we observed a similar result, with no signs of cropland expansion reaching common land. For households, these changes allowed them to expand through land purchases. Landless households also took this opportunity to invest in and own properties. Thus, while the total area of land under agricultural production remained the same, important changes in livelihood assets were found. Torres-Mazuera (2015) explains that the easier transfer of land ownership reduces the number of households on populated areas, because when farmers sell their land to dedicate themselves to other economic activities, it stimulates migration. Communities as acted as drivers of landscape and household change. This was particularly clear in the context of animal production-communities restricted goat production, and forbade them from grazing on common land because they associated this practice with low forest regeneration. At the landscape level, this resulted in more forest cover. This effect could not be observed in the watershed level analysis, as it does not allow an assessment of local regulations that could affect grazing. Goats have long been perceived to cause damage to the landscape in the region (Mindek, 2003; Morett-Sánchez and Cosío-Ruiz, 2017; Taylor, 2003). Some studies suggest that keeping goats away from forest regeneration areas will increase conservation success (Nuñez and Marten, 2010). Households responded to changes in grazing regulations by replacing goats with sheep. However, this type of strategy might not always be possible. For instance, I observed that some households had to sell their animals during a time of financial stress, from which ultimately, they 
could not recover and re-invest in new livestock. Local regulations (such as the one that restricted goat production) would force households to sell or consume their animals to adjust to the new regulation, therefore imposing a stress from which they might not recover.

To synthesize, migration either impacted households by restricting their labor or by allowing them to invest in agriculture. These changes at the household level triggered land use change, such as forest growth in abandoned croplands. Land tenure processes that took place in Mexico imposed landscape restrictions and avoided agricultural expansion, but at the same time brought significant changes to households by allowing them to own more land. As suggested by Torres-Mazuera (2015), the changes in land tenure might have contributed to land abandonment, as households were allowed to sell their land and dedicate themselves to other activities. This type of cause-and-effect demonstrates the relevance of studying landscape and household trajectories together.

\subsection{The role of communities in landscape conserva- tion}

According to Barnes (2009), communities gradually began losing control over their lands from the Spanish colonization period until the Mexican revolution in 1917, which marked the period when these lands were given back to communities. Bray and MerinoPérez (2007) estimate that $80 \%$ of the total forested area in Mexico belongs to communities, although acknowledge that a better estimation is required. They also mention that landscapes managed by communities offer a potential for ecosystem services, mentioning that more studies are still needed.

Ellis and Porter-Bolland (2008) contrasted community-based forestry management against forestry management in protected areas, showing how communities can fight against deforestation and suggesting that they be included in conservation strategies. Navarro-Cerrillo et al. (2019) recorded reforestation cases in community-managed landscapes of Sierra de Juarez, Oaxaca. In contrast to these positive findings, Honey-Rosés (2009) found illegal logging being ignored when communities' organizational structures were weak and allowed corruption to enter. In Chapter 3, I showed that the two case study communities increased their forested areas. This occurred because, firstly, communities had authority over the common land, and secondly, a clear separation between common and private land granted communities tighter control over land use change, particularly in regards to logging and restricting agricultural activities that would damage forests. Separating the common area from the private area proved to be effective against deforestation (Bray, 2004; Dalle and de Blois, 2006; Ellis and Porter-Bolland, 
2008). This separation is no guarantee for avoiding deforestation, as shown by Pfaff et al. (2015) for the Brazilian context, in which protected areas close to cities or roads had high deforestation rates. Based on my findings and on the literature, I argue that a weak community interest in preserving the landscape or an unclear definition of land titles threaten the success of community-based land conservation.

\subsection{Integrating multi-scale trajectories in landscape management}

Trajectory assessment adds a deeper understanding of the socio-economic and environmental contexts. With (2007) states that ignoring trajectories is risky from a conservation or management perspective, because landscapes are dynamic. Adopting a time perspective allows managers to better define goals that meet societal needs for goods and services. Masunungure and Shackleton (2018) studied trajectories to propose alternatives that would improve household responses to drivers of change. Shackleton et al. (2019) argue that trajectory analysis helps to identify poorly adapted responses, as well as avoid their repetition. Bathfield et al. (2016) used household trajectories to describe how coffee and honey farmers make their decisions based on uncertainties, such as the international market. Renard et al. (2015) showed how ecosystem service bundles can change overtime. Though these studies show the importance of trajectory studies, they usually only consider one level of analysis, which is either household or landscape. Integrating these different levels (as was done in this study) provides a better understanding of the context. Interventions that fail to consider socio-economic and political contexts can bring negative consequences to ecosystem services and households (Shackleton et al., 2019).

In Chapter 3, I discuss how a mismatch between government goals has the potential to revert communities' landscape progress. Recently, the Mexican government has pushed goals for boosting animal production, which could reintroduce goat production into the communities and intensify the soil degradation process. Scheba (2018) encountered this mismatch between governance institutions and communities in Tanzania, stating that this is an issue that arises from top-down, market-oriented conservation plans. These mismatches might also arise from incompatible community and individual household goals, such as seen with the example of grazing regulations that were reinforced by communities (and their effects on households that raised goats).

While the multi-level trajectory analysis helps to highlight these mismatches, it also helps to identify potential landscape management options. In Chapter 3, I discuss a 
governmental program, which seeks to incorporate fruit trees into the traditional milpa systems, as aligned with communities' goals. The program aims to improve households' food production while, at the same time, promoting more vegetative coverage. Municipal and farmers goals are pursued synergistically. To the municipalities, the program aligns with their trajectory of improving forest cover and fighting erosion. Farmers that were interviewed for Chapter 2 expressed that they wanted more fruit trees, but their availability was scarce and they were expensive, making the program a welcome addition to household trajectories.

Trajectory studies also reveal long-persistent problems, which should be addressed in landscape management. At the household level, we observed disinterest in the milpa systems, which is a nationwide trend in Mexico (Gutierrez-Carbajal and Magaña-Magaña, 2017; Kontoleon et al., 2009; Otero Prevost et al., 2018; Vázquez González et al., 2018). In Chapter 4, we revealed how this lack of interest in milpa systems translated to low production of vitamins A and C. This problem dates from at least the early 1990s and requires a new solution. For that purpose, assessing whether the landscapes can provide healthy nutrition becomes essential to attaining populations' food demands.

\section{5 | The importance of nutrition-sensitive landscapes approach}

In Chapter 5, I explored landscape configuration alternatives that were based on objectives defined by multiple stakeholders. These objectives aimed to improve natural resource conservation by reducing soil erosion, increasing forested area, increasing crop production, and reducing labor requirements. Increasing crop production was a point raised by all stakeholders. When defining these goals, stakeholders were mostly referring to maize and bean production. The analysis showed how focusing only on increasing maize and bean production can have some nutritional pitfalls.

Vitamin A deficiencies have been a topic of concern across Latin America for a long time (Mora et al., 1998). Some countries, like Guatemala and Costa Rica, were able to eliminate the problem through food fortification (or food enrichment with nutritional elements) with vitamin A. Other countries in Africa successfully fought vitamin A deficiency with biofortification of maize (plant breeding for higher vitamin concentration in the plant) (Govender et al., 2019; Menkir et al., 2018). Mexico, however, proved to be less effective in eliminating vitamin A deficiency, and severe rates of deficiency for children exist (Cediel et al., 2015; de Romaña and Cediel, 2017). Vitamin A is present in high quantities in squash (INCAP, 2006), which is commonly found in milpa systems. 
Leatherman et al. (2019) found that households with marginal milpa production have vitamin A, C, and zinc deficiencies in Yucatán, Mexico. While we did not measure the actual nutritional deficiencies, we estimated the production of dietary energy, nutrients and vitamins from current crop production. Both case study municipalities had very low production of vitamin A and C, and SCA showed even lower production of other nutritional factors. Leatherman et al. (2019) also discuss that deficiencies of vitamins and micronutrients can be exacerbated by maize-rich diets. To my knowledge, there are no studies relating nutrient deficiencies in Mexico to the decline of milpa production over the last decades. Since milpa offers higher nutritional benefits than monocropping systems (Chapter 4) we could infer that food security decline is related to farmers' abandonment of milpa. This is especially important for subsistence agriculture, such as that in the case studies. A lack of nutritional self-sufficiency, in combination with landscapelevel issues (like high soil erosion levels), clearly calls for an NSL approach, which still has not been widely applied. Kennedy et al. (2017) applied the NSL approach in three African countries to understand nutritional gaps and to identify potential cropping systems for producing higher food diversity. They did not explicitly integrate ESs in their assessment, and results from chapters 4 and 5 lead me to conclude that this factor is paramount for assessing landscape options.

\subsection{Bringing the nutrition-sensitive landscapes ap- proach to the Mixteca Alta and other contexts}

Based on studies by Kennedy et al. (2017), I summarize NSL as those landscapes that are able to sustain the population with a balanced diet, without causing environmental damage. To attain this goal, we explored landscape alternatives using the LandscapeIMAGES framework. Results revealed how to solve some of the nutritional self-sufficiency issues at the political and technical level to enable greater provision of landscape ecosystem services.

The modelling framework showed that with current practices, nutritional selfsufficiency could only be achieved in SCA by producing milpa on 30\% of its territory. This solution can be achieved only at the cost of other ecosystem services, since an adequate supply of milpa would require a large part of the territory and thus a reduction in habitat connectivity and an increase in soil erosion. In order to improve both nutritional self-sufficiency and ecosystem services, interventions are needed.

At the technical level, interventions should consider that households in the area avoid milpa production due to its high labor demands. Cropping systems involving 
multiple species are known for their elevated labor input (Dahlin and Rusinamhodzi, 2019; Gliessman et al., 1998; Yamane et al., 2016). In the case study, applying fertilizer usually causes damage to companion crops (Reyna et al.), and therefore, from a production perspective, efforts should be made towards finding alternatives that reduce labor requirements for weeding. In Chapter 4, I show how milpa produces less food per hour worked.

At the policy level, interventions should target benefits to farmers for growing milpa. Based on my findings in Chapter 2, households receiving direct payments to grow specific crops tend to rely more on farming activities than on off-farm income. Considering that plots with milpa are not eligible for receiving financial benefits from PROCAMPO, I argue that revising the program to include milpa would not only stimulate farmers to maintain their farming activities, but would also improve households' nutritional self-sufficiency.

Other interventions, such as biofortification of maize with vitamin A, would not require major changes to current agricultural systems. This option has the potential to improve the vitamin A deficiency in Mexico, especially when considering the country's struggle in fighting the deficiency. Nevertheless, this solution does not address other nutritional shortcomings, and a greater food diversity is always a more-desired option for better nutrition (EAT-Lancet Commission, 2019; Kennedy et al., 2010; Ngala, 2015; Remans et al., 2011). Biofortification with vitamin A could reduce shortcomings in SCA and SCT 1, but it would not solve other production deficiencies such as vitamin $\mathrm{C}$ and zinc. This shows that "one size fits all" approach should be avoided (Cleary and van Caenegem, 2017; Pannell et al., 2014; Thierfelder et al., 2015). Approaches such as NSL explicitly consider locally specific interactions between ESs and nutritional selfsufficiency.

While this study focused on the Mixtec context, other regions share similar problems with food insecurity and high degradation of ecosystem services (Bommarco et al., 2018; Gomiero, 2016; Mekuria, 2019). This study shows a case of low crop yields constraining options for improving both nutritional self-sufficiency and ecosystem services. To solve this issue, interventions should focus on finding alternatives for improving crop yields of systems that offer nutritional diversity. Such approach would require less land to reach nutritional self-sufficiency and allow more room for improving other ecosystem services.

During our stay in the area, the local NGO and official authorities expressed their desire to develop a land use plan. They want to use this plan to obtain funding that could be invested in community land. Results from Chapter 5 will be shared with these stakeholders to offer an opportunity to put our findings into practice. Work in the area 
will continue and will stimulate uptake of results in locally appropriate ways.

\section{7 | Conclusions}

This study connected landscape and household trajectories to several drivers of change, shedding light on the role that communities play as drivers of change. The trajectory analysis revealed the relationship between long-persistent problems, such as migration, decline of milpa, and low nutritional self-sufficiency. The main conclusions of this thesis are:

- The diversity of household types is dynamic and can be affected by drivers such as migration, government support and land tenure policy changes;

- Communities have an important role as drivers of landscape and household change, reinforcing or counteracting the perceived effects of higher-level drivers;

- The replacement of traditional polycropping systems for monocropping systems poses threats to rural food security by reducing their nutritional self-sufficiency, and;

- It is possible to reconstruct landscapes to produce healthy food while improving other ecosystem services, as long as local constraints are understood and considered when proposing interventions.

- Although at the landscape level there are trade-offs between nutritional factors (e.g. dietary energy and other nutritional components) and ecosystem services, such as soil erosion control, habitat connectivity and carbon stocks, this study revealed that there is also room for synergies between these at both household and landscape level.

The majority of forests in Mexico is under communities' governance, and communities have shown great promises in conserving natural resources, and their importance should not be disregarded. 


\section{References}

Aberman, N.-L., J. Meerman, and T. D. Benson, eds.

2018. Agriculture, food security, and nutrition in Malawi: leveraging the links, Food policy report. Washington, DC: International Food Policy Research Institute.

Aguilar, d. 1. P.

2008. Pobreza y marginación en la Mixteca Poblana: un análisis desde el enfoque de sistemas complejos. In Sistemas complejos, medio ambiente y desarrollo, G. Duval and B. Ortiz, eds. Puebla: Universidad Iberoamericana Puebla : Colegio de Posgraduados Puebla : Secretaría del Medio Ambiente y Recursos Naturales, Puebla. OCLC: ocn368563856.

Ahearn, M. C., H. El-Osta, and J. Dewbre

2006. The Impact of Coupled and Decoupled Government Subsidies on Off-Farm Labor Participation of U.S. Farm Operators. American Journal of Agricultural Economics, 88(2):393-408.

Aide, T. M., M. L. Clark, H. R. Grau, D. López-Carr, M. A. Levy, D. Redo, M. Bonilla-Moheno, G. Riner, M. J. Andrade-Núñez, and M. Muñiz

2012. Deforestation and Reforestation of Latin America and the Caribbean (2001-2010). Biotropica, 45(2):262-271.

Aide, T. M., J. K. Zimmerman, J. B. Pascarella, L. Rivera, and H. Marcano-Vega

2000a. Forest Regeneration in a Chronosequence of Tropical Abandoned Pastures: Implications for Restoration Ecology. Restoration Ecology, 8(4):328-338.

Aide, T. M., J. K. Zimmerman, J. B. Pascarella, L. Rivera, and H. Marcano-Vega

2000b. Forest Regeneration in a Chronosequence of Tropical Abandoned Pastures: Implications for Restoration Ecology. Restoration Ecology, 8(4):328-338.

Alders, R. and R. Kock

2017. What's food and nutrition security got to do with wildlife conservation? Australian Zoologist, 39(1):120-126.

Altieri, M. A., F. R. Funes-Monzote, and P. Petersen

2012. Agroecologically efficient agricultural systems for smallholder farmers: contributions to food sovereignty. Agronomy for Sustainable Development, 32(1):1-13.

Altieri, M. A. and C. I. Nicholls

2008. Scaling up Agroecological Approaches for Food Sovereignty in Latin America. Development, 51(4):472-480.

Alvarez, S., S. Paas, K. Descheemaeker, P. Tittonell, and J. Groot

2014. Typology construction, a way of dealing with farm diversity: General guidelines for Humidtropics. Andersson, E., B. Nykvist, R. Malinga, F. Jaramillo, and R. Lindborg 
2015. A social-ecological analysis of ecosystem services in two different farming systems. AMBIO, 44(S1):102-112.

Angelsen, A.

1995. Shifting cultivation and "deforestation": A study from Indonesia. World Development, 23(10):17131729.

Ashraf, J., R. Pandey, and W. de Jong

2017. Assessment of bio-physical, social and economic drivers for forest transition in Asia-Pacific region. Forest Policy and Economics, 76:35-44.

Assennato, B. and P. León

2007. La democracia interna en el ejido. Procuradoría Agraria, P. 16.

Atamanov, A. and M. Van den Berg

2012. Heterogeneous Effects of International Migration and Remittances on Crop Income: Evidence from the Kyrgyz Republic. World Development, 40(3):620-630.

Audley, J. J., D. G. Papademetriou, S. Polaski, and S. Vaughan

2003. NAFTA's Promise and Reality: lessons from Mexico for the hemisphere. Technical report, Carnegie Endowment for International Peace.

Avalos, A. and E. Graillet

2013. Corn and Mexican Agriculture: What Went Wrong? American Journal of Economics and Sociology, 72(1):145-178.

Bagchi, D. K., P. Blaikie, J. Cameron, M. Chattopadhyay, N. Gyawali, and D. Seddon 1998. Conceptual and methodological challenges in the study of livelihood trajectories: case-studies in Eastern India and Western Nepal. Journal of International Development, 10(4):453-468.

Bai, Z., D. Dent, Y. Wu, and R. de Jong 2013. Land Degradation and Ecosystem Services. In Ecosystem Services and Carbon Sequestration in the Biosphere, R. Lal, K. Lorenz, R. F. Hüttl, B. U. Schneider, and J. von Braun, eds., Pp. 357-381. Dordrecht: Springer Netherlands.

Balbi, S., A. d. Prado, P. Gallejones, C. P. Geevan, G. Pardo, E. Pérez-Miñana, R. Manrique, C. HernandezSantiago, and F. Villa

2015. Modeling trade-offs among ecosystem services in agricultural production systems. Environmental Modelling $\mathcal{E}$ Software, 72:314-326.

Balmford, A. and W. Bond 2005. Trends in the state of nature and their implications for human well-being: Trends in the state of nature. Ecology Letters, 8(11):1218-1234.

Bank, W.

2005. generacion de ingresos y proteccion social para los pobres. Executive report 36853, World Bank, Mexico.

Barnes, G.

2009. The evolution and resilience of community-based land tenure in rural Mexico. Land Use Policy, 26(2):393-400.

Bathfield, B., P. Gasselin, L. García-Barrios, R. Vandame, and S. López-Ridaura

2016. Understanding the long-term strategies of vulnerable small-scale farmers dealing with markets' uncertainty. The Geographical Journal, 182(2):165-177.

Bautista-Sánchez, G., C. Eusébio Pedro-Santo, and Álvarez Olguín

2013. Participación y acción comunitaria en el manejo de recursos naturales de uso común en la Mixteca Oaxaqueña. Universidad Autónoma Indígena de México, 9(2):89-98. 
Baynes, J., J. Herbohn, C. Smith, R. Fisher, and D. Bray

2015. Key factors which influence the success of community forestry in developing countries. Global Environmental Change, 35:226-238.

Berkes, F.

2004. Rethinking Community-Based Conservation. Conservation Biology, 18(3):621-630.

Bernard, S. and R. Koninck

1997. THE RETREAT OF THE FOREST IN SOUTHEAST ASIA: A CARTOGRAPHIC ASSESSMENT. Singapore Journal of Tropical Geography, 17(1):1-14.

Berumen Barbosa, $\mathrm{M}$.

2004. Región Mixteca: aspectos socio económicos y propuestas de acción para su crecimiento y desarrollo. Place of publication not identified: Eumed.net. OCLC: 823655859.

Bhattacharyya, T., P. Chandran, S. K. Ray, C. Mandal, P. Tiwary, D. K. Pal, U. K. Maurya, A. M. Nimkar, H. Kuchankar, S. Sheikh, B. A. Telpande, and A. Kolhe

2015. Walkley-Black Recovery Factor to Reassess Soil Organic Matter: Indo-Gangetic Plains and Black Soil Region of India Case Studies. Communications in Soil Science and Plant Analysis, 46(20):2628-2648.

Bioversity International

2014. Concept Note: Nutrition-sensitive landscapes. Technical report, Bioversity International and The Earth Institute, Columbia University.

Birol, E., E. R. Villalba, and M. Smale

2009. Farmer preferences for milpa diversity and genetically modified maize in Mexico: a latent class approach. Environment and Development Economics, 14(4):521-540.

Bixler, R. P.

2014. From Community Forest Management to Polycentric Governance: Assessing Evidence from the Bottom Up. Society \& Natural Resources, 27(2):155-169.

Bocco, G., B. S. Castillo, Q. Orozco-Ramírez, and A. Ortega-Iturriaga 2019. La agricultura en terrazas en la adaptación a la variabilidad climática en la Mixteca Alta, Oaxaca, México. Journal of Latin American Geography, 18(1):141-168.

Boit, A., B. Sakschewski, L. Boysen, A. Cano-Crespo, J. Clement, N. Garcia-alaniz, K. Kok, M. Kolb, F. Langerwisch, A. Rammig, R. Sachse, M. van Eupen, W. von Bloh, D. Clara Zemp, and K. Thonicke 2016. Large-scale impact of climate change vs. land-use change on future biome shifts in Latin America. Global Change Biology, 22(11):3689-3701.

Bommarco, R., G. Vico, and S. Hallin

2018. Exploiting ecosystem services in agriculture for increased food security. Global Food Security, 17:57-63.

Bray, D.

2004. Community forestry as a strategy for sustainable management: perspectives from Quintana Roo, Mexico. In Working forests in the Neotropics: conservation through sustainable management. New York: Columbia University.

Bray, D., E. Duran, V. Ramos, J.-F. May, A. Velazquez, R. McNab, D. Barry, and J. Radachowsky 2008. Tropical Deforestation, Community Forests, and Protected Areas in the Maya Forest. Department of Earth and Environment.

Bray, D. B. and L. Merino-Pérez

2007. Los bosques comunitarios de México: manejo sustentable de paisajes forestales. Instituto Nacional de Ecología. Google-Books-ID: XtCvfh0zLVUC.

Bressani, R. 
2015. Caracterización química y nutricional de la semilla, pulpa y cáscara de chilacayote (cucúrbita ficifolia) y aplicaciones en el desarrollo de productos. Final report PROYECTO FODECYT No. 023-2008, Universidad del Valle de Guatemala.

Brito, A., M. F. Mujica-Coopman, M. Olivares, D. López de Romaña, H. Cori, and L. H. Allen 2015. Folate and vitamin b12 status in latin america and the caribbean: An update. Food and Nutrition Bulletin, 36(2_suppl):S109-S118.

Broegaard, R. B., L. V. Rasmussen, N. Dawson, O. Mertz, T. Vongvisouk, and K. Grogan 2017. Wild food collection and nutrition under commercial agriculture expansion in agriculture-forest landscapes. Forest Policy and Economics, 84:92-101.

Busch, J. and K. Ferretti-Gallon 2017. What Drives Deforestation and What Stops It? A Meta-Analysis. Review of Environmental Economics and Policy, 11(1):3-23.

Calix de Dios, H., H. Putnam, S. Alvarado Dzul, W. Godek, S. Kissmann, J. L. Pierre, and S. Gliessman 2014. The challenges of measuring food security and sovereignty in the Yucatán Peninsula. Development in Practice, 24(2):199-215.

Carabias, J., J. Sarukhán, J. de la Maza, and C. Galindo

2010. Patrimonio natural de México: cien casos de éxito. México, D.F.: Comisión Nacional para el Conocimiento y Uso de la Biodiversidad.

Carney, D., ed.

1998. Sustainable rural livelihoods: what contribution can we make? London: Dept. for International Development.

Carr, D. L.

2008. Farm households and land use in a core conservation zone of the maya biosphere reserve, guatemala. Human Ecology, 36(2):231.

Cassidy, E. S., P. C. West, J. S. Gerber, and J. A. Foley

2013. Redefining agricultural yields: from tonnes to people nourished per hectare. Environmental Research Letters, 8(3):034015.

Cediel, G., M. Olivares, A. Brito, D. L. d. Romaña, H. Cori, and M. R. L. Frano 2015. Interpretation of Serum Retinol Data From Latin America and the Caribbean. Food and Nutrition Bulletin, 36(2_suppl):S98-S108.

Chappell, M. J. and L. A. LaValle

2011. Food security and biodiversity: can we have both? An agroecological analysis. Agriculture and Human Values, 28(1):3-26.

Chopin, P., J. M. Blazy, and T. Doré

2015. A new method to assess farming system evolution at the landscape scale. Agronomy for Sustainable Development, 35(1):325-337.

Clapp, J.

2017. Food self-sufficiency: Making sense of it, and when it makes sense. Food Policy, 66:88-96.

Cleary, J. and W. van Caenegem

2017. Mitigating 'One-Size-Fits-All' Approaches to Australian Agriculture: Is There a Case to Be Made for Geographical Indications? In The Importance of Place: Geographical Indications as a Tool for Local and Regional Development, W. van Caenegem and J. Cleary, eds., volume 58, Pp. 111-145. Cham: Springer International Publishing.

Collins, J. L.

2017. Princeton Legacy Library: Unseasonal Migrations : The Effects of Rural Labor Scarcity in Peru. Princeton, 
UNITED STATES: Princeton University Press. OCLC: 976396604.

CONABIO

2010. Mexican biodiversity. Technical report, Comisión Nacional para el Conocimiento y Uso de la Biodiversidad, Mexico.

\section{CONABIO}

2012. Portal de geoinformación: sistema nacional de información sobre biodiversidad. Technical report, Comisión Nacional para el Conocimiento y Uso de la Biodiversidad.

\section{CONAPO}

2016. Dinámica demográfica 1990-2010 y proyecciones de población 2010-2030. Technical report, Consejo Nacional de Población, Mexico.

\section{CONEVAL}

2018. Medición de la pobreza. Technical report, Consejo Nacional de Evaluación de la Política de Desarrollo Social, Mexico.

Contreras-Hinojosa, J. R., V. Volke-Haller, J. Oropeza-Mota, C. Rodríguez-Franco, T. Martínez-Saldaña, and Martínez-Garza

2003. Estado actual y causas de la degradacion de los agostaderos en el municipio de Yanhuitlan, Oaxaca. Terra Latinoamericana, 21(3):427-435.

Contreras-Hinojosa, J. R., V. Volke-Haller, J. Oropeza-Mota, C. Rodríguez-Franco, T. Martínez-Saldaña, and Martínez-Garza

2005. Reducción del rendimiento de maíz por la erosión del suelo en Yanhuitlán, Oaxaca, México. Terra Latinoamericana, 23(3):399-408.

Corona, R., L. Galicia, J. L. Palacio-Prieto, M. Bürgi, and A. Hersperger

2016. Local deforestation patterns and driving forces in a tropical dry forest in two municipalities of southern Oaxaca, Mexico (1985-2006)). Investigaciones Geográficas, Boletín del Instituto de Geografía, 2016(91):86-104.

Cárdenas-Hernández, O. G. and P. Gerritsen

2015. Dinámica paisajística y cambio de cobertura en la comunidad indígena de Cuzalapa, Reserva de la Biosfera Sierra de Manantlán (1972 a 2000). P. 12.

Dahlin, A. S. and L. Rusinamhodzi

2019. Yield and labor relations of sustainable intensification options for smallholder farmers in subSaharan Africa. A meta-analysis. Agronomy for Sustainable Development, 39(3):32.

Dalle, S. P. and S. de Blois 2006. Shorter Fallow Cycles Affect the Availability of Noncrop Plant Resources in a Shifting Cultivation System. Ecology and Society, 11(2):art2.

Dalle, S. P., S. de Blois, J. Caballero, and T. Johns

2006. Integrating analyses of local land-use regulations, cultural perceptions and land-use/land cover data for assessing the success of community-based conservation. Forest Ecology and Management, 222(13):370-383.

Daniel, R., R. Mascorro de Loera, B. Ferguson, H. Perales-Rivera, and F. Charbonnier 2019. Herbicidas en la milpa: Estrategias de aplicación y su impacto sobre el consumo de arvenses Herbicide milpa: Application strategy and its impact on edible weeds consumption. 6:477-486.

Das, P. K., R. V. Bhavani, and M. S. Swaminathan

2014. A Farming System Model to Leverage Agriculture for Nutritional Outcomes. Agricultural Research, 3(3):193-203.

de Frece, A. and N. Poole 
2008. Constructing Livelihoods in Rural Mexico: Milpa in Mayan Culture. The Journal of Peasant Studies, 35(2):335-352.

de Groot, R., L. Brander, S. van der Ploeg, R. Costanza, F. Bernard, L. Braat, M. Christie, N. Crossman, A. Ghermandi, L. Hein, S. Hussain, P. Kumar, A. McVittie, R. Portela, L. C. Rodriguez, P. ten Brink, and P. van Beukering

2012. Global estimates of the value of ecosystems and their services in monetary units. Ecosystem Services, 1(1):50-61.

de Romaña, D. L. and G. Cediel

2017. Current Situation of Micronutrients in Latin America and the Caribbean, Pp. 6-21.

de Ruiter, H., J. I. Macdiarmid, R. B. Matthews, and P. Smith

2018. Moving beyond calories and protein: Micronutrient assessment of UK diets and land use. Global Environmental Change, 52:108-116.

de Valença, A., A. Bake, I. Brouwer, and K. Giller

2017. Agronomic biofortification of crops to fight hidden hunger in sub-Saharan Africa. Global Food Security, 12:8-14.

Deckelbaum, R. J., C. Palm, P. Mutuo, and F. DeClerck

2006. Econutrition: Implementation Models from the Millennium Villages Project in Africa. Food and Nutrition Bulletin, 27(4):335-342.

DeFries, R., J. Fanzo, R. Remans, C. Palm, S. Wood, and T. L. Anderman 2015. Metrics for land-scarce agriculture. Science, 349(6245):238-240.

Deininger, K. and B. Minten 1999. Poverty, Policies, and Deforestation: The Case of Mexico. Economic Development and Cultural Change, 47(2):313-344.

Dorward, A. 2009. Integrating Contested Aspirations, Processes and Policy: Development as Hanging In, Stepping Up and Stepping Out. Development Policy Review, 27(2):131-146.

Dulal, N., M. Jaisi, S. Khanal, L. Chhetri, and B. Kandel 2018. Effect of remittance on farmer's livelihood: A case of sundarbazar municipality, lamjung. Pp. 1-6.

Duran, E., J. Mas, and A. Velázquez 2005. Land use/cover change in community-based forest management regions and protected areas in Mexico. In The Community Forests of Mexico: Managing for Sustainable Landscapes, Pp. 215-238.

EAT-Lancet Commission 2019. Food, Planet, Health. Summary report.

Ebel, R., J. P. C. Gonzalo, F. M. Soria, and J. G. Cruz 2017. Manejo orgánico de la milpa: rendimiento de maíz, frijol y calabaza en monocultivo y policultivo. Terra Latinoamericana, (35):149-160.

Egas, J. J. and C. P. De Salvo 2018. Agricultural Support Policies in Latin America and the Caribbean: 2018 Review. Inter-American Development Bank.

Ellis, E. A. and L. Porter-Bolland 2008. Is community-based forest management more effective than protected areas? Forest Ecology and Management, 256(11):1971-1983.

Estrada-Carmona, N., A. K. Hart, F. A. DeClerck, C. A. Harvey, and J. C. Milder 2014. Integrated landscape management for agriculture, rural livelihoods, and ecosystem conservation: An assessment of experience from Latin America and the Caribbean. Landscape and Urban Planning, 
129:1-11.

Fabricius, C., C. Folke, G. Cundill, and L. Schultz

2007. Powerless spectators, coping actors, and adaptive co-managers: a synthesis of the role of communities in ecosystem management. Ecology and Society, 12(1).

Falconnier, G. N., K. Descheemaeker, T. A. V. Mourik, O. M. Sanogo, and K. E. Giller

2015. Understanding farm trajectories and development pathways: Two decades of change in southern Mali. Agricultural Systems, 139:210-222.

FAO

1996. Rome declaration and world food summit plan of action. Technical report, Food and Agriculture Organization, Rome, Italy.

FAO

2000. The elimination of food insecurity in the Horn of Africa. Technical report, Food and Agriculture Organization.

FAO

2003. La pobreza rural en América Latina: lecciones para una reorientación de las políticas. P. 248. Food and Agriculture Organization.

FAO

2006. Food security. Policy Brief, Food and Agriculture Organization.

FAO

2008. The State of food and agriculture: Addressing food insecurity in protracted crises, number 2008. Rome: Food and Agriculture Organization. OCLC: 731543308.

FAO

2014. Nutrition-sensitive agriculture. Rome. Food and Agriculture Organization.

FAO, IFAD, IOM, and WFP

2018. The linkages between migration, agriculture, food security and rural development: technical report. Food and Agriculture Organization, International Fund For Agricultural Development, International Organization for Migration, World Food Programme. OCLC: 1078890141.

FAO and UN

1995. Sorghum and millets in human nutrition, number no. 27 in FAO food and nutrition series. Rome : Lanham, MD: Food and Agriculture Organization of the United Nations ; UNIPUB [distributor].

Flores-Sánchez, D., J. C. Groot, E. A. Lantinga, M. J. Kropff, and W. A. Rossing

2015. Options to improve family income, labor input and soil organic matter balances by soil management and maize-livestock interactions. Exploration of farm-specific options for a region in Southwest Mexico. Renewable Agriculture and Food Systems, 30(4):373-391.

Foley, M. W.

1995. Privatizing the Countryside:The Mexican Peasant Movement and Neoliberal Reform. Latin American Perspectives, 22(1):59-76.

Frison, E. A., I. F. Smith, T. Johns, J. Cherfas, and P. B. Eyzaguirre

2006. Agricultural Biodiversity, Nutrition, and Health: Making a Difference to Hunger and Nutrition in the Developing World. Food and Nutrition Bulletin, 27(2):167-179.

Galindo, M. S., D. S. F. Reynoso, M. M. Menes, E. R. Granados, and J. D. R. Berber

2017. Modelo hidrológico de la cuenca del río Sordo, Oaxaca, México, con SWAT. Tecnología y ciencias del agua, 8(5):141-156.

Galán, C., P. Balvanera, and F. Castellarini

2012. Políticas Públicas hacia la sustentabilidad: Integrando la visión ecosistémica. Technical report, 
Mexico City, Mexico.

García-Barrios, L., Y. M. Galván-Miyoshi, I. A. Valsieso-Pérez, O. R. Masera, G. Bocco, and J. Vandermeer 2009. Neotropical Forest Conservation, Agricultural Intensification, and Rural Out-migration: The Mexican Experience. BioScience, 59(10):863-873.

Gaveau, D. L., M. Linkie, Suyadi, P. Levang, and N. Leader-Williams 2009. Three decades of deforestation in southwest Sumatra: Effects of coffee prices, law enforcement and rural poverty. Biological Conservation, 142(3):597-605.

Geist, H. J. and E. F. Lambin

2002. Proximate Causes and Underlying Driving Forces of Tropical Deforestation. BioScience, 52(2):143.

Gliessman, S., E. Engles, and R. Krieger

1998. Agroecology: Ecological Processes in Sustainable Agriculture. CRC-Press.

Glover, T. D., W. P. Stewart, and K. Gladdys

2008. Social Ethics of Landscape Change: Toward Community-Based Land-Use Planning. Qualitative Inquiry, 14(3):384-401.

Gomiero, T.

2016. Soil Degradation, Land Scarcity and Food Security: Reviewing a Complex Challenge. Sustainability, 8(3):281.

González, A. E. and M. V. Alferes

2010. Competitividad y ventajas comparativas de la producción de maíz en México. Revista mexicana de ciencias agrícolas, 1:381-396.

González-Cortés, N., H. Silos-Espino, J. C. C. Estrada, J. A. Chávez-Muñoz, and L. J. Tejero

2016. Characteristics and properties of maize (Zea mays L.) grown in native Aguascalientes, Mexico. Revista Mexicana de Ciencias Agrícolas, 7(3):669-680.

Gordillo, G. d. A.

2004. Seguridad alimentaria y agricultura familiar. Revista de la CEPAL, (83):71-84.

Govender, L., K. Pillay, M. Siwela, A. T. Modi, and T. Mabhaudhi

2019. Improving the Dietary Vitamin A Content of Rural Communities in South Africa by Replacing Non-Biofortified White Maize and Sweet Potato with Biofortified Maize and Sweet Potato in Traditional Dishes. Nutrients, 11(6):1198.

Gowda, J. H., T. Kitzberger, and A. C. Premoli

2012. Landscape responses to a century of land use along the northern Patagonian forest-steppe transition. Plant Ecology, 213(2):259-272.

Graham, R. D., R. M. Welch, D. A. Saunders, I. Ortiz-Monasterio, H. E. Bouis, M. Bonierbale, S. de Haan, G. Burgos, G. Thiele, R. Liria, C. A. Meisner, S. E. Beebe, M. J. Potts, M. Kadian, P. R. Hobbs, R. Gupta, and S. Twomlow

2007. Nutritious Subsistence Food Systems. In Advances in Agronomy, volume 92, Pp. 1-74. Elsevier.

Groot, J. C., A. Jellema, and W. A. Rossing

2010. Designing a hedgerow network in a multifunctional agricultural landscape: Balancing trade-offs among ecological quality, landscape character and implementation costs. European Journal of Agronomy, 32(1):112-119.

Groot, J. C., W. A. Rossing, A. Jellema, D. J. Stobbelaar, H. Renting, and M. K. Van Ittersum

2007. Exploring multi-scale trade-offs between nature conservation, agricultural profits and landscape quality-A methodology to support discussions on land-use perspectives. Agriculture, Ecosystems $\mathcal{E}$ Environment, 120(1):58-69.

Groot, J. C., W. A. Rossing, M. Tichit, N. Turpin, A. Jellema, J. Baudry, P. H. Verburg, L. Doyen, and G. W. 
van de Ven

2009. On the contribution of modelling to multifunctional agriculture: Learning from comparisons. Journal of Environmental Management, 90:S147-S160.

Groot, J. C., S. G. Yalew, and W. A. Rossing

2018. Exploring ecosystem services trade-offs in agricultural landscapes with a multi-objective programming approach. Landscape and Urban Planning, 172:29-36.

GSARS

2017. Methodology for estimation of crop area and crop yield under mixed and continuous cropping. Technical Report GO-21-2017, Global Strategy to improve agricultural and rural statistics (GSARS).

Guerrero-Arenas, R., E. Jiménez-Hidalgo, and H. S. Romero

2010. La transformación de los ecosistemas de la Mixteca Alta oaxaqueña desde el Pleistoceno Tardío hasta el Holoceno. Ciencia y Mar, 14(40):61-68.

Gulickx, M., P. Verburg, J. Stoorvogel, K. Kok, and A. Veldkamp

2013. Mapping landscape services: a case study in a multifunctional rural landscape in The Netherlands. Ecological Indicators, 24:273-283.

Gurri, F. and E. Moran

2002. Who is Interested in Commercial Agriculture?: Subsistence Agriculture and Salaried Work in the City Among Yucatec Maya from the State of Yucatan. Culture and Agriculture, 24(1):42-48.

Gutierrez-Carbajal, M. G. and M. Magaña-Magaña 2017. Migración e influencia urbana en el consumo de alimentos en dos comunidades Mayas de Yucatán. Estudios Sociales. Revista de Alimentación Contemporánea y Desarrollo Regional, 27(50).

Hammond, J., S. Fraval, J. van Etten, J. G. Suchini, L. Mercado, T. Pagella, R. Frelat, M. Lannerstad, S. Douxchamps, N. Teufel, D. Valbuena, and M. T. van Wijk

2017. The Rural Household Multi-Indicator Survey (RHoMIS) for rapid characterisation of households to inform climate smart agriculture interventions: Description and applications in East Africa and Central America. Agricultural Systems, 151:225-233.

Hennessy, T. C. and T. Rehman

2008. Assessing the Impact of the 'Decoupling' Reform of the Common Agricultural Policy on Irish Farmers' Off-farm Labour Market Participation Decisions. Journal of Agricultural Economics, 59(1):41-56.

Hernández, E. X. and E. B. Bello

1995. La milpa en Yucatán: un sistema de producción agrícola tradicional. Technical report.

Herrmann, T. M.

2006. Indigenous Knowledge and Management of Araucaria Araucana Forest in the Chilean Andes: Implications for Native Forest Conservation. Biodiversity and Conservation, 15(2):647-662.

Hidrobo, M., J. Hoddinott, N. Kumar, and M. Olivier 2018. Social Protection, Food Security, and Asset Formation. World Development, 101:88-103.

Honey-Rosés, J.

2009. Illegal Logging in Common Property Forests. Society \& Natural Resources, 22(10):916-930.

Horlings, L. and T. Marsden

2011. Towards the real green revolution? Exploring the conceptual dimensions of a new ecological modernisation of agriculture that could 'feed the world'. Global Environmental Change, 21(2):441-452.

Horst, O.

1989. The Persistence of Milpa Agriculture in Highland Guatemala1. Journal of Cultural Geography, 9(2):13-29.

Hu, G., H. Liu, Y. Yin, and Z. Song 
2016. The Role of Legumes in Plant Community Succession of Degraded Grasslands in Northern China. Land Degradation \& Development, 27(2):366-372.

Ibarrola-Rivas, M. J. and L. Galicia

2017. Rethinking Food Security in Mexico: Discussing the Need for Sustainable Transversal Policies Linking Food Production and Food Consumption. Investigaciones Geográficas, (94).

Ickowitz, A., B. Powell, D. Rowland, A. Jones, and T. Sunderland

2019. Agricultural intensification, dietary diversity, and markets in the global food security narrative.

Global Food Security, 20:9-16.

\section{IFPRI}

2014. 2014 global nutrition report: actions and accountability to accelerate the world's progress on nutrition. International Food Policy Research Institute. OCLC: 994009830.

IFPRI

2016. Global Nutrition Report 2016 From Promise to Impact Ending Malnutrition by 2030. Technical report, International Food Policy Research Institute, Washington, DC.

IFPRI

2018. 2018 Global food policy report. Technical report, International Food Policy Research Institute, Washington, DC.

INCAP

2006. Tabla de Composición de alimentos para Centroamérica, 2 edition. Instituto de Nutrición de Centroamérica y Panamá.

INEGI

1980. Censo de Población y Vivienda 1980. Census, Instituto Nacional de Estadística y Geografía, Mexico.

INEGI

1990. Censo de Población y Vivienda 1990. Census, Instituto Nacional de Estadística y Geografía, Mexico.

INEGI

2000. Censo de Población y Vivienda 2000. Census, Instituto Nacional de Estadística y Geografía, Mexico.

INEGI

2005. Censo de Población y Vivienda 2005. Census, Instituto Nacional de Estadística y Geografía, Mexico.

INEGI

2010. Censo de Población y Vivienda 2010. Census, Instituto Nacional de Estadística y Geografía, Mexico.

INEGI

2015. Censo de Población y Vivienda 2015. Census, Instituto Nacional de Estadística y Geografía, Mexico.

Ingram, J.

2011. A food systems approach to researching food security and its interactions with global environmental change. Food Security, 3(4):417-431.

Innah, H. S., D. Suharjito, A. H. Dharmawan, and D. Darusman

2013. Collective Action Typologies and Reforestation in Indigenous Community of Biak-Papua. Jurnal Manajemen Hutan Tropika (Journal of Tropical Forest Management), 19(1):11-22.

IPEA 
2013. A Produção para Autoconsumo no Brasil uma análise a partir do Censo Agropecuário 2006. Technical report, Instituto de Pesquisa Econômica Aplicada - IPEA, Brasilia, Brazil.

Iraizoz, B., M. Gorton, and S. Davidova

2007. Segmenting farms for analysing agricultural trajectories: A case study of the Navarra region in Spain. Agricultural Systems, 93(1-3):143-169.

Isakson, S. R.

2009. No hay ganancia en la milpa: the agrarian question, food sovereignty, and the on-farm conservation of agrobiodiversity in the Guatemalan highlands. The Journal of Peasant Studies, 36(4):725-759.

Ita, A. d.

2006. Land Concentration in Mexica after PROCEDE. In Promised land: competing visions of agrarian reform. Oakland, California: Food First Books ; Distributed by CDS.

Iverson, L., C. Echeverria, L. Nahuelhual, and S. Luque

2014. Ecosystem services in changing landscapes: An introduction. Landscape Ecology, 29(2):181-186.

Izquierdo, A. E., H. R. Grau, and T. M. Aide

2011. Implications of rural-urban migration for conservation of the Atlantic Forest and urban growth in Misiones, Argentina (1970-2030). Ambio, 40(3):298-309.

Jacob, A. L., M. J. Lechowicz, and C. A. Chapman

2017. Non-native fruit trees facilitate colonization of native forest on abandoned farmland: Non-native fruit trees facilitate forest recovery. Restoration Ecology, 25(2):211-219.

Jahnke, H. E.

1982. Livestock production systems and livestock development in tropical Africa. Kiel: Wiss. Verl. Vauk. OCLC: 9856613.

Janitza, S. and R. Hornung

2018. On the overestimation of random forest's out-of-bag error. PLOS ONE, 13(8):e0201904.

Jokisch, B. D.

2002. Migration and agricultural change: The case of smallholder agriculture in highland ecuador. Human Ecology, 30(4):523-550.

Juárez, A. and A. Margarita

2008. Migración y pobreza en Oaxaca. El cotidiano, 23(148).

Juárez, L. and T. Pfutze

2015. The Effects of a Noncontributory Pension Program on Labor Force Participation: The Case of $70 \mathrm{y}$ Más in Mexico. Economic Development and Cultural Change, 63(4):685-713.

Kadoya, T. and I. Washitani

2011. The Satoyama Index: A biodiversity indicator for agricultural landscapes. Agriculture, Ecosystems E Environment, 140(1-2):20-26.

Katz, E.

2008. Vapor, aves y serpientes. Meteorología en la "Tierra de la Lluvia" (Mixteca alta, Oaxaca). In Aires y lluvias. Antropología del clima en México, A. Lammel, M. Goloubinoff, and E. Katz, eds., Pp. $283-322$. Centro de estudios mexicanos y centroamericanos.

Kayeke, M. J., N. Nhamo, and D. Chikoye

2017. Reducing Risk of Weed Infestation and Labor Burden of Weed Management in Cropping Systems. In Smart Technologies for Sustainable Smallholder Agriculture, Pp. 123-143. Elsevier.

Kc, K. B., L. P. Pant, E. D. G. Fraser, P. K. Shrestha, D. Shrestha, and A. Lama

2016. Assessing links between crop diversity and food self-sufficiency in three agroecological regions of Nepal. Regional Environmental Change, 16(5):1239-1251. 
Kebede, Y.

2019. Hide and seek: management and landscape factors affecting maize stemborers Busseola fusca (Fuller) infestation levels in Ethiopia. PhD Thesis, Wageningen University.

Keeler, B. L. and S. Polasky

2014. Land-use change and costs to rural households: a case study in groundwater nitrate contamination. Environmental Research Letters, 9(7):074002.

Kennedy, G., N. Fanou-Fogny, C. Seghieri, M. Arimond, Y. Koreissi, R. Dossa, F. J. Kok, and I. D. Brouwer 2010. Food Groups Associated with a Composite Measure of Probability of Adequate Intake of $11 \mathrm{Mi}-$ cronutrients in the Diets of Women in Urban Mali. The Journal of Nutrition, 140(11):2070S-2078S.

Kennedy, G., J. Raneri, C. Termote, V. Nowak, R. Remans, J. C. Groot, and S. H. Thilsted 2017. Nutrition-sensitive landscapes: Approach and methods to assess food availability and diversification of diets. In Sustainable Intensification in Smallholder Agriculture: An Integrated Systems Research Approach, I. Oborn, B. Vanlauwe, M. Phillips, R. Thomas, K. AttaKrah, and W. Brooijmans, eds., Pp. 247258. Taylor and Francis Inc.

Khan, S. R. and S. R. Khan

2009. Assessing poverty-deforestation links: Evidence from Swat, Pakistan. Ecological Economics, 68(10):2607-2618.

Klepeis, P. and C. Vance

2003. Neoliberal Policy and Deforestation in Southeastern Mexico: An Assessment of the PROCAMPO Program. Economic Geography, 79(3):221-240.

Klepeis, P., C. Vance, E. Keys, P. Macario, and B. L. Turner II 2004. Subsistence Sustained: Swidden or Milpa Cultivation, Pp. 189-206.

Klooster, D.

2000. Community Forestry and Tree Theft in Mexico: Resistance or Complicity in Conservation? Development and Change, 31(1):281-305.

Kontoleon, A., U. Pascual, and M. Smale, eds. 2009. Agrobiodiversity conservation and economic development, number 11 in Routledge explorations in environmental economics. London; New York: Routledge. OCLC: ocn215177086.

Kull, C. A., C. K. Ibrahim, and T. C. Meredith 2007. Tropical Forest Transitions and Globalization:Neo-Liberalism, Migration, Tourism, and International Conservation Agendas. Society \& Natural Resources, 20(8):723-737.

Laillou, A., T. V. Pham, N. T. Tran, H. T. Le, F. Wieringa, F. Rohner, S. Fortin, M. B. Le, D. T. Tran, R. MoenchPfanner, and J. Berger

2012. Micronutrient Deficits Are Still Public Health Issues among Women and Young Children in Vietnam. PLoS ONE, 7(4):e34906.

Lambin, E. F., H. J. Geist, and E. Lepers

2003. Dynamics of land use and cover change in tropical regions. Annual Review of Environment and Resources, 28(1):205-241.

Lambin, E. F. and P. Meyfroidt

2011. Global land use change, economic globalization, and the looming land scarcity. Proceedings of the National Academy of Sciences, 108(9):3465-3472.

Leatherman, T., A. H. Goodman, and J. T. Stillman 2019. A Critical Biocultural Perspective on Tourism and the Nutrition Transition in the Yucatan. In Culture, Environment and Health in the Yucatan Peninsula, H. Azcorra and F. Dickinson, eds., Pp. 97-120. Cham: Springer International Publishing. 
Lebel, J.

2003. Health: an ecosystem approach, In focus. Ottawa: International Development Research Centre. OCLC: ocm52241135.

León Portilla, M. and U. N. A. de México, eds.

2013. Historia documental de México, number 4 in Serie documental / Instituto de Investigaciones Históricas, cuarta edición corregida y aumentada edition. México, D.F: Universidad Nacional Autónoma de México.

Lozada-Aranda, M., I. Rojas, A. Mastretta, A. Ponce-Mendoza, C. Burgeff, A. Orjuela-R, and O. Oliveros 2017. Las milpas en México. Oikos=, 17:10-12.

López, d. J. R.

2015. El paisaje de la Mixteca Alta. Bitácora arquitectura, (31):76.

Mabrouk, F. and M. M. Mekni

2018. Remittances and Food Security in African Countries. African Development Review, 30(3):252-263.

Madrid, L.

2008. La actividad forestal en el estado de Oaxaca. Technical report, Consejo Civil Mexicano para la Silvicultura Sostenible, Mexico.

Maharjan, A., S. Bauer, and B. Knerr

2013. Migration for labour and its impact on farm production in Nepal, number 4 in Working paper. Kathmandu: Centre for the Study of Labour and Mobility.

Malavasi, M., M. L. Carranza, D. Moravec, and M. Cutini

2018. Reforestation dynamics after land abandonment: a trajectory analysis in Mediterranean mountain landscapes. Regional Environmental Change, 18(8):2459-2469.

Mann, C. C.

2006. 1491: new revelations of the Americas before Columbus, 1st vintage books ed edition. New York: Vintage.

Mapedza, E., J. Wright, and R. Fawcett

2003. An investigation of land cover change in Mafungautsi Forest, Zimbabwe, using \{GIS\} and participatory mapping. Applied Geography, 23(1):1-21.

Martin, R., A. Linstädter, K. Frank, and B. Müller

2016. Livelihood security in face of drought - Assessing the vulnerability of pastoral households. Environmental Modelling \& Software, 75:414-423.

Martín-López, B., I. Iniesta-Arandia, M. García-Llorente, I. Palomo, I. Casado-Arzuaga, D. G. D. Amo, E. Gómez-Baggethun, E. Oteros-Rozas, I. Palacios-Agundez, B. Willaarts, J. A. González, F. SantosMartín, M. Onaindia, C. López-Santiago, and C. Montes

2012. Uncovering Ecosystem Service Bundles through Social Preferences. PLoS ONE, 7(6):e38970.

Mas, J. F. and G. Cuevas

2015. Local Deforestation Patterns in Mexico - An Approach using Geographiccally Weighted Regression:. In Proceedings of the 1st International Conference on Geographical Information Systems Theory, Applications and Management, Pp. 54-60, Barcelona, Spain. SCITEPRESS - Science and and Technology Publications.

Masunungure, C. and S. Shackleton

2018. Exploring Long-Term Livelihood and Landscape Change in Two Semi-Arid Sites in Southern Africa: Drivers and Consequences for Social-Ecological Vulnerability. Land, 7(2):50.

Mather, A. S., C. L. Needle, and J. Fairbairn

1998. The human drivers of global land cover change: the case of forests. Hydrological Processes, 12(13- 
14):1983-1994.

Matković, A., D. Božić, V. Filipović, D. Radanović, S. Vrbničanin, and T. Marković

2015. Mulching as a physical weed control method applicable in medicinal plants cultivations. Lekovite sirovine, (35):37-51.

MDS

2015. Renda das famílias extremamente pobres no campo melhorou em 88\%. Ministério do Desenvolvimento Social.

Mekasha, A., B. Gerard, K. Tesfaye, L. Nigatu, and A. J. Duncan

2014. Inter-connection between land use/land cover change and herders'/farmers' livestock feed resource management strategies: a case study from three Ethiopian eco-environments. Agriculture, Ecosystems E Environment, 188:150-162.

Mekuria, W.

2019. Restoring degraded landscapes for improved ecosystem services. In Climate-Smart AgricultureEnhancing Resilient Agricultural Systems, Landscapes and Livelihoods in Ethiopia and Beyond, Pp. 75-80. Nairobi, Kenya: World Agroforestry (ICRAF).

Menkir, A., N. Palacios-Rojas, O. Alamu, M. Dias Paes, T. Dhliwayo, B. Maziya-Dixon, W. Mengesha, T. Ndhlela, P. E. Oliveira Guimarães, K. Pixley, and T. Rocheford

2018. Vitamin A-Biofortified Maize: Exploiting Native Genetic Variation for Nutrient Enrichment. Science Brief: Biofortification No. 2, CIMMYT, IITA, EMBRAPA, HarvestPlus and Crop Trust, Bonn, Germany.

Menze, B. H., B. M. Kelm, R. Masuch, U. Himmelreich, P. Bachert, W. Petrich, and F. A. Hamprecht 2009. A comparison of random forest and its Gini importance with standard chemometric methods for the feature selection and classification of spectral data. BMC Bioinformatics, 10(1):213.

Merino-Perez, L.

2013. Conservation and Forest Communities in Mexico: Experiences, Visions, and Rights. In Community Action for Conservation: Mexican Experiences, L. Porter-Bolland, I. Ruiz-Mallén, C. Camacho-Benavides, and S. R. McCandless, eds., Pp. 25-44. New York, NY: Springer New York.

Mestries, F.

2013. Los migrantes de retorno ante un futuro incierto. Sociológica (México), 28:171-212.

Meyfroidt, P., E. F. Lambin, K.-H. Erb, and T. W. Hertel

2013. Globalization of land use: distant drivers of land change and geographic displacement of land use. Current Opinion in Environmental Sustainability, 5(5):438-444.

Mignolet, C., C. Schott, and M. Benoît

2007. Spatial dynamics of farming practices in the Seine basin: Methods for agronomic approaches on a regional scale. Science of The Total Environment, 375(1-3):13-32.

Millennium Ecosystem Assessment, ed.

2005. Ecosystems and human well-being: synthesis. Washington, DC: Island Press. OCLC: ocm59279709.

Mindek, D.

2003. Mixtecos. México, D.F.: CDI, Comisión Nacional para el Dearrollo de los Pueblos Indígenas : PNUD México. OCLC: 891562684.

Minot, Nicholas, and Pelijor

2010. Food security and food self sufficiency in Bhutan. Technical report, International Food Policy Research Institute (IFPRI) and Ministry of Agriculture and Forests (MoAF).

Misselhorn, A. A.

2005. What drives food insecurity in southern Africa? a meta-analysis of household economy studies. 
Global Environmental Change, 15(1):33-43.

Mora, J. O., M. Gueri, and O. L. Mora

1998. Vitamin A deficiency in Latin America and the Caribbean: an overview. Revista Panamericana de Salud Pública, 4(3).

Morales, H., M. C. Aguilar-Støen, and E. J. Castellanos-López

2015. Migración y remesas: ¿están afectando la sustentabilidad de la agricultura y la soberanía alimentaria en chiapas? LiminaR, 13:29 - 40.

Morett-Sánchez, J. C. and C. Cosío-Ruiz

2017. Panorama de los ejidos y comunidades agrarias en México. Agricultura, sociedad y desarrollo, 14(1):125-152.

Mouchet, M. A., P. Lamarque, B. Martín-López, E. Crouzat, P. Gos, C. Byczek, and S. Lavorel

2014. An interdisciplinary methodological guide for quantifying associations between ecosystem services. Global Environmental Change, 28:298-308.

Mueller, R. G., A. A. Joyce, and A. Borejsza

2012. Alluvial archives of the Nochixtlan valley, Oaxaca, Mexico: Age and significance for reconstructions of environmental change. Palaeogeography, Palaeoclimatology, Palaeoecology, 321-322:121-136.

Murali, K. S. and R. Hedge

1997. Patterns of tropical deforestation. Journal of Tropical Forest Science, 9(4):465-476.

Murungu, F., C. Chiduza, P. Muchaonyerwa, and P. Mnkeni

2011. Mulch effects on soil moisture and nitrogen, weed growth and irrigated maize productivity in a warm-temperate climate of South Africa. Soil and Tillage Research, 112(1):58-65.

Mushongah, J.

2009. Rethinking Vulnerability: livelihood change inSouthern Zimbabwe, 1986-2006. PhD dissertation, University of Sussex.

Mushongah, J. and I. Scoones

2012. Livelihood Change in Rural Zimbabwe over 20 Years. Journal of Development Studies, 48(9):12411257.

Naranjo-Macias, S. A.

2019. Assessing the effect of different spatial resolutions in soil erosion modeling - Case study in a highland tropical watershed in southeast Mexico. Master's thesis, University of Hohenheim, Germany.

National Academy of Sciences 2011. Nutrient Recommendations: Dietary Reference Intakes (DRI). Technical report.

Naude, A. Y., G. D. Leal, F. R. Ramírez, and O. S. Arana

2015. Evaluación del impacto conjunto de programas de transferencia condicionadas y de apoyo a la producción agrícola sobre la pobreza y la producción de alimentos: el caso de PROSPERA y PROCAMPO en México. Sobre México. Revista de Economía, 3(1):14-33.

Navarro-Cerrillo, R. M., D. J. Esteves-Vieira, S. Ochoa-Gaona, B. H. J. de Jong, and M. D. S. del Mar 2019. Land cover changes and fragmentation in mountain neotropical ecosystems of Oaxaca, Mexico under community forest management. Journal of Forestry Research, 30(1):143-155.

Ngala, S. A.

2015. Evaluation of dietary diversity scores to assess nutrient adequacy among rural Kenyan women. OCLC: 919494869.

Nguyen, D. L., U. Grote, and T. T. Nguyen

2019. Migration, crop production and non-farm labor diversification in rural Vietnam. Economic Analysis and Policy, 63:175-187. 
Nicita, A.

2004. Who Benefited from Trade Liberalization in Mexico? Measuring the Effects on Household Welfare, Policy Research Working Papers. The World Bank.

Nigh, R. and S. A. Diemont

2013. The Maya milpa: fire and the legacy of living soil. Frontiers in Ecology and the Environment, 11(s1).

Njwaxu, A. and C. M. Shackleton

2019. The Availability of Non-Timber Forest Products under Forest Succession on Abandoned Fields along the Wild Coast, South Africa. Forests, 10(12):1093.

Noromiarilanto, F., K. Brinkmann, M. H. Faramalala, and A. Buerkert

2016. Assessment of food self-sufficiency in smallholder farming systems of south-western Madagascar using survey and remote sensing data. Agricultural Systems, 149:139-149.

Nuñez, D. and G. Marten

2010. Mexico - Mixteca Region (Oaxaca) - Fighting Desertification with Community Reforestation and Sustainable Agriculture.

Núñes, M. C. M.

2000. Estudios Agrarios, Revista de la Procuradoria Agraria. Technical report, Procuradoria Agraria, Mexico City, Mexico.

Oikos

2017. La ciencia de la milpa. Mexico City, Mexico: Instituto de Ecologia UNAM.

Osorio, F.

1999. El conflicto agrario en Oaxaca. Estudios Agrarios, 5(13).

Otero, G.

2011. Neoliberal Globalization, NAFTA, and Migration: Mexico's Loss of Food and Labor Sovereignty. Journal of Poverty, 15(4):384-402.

Otero Prevost, D. E., F. D. Gurri García, R. Mariaca Méndez, and F. Guízar Vázquez Jr.

2018. La incorporación y el aumento de oferta de alimentos industrializados en las dietas de las unidades domésticas y su relación con el abandono del sistema de subsistencia propio en las comunidades rurales mayas de Yucatán, México. Cuadernos de Desarrollo Rural, 14(80).

Ottaviani, D.

2011. Payments for ecosystem services and food security. Rome: FAO and UN. OCLC: 759825705.

PA

1992. Marco Legal Agrario. Procuradoría Agrária.

Pagdee, A., Y.-s. Kim, and P. J. Daugherty

2006. What Makes Community Forest Management Successful: A Meta-Study From Community Forests Throughout the World. Society \& Natural Resources, 19(1):33-52.

Palacio-Prieto, J. L., E. Rosado-González, X. Ramírez-Miguel, O. Oropeza-Orozco, S. Cram-Heydrich, M. A. Ortiz-Pérez, J. M. Figueroa-Mah-Eng, and G. F. de Castro-Martínez

2016. Erosion, Culture and Geoheritage; the Case of Santo Domingo Yanhuitlán, Oaxaca, México. Geoheritage, 8(4):359-369.

Panneerselvam, P., J. E. Hermansen, and N. Halberg 2010. Food Security of Small Holding Farmers: Comparing Organic and Conventional Systems in India. Journal of Sustainable Agriculture, 35(1):48-68.

Pannell, D. J., R. S. Llewellyn, and M. Corbeels

2014. The farm-level economics of conservation agriculture for resource-poor farmers. Agriculture, Ecosystems \& Environment, 187:52-64. 
Parraguez-Vergara, E., B. Contreras, N. Clavijo, V. Villegas, N. Paucar, and F. Ther 2018. Does indigenous and campesino traditional agriculture have anything to contribute to food sovereignty in Latin America? Evidence from Chile, Peru, Ecuador, Colombia, Guatemala and Mexico. International Journal of Agricultural Sustainability, 16(4-5):326-341.

Parsons, D., L. Ramírez-Aviles, J. H. Cherney, Q. M. Ketterings, R. W. Blake, and C. F. Nicholson 2009. Managing maize production in shifting cultivation milpa systems in Yucatán, through weed control and manure application. Agriculture, Ecosystems \& Environment, 133(1-2):123-134.

Partida de la Peña, J. A., F. G. Ríos Rincón, L. De la Cruz Colín, I. A. Domínguez Vara, and G. Buendía Rodríguez

2017. Caracterización de las canales ovinas producidas en México. Revista Mexicana de Ciencias Pecuarias, 8(3):269.

Patel, R. and G. Henriques 2003. Agricultural trade liberalization and Mexico. Food First Policy Brief, (7).

Pfaff, A., J. Robalino, D. Herrera, and C. Sandoval 2015. Protected Areas' Impacts on Brazilian Amazon Deforestation: Examining Conservation - Development Interactions to Inform Planning. PLOS ONE, 10(7):e0129460.

Pfeiffer, L., A. López-Feldman, and E. J. Taylor 2009. Is off-farm income reforming the farm? Evidence from Mexico. Agricultural Economics, 40(2):125138.

Ploeg, J. D. v. d.

2009. The new peasantries: struggles for autonomy and sustainability in an era of empire and globalization. OCLC: 1040441520.

Powell, B., S. H. Thilsted, A. Ickowitz, C. Termote, T. Sunderland, and A. Herforth 2015. Improving diets with wild and cultivated biodiversity from across the landscape. Food Security, 7(3):535-554.

Pérez, A. O.

2017. Congregaciones en la Mixteca Alta. Signos Históricos, 19(38):56-87.

Pérez, J. C. C. and H. Mackinlay

2015. ¿existe aún la propiedad social agraria en méxico? Polis, 11:45 - 82.

Pérez, V. R.

2006. Sociedades complejas y paisajes agrícolas: un estudio regional de asentamientos y terrazas en la Mixteca Alta, Oaxaca, Mexico. In La aplicación de los SIG en la arqueología del paisaje, Pp. 247-254. Publicaciones de la Universidad de Alicante.

Pérez-Soto, F., E. Figueroa-Hernández, and L. GodÍnez-Montoya 2016. Efectos de PROCAMPO en la producción e importación de maiz y sorgo en México (1990-2015). Desarrollo Económico, 3(9):1-14.

Queiroz, C., M. Meacham, K. Richter, A. V. Norström, E. Andersson, J. Norberg, and G. Peterson 2015. Mapping bundles of ecosystem services reveals distinct types of multifunctionality within a Swedish landscape. AMBIO, 44(S1):89-101.

Quintas-Soriano, C., A. J. Castro, H. Castro, and M. García-Llorente

2016. Impacts of land use change on ecosystem services and implications for human well-being in Spanish drylands. Land Use Policy, 54:534-548.

\section{RAN}

2019a. Tierra de uso común. Technical report, Registro Agrario Nacional, Mexico. 
2019b. Zonas de tierras parceladas. Technical report, Registro Agrario Nacional, Mexico.

Ravindranath, N. H., R. K. Chaturved, and I. K. Murthy

2008. Forest conservation, afforestation and reforestation in India: Implications for forest carbon stocks. Current Science, 95(2).

Reidsma, P., F. Ewert, A. O. Lansink, and R. Leemans

2010. Adaptation to climate change and climate variability in European agriculture: The importance of farm level responses. European Journal of Agronomy, 32(1):91-102.

Remans, R., D. F. B. Flynn, F. DeClerck, W. Diru, J. Fanzo, K. Gaynor, I. Lambrecht, J. Mudiope, P. K. Mutuo, P. Nkhoma, D. Siriri, C. Sullivan, and C. A. Palm

2011. Assessing Nutritional Diversity of Cropping Systems in African Villages. PLoS ONE, 6(6):e21235.

Renard, D., J. M. Rhemtulla, and E. M. Bennett

2015. Historical dynamics in ecosystem service bundles. Proceedings of the National Academy of Sciences, 112(43):13411-13416.

Reyna, C., M. Fuentes-Ponce, S. López-Ridaura, W. Rossing, and J. Groot

. Title to be defined.

Reyna-Ramírez, C. A., L. M. Rodríguez-Sánchez, G. Vela-Correa, J. Etchevers-Barra, and M. Fuentes-Ponce 2018. Redesign of the traditional Mesoamerican agroecosystem based on participative ecological intensification: Evaluation of the soil and efficiency of the system. Agricultural Systems, 165:177-186.

Ricciardi, V., N. Ramankutty, Z. Mehrabi, L. Jarvis, and B. Chookolingo 2018. How much of the world's food do smallholders produce? Global Food Security, 17:64-72.

Richard, A.

2008. Withered milpas: Governmental disaster and the mexican countryside. The Journal of Latin American and Caribbean Anthropology, 13(2):387-413. Name - Duke University Press; La Jornada; Copyright - Copyright Blackwell Publishing Ltd. Nov 2008; Last updated - 2019-11-23; SubjectsTermNotLitGenreText - Mexico; United States-US.

Rodriguez, A. and L. Arias

2014. La milpa y el maizal: retos al desarrollo rural en méxico y perú. Etnobiología, 12:76-89.

Rodríguez, J., J. Beard, E. Bennett, G. Cumming, S. Cork, J. Agard, A. Dobson, and G. Peterson 2006. Trade-offs across Space, Time, and Ecosystem Services. Ecology and Society, 11(1).

Romero-Calcerrada, R. and G. L. Perry 2004. The role of land abandonment in landscape dynamics in the SPA 'Encinares del rio Alberche y Cofio, Central Spain, 1984-1999. Landscape and Urban Planning, 66(4):217-232.

Rosales, M. G., I. F. Solís, and A. Alejandro

2003. Problemática Campesina, Retos y Perspectivas de la Investigación y el Servicio para el Mejoramiento de la Milpa en Yucatán. Technical report, INIFAP, INAH, EDUCE, Mérida, Yucatán.

Rudel, T. and J. Roper 1996. Regional patterns and historial trends in tropical deforestation, 1976-1990: A qualitative comparative analysis. Centro Internacional de Agricultura Tropical, (1996.25(3)):160-166.

Ruel, M. T., A. R. Quisumbing, and M. Balagamwala 2018. Nutrition-sensitive agriculture: What have we learned so far? Global Food Security, 17:128-153.

Rusinamhodzi, L., M. Corbeels, J. Nyamangara, and K. E. Giller 2012. Maize-grain legume intercropping is an attractive option for ecological intensification that reduces climatic risk for smallholder farmers in central Mozambique. Field Crops Research, 136:12-22.

Sadoulet, E., A. de Janvry, and B. Davis

2001. Cash Transfer Programs with Income Multipliers: PROCAMPO in Mexico. World Development, 
29(6):1043-1056.

SAGARPA

2016. Programa de Fomento a la Agricultura Componente PROAGRO Productivo. Technical Report 1st, Secretaría de Agricultura, Ganadería Desarrollo Rural, Pesca y Alimentación, Mexico.

Sallu, S. M., C. Twyman, and L. C. Stringer

2010. Resilient or Vulnerable Livelihoods? Assessing Livelihood Dynamics and Trajectories in Rural Botswana. Ecology and Society, 15(4).

Sayer, J., T. Sunderland, J. Ghazoul, J.-L. Pfund, D. Sheil, E. Meijaard, M. Venter, A. K. Boedhihartono, M. Day, C. Garcia, C. van Oosten, and L. E. Buck

2013. Ten principles for a landscape approach to reconciling agriculture, conservation, and other competing land uses. Proceedings of the National Academy of Sciences, 110(21):8349-8356.

Scheba, A.

2018. Market-Based Conservation for Better Livelihoods? The Promises and Fallacies of REDD+ in Tanzania. Land, 7(4):119.

Schild, J. E., J. E. Vermaat, R. S. de Groot, S. Quatrini, and P. M. van Bodegom

2018. A global meta-analysis on the monetary valuation of dryland ecosystem services: The role of socio-economic, environmental and methodological indicators. Ecosystem Services, 32:78-89.

Scoones, I.

2009. Livelihoods perspectives and rural development. The Journal of Peasant Studies, 36(1):171-196.

Scoones, I., S. Devereux, and L. Haddad

2005. Introduction: New Directions for African Agriculture. IDS Bulletin, 36(2):1-12.

SEMARNAT

2014. Coeficientes de agostadero por entidad (hectárea por unidad animal). Compendium, Secretaria de Medio Ambiente y Recursos Naturales, Mexico.

SEMARNAT and CONAFOR

2011. Manual y procedimientos para el muestreo de campo: re-muestreo 2011. Inventory manual, Secretaria de Medio Ambiente y Recursos Naturales \& Comisión Nacional Forestal, Mexico.

Semillas de Vida

2014. La milpa de nuestros abuelos: Tlalmilli to Huehue. Mexico City, Mexico: Semillas de Vida. OCLC: 954513135.

Shackleton, S. and M. Luckert

2015. Changing Livelihoods and Landscapes in the Rural Eastern Cape, South Africa: Past Influences and Future Trajectories. Land, 4(4):1060-1089.

Shackleton, S., V. Masterson, P. Hebinck, C. I. Speranza, D. Spear, and M. Tengö

2019. Editorial for Special Issue: "Livelihood and Landscape Change in Africa: Future Trajectories for Improved Well-Being under a Changing Climate". Land, 8(8):114.

Shwedel, S. K.

1994. The future of agro-subsidies. Business Mexico, 4(1):16-18.

Sibande, L., A. Bailey, S. Davidova, L. Sibande, A. Bailey, and S. Davidova

2015. The impact of farm input subsidies on household welfare in Malawi. Unknown.

Sibhatu, K. T. and M. Qaim

2017. Rural food security, subsistence agriculture, and seasonality. PLOS ONE, 12(10):e0186406.

Sierra, A., A. Molina, J. Delgado, J. Hernández, and M. Rivera

1997. Zootechnical description of the creole goat of the Oaxaca region (Mexico). Animal Genetic Resources Information, 21:61-70. 
Sitzia, T., P. Semenzato, and G. Trentanovi

2010. Natural reforestation is changing spatial patterns of rural mountain and hill landscapes: A global overview. Forest Ecology and Management, 259(8):1354-1362.

Smith, J. H.

2001. Land Cover Assessment of Indigenous Communities in the BOSAWAS Region of Nicaragua. Human Ecology, 29(3):339-347.

Speelman, E. N., J. C. J. Groot, L. E. Garcia-Barrios, K. Kok, H. van Keulen, and P. Tittonell

2014. From coping to adaptation to economic and institutional change-trajectories of change in landuse management and social organization in a Biosphere Reserve community, Mexico. Land Use Policy, 41:31-44.

Stamoulis, K. and A. Zezza

2003. A Conceptual Framework for National Agricultural, Rural Development, and Food Security Strategies and Policies. P. 55.

Swallow, B. M., J. K. Sang, M. Nyabenge, D. K. Bundotich, A. K. Duraiappah, and T. B. Yatich 2009. Tradeoffs, synergies and traps among ecosystem services in the Lake Victoria basin of East Africa. Environmental Science \& Policy, 12(4):504-519.

Sweeney, S., D. G. Steigerwald, F. Davenport, and H. Eakin

2013. Mexican maize production: Evolving organizational and spatial structures since 1980. Applied Geography, 39:78-92.

Tapia-Armijos, M. F., J. Homeier, C. I. Espinosa, C. Leuschner, and M. de la Cruz 2015. Deforestation and Forest Fragmentation in South Ecuador since the 1970s - Losing a Hotspot of Biodiversity. PLOS ONE, 10(9):e0133701.

Taylor, J. E., A. Yunez-Naude, and G. Dyer 1999. Agricultural Price Policy, Employment, and Migration in a Diversified Rural Economy: A VillageTown CGE Analysis from Mexico. American Journal of Agricultural Economics, 81(3):653-662.

Taylor, P. 2003. Distributed agency within intersecting ecological, social, and scientific processes. In Contingency: developmental systems and evolution, Pp. 313-332. Cambridge, MA: MIT.

Thierfelder, C., L. Rusinamhodzi, A. R. Ngwira, W. Mupangwa, I. Nyagumbo, G. T. Kassie, and J. E. Cairns 2015. Conservation agriculture in Southern Africa: Advances in knowledge. Renewable Agriculture and Food Systems, 30(4):328-348.

Thornton, P. K., A. M. Loboguerrero, B. M. Campbell, K. S. Kavikumar, L. Mercado, and S. Shackleton 2019. Rural livelihoods, food security and rural transformation under climate change. Background paper, CGIAR, Rotterdam and Washington, DC.

Timler, C., S. Alvarez, F. DeClerck, R. Remans, J. Raneri, N. Estrada Carmona, N. Mashingaidze, S. Abe Chatterjee, T. W. Chiang, C. Termote, R.-Y. Yang, K. Descheemaeker, I. D. Brouwer, G. Kennedy, P. A. Tittonell, and J. C. Groot

2020. Exploring solution spaces for nutrition-sensitive agriculture in Kenya and Vietnam. Agricultural Systems, 180:102774.

Timms, B. F., J. Hayes, and M. McCracken

2013. From deforestation to reforestation: applying the forest transition to the Cockpit Country of Jamaica: From deforestation to reforestation. Area, 45(1):77-87.

Tittonell, $\mathrm{P}$.

2014. Livelihood strategies, resilience and transformability in African agroecosystems. Agricultural Systems, 126:3-14. 
Tittonell, P., A. Muriuki, D. Mugendi, K. C. Kaizzi, J. Okeyo, L. Verchot, R. Coe, and B. Vanlauwe 2010. The diversity of rural livelihoods and their influence on soil fertility in agricultural systems of East Africa - A typology of smallholder farms. Agricultural Systems, 103(2):83-97.

Tolessa, T., F. Senbeta, and M. Kidane 2017. The impact of land use/land cover change on ecosystem services in the central highlands of Ethiopia. Ecosystem Services, 23:47-54.

Tomscha, S. and S. Gergel 2016. Ecosystem service trade-offs and synergies misunderstood without landscape history. Ecology and Society, 21(1).

Torres-Mazuera, G.

2015. Las consecuencias ocultas de la enajenaciÃn de tierras ejidales: proliferaciÃn de disonancias normativas. Desacatos, Pp. $150-167$.

Twongyirwe, R., M. Bithell, and K. S. Richards

2018. Revisiting the drivers of deforestation in the tropics: Insights from local and key informant perceptions in western Uganda. Journal of Rural Studies, 63:105-119.

UN

2014. Mexico's agricultural development: Perspectives and Outlook. Conference, United Nations, Switzerland.

UN

2016. Sustainable Development Goals Report 2016. United Nations.

UN

2018. Ending Poverty. Technical report, United Nations.

Urban, D. and T. Keitt

2001. Landscape connectivity: A graph-theoretic perspective. Ecology, 82(5):1205-1218.

USDA

2010a. Food Security and Nutrition in Mexico. Technical Report MX0043, USDA Foreign Agricultural Service, Mexico.

USDA

2010b. FoodData central. Data base.

Velázquez, A., E. Durán, I. Ramirez, J.-F. Mas, G. Bocco, G. Ramırez, and J.-L. Palacio 2003. Land use-cover change processes in highly biodiverse areas: the case of Oaxaca, Mexico. Global Environmental Change, 13(3):175-184.

Villamagna, A. M., P. L. Angermeier, and E. M. Bennett

2013. Capacity, pressure, demand, and flow: A conceptual framework for analyzing ecosystem service provision and delivery. Ecological Complexity, 15:114-121.

Vázquez González, L. B., M. R. Parra Vázquez, and M. A. Gracia

2018. Transformaciones en la agricultura de los mayas peninsulares: Un contraste de los casos de Kampocolché y Xohuayán. Mundo Agrario, 19(41):e084.

Walker, R. T.

2010. Land Use Transition and Deforestation in Developing Countries. Geographical Analysis, 19(1):18-30.

White, A. and A. Martin

2002. Who owns the world's forests? Forest tenure and public forests in transition. Washington, DC: Center for International Environmental Law. OCLC: 254081042.

Willett, W., J. Rockström, B. Loken, M. Springmann, T. Lang, S. Vermeulen, T. Garnett, D. Tilman, F. DeClerck, A. Wood, M. Jonell, M. Clark, L. J. Gordon, J. Fanzo, C. Hawkes, R. Zurayk, J. A. Rivera, 
W. De Vries, L. Majele Sibanda, A. Afshin, A. Chaudhary, M. Herrero, R. Agustina, F. Branca, A. Lartey, S. Fan, B. Crona, E. Fox, V. Bignet, M. Troell, T. Lindahl, S. Singh, S. E. Cornell, K. Srinath Reddy, S. Narain, S. Nishtar, and C. J. L. Murray

2019. Food in the Anthropocene: the EAT-Lancet Commission on healthy diets from sustainable food systems. The Lancet, 393(10170):447-492.

Wily, L.

2010. The tragedy of public lands: the fate of the commons under global commerical pressure. International Land Coalition. OCLC: 1110619560.

Winters, P. and B. Davis

2009. Designing a Programme to Support Smallholder Agriculture in Mexico: Lessons from PROCAMPO and Oportunidades. Development Policy Review, 27(5):617-642.

With, K. A.

2007. Invoking the Ghosts of Landscapes Past to Understand the Landscape Ecology of the Present ... and the Future. In Temporal Dimensions of Landscape Ecology, J. A. Bissonette and I. Storch, eds., Pp. 43-58. Boston, MA: Springer US.

Wittes, J. and S. Wallenstein

1987. The Power of the Mantel-Haenszel Test. Journal of the American Statistical Association, 82(400):1104-1109.

$\mathrm{Wu}, \mathrm{J}$.

2013. Landscape sustainability science: ecosystem services and human well-being in changing landscapes. Landscape Ecology, 28(6):999-1023.

$\mathrm{Xu}$, W., Y. Yin, and S. Zhou

2007. Social and economic impacts of carbon sequestration and land use change on peasant households in rural China: A case study of Liping, Guizhou Province. Journal of Environmental Management, 85(3):736-745.

Yamane, K., A. Ikoma, and M. Iijima

2016. Performance of double cropping and relay intercropping for black soybean production in smallscale farms. Plant Production Science, 19(4):449-457.

Yang, J., H. Wang, S. Jin, K. Chen, J. Riedinger, and C. Peng

2016. Migration, local off-farm employment, and agricultural production efficiency: evidence from China. Journal of Productivity Analysis, 45(3):247-259.

Yang, Y., H. Zheng, L. Kong, B. Huang, W. Xu, and Z. Ouyang

2019. Mapping ecosystem services bundles to detect high- and low-value ecosystem services areas for land use management. Journal of Cleaner Production, 225:11-17.

Yin, R. K.

2018. Case study research and applications: design and methods, sixth edition edition. Los Angeles: SAGE.

Yúnez, A. N. and F. Barceinas

2000. Efectos de la desaparición de la Conasupo en el comercio y en los precios de los cultivos básicos. Estudios Económicos, 15(2):189-227.

Zarazúa-Escobar, J. A., G. Almaguer-Vargas, and J. G. Ocampo-Ledesma

2011. El programa de apoyos directos al campo (PROCAMPO) y su impacto sobre la gestión del conocimiento productivo y comercial de la agricultura del Estado de México. Agricultura, sociedad y desarrollo, 8(1):89-105.

Zhang, W., T. H. Ricketts, C. Kremen, K. Carney, and S. M. Swinton

2007. Ecosystem services and dis-services to agriculture. Ecological Economics, 64(2):253-260. 


\section{Zimmerer, K.}

2007. Agriculture, livelihoods, and globalization: The analysis of new trajectories (and avoidance of just-so stories) of human-environment change and conservation. Agriculture and Human Values, 24(1):916.

Zimmerer, K. S.

1994. Human Geography and the "New Ecology": The Prospect and Promise of Integration. Annals of the Association of American Geographers, 84(1):108-125.

Ávalos-Sartorio, B.

2006. What can we learn from past price stabilization policies and market reform in Mexico? Food Policy, 31(4):313-327. 

Appendices 

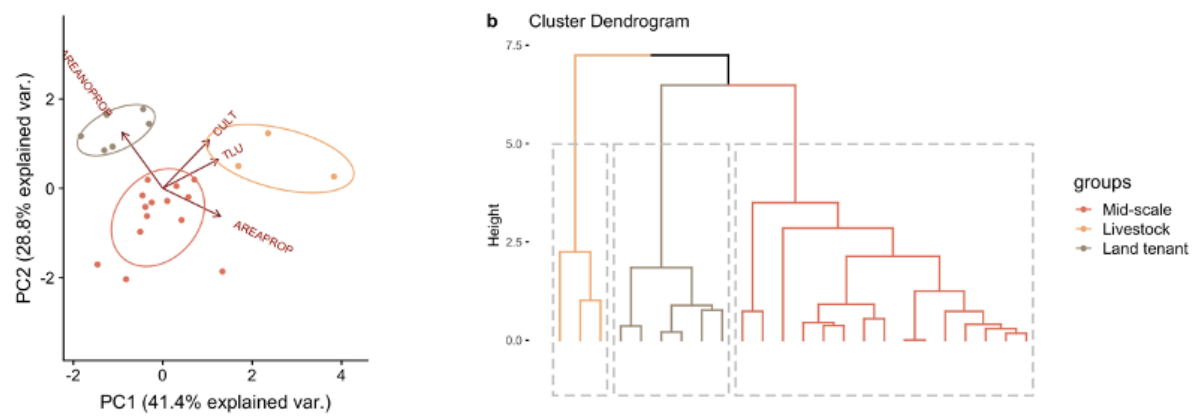

1998-2007

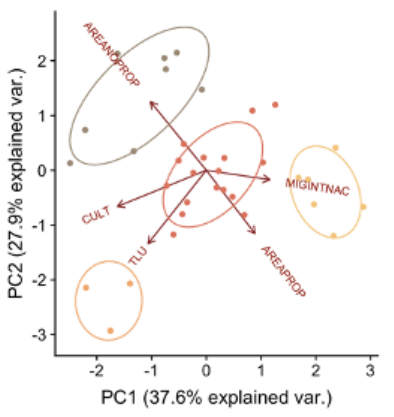

d Cluster Dendrogram

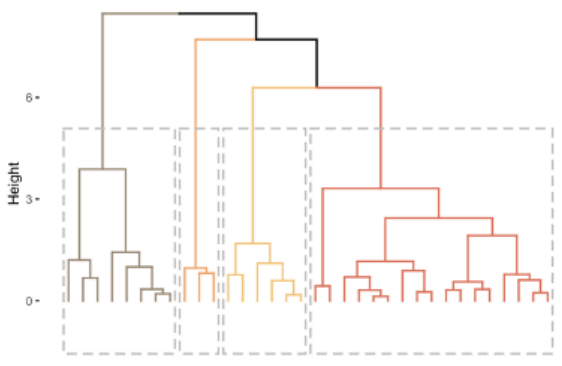

groups

- Mid-scale

- Land tenant
- Labor migrant

2008-2017
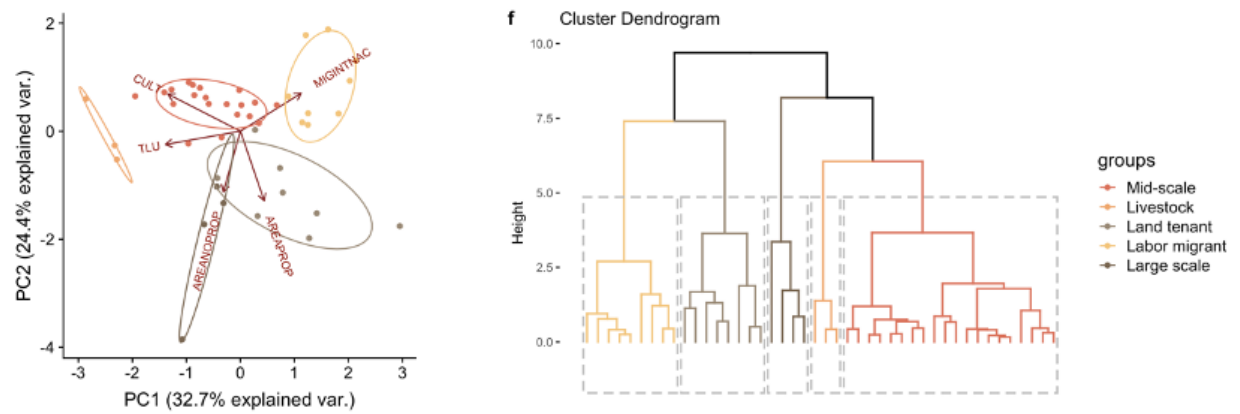

Figure 1: PCA analysis and HCA on 24, 34 and 44 household in 1988-1997, 1998-2007 and 2008-2017 periods, respectively. 


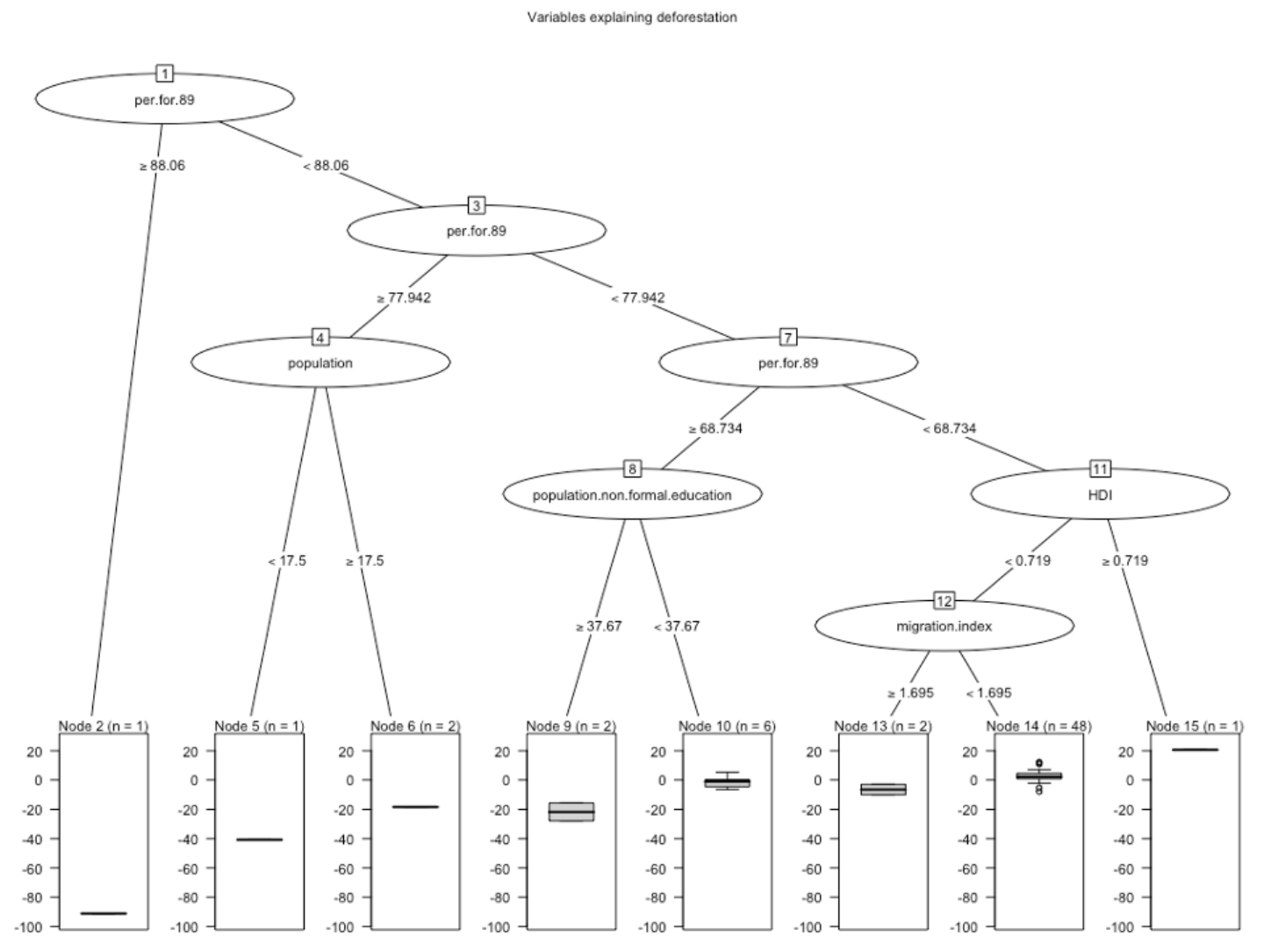

Figure 2: Regression tree with forest cover difference between 1984 and 2017 as target variable. 



\section{Summary}

Chapter 1 provides a general introduction for this thesis, focusing on humans drive land use change and affect the capacity of landscapes to provide ecosystem services. These changes influence the livelihood and food security of the rural people and may have undesirable socio-economic consequences such as induced marginalization, migration, and land abandonment. The development of landscape-level alternatives that aim at improving landscapes' capacity to provide ecosystem services and nutritious food should consider the interplay between household and landscape trajectories. Rapid land use change in the Mixteca region began with the Spanish colonization. A combination of land abandonment, overgrazing, and logging stimulated by colonists led to a severe soil degradation process, which is perceived to this day. Soil degradation negatively affected ecosystem services such as food provision and water regulation. In addition to landscape issues, more than $60 \%$ of the population in the region lives under poverty. Rural households typically face problems with low crop and animal productivity, lack of technical support for agriculture, lack of employment alternatives, and elevated rates of population migration. Policies against rural poverty targeted promoting the cultivation of profitable crops while trying to move farmers' interest away from traditional poly-cropping systems such as milpa, increasing risks of food insecurity. Understanding these trajectories is essential for identifying constraints and potentials for effective landscape-management solutions that help improving ecosystem services while providing food to satisfy the population's nutritional needs. Therefore, this thesis aimed to assess the effect of drivers of change on household and landscape trajectories; to evaluate current landscape performance in terms of ecosystem services and food provision; and to explore landscape alternatives that would improve nutritional self-sufficiency without degrading other ecosystem services. This study was conducted in two municipalities situated in the Mixteca Alta region, Santa Catarina Tayata (SCT) and San Cristóbal Amoltepec (SCA).

Chapter 2 assesses the evolution of households and the relation between household 
type diversity and major drivers of change. The starting point revealed three household types, characterized by landless farmers (relying on renting and borrowing land), midsized farmers and animal production focused. As more people started migrating, a new household type was formed, defining the labor migrant household type. With changes in land tenure, households were allowed to purchase land, forming a relatively largescale household type. Also as a consequence of changes in land tenure policies, the household type marked by landless farmers decreased, as a number of them started acquiring land. According to different strategies, half of the households changed to different household types, while the other half remained in the same household type. The type of government support affected the household's activities. Agriculture-related subsidies tended to keep the household's activities restricted to farming, as several rules had to be complied with to continue receiving the support. On the other hand, familyallowance supports were not related to any activity and gave households more freedom to explore other sources of income. Such a study can be used to articulate better policies by monitoring their impact and households' strategic response.

Chapter 3 evaluates land use change at the watershed and municipal level. The study uses random forest models to describe regional variables affecting land use changes in the Rio-Sordo watershed. Places with high marginalization and more than $70 \%$ of forest cover were prone to deforestation. Places with elevated migration and high risks of drought were likely to abandon agricultural activities. At the municipal level, communities played an important role as drivers of change. By asserting governance over common land, communities mobilized to tackle deforestation and soil degradation. To solve these issues, communities enforced local regulations that targeted logging and overgrazing while promoting reforestation campaigns. These actions had a positive impact on forest growth and bare soil reduction over the last 30 years. Communities' role in landscape conservation is promising, especially when considering that the majority of forests in Mexico are under communities' governance. Nevertheless, national policies can revert communities' conservation progress. For instance, a current national program aims at stimulating animal production by offering farmers animals to start a breeding process. Such a could bring back grazing issues among the community and resume processes of deforestation and soil degradation. While these programs could potentially benefit households, they should be carefully analyzed to avoid conflict of interest and hamper communities' landscape conservation plans.

Chapter 4 analyses the role of traditional milpa in food security and self-sufficiency. As a result of several national policies and cultural, demographic shifts in Mexico, milpa systems are declining. This chapter focuses on contrasting milpa against monoculture of maize and bean in SCT and SCA. The two municipalities differed in terms of nutri- 
tional self-sufficiency. SCT provided its population with sufficient amounts of dietary energy, protein, micronutrients, and most vitamins. SCA had low production of several nutritional elements. The low nutritional self-sufficiency in SCA was attributed to low crop yields and large population size. Both municipalities had an insufficient production of Vitamin A and C, as a consequence of decreasing milpa production. Milpa system produced a full set of nutritional elements (except for vitamin B12), being able to feed completely at least two persons per hectare per year. Bean grown as sole crop provided high amounts of vitamin B9, being able to feed at least four persons per hectare per year. Because of its high vitamin B9 production, a monoculture of bean offers an alternative to remedy nutritional deficiencies associated with the vitamin, but it lacked other nutritional elements. Finally, maize lacked in zinc and vitamins A and C. This chapter shows the importance of assessing crops in terms of their nutritional benefits, instead of mainly focusing on volume or calories produced, providing thus a complete panorama on the nutritional self-sufficiency. It also shows the benefits of poly-cropping systems for their nutritional complementarity.

Chapter 5 builds upon the previous chapter. It uses the nutrition-sensitive landscapes approach to explore landscape alternatives for improving the nutritional selfsufficiency and ecosystem services of the case studies. The LandscapeIMAGES framework was used to explore trade-offs and synergies between multiple objectives. Results revealed trade-offs between the production of vitamin A and habitat connectivity, carbon stock, and soil erosion. Production of vitamin A was also related to higher labor demands. Both communities could potentially reach nutritional self-sufficiency. Nevertheless, SCA would require growing milpa on around $30 \%$ of its territory to reach its self-sufficiency, while SCT would require a land share of $10 \%$. By requiring less land to reach its self-sufficiency, SCT has more room for improving other ecosystem services. While both communities could potentially reach a nutritional self-sufficiency status through milpa production, the reality showed that farmers avoid this system due to its high labor demands and also due to public policies that largely discouraged farmers to grow milpa. Therefore, interventions should focus on targeting low crop production and providing farmers with alternatives for growing milpa that maximizes the production per hour worked. By increasing milpa yields, less land with milpa would be required to reach nutritional self-sufficiency, thus increasing the number of alternatives for improving other ecosystem services.

Lastly, Chapter 6 summarizes and integrates the findings of this study. It highlights the importance of connecting household, community, and watershed level trajectories. It also discusses the role of communities in landscape management and conservation. The chapter finishes by discussing how to integrate nutrition-sensitive landscapes ap- 
proach in the Mixtec context and shows its relevance to similar contexts. 


\section{Samenvatting}

Hoofdstuk 1 Door het wisselende grondgebruik beïnvloedt de mens de capaciteit van landschappen om een bijdrage te leveren aan het ecosysteem. Deze veranderingen beïnvloeden de voedselzekerheid en leefomstandigheden van de rurale bevolking met mogelijke onbedoelde sociaaleconomische consequenties zoals marginalisatie, migratie en degradatie van land. De ontwikkelingen van alternatieve strategieën, die ogen op verbetering van de bijdrage aan het landschap en haar ecosysteembijdrage en voedingswaarde van voedsel, moeten ook rekening houden met de wisselwerking tussen huishoudens en landschap in een bepaald tijdsbestek. Het snel veranderen van grondgebruik in de La Mixteca regio begon met de Spaanse kolonisatie. Een combinatie van landdegradatie, overbegrazing en ontbossing, die werd gestimuleerd door de kolonisten, heeft geleid tot heftige bodemvervuiling, waarvan de effecten nog steeds te vinden zijn. Grondvervuiling heeft een negatief effect op de bijdrage van het ecosysteem in de vorm van verminderde voedselproductie en waterregulatie. Naast de landschapsproblematiek, leeft meer dan $60 \%$ van de populatie in armoede. Plattelandshuishoudens hebben vaak te maken met een lage gewas opbrengst en dierproductie. Ook is er gebrek aan technologische hulp in de agricultuur, gebrek aan alternatieve banen en is de emigratie hoog. Beleid tegen de rurale armoede was gericht op de verhoging van de cultivatie van winstgevende monoculturen en de interesse van de boeren te verlagen in de traditionele polycultuur zoals milpa, wat zorgt voor grotere voedselonzekerheid. Het begrijpen van deze gebeurtenissen is essentieel voor het identificeren van beperkingen en mogelijkheden van effectieve landschapsmanagement methodes die een positieve invloed kunnen hebben op het ecosysteem en tegelijkertijd voedselzekerheid brengen bij het volk op het platteland. Daarom is het doel van deze thesis het analyseren van de factoren die effect hebben op veranderingen in huishoudens en landschap. Deze worden geëvalueerd door de huidige landschapseffectiviteit op basis van ecosysteem bijdrages en voedsel voorzieningen te meten, en het verkennen van alternatieve mogelijkheden die de voedingsrijke zelfvoorziening van het landschap verhogen zonder 
negatieve bijeffecten op het ecosysteem. Deze studie was gedaan in twee gemeenten die zich bevinden in de Mixteca alta regio genaamd Santa Catarina Tayata (SCT) en San Cristobal Amoltepec (SCA).

Hoofdstuk 2 analyseert de evolutie van de huishoudens en het verband tussen diversiteit in huishoudtypes en de grote drijfveren voor veranderingen. Het begon met drie huishoudtypes, boeren zonder land (deze zijn afhankelijk van het huren en lenen van land), middel grote boeren en boeren met een focus op veehouderij. Toen er meer mensen gingen migreren ontstond een vierde huishoudtype, de werkende migrant. Door de veranderingen in ambtscontracten van het land, kregen huishoudens de mogelijkheid om land te kopen, wat resulteerde in een relatief groot huishoudtype, genaamd groot huishoudtype. Nog een gevolg van deze verandering is dat het huishoudtype van landloze boeren daalde, omdat zij nu ook land konden kopen. Volgens verschillende strategieën wijzigde de helft van de huishoudtypes van type, waar de andere helft in hetzelfde huishoudtype bleef. Het type hulp wat de overheid bood had ook effect op de activiteiten van huishoudens. De subsidies agricultuur gerelateerd waren, resulteerde in dat de activiteiten van huishoudens beperkt bleven tot werken op het land, wegens regels die vastzaten aan de subsidies. Aan de andere kant, waren er ook subsidies gefocust op gezinnen, deze hadden geen regels die de activiteiten van de huishoudens beperkte en gaven de gezinnen meer vrijheid om andere mogelijkheden van inkomen te verkennen. De studie kan gebruikt worden om betere beleidsvormen te gebruiken en door te voeren door het monitoren van de impact op huishoudens en de strategische keuze van het huishouden.

Hoofdstuk 3 evalueert de verandering van het landgebruik op de stroomgebied en gemeentelijk niveau. De studie gebruikt willekeurig geselecteerde beslisbomen om de regionale variabelen te beschrijven die effect hebben op het grond gebruik in het stroomgebied van de Rio-Sordo. Plekken met een hoge marginalisatie en meer dan $70 \%$ bos waren meer vatbaar voor ontbossing. Plekken met verhoogde migratie en hogere kansen op droogte hadden een verhoogde kans op een vermindering van agriculturele bezigheden. Op gemeentelijke niveau waren de gemeenschappen een belangrijke drijfveer voor verandering. Door het vergeven van autoriteit over een stuk land konden gemeenschappen gezamenlijk ontbossing en bodemvervuiling tegen gaan. De gemeenschappen dwongen regels af betreffende houtkappen en overbegrazing waarbij ze tegelijkertijd een campagne voerde voor herbebossing van deze gebieden. Deze acties leidde tot een positief effect op de bebossing en kale grond vermindering in de laatste 30 jaar. De rol van gemeenschappen in landschapsconservatie is veelbelovend, omdat de grootste stukken bos in Mexico vallen onder het bestuur van gemeenschappen. Toch kan nationaal beleid de vooruitgang van landschapsconservatie teniet doen. 
Bijvoorbeeld, het huidig nationaal beleid oogt op het stimuleren van de vleesproductie door het bieden van dieren aan boeren die willen starten met het fokken ervan. Zo'n beleid kan de overbegrazing weer terugbrengen samen met de mogelijke ontbossing en grond vervuiling. Hoewel deze strategieën potentiele voordelen hebben voor huishoudens, is het essentieel dat ze zorgvuldig moeten worden geanalyseerd om plannen van gemeenschappen voor landschapsconservatie niet in de weg te staan.

Hoofdstuk 4 analyseert de rol van traditionele milpa in voedselzekerheid en zelfvoorzieningsmogelijkheden. Als gevolg van een paar nationale beleid stukken, cultuur en demografische veranderingen in Mexico daalt de hoeveelheid milpa systemen. Dit hoofdstuk focust zich op het vergelijken van de milpa en de monoculturen mais en bonen in SCT en SCA. Deze twee gemeenschappen verschillen op grond van voedselzelfvoorziening. SCT levert zijn populatie genoeg energie, eiwitten, micronutriënten en vitamines, waar SCA een lage productie heeft van verschillende nutriënten. De lage voedselzelfvoorziening wat betreft nutriënten in SCA komt door de lage voedselopbrengst en de hoge populatie grootte. Beide gemeenschappen hebben een tekort aan vitamine $\mathrm{A}$ en $\mathrm{C}$ als consequentie van de vermindering van milpa productie. Milpa produceert een groot scala aan nutriënten (afgezien va B12), wat het mogelijk maakt om 2 personen volledig te voeden per hectare per jaar. Bonen bieden grote hoeveelheden aan vitamine B9, genoeg voor minstens 4 mensen per hectare per jaar. Vanwege de hoge vitamine B9 productie bieden bonen als een monocultuur een alternatieve oplossing voor gebreken aan deze vitamine, maar er missen wel veel andere belangrijke nutriënten. Als laatste mist mais zink, vitamine A en C. Dit hoofdstuk benadrukt de essentie van het beoordelen van gewassen op grond van hun nutriëntele waarden.in plaats van enkel de hoeveelheid productie en calorieën, om een bevolking te kunnen voorzien van al hun nutriëntele behoeftes. Ook benadrukt dit de essentie van de polygewassen in het voorzien van een dieet bestaande uit alle benodigde nutriënten.

Hoofdstuk 5 bouwt verder op het vorige hoofdstuk. Het gebruik de voedingsgevoelige landschap benadering om alternatieve mogelijkheden te vinden om de zelfvoorziening en ecosysteem van de casus studies te verbeteren. Het model van LandscapeIMAGES is gebruikt om compromissen en mogelijke interacties te onderzoeken tussen verschillende waarnemingen. Resultaten toonde compromissen tussen de productie van vitamine A en verbondenheid met de leefomgeving, stikstofvoorraad en bodemerosie. Productie van vitamine A was ook verwant met hogere arbeid eisen. Beide gemeenschappen kunnen uiteindelijk in nutriëntele behoefte zelfvoorzienend zijn. Desalniettemin zal SCA milpa moeten gebruiken in ongeveer $30 \%$ van haar grondgebied om zelfvoorzienend te zijn, waarbij SCT dit 10\% is. Omdat SCT minder land moet omzetten om een verbetering te krijgen in zelfvoorziening heeft SCT meer 
ruimte om te groeien in andere aspecten van het ecosysteem. Alhoewel beide gebieden volledig zelfvoorzienend kunnen worden door het milpa systeem meer te gebruiken toont de realiteit aan de boeren milpa vermijden vanwege de hoge arbeid eisen. Daarom zou een interventie zich moeten focussen op de op lage productie en boeren voorzien van alternatieven wijze om milpa toe te passen zodat productie per gewerkt uur gemaximaliseerd kan worden. Meer milpa systemen zou betekenen dat minder land nodig is volledig zelfvoorziening te bereiken en de mogelijkheden geven om ook andere aspecten van het ecosysteem te verbeteren.

Hoofdstuk 6 vat de vindingen van de studie samen. Het toont de essentie aan van het verbinden van plannen van huishoudens, gemeenschappen en stroomgebieden. Het bespreekt ook de rol van de gemeenschap in het beheren van het land en de conservatie hiervan. Het laatste hoofdstuk eindigt met een discussie over hoe huidige aanpak kan worden geïntegreerd in de Mixtec context en de relevantie in vergelijkbare situaties. 
Resumen

El Capitulo 1 introduce la interacción entre humanos y medio ambiente, enfocándose en el impacto de los cambios de uso de suelo y los servicios ecosistémicos. Esos cambios influyen en los modos de vida y la seguridad alimentaria de la población rural, con efectos socioeconómicos indeseables como la marginalización, migración y el abandono de la tierra. El desarrollo y diseño de paisajes, que tienen como objetivo mejorar la capacidad de los sistemas para proveer servicios ecosistémicos y alimentos nutritivos, deben de considerar la conexión entre las unidades de producción familiar y las trayectorias del paisaje. El rápido proceso del cambio de uso de suelo en la Mixteca, Oaxaqueña comenzó con la colonización española. Una combinación entre abandono de la tierra, sobrepastoreo y tala de arboles, estimulada por los colonizadores, condujo a un proceso de erosión severo. La degradación del suelo afectó negativamente servicios ecosistémicos como la producción de comida y la regulación de los ciclos hídricos. Además de los problemas a nivel de paisaje, mas del $60 \%$ de la población de la zona vive actualmente en situación de pobreza. Los sistemas de producción familiar enfrentan problemas como la baja producción animal y vegetal, falta de soporte técnico para la agricultura, falta de alternativas de empleos y elevadas tasas de emigración. Políticas contra la pobreza provocaron el desinterés de los agricultores hacia los sistemas de subsistencia, ya que se promovía la producción de cultivos con mayor potencial económico, poniendo en riesgo la seguridad alimentaria. La comprensión de las trayectorias del uso de suelo, de las unidades de producción familiar y de las políticas publicas es esencial para identificar restricciones y potenciales para un manejo eficiente del paisaje, que visa en mejorar los servicios ecosistémicos mientras considera la demanda de la población por una alimentación nutritiva. Por lo tanto, los objetivos de esa tesis fueron evaluar el efecto de los "drivers of change" en las unidades de producción familiar y paisaje; dimensionar la incidencia de los arreglos del paisaje en cuanto a los servicios ecosistémicos y la producción de alimentos; así como explorar alternativas de configuración del paisaje para mejorar la autosuficiencia nutricional sin causar degradación en los servicios ecosistémi- 
cos. Este estudio fue conducido en dos municipios, Santa Catarina Tayata (SCT) y San Cristóbal Amoltepec (SCA), ambos situados en la Mixteca Alta Oaxaqueña.

El Capitulo 2, Se evaluó la evolución de las unidades de producción familiar y su relación con los impulsores del cambio en el tiempo. En 1987, tres distintos tipos de unidades de producción familiar fueron identificados: (1) agricultores sin terrenos propios (i.e. dependientes de terrenos prestados o rentados), (2) agricultores de mediana escala y (3) agricultores dedicados mayormente a la producción animal. Con el incremento de la migración, un nuevo tipo de unidad de producción familiar apareció, definido como trabajadores migrantes. La consolidación de la reforma agraria en la década de los noventas permitió la emergencia de un quinto tipo de agricultores, con base en una mayor propiedad de terrenos. Impulsados por la reforma de la tierra, varias unidades de producción que antes no tenían terreno propio lograron comprar parcelas y pasar a otro tipo de unidad de producción. Según las diferentes estrategias adoptadas, la mitad de las unidades de producción cambiaron a otro grupo, mientras la otra mitad permaneció dentro de su mismo grupo a lo largo de los últimos 30 años. En ese capitulo también se discutió que el tipo de soporte gubernamental puede afectar la actividad agrícola y no agrícola de las unidades de producción. Los subsidios enfocados a la producción agrícola tienden a mantener a los campesinos trabajando exclusivamente en actividades agropecuarias, sin embargo, soportes económicos enfocados a la familia permiten mayores posibilidades a los agricultores para explorar otras actividades económicas afuera de la agricultura. Los resultados de este estudio pueden ser insumos para mejorar la articulación y monitorear del impacto de las políticas publicas sobre los agricultores.

El Capitulo 3 evalúa los cambios de uso de suelo en dos niveles, cuenca y municipio, para ello se uso el modelo Random Forests para identificar las variables que explican mayormente los cambios de uso de suelo a nivel de cuenca. Los municipios con mayores grados de marginalización y más del 70\% de su territorio con bosque fueron mas propensos a la deforestación. Comunidades con elevados índices de migración y mayor riesgo por sequía mostraron mayor abandono de las actividades agrícolas. A nivel de municipio, los dos estudios de caso mostraron el papel de las comunidades en los cambios de uso de suelo. A través del control comunitario sobre el manejo del paisaje, las comunidades fueron capaces de controlar problemas como la deforestación y la degradación del suelo, por medio de toma de decisiones colectivas en asambleas e implementaron regulaciones para controlar la tala de arboles y el sobrepastoreo, mientras promovían campañas de reforestación. Estas acciones tuvieron un impacto positivo en el aumento del área forestal y la reducción de las áreas erosionadas. El papel de las comunidades en la conservación de los recursos naturales es prometedor, especialmente 
cuando se considera que mas de la mitad de los bosques en México está en manos de las comunidades rurales. Sin embargo, políticas publicas pueden revertir el proceso de conservación. Por ejemplo, programas como que estimulan la producción animal pueden anular el progreso que las comunidades han tenido para controlar el sobrepastoreo. Por lo tanto, es importante que las políticas publicas se orienten conjuntamente con las comunidades para aumentar la eficacia de los programas de desarrollo.

En el Capítulo 4 se analiza el papel de la milpa en la soberania alimentaria y la autosuficiencia nutricional. Como resultado de diversos cambios políticos, culturales y demográficos en México, la milpa ha sido abandonada. Este capitulo se enfoca en mostrar el contraste entre la milpa y otros sistemas agrícolas, como el monocultivo de maíz y frijol en SCT y SCA. Los dos municipios difieren en cuanto a su autosuficiencia nutricional, SCT proveyó a su población la cantidad suficiente de calorías, proteína, micronutrientes y la mayoría de las vitaminas, mientras que SCA tuvo una baja producción de dichos elementos nutricionales. La baja autosuficiencia nutricional en SCA fue atribuida a la baja producción de los cultivos y a su mayor demografía. Ambos municipios tuvieron una producción deficiente de vitamina A y C debido a la baja producción en cuanto a la área con milpa. El sistema milpa produjo un conjunto de componentes nutricionales completo (excepto por la vitamina B12), siendo capaz de producir la cantidad mínima de nutrientes y vitaminas para alimentar hasta un promedio de 2 personas por hectárea. El monocultivo de frijol proveyó altas cantidades de vitamina B9, siendo capaz de alimentar hasta 4 personas por hectárea, sin embargo, la producción en otras vitaminas y micronutrientes fue baja. El maíz es un cultivo que ofrece casi todos micronutrientes y vitaminas. Sin embargo, el maíz no ofrece cantidades significativas de zinc, de vitamina A y C. Este capitulo muestra la importancia de evaluar los cultivos en cuanto a sus beneficios nutricionales en lugar de enfocarse solamente en el volumen o calorías producidos. Por lo tanto, este estudio ofrece un panorama mas completo en cuanto a la autosuficiencia nutricional, así como los beneficios de los policultivos en su complementariedad nutricional.

El Capitulo 5 se construye a partir del anterior. Aquí el principio de relación del paisaje con la nutrición (nutrition-sensitive landscapes) fue explorar diferentes alternativas de configuración del uso de suelo para aumentar la autosuficiencia nutricional y la provisión de los servicios ecosistémicos en los municipios de estudio. El marco de referencia, LandscapeIMAGES, fue usado para para explorar las relaciones entre cambios en el paisaje y los servicios ecosistémicos. Los resultados revelaron una relación entre la producción de vitamina A, la conectividad del hábitat, el almacenamiento de carbono y la erosión del suelo. La producción de vitamina A estuvo relacionada con una mayor demanda de mano de obra requerida con un aumento en la producción de milpa. Ambas 
comunidades tienen el potencial de alcanzar la autosuficiencia nutricional, sin embargo para ello, SCA requeriría que el 30\% de su territorio fuera cultivado en forma de milpa, mientras SCT necesitaría sólo el 10\% de su territorio bajo la producción de milpa, por lo cual SCT tiene mas margen de maniobra para tener otros usos de suelo, dándole mas opciones para aumentar la producción de servicios ecosistémicos. Ambas comunidades tienen un potencial para alcanzar la autosuficiencia nutricional por medio del cultivo de milpa, sin embargo los agricultores no utilizan dicho manejo debido a programas gubernamentales que desestimulan su producción y a la alta demanda de mano de obra. Por lo tanto, las intervenciones deben de enfocarse no solo en aumentar la producción de alimentos por área, sino también ofrecer alternativas de cultivo de milpa que requiera menos mano de obra, maximizando entonces la cantidad de alimento producida por hora trabajada. De tal forma, con una mayor producción por área de milpa, menos área bajo ese sistema sería requerida y por lo tanto se aumentaría la oportunidad para mejorar otros servicios ecosistémicos. El ultimo capítulo resume y integra los hallazgos de ese estudio. Se destaca la importancia de conectar las trayectorias de las unidades de producción familiar, comunidades y paisaje. También se discute el papel de las comunidades en el manejo del paisaje y su conservación. El capítulo finaliza discutiendo la integración de la provisión nutricional y el manejo del paisaje en el contexto de la Mixteca Oaxaqueña y la relevancia para contextos similares. 


\section{Acknowledgments}

This Ph.D. has been a long and exciting journey. I have faced and overcome many challenges since I embarked on this project and I only came to this point with the help of those around me. For that, I thank my supervisory team, Pablo Tittonell, Walter Rossing, Mariela Fuentes-Ponce and Santiago López-Ridaura, who accompanied my growth as a researcher. Pablo, thank you for introducing me to this amazing supervisory team and thank you for your inspiration and guidance. Thank you for making me feel at home in Bariloche and for introducing me to all your co-workers. Walter, thank you for your precision and scientific rigor, always keeping me on track and guaranteeing I was meeting the highest scientific standards. I also thank you for worrying about all the steps of my Ph.D. Mariela, thank you for always accompanying and assisting me in the most difficult moments. I also thank you for making the navigation through the bureaucracy of our beautiful Mexico tolerable. You inspired me to reflect on how I could help others with my research. Santiago, I thank you for always trying to integrate me with other researchers. I also thank you for your encouraging passion for agriculture and for always bringing clever and exciting ideas to ensure refreshing research.

I would like to give my special thanks to Luis Manuel Rodríguez, who offered me a roof when I first came to Mexico. You also made me improve my Spanish and gave me an introduction to Mexican culture.

This Ph.D. was only made possible thanks to the fieldwork done in Oaxaca, Mexico. The connection with the local communities of Santa Catarina Tayata and San Cristóbal Amoltepec would have never been made without Mariela Fuentes Ponce, Luis Manuel Rodríguez and Alexanders Bautista Aguilar. Thank you, Jesus Cruz Galicia, for being our guide and friend in the field, and for your constant good humor. Tia Nati, I thank you for your outstanding cooking skills and for introducing me to many delicious typical dishes from the always colorful Oaxaca. Omar Aguilar Bautista, you always had a place for us in Santa Catarina Tayata. Ester Sosa and Marta Sosa, thank you for all the guidance through San Cristóbal Amoltepec. The work you have done and the care you 
give for your lovely pueblo is encouraging.

Every good fieldwork is done as a team. My colleagues and friends, Erick Alejandro Rebollo, Dulce Maria Zuñiga, Tim Bos, Beatriz Alvarado Perry, Susana Prieto Bravo, and Cristian Reyna Ramírez were constantly with me, making the fieldwork always a joy. Dulce and Erick not only helped me on the field, but also became dear friends to me.

I thank my colleagues from Bariloche, Argentina. Valeria Álvarez, Luciana Laborda, Juan de Pascuale, Ceci Roldán, Jorge Arias, Fabio Trinco and Gimena Vilardo. You made me feel at home in Bariloche, with outdoor activities and barbecues that kept me sane in stressing moments.

Although I only spent a short period in Wageningen, my last and most stressful months were among the incredible people from the Farming Systems Ecology group, who always kept me motivated. Wampie van Schouwenburg, apart from your excellent efficiency, you were always happy, helpful and kind to us all. Jeroen Groot, thank you for making it possible to complete the penultimate chapter of this thesis. Heitor Teixeira and Carl Timler, I appreciate your disposition to help me with the last steps of my thesis.

I thank my lovely housemates from Ooststeeg, with whom I shared many dinners and who kept me company during these difficult times of confinement caused by the COVID-19. Thank you, Eric van Honk and Jaenet Ter Schure, for translating the summary of this thesis to Dutch.

Thank you Claudius van de Vijver for assisting and guiding me over the many steps required to attain our esteemed university's requirements.

I also thank Livia de Castro e Mello who long gave me support ever since I started my studies in agronomy in Brazil.

To Gala Rojas, I give my sincere thanks for staying by my side over the last year of my Ph.D., always giving me strength, love, and care. It fills me with joy that I can share this milestone and achievement with you by my side.

Finally, I thank my family, who was always there for me and who supported every decision I made. They made sure that I was constantly happy and motivated. 


\section{About the author}

Ivan Pontin Novotny was born in Brazil, in 1987. He has Italian, Czech and French roots. At the age of 18, he went to study agronomy at the University of São Paulo. During his study in Brazil, Ivan had the opportunity to work with several kinds of production systems such as extensive agriculture, high-input crop production in glass houses, hydroponic systems and small-holder farming systems. Towards the end of his study, he found a new passion, agroecology, and sustainable agriculture, which set his academic path. He went to Wageningen University and Research to start his mas-

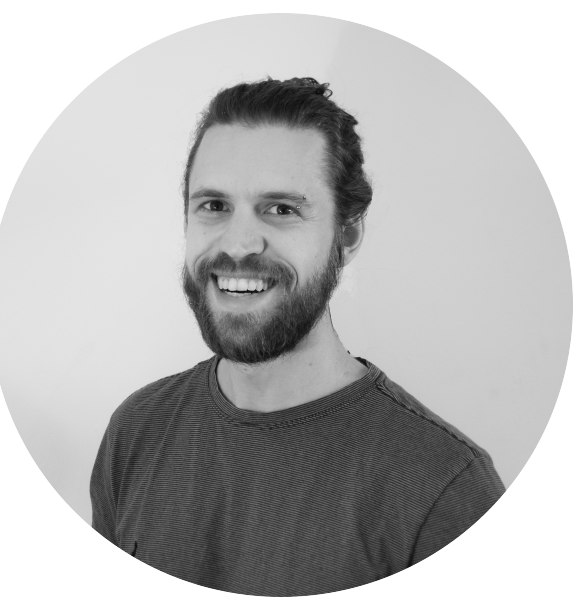
ters in Organic Agriculture in 2012. His interest and fascination for different farming systems around the world led him to do his master thesis in Uganda, where he studied coffee-based agroforestry systems. During his thesis, he was lucky to get in contact with Pablo Tittonell, who guided him to pursue a Ph.D.

His Ph.D. led him to study agricultural landscapes in the highlands of southern Mexico. This gave him a first-hand experience with the traditional Mesoamerican maizebased polycropping system, known as milpa. During his Ph.D. he had close contact with rural communities and gained experience on collective natural resource conservation management. In 2020, Ivan returned to Wageningen to conclude his Ph.D. and embrace his exciting academic journey. 



\section{List of publications}

\section{Articles under review:}

Ivan P. Novotny, Mariela H. Fuentes-Ponce, Santiago López-Ridaura, Pablo Tittonell, Walter A.H. Rossing. Longitudinal analysis of household types and livelihood trajectories in Oaxaca, Mexico. Journal of Rural Studies.

Ivan P. Novotny, Mariela H. Fuentes-Ponce, Santiago López-Ridaura, Pablo Tittonell, Walter A.H. Rossing. Back to the people: the role of global drivers versus communitybased responses at shaping landscape trajectories in Oaxaca, Mexico. Land Use Policy.

Ivan P. Novotny, Pablo Tittonell, Mariela H. Fuentes-Ponce, Santiago López-Ridaura, Walter A.H. Rossing. The role of traditional polycropping system, milpa, in food security and nutritional self-sufficiency in the highlands of Oaxaca, Mexico. Food Security.

\section{Articles to be submitted:}

Ivan P. Novotny, Jeroen C.J. Groot, Pablo Tittonell, Santiago López-Ridaura, Mariela H. Fuentes-Ponce, Walter A.H. Rossing. Exploring nutrient-sensitive landscape solutions for indigenous communities in South Mexico.

\section{Conference/Symposium Proceedings}

Rafael Campagnol, Ivan P. Novotny, Ricardo T. Matsuzaki, Gabriel S. Mattar, Simone d.C. Mello, 2010a. Sistemas de condução e espaçamento entre plantas no rendimento de mini melancia em ambiente protegido, in: 50 Congresso Brasileiro de Olericultura. Horticultura Brasileira, Guarapari, Brazil, pp. 336-342.

Rafael Campagnol, Ivan P. Novotny, Ricardo T. Matsuzaki, Gabriel S. Mattar, Simone d.C. Mello, 2010b. Qualidade de mini melancia cultivada em ambiente protegido em 
função do sistema de condução e densidade de plantas, in: 50 Congresso Brasileiro de Olericultura. Horticultura Brasileira, Guarapari, Brazil, pp. 343-348.

Ivan P. Novotny, Rafael Campagnol, Simone d.C Mello, 2010a. Influence of Training Systems and Plant Density on the Yield of Mini Watermelon in Greenhouse. Presented at the Brazilian Congress of Horticulture, Brazil.

Ivan P. Novotny, Guilherme G. Despontin, Simone d.C Mello, 2010b. Application of Silicon in the Nutrient Solution for the Hydroponic Cultivation of Parsley. Presented at the 18th International Symposium of Scientific Initiation and Technology, University of São Paulo, São Paulo, Brazil.

Ivan P. Novotny, Mariela H. Fuentes-Ponce, Walter A.H. Rossing, Santiago López-Ridaura, Pablo Tittonell, 2019. Longitudinal analysis of household types and livelihood trajectories in Oaxaca, Mexico. Presented at the 6th Farming Systems Design Symposium, Montevideo, Uruguay.

Ivan P. Novotny, Mello, S., 2010. Performance of lettuce varieties in Piracicaba (SP). Presented at the International Symposium of Scientific Initiation and Technology, University of São PAulo, São Paulo, Brazil.

Ivan P. Novotny, Walter A.H. Rossing, Santiago López-Ridaura, Pablo Tittonell, Mariela H. Fuentes-Ponce, 2019. Landscape trajectories: drivers of change and communitybased responses in Oaxaca, Mexico. Presented at the British Ecological Society, Belfast, Northern Ireland. 


\section{PE\&RC Training and Education Statement}

With the training and education activities listed below the PhD candidate has complied with the requirements set by the C.T. de Wit Graduate School for Production Ecology and Resource Conservation (PE\&RC) which comprises of a minimum total of 32 ECTS ( $=22$ weeks of activities)

\section{Review of literature (4.5 ECTS)}

Evaluating historical trajectories for strengthening re-design plans for regional scales (2016)

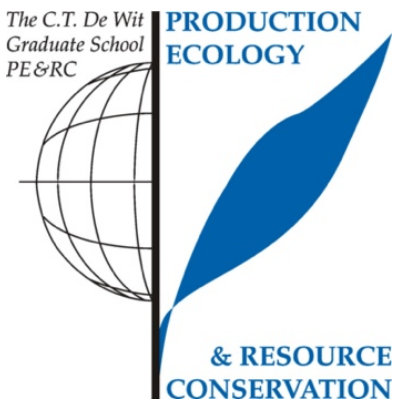

\section{Writing of Project proposal (4.5 ECTS)}

Trajectories of change and pathways for the ecological intensification of smallholder maize-based systems in the highlands of central Mexico and western Guatemala (2016)

\section{Post-graduate courses (2.6 ECTS)}

GIS-Python-R integration and application for automating carbon and biodiversity inventories;

Programa Mexicano del Carbono (2017)

Biomat; Escuela Argentina de Biologia y Matematica (2018)

\section{Competence strengthening / skills courses (2.15 ECTS)}

Scientific work sharing; Universidad Nacional Autonoma Metropolitana

Research data management; WGS

Adobe Indesign; WGS

- Brain friendly working and writing; WGS

\section{Scientific integrity / ethics in science activity (0.9 ECTS)}

Ethics, politics and social injustice; Universidad Autonoma Metropolitana (2017)

- Scientific integrity; WGS (2020)

\section{PE\&RC Annual meetings, seminars and the PE\&RC weekend (1.2 ECTS)}

PE\&RC Midterm weekend (2016)

- $\quad$ PE\&RC Last years weekend (2020)

\section{Discussion groups / local seminars / other scientific meetings (4.5 ECTS)}

- Seminars offered by CONABIO Comisión Nacional para el Conocimientos y uso de la Biodiversidad (2018)

- University seminar about society, environment and institutions at Universidad Nacional Autónoma Metropolitana (2018-2019)

- Debate on social sciences at Facultad Latinoamericana de Ciencias Sociales (2019)

\section{International symposia, workshops and conferences (4.4 ECTS)}

6th International Symposium for Farming Systems Design; Montevideo, Uruguay (2019)

British Ecological Society; Belfast, Northern Ireland (2019)

\section{Societally relevant exposure (0.7 ECTS)}

Photo exposition of my research (2018)

- Interview about rural development in indigenous communities in the South of Mexico (2018)

\section{Lecturing / supervision of practicals / tutorials (2.7 ECTS)}

- Introduction to R (2015)

\section{Supervision of MSc students (3 ECTS)}

Household trajectories

Biodiversity in fallow lands of South Mexico

- Carbon stocks in Pine-Oak forests of South Mexico 
This thesis was part of the project 'Agro-ecosystem diversity and the Trajectories and Trade-offs for Intensification of Cereal-based systems' (ATTIC, grant agreement: A4032.09.20), which was made possible by the generous support provided of CGIAR Research Maize Program (www.maize.org). Any findings, conclusions, recommendations, or opinions expressed in this thesis are those of the author and do not necessarily reflect those of CGIAR Research Maize Program.

Photography by Ivan Pontin Novotny

Printed by ProefschriftMaken, Wageningen, The Netherlands. 


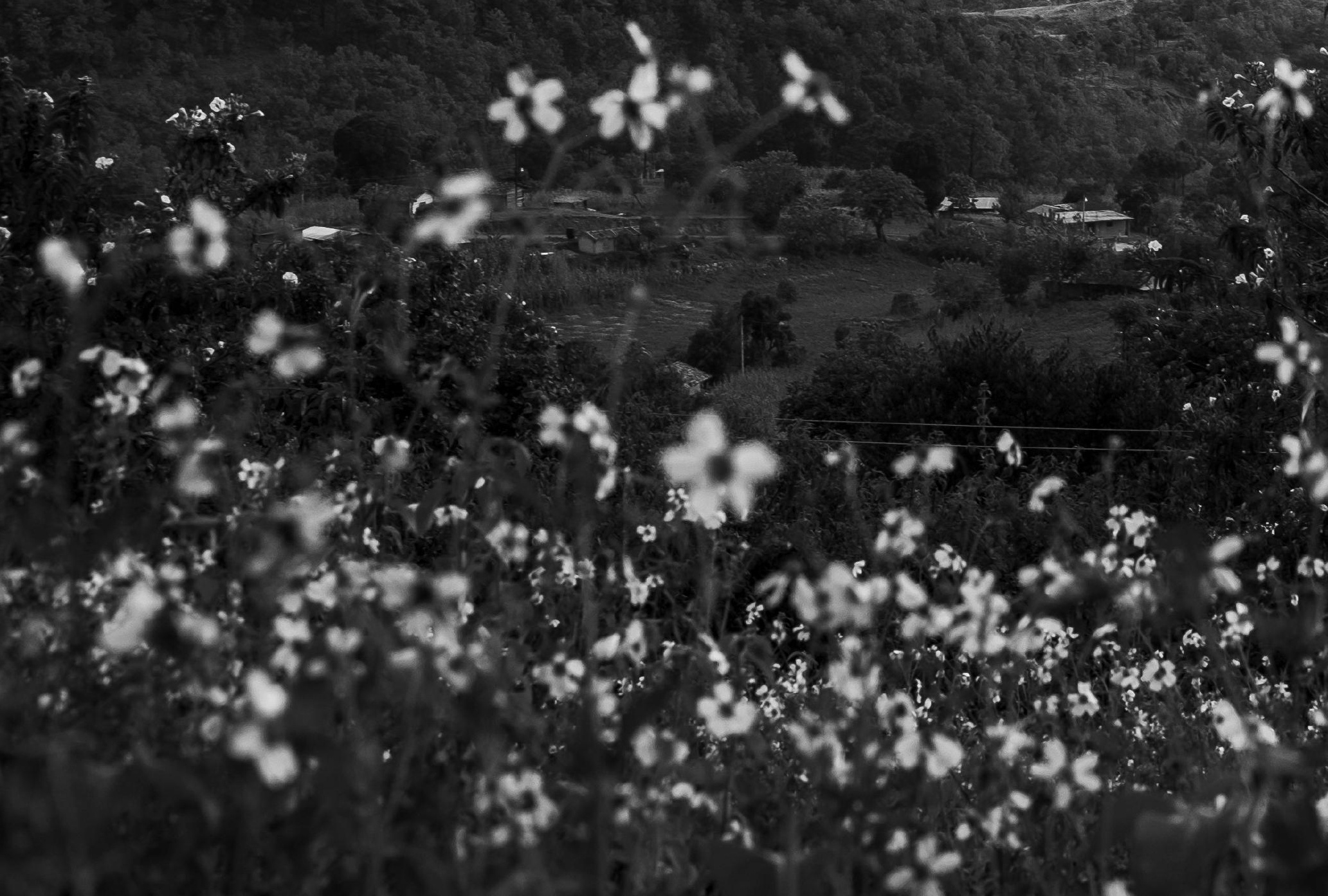

